\title{
Disequilibrium Theory : reflections towards a revival of learning
}

Citation for published version (APA):

Schinkel, M. P. (2001). Disequilibrium Theory : reflections towards a revival of learning. [Doctoral Thesis, Maastricht University]. Universitaire Pers Maastricht. https://doi.org/10.26481/dis.20011214ms

Document status and date:

Published: 01/01/2001

DOI:

10.26481/dis.20011214ms

Document Version:

Publisher's PDF, also known as Version of record

\section{Please check the document version of this publication:}

- A submitted manuscript is the version of the article upon submission and before peer-review. There can be important differences between the submitted version and the official published version of record.

People interested in the research are advised to contact the author for the final version of the publication, or visit the DOI to the publisher's website.

- The final author version and the galley proof are versions of the publication after peer review.

- The final published version features the final layout of the paper including the volume, issue and page numbers.

Link to publication

\footnotetext{
General rights rights.

- You may freely distribute the URL identifying the publication in the public portal. please follow below link for the End User Agreement:

www.umlib.nl/taverne-license

Take down policy

If you believe that this document breaches copyright please contact us at:

repository@maastrichtuniversity.nl

providing details and we will investigate your claim.
}

Copyright and moral rights for the publications made accessible in the public portal are retained by the authors and/or other copyright owners and it is a condition of accessing publications that users recognise and abide by the legal requirements associated with these

- Users may download and print one copy of any publication from the public portal for the purpose of private study or research.

- You may not further distribute the material or use it for any profit-making activity or commercial gain

If the publication is distributed under the terms of Article $25 \mathrm{fa}$ of the Dutch Copyright Act, indicated by the "Taverne" license above, 
Disequilibrium Theory

Reflections towards a Revival of Learning 
This book was typeset by the author, using Scientific WorkPlace 3.0, in a modified version of the Springer-Verlag style modified with additional LTEX-fields. References are set in a modified American Economic Review style.

Cover: Carla Nuis

(C) Marten Pieter Schinkel, Maastricht.

All rights reserved. No part of this publication may be reproduced, stored in a retrieval system, or transmitted, in any form, or by any means, electronic, mechanical, photocopying, recording or otherwise, without the prior permission in writing, from the anthor.

Published by Universitaire Pers Maastricht

ISBN $90-5278-333-0$

Printed in The Netherlands by Datawyse Maastricht 


\section{DISEQUILIBRIUM THEORY \\ Reflections towards a Revival of Learning}

\section{PROEFSCHRIFT}

ter verkrijging van de graad van doctor aan

de Universiteit Maastricht,

op gezag van de Rector Magnificus,

Prof. Dr. A.C. Nieuwenhuijzen Kruseman, volgens het besluit van het College van Decanen, in het openbaar te verdedigen op vrijdag 14 december 2001 om 14.00 uur

door

Maarten Pieter Schinkel

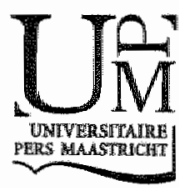




\section{Promotores:}

Prof. dr. J.A.H. Maks

Prof. dr. F.M. Fisher (Massachusetts Institute of Technology, U.S.A.)

\section{Co-promotor:}

Dr. A.J. Vermeulen

Beoordelingscommissie:

Prof. dr. P.J.J. Herings (voorzitter)

Prof. dr. H.J.M. Peters

Prof. dr. E.R. Weintraub (Duke University, U.S.A.) 
Yu Tzu said, "Of the things brought about by the rites, harmony is the most valuable. Of the ways of the Former Kings, this is the most beautiful, and is followed alike in the matters great and small, yet this will not always work: to aim always at harmony without regulating it by the rites simply because one knows only about harmony will not, in fact, work."

(Confucius, The Analects, Book I, 12)

They are just looking at me so I continue: "Laws of nature are human inventions, like ghosts. Laws of logic, of mathematics are also human inventions, like ghosts. The whole blessed thing is a human invention, including the idea that it isn't a human invention. The world has no existence whatsoever outside the human imagination. It's all a ghost, ... the whole blessed world we live in. It's run by ghosts. We see what we see because these ghosts show it to us .... (...) Your common sense is nothing more than the voices of thousands and thousands of the ghosts from the past. Ghosts and more ghosts. Ghosts trying to find their place among the living."

(Robert Pirsig, Zen and the Art of Motorcycle Maintenance)

"Its a miracle

Another miracle

By the grace of God Almighty

And the pressures of the market place

The human race has civilized itself."

(Roger Waters, Amuzed to Death)

"Ah? Did the demanded supply let the prices explode again since yesterday's market?"

(Obelix in Obelix $\mathrm{Co}$ ) 



\section{Contents}

Acknowledgments ix

1 Disequilibrium Theory: An Introduction 1.

1.1 An Illustration . . . . . . . . . . . . . . . . . . . 6

1.2 Some Conceptual Issues . . . . . . . . . . . . . . . . . . . 9

1.2 .1 General Equilibrium . . . . . . . . . . . . . . 10

1.2 .2 Out-of-Equilibrium, or Disequilibrium .......... 11

1.2.3 General Disequilibrium Analysis . . . . . . . . . . . . 14

1.2.4 Information and Expectations . . . . . . . . . . . . . 16

1.2 .5 Equilibrium as a Rest-Point . . . . . . . . . . . . 19

1.2 .6 Statics and Dynamics ................... . . 20

1.2.7 Time, Distance, and Speed of Adjustment . . . . . . . . 22

1.2 .8 Convergence and Stability . . . . . . . . . . . . 23

1.3 The Need for Disequilibrium Theory . . . . . . . . . . . 25

1.4 Outline of the Book . . . . . . . . . . . . . . 33

2 Economics as a Science $\mathbf{3 5}$

2.1 Inductivism versus Deductivism . . . . . . . . . . . . . 36

2.2 Falsificationism and Quasi-Induction . . . . . . . . . . 39

2.3 Methodology of Scientific Research Programs . . . . . . . . . . 41

2.4 Empirical Apriorism . . . . . . . . . . . . . . . . . 44

2.5 Economics' Scientific Research Program . . . . . . . . . . . . 48 
3 A History of Disequilibrium Theory $\quad 57$

3.1 Walras' Theory of Tâtonnement ................ 58

3.2 The Hicks-Samuelson Dispute on 'Truly Dynamic Stability' . . . . . 64

3.3 Global Stability Theory . . . . . . . . . . . . . . . . . 73

3.4 The Subsequent Development of the Theory of Tâtonnement . . . . 78

3.5 Scarf"s Counter-examples and their Generalization . . . . . . . . 82

3.6 Computational Algorithms . . . . . . . . . . . . . . 83

3.7 The Distributional Approach . . . . . . . . . . . . . . . . . 88

3.8 Trading Processes . . . . . . . . . . . . . . . . . . . . 89

3.8.1 The Edgeworth-Process and Extensions ............ 91

3.8.2 The Hahn-Process and Extensions . . . . . . . . . . 96

4 On a Homunculus Explanation in Economic Theory 101

4.1 The Disequilibrinm Research Program . . . . . . . . . . . . . 103

4.2 A Homunculus Explanation . . . . . . . . . . . . . . . . 106

4.3 Early Reflections on the Homunculus . . . . . . . . . . . . 108

4.4 Exemplifying Theory ... . . . . . . . . . . . . 111

5 Market Makers in Competition $\mathbf{1 1 5}$

5.1 A Note on the Rationality of Profit Maximization . . . . . . . 117

5.2 The Lange-Conjecture . . . . . . . . . . . . . . . 118

5.3 Monopolistic Competition and General Equilibrium . . . . . . . . 120

5.4 On the Objective Demand Approach . . . . . . . . . . . 128

5.5 Market Makers with Subjective Conjectures . . . . . . . . . . . . 133

5.6 Individually Rational Prices: A Conclusion . . . . . . . . . . 139

6 Market Makers in Disequilibrium 141

6.1 The Stockholm School of Thought . . . . . . . . . . . . . . . 142

6.2 Expectations and General Equilibrium . . . . . . . . . . . . . . . . 147

6.4 Conjectural Variations $\ldots \ldots \ldots . . \ldots 150$

6.5 Adjusting Conjectures $\ldots \ldots \ldots \ldots . \ldots . \ldots . \ldots . \ldots 151$

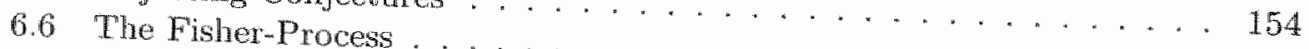

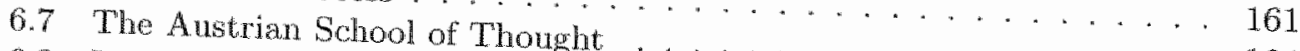

6.8 Imperfect Information and Learning . . . . . . . . . 164

6.9 Individually Rational Price Adjustong . . . . . . . . . 167

7 The Correspondence Principle in the Large 171

$\begin{array}{ll}7.1 & \text { Taking Methodological Stock . . . . . . . . . . . . . . . } 1717 \\ 7.2 & \text { On a Competitive Ending }\end{array}$

7.3 On the Law of Supply and Demand Again . . . . . . . . . 175

$\begin{array}{ll}\text { A Theory of Disequilibrium Behavior } & 185 \\ 8.1 \text { Objective Demand and Subjective Perceptions }\end{array}$

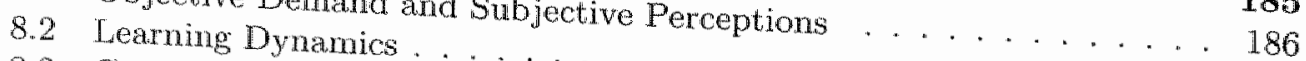

8.3 Conjectural Equilibrium $\ldots \ldots \ldots \ldots . . \ldots \ldots$ 
8.4 Elementary Properties of Rational Learning . . . . . . . . . . . 190

8.5 Convergence of Beliefs and Prices . . . . . . . . . . . . . . . . . 196

8.5.1 Infinite Histories and Beliefs . . . . . . . . . . . . . . 196

8.5.2 Subjective Almost Sure Convergence of Beliefs and Prices ... 198

8.6 The Nature of Limit Behefs and Prices . . . . . . . . . . . . . . 201

8.6.1 Unique Limit Beliefs . . . . . . . . . . . . . . . . . . . . . . 201

8.6.2 Individual Conjectural Equilibrium . . . . . . . . . . . 206

8.7 Objective Convergence to Conjectural Equilibrium . . . . . . . . . 206

9 Concluding Thoughts $\quad 211$

$\begin{array}{lr}\text { A Ordinary Least Squares Learning } & 219\end{array}$

B Topics in Real Analysis $\quad 229$

B.1 Probability Measures . . . . . . . . . . . . . . . . . . . . 229

B.2 Weak Convergence . . . . . . . . . . . . . . . . . . . . . . . . . . . . . . . . . . . . . . . . . .

B.2.1 Topology . . . . . . . . . . . . . . . . . 231

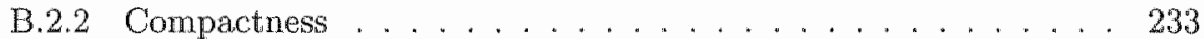

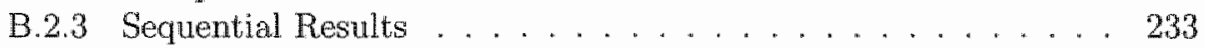

C Martingale Convergence Theory 235

C.1 Conditional Expectation . . . . . . . . . . . . . . . . 235

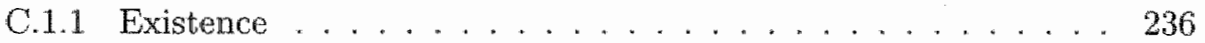

C.1.2 Uniqueness . . . . . . . . . . . . . . 237

C.2 Martingales . . . . . . . . . . . . . . . . . 237

$\begin{array}{ll}\text { References } & 245\end{array}$

$\begin{array}{ll}\text { Samenvatting (Summary in Dutch) } & 267\end{array}$

$\begin{array}{ll}\text { Professional Currïculum Vitae } & 273\end{array}$ 



\section{List of Figures}

1.1 An illustration of the relevance of out-of-equilibrium theory. . . . . 7

1.2 The cobweb model as a partial ont-of-equilibrium theory. . . . . . 15

1.3 The irrelevance of stability analysis in the Cournot duopoly model. . . . . 17

1.4 Some stability concepts illustrated. . . . . . . . . . . . 25

2.1 An illustration of the structure of theories. . . . . . . . . . 37

2.2 The structure of economics' scientific research program. . . . . . . . . 51

4.1 Disequilibrium research in general equilibrium theory. . . . . . . . . 104

4.2 A homunculus explanation of the hunuan mind. . . . . . . . . . 107

5.1 The Lange-conjecture illustrated for a monopsonistically buying and monopolistically selling firm. . . . . . . . . . . . . . . . 119

6.1 An illustration of a firm's trouble in establishing equilibrium price. . . . . 160

7.1 An illustration of the general failure of the law of supply and demand. . . 182

7.2 Typical individually rational price adjustment. . . . . . . . . 183

8.1 The development of beliefs and prices. . . . . . . . . . . . 196

8.2 An illustration of 'No Statistical Surprise'. . . . . . . . . . . 208

C.1 Up- and downcrossings of a martingale. . . . . . . . . . 241 



\section{Acknowledgments}

There is a typical saying in Dutch, naturally stemming from the nation's great seafaring days, that: "De beste stuurlui staan aan wal" ("The best helmsmen stand ashore.") This book is to a large extent a critique of past economic thinking and model building done by others. The seed of that critique fell on me some ten years ago--I was still an undergraduate student then. It struck me as rather odd that there is a great amount of trust amongst economists in the rellevance of the equilibria of their models when they intend to understand the world, yet very little formal reasoning and modelling to justify such confidence. It seemed to me that this situation left the foundations of economic reasoning quite shaky. I believe this seed has grown in me. What came out of it are reflections from ashore. I felt obliged, however, to accompany my critical reflections with an alternative theory-do a little sailing for myself, that is, and find out how it felt. The past three years, I have spent working on that - between very many distractions I must say, all resulting from my own unwise habit not to ignore them. Some, shipbuilders that I admire and look up to, told me I was not cut out for the job. Others went as far as to deny the presence of waters to sail. Yet, I also met with strong encouragement. In the end, I think I was able to venture offshore some. The boat may leak, and not be entirely seaworthy, but I sailed. Last summer I was finally able to marry criticism and alternative. What I now offer is Disequilibrium Theory: Reflections towards a Revival of Learning.

There are many people whom I owe for the completion of this work. Closest to my profession, I thank Hans Maks, who handpicked me in the mensa when I was a second year undergraduate student, hired me and never gave up supporting me. Although Hans likes to stress the points where, according to him, we still disagree, his teachings and comments have certainly gone into the present text. Similar encouragement and support I received from Franklin Fisher. He and I first met in person in Theresa's 
office at MT's Department of Economics end of August 1997-I still regret that I was not quick enough to reply his: "You must be Martin-Peter Schinkel" with "Dr. Fisher, I presume" - I mumbled something shy instead. Before that, since 1994, we had corresponded extensively on the subject of disequilibrium and Frank's landmark 1983 book on the matter. Frank has never tired in unbelievably promptly commenting on my papers and chapter drafts. The book has greatly benefited from that. I feel very privileged that he refers to me as "the only sane person that ever followed up on my book" - even though I know this is not true. I am very happy that Hans and Frank promote me.

For his long-term academic support and encouragement, I thank Hans Peters, and for their eye-opening expert teachings on general equilibrium theory, Gerard van der Laan and Peter Diamond. In the final phase of this project, I found new energy in the trust placed in me by Jean-Jacques Herings. He read and commented on earlier papers and plans, and then hired me, despite my history of postponing finishing this project. His detailed remarks to the manuscript have led to major improvements. Valuable critical comments I have also received from Roy Weintraub. For editorial help with the infamous Scientific WorkPlace, and particularly his unmatched ability to trick this program into doing what I wanted with little supplementary IATEX-fields, I thank Ronald Peeters.

Bridging professional and personal life, I am indebted to Dries Vermeulen and Jan Tuinstra. I like to believe that both now share my passion for serious, non-meutral disequilibrium adjustment processes. It is a real pleasure to work-but particularly also drink, mason and snowboard-with such diverse intellect. During my stay in the U.S., I survived largely thanks to Dirk Niepelt-who now does macro but can be trusted with it--and particularly Jaime Villareal, a very special person, and brother in arms battling MIT technicalities. Closest to my personal life, I thank my mother, Ella Schinkel-Kuijpers, and father, Frank Schinkel-who frowned upon my choice of profession, yet advises me still today on its day-to-day particulars-and my dear friends and examples: Jeroen Tops, Martijn Houtman-who stand by me in the public defense of this thesis-Mark Verlaan and Vincent Malingré- who offered me his house for much needed sechusion. Finally, of course, I thank my dearest friend and love, Carla Nuis, who had to put up with this dissertation as an excuse to postpone so much beyond
today.

MPS, Maastricht, October 20, 2001. 


\section{1}

\section{Disequilibrium Theory: An Introduction}

One of the most quoted and referred to passages in economic writing is a metaphor on the working of markets by Adam Smith. In a chapter on international trade in Volume I of the Wealth of Nations, originally published in 1776, in which he strongly argues against government-imposed restrictions on imports to support the home industry, Smith wrote:

"And every individual, therefore, endeavours as much as he can both to employ his capital in the support of domestic industry, and so to direct that industry that its produce may be of the greatest value; every individual necessarily labours to render the annual revenue of the society as great as he can. He generally, indeed, neither intends to promote the public interest, nor knows how much he is promoting it. By preferring the support of domestick to that of foreign industry, he intends only his own security; and by directing that industry in such a manner as its produce may be of greatest value, he intends only his own gain, and he is in this, as in many other cases, led by an invisible hand to promote an end which was no part of his intention. (...) By pursuing his own interest he frequently promotes that of society more effectually than when he really intends to promote it." (Smith, 1979, p.456, emphasis added)

The metaphor of the 'invisible hand of the market mechanism' came for many to capture the idea that a system of competitive markets with little or no government intervention other than providing a legal infrastructure can well be relied upon to channel unorchestrated independent individual choices, made primarily to advance private well-being and possibilities and restricted only by property law, into a socially desirable and stable order. Today, it formes one of the key concepts of economics, refined by scholars, adopted by laymen, and increasingly appealed to by governments. 
In this respect, it is of interest to consider the well informed opinion of John Maynard Keymes, who combined his academic career with important civil service. Keynes wrote, concluding his General Theory, on the application of economic insight to practice:

"TThe ideas of economists and political philosophers, both when they are right and when they are wrong, are more powerful than is commonly under stood. Indeed the world is ruled by little else. Practical men, who believe themselves to be quite exempt from any intellectual infuences, are usually the slaves of some defunct economist. Madmen in authority, who hear voices in the air, are distilling their frenzy from some academic scribbler of a few years back." (Keynes, 1936, p.383)

The invisible hand is such a frenzy, and one carried by dominant voices-in fact, it was the classical idea of spontaneously stabilizing economies that Keynes here and elsewhere argued against. This can be stated with all due respect to Smith, since he spoke of the invisible hand only three times, on three different occasions in his collected writings. Moreover, as recently quite convincingly argued by Emma Rothschild, he "... did not particularly esteem the invisible hand and thought of it as an ironic but useful joke." Instead, Smith was very conscious of the role of good government.

Whereas traditionally, to various degrees in different countries, structures for political and institutional order were set up and maintained with a keen eye for the existence of both market failures and undesirable distributional aspects of free competition, in recent years the idea of a reliable invisible hand of the market mechanism has become increasingly popular. Often it is presented as 'no-nonsense' or 'back-to-basics' politics. The term and, more importantly, the underlying vision on market processes are appealed to time and again, not only at cocktail parties of collected middle management, but also accompanying policy proposals to enforce 'the market' by increasing the "flexibility of the work force' with which to 'fight unemployment", by 'priwatizing" traditional government tasks in order to circumvent the slackening infuence of "incentiveless civil servants', or by lowering unemployment benefits in order to push 'idle workers' back into the work force again. Advocating the invisible hand and "letting
the market rule" is fashionable."

\footnotetext{
Rothschild (1994), p.319. The thee teferences to the invisible hand by Smith are in History of Astronomy, written in the $1750^{\circ}$, although published posthumously, The Theory of Moral Sentiments,

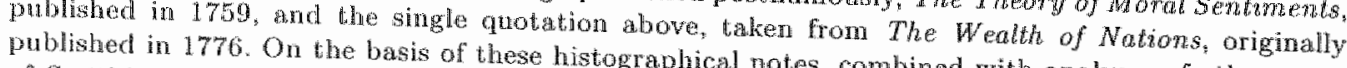
of Smith's work, Rothschild (1994) concludographical notes, combined with analyses of other parts parts of Smith"s work; that is the cort of ides that "... the invisible hand is in conflict with other applies ther insights to criticize the mechandea the would not have liked" (op.cit. "p.319). Rothschild the tatomement. literature. Although not istic interpretation of out-of-equilibrim processes in, en., Mandeville"s Fable of the Bees, published in 1725 , to by Rothschild, Smith's rejection of Bemard based on mimimal structure, is a strong ar 1725 , which is a real apology of the market mechanism

2 It is not difficult to give examples of this tendepporing her conclusion.

or the use of parts of infrastructure, such this tendency. One could think of the privitization of parts networks, the rather forceful intervention of antitrust, electricity, telewision and telecommunication wicle public support, or the specification of property rights to rites in recent years, that is met with
} 
The consequences of these public choices often have a profound influence on people's lives. Therefore, it seems natural to ask that they be rooted strongly in theory. Yet, most panegyrics on the graces of the market rest on negative proof. Instead of thoroughly investigating the powers that are taken to work so well when set free in the market, the disasters and cruelties prevailing under systems that do not rely upon them are set out at length. Of course, to a large extent these negative features of socialist societies were and are existent, and caused and still cause poignant sorrow. However, they provide a case against centrally planned economies, socialism or communism, and not necessarily in fayor of any particular alternative. If a system is to be praised, it has to be on the basis of its own positive features, and not by the negative aspects of some other system, combined with the impression that the latter is the only altemative. What is necessary for an appraisal of the market mechanism, in other words, is a plausible theory of the market mechanism. It does not suffice to appeal to the poetic notion of the invisible hand. It requires economic theory on the working of markets.

Strangely enough, however, economics largely lacks such theory. Instead, it is predominantly concerned with equilibrium. That is, in its various types of models, it mainly studies positions of rest, where all the plans and expectations of individuals match, and where, therefore, no individual has an incentive to do anything different from what it does. About what takes place when an economy happens not to be in equilibrium, whether competitive or not, modern economic theory has little to say.

This state of affairs is peculiar, to say the least. The central question in economics is whether and through what mixture of institutional and market structure individuals in an economy, each with his or her own plans based on personal knowledge, desires and possibilities, will be able to coordinate by means of inmovation, production and trade on allocations in which individuals are able to carry out their plans and better themselves in the process. With equilibrium theory, economics only provides answers to this question based on models in which such coordination has already taken place to the full. These models, and hence by and large the discipline, are silent on how it may have come about.

Although the focus of economic theory on equilibrium has a long history, the lack of attention for out-of-equilibrium behavior is not of all times. ${ }^{3}$ In an in its times widely read textbook by Peter Newman, titled The Theory of Exchange and first published in 1965, the need to justify equilibrium analysis is fully acknowledged. After discussing equilibrium and its efficiency properties in the context of bilateral exchange. Newman posed the following question.

"But starting-as we usually do-from an initial point that is inefficient, how can we be sure that the process of bargaining will ever lead to an efficient trade? Its seems paradoxical that we have blithely been deriving

3 For an extensive survey of the lack of attention for ont-of-equilibrinm processes andorg the classical economists - which goes as far back as Aristotle-see Keesing (1939), which is an attempt to explain the wedge between economic theory and its application by arguing the need for insight into equilibrim tendencies for the latter. A contemporary survey, in Lundberg (1937), cribicizes particularly Keynes for his focus on equilibrium. Erik Lundberg"s contributions to an alternative theory will be discussed later. 
theorems about trading sets and contract curves without once discussing the bargaining process which may-or may not lead the protagonists to an efficient trade ..." (op.cit., p.62)

In the remainder of his book, Newman considered several equilibrating mechanisms, involving barter as well as trade at unique price ratio's. His approach provides an eyeopening red line through the works of Smith, Leon Waras, Alfred Marshall, Francis Edgeworth, Joseph Schumpeter, John Hicks, Paul Samuelson, and many contributions made in the early 1960 's-on which it offers wery rich notes. It is radically different: from the focus of later textbooks, particularly-after Takayama (1973, 1985) that still has an extensive chapter on out-of-equilibrium theory-the influential Varian (1978, 1984), and the currently authoritative Mas-Colell, Whinston and Green (1995), in which equilibrium analysis is developed through nany types of equilibrium in various types of models, and at center stage, but in which questions concerning its relevance have gradually seized to been asked.

In fact, there seems to have grown over time a common perception among many working economists that out-of-equilibrium issues are of little consequence-and it is, of course, a classical causality problem whether the gradual disappearance of outof-equlibrium issues from the prime textbooks has been a consequence of this, or rather a cause. Views then vary from the understanding that answers to questions on the working of markets are sufficiently addressed by existing equilibrium theory, or have long ago been solved satisfactory otherwise in old and settled research, to the idea that problems of an out-of-equilibrium nature are non-existent, and instability no great concern.

Several reasons for the shift in emplasis to equilibrium theory reflected in modem textbook treatment that locked economic theory in a state of asymmetric development will be discussed in this book. An early role of importance in directing research has been played, in this respect, by Samuelson's Foundations of Economic Analysis, which first appeared in widely read print in 1947. It was appreciated for the innovative text it was at the time and had a far-reaching impact on the study of economics-including that of out-of-equilibrium processes. In its introduction, where some basic assumptions are staged, Samuclson made perfectly clear that he did not consider the, what he called, "second order dynamic problem" of out-of-equilibrium behavior of much interest:

"TThe hypothesis is made that the system is in "stable" equilibrium or motion. (...) The plausibility of such a stability hypothesis is suggested by the consideration that positions of unstable equilibrium, even if they exist, are transient, nonpersistent states, and hence on the crudest probability calculation would be observed less frequently than stable states. How many times has the reader seen an egg standing upon its end?" (Samuelson, 1963,
p.5)

Various renowned theorists nevertheless kept stressing the importance of the study von Hayek, who concluded his eminent "The Use of Knowledge in Society," originally
published in 1945 in American Economic Revew, as follows. 
"I am far from denying that in our system equilibrium analysis has a useful function to perform. But when it comes to the point where it misleads some of our leading thinkers into believing that the situation which it describes has direct relevance to the solution of the practical problems, it is high time that we remember that is does not deal with the social process at all and that it is no more than a useful preliminary to the study of the main problem." (Hayek, 1949, p.91.)

And in Prices and Production, published some twenty years later, Hayek testified still that:

"It is my conviction that if we want to explain economic phenomena at all, we have no means available but to build on the foundations given by the tendency towards an equilibrium." (Hayek, 1967, p.34)

More recently, Frank Hahn, who reflected extensively on the need for out-of-equilibrium analysis in his work, retumed Samuelson's rhetorical question on eggs by turning it around in a lecture titled "Reffections on the Invisible Hand":

"Suppose, for instance, it is possible for an egg to stay standing on its tip until it is disturbed. We should not attach great practical significance to this equilibrium of the egg untid. we were told some causal story of how it comes to be in that state. In exactly the same way, the proposition that, in certain circumstances, there is a set of prices which ensures equality between demand and supply in all markets tells us nothing of whether these prices will indeed be established by a market economy. On this central question neither economic theory nor evidence is at all satisfactory." (Hahn, 1982, p.13)

In this lecture, Hahn speaks of "significant lacuna" in economic theory, and criticizes economic schools that go about ignoring these particularly the Chicago school of thought and its at the time prominent and infuential followers in politics, Margaret Thatcher and Ronald Reagan. ${ }^{4}$ Since theories on out-of-equilibrium behavior are diverse and in an unsatisfactory state, predictions based on the presumed workings of the invisible hand come, according to Hahn, "under the heading of religion and magic." Hahn closes his warning for the rudimentary state of out-of-equilibrium theory with advice to consider policy cases on their individual characteristics, applying a "wishywashy, step by step, case by case approach," and not trust on the invisible hand as a healing device sine qua non.

"But many people, to my surprise, prefer to go ont with a bang rather than a whimper. Very few people can live with a shadowy and ill-clefined picture of our world. So I place no bets on the reasonable approach winning

4 Op.cit. pp 13-4. It is of interest to notes that in 1981 Milton Friedman delived his Singapore Lecture "The Invisible Hand in Economics and Politics," in which he praised an increased reliance in British and U.S. politics on the market mechanism. 
through. In this country it is very likely that the non-fulfillment of the vastly exaggerated claims for the invisible hand will lead to a reaction in which the hand, to our great loss, will be amputated forever. "The age of prophets and witches is upon us and such an age is not friendly to reason." (op.cit, p. 21)

The most active advocate of out-of-equilibrium theory probably today is Frankli Fisher. Originally inspired by Hahn, he worked as one of very few on out-of-equilibriur processes through the 1970's and 1980's, and played a very important role in thei scientific development. In 1979, Fisher opened his Presidential Address to the Econc metric Society as follows.

"One of the central unsolved problems of microeconomics is the construction of a satisfactory adjustment model which converges to equilibrium as a result of rational behavior on the part of the decision-making agents involved." (Fisher, 1981, p.279)

Two decades of development in economic theory have passed since then. Yet, in : reflection on his career in economics, reprinted in Schinkel, ed (1999), Fisher wrote very recently:

"There is a general presumption that an economy of rational agents will be driven to equilibrium, but no proper theory of how or whether this happens." (op.cit., pp.551-2)

Clearly, the subject of out-of-equilibrium theory and its relation to equilibrium theory carries with it large issues, both of political and of theoretical concern, and has been visited by large minds. Yet, it offers many open questions still. It is at the heart of fundamental economic theory, and thereby of economic insight and advice. This is a book on its intriguing history, with some contributions to its further development.

\subsection{An Illustration}

The relevance of out-of-equilibrium considerations for understanding economics is already well illustrated in the simplest of possible coordination problems, that of two individuals that engage in the exchange of two commodities that are available in fixed amounts. This permits the textbook treatment by means of an Edgeworth-Bowley box as the one drawn in Figure 1.1 below. Two individuals have an initial endowment of commodities $x_{1}$ and $x_{2}$. Added up these define the total size of the box. The arbitrarily
given distribution of these endowments is drawn in as $X^{0}$.

Both individuals derive utility from their initial bundle of goods. These utility levels are constant on the indifference curves $I_{1}^{0}$ and $I_{2}^{0}$, respectively. Indifference curves are convex also for other combinations of $x_{1}$ and $x_{2}$ under acceptable conditions on preferences-i.e, they are representable by a quasi-concave utility function. Among between the two ind to distribute the total available amount of the two commodities between the two individuals are ways to do so efficiently, that is, in such a way that no 


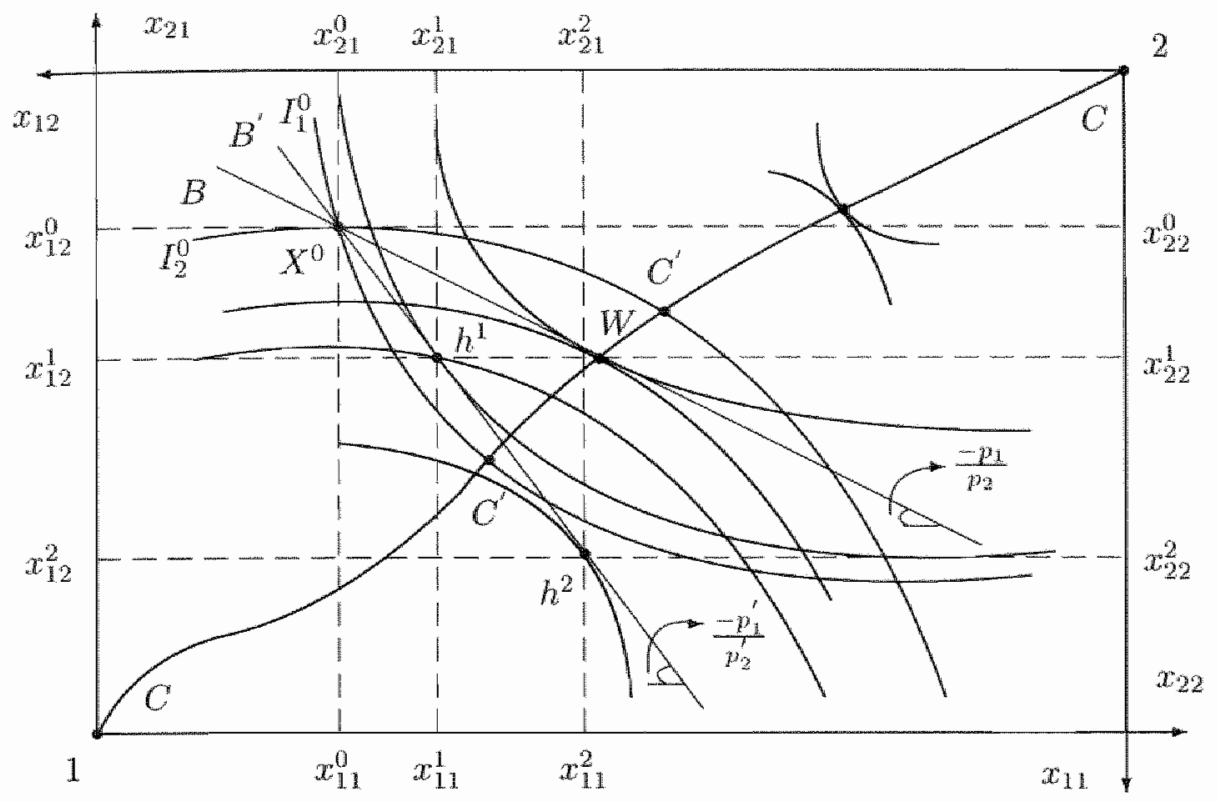

Figure 1.1 An illustration of the relevance of out-of-equilibrium theory.

individual can be made better off without affecting the other individual's well-being, or making the other worse off. Each allocation at which indifference curves touch has this property, since neither individual can be made better of without making the other individual worse off. Together these efficient allocations make up the contract set, curve $C C$. Once one of these allocations is, for one reason or another, agreed upon, at least one of the two individuals will object against any altemative proposal. In that sense, all allocations on $C C$ are equilibria.

The indifference curves $I_{1}^{0}$ and $I_{2}^{0}$ seal off a portion of the contract curve with ef flcient allocations that are preferred over the initial allocation by both individuals. This is, for this two-person economy, the core $C^{\prime} C^{\prime}$. It collects all of the previously identified equilibria that can be reached from the initial allocation through voluntary trade. Still $C^{\prime} C^{\prime}$ contains an infinite amount of equilibria. A so-called Walrasian equilibrium is a core allocation that has the property that it is reached through vohuntary bilateral trade against a particular price ratio. Point $W$ is such an equilibrium. The line $B$ has slope $-\frac{p_{1}}{p_{2}}$, where $p_{1}$ and $p_{2}$ are the prices of commodities 1 and 2 respectively, expressed in some currency-which one is, of course, immaterial. It allows both individuals to afford their part of the core allocation $W$ when they trade their part of the initial allocation $X^{0}$. In other words, $B$ represents the budget constraint for both individuals in their respective individual choice problems. The prices $p_{1}$ and $p_{2}$ are Walrasian equilibrium prices. 
So far, the analysis is straightforward and well-known. The point of providing it is the following. Once the prices $p_{1}$ and $p_{2}$ are established, neither individual can do better than trade up to $W$. Both therefore will, and a Walrasian equilibrim is established. There is, however, no particular reason why $p_{1}$ and $p_{2}$, or any other prices that contritute the same price ratio $\frac{y_{1}}{p_{2}}$, should be prevailing, particularly not initially, right after the two individuals met. Neither of them has the information to piece together the complete figure, nor is there necessarily some institution that realizes the appropriate relative prices. Instead, generally the individuals will initially be confronted with prices that differ from $p_{1}$ and $p_{2}$.

Let these different prices be $p_{1}^{\prime}$ and $p_{2}^{\prime}$ respectively, such that $-\frac{p_{1}^{\prime}}{p_{3}^{\prime}}<-\frac{p_{1}}{p_{2}}$. Hence, each individual faces the budget line $B^{\prime}$. At these prices, individual 1 prefers to trade up to $h$ and individual 2 up to $h^{2}$. With these allocations come trade plans. These plans, however, do not match and hence cannot both be carried out fully. After all, individual 1 would want to buy an amount $x_{11}^{1}-x_{11}^{0}$ of commodity 1 in exchange for an amount $x_{12}^{0}-x_{12}^{1}$ of 2 , that he is willing to give up. Yet individual 2 wants to sell more of commodity 1 , namely $x_{21}^{0}-x_{21}^{2}$, in exchange for more of commodity $2, x_{22}^{2}-x_{22}^{0}$. Consequently, there is an excess supply of commodity 1 , of the size $x_{11}^{2}-x_{11}^{1}$, and an excess demand for commodity 2 , of the size $x_{12}^{2}-x_{12}^{1}$. Notional and effective trade differ for at least one of the two individuals. Consequently, at least one of them is rationed.

What will happen now, and this is the point here, depends crucially on the perception of things each individual has-as well as on the possible intervention of a third party. It may be that both refrain from trade and that one of them proposes a different price, such that the price ratio is closer to $-\frac{p_{1}}{p_{2}}$. This brings their plans closer together. Prices could, however, also move away from the equilibrium values. Likewise, it may also be that the individuals agree to exploit whatever trading possibilities theve exist between them at the current prices. Any allocation between $X^{0}$ and $h^{1}$ does so partially, and at best it will lead them up to allocation $h^{1}$, where individual 1 no longer wants to partake in further deals. Both traders are better off by this move, although
individual 2 is rationed.

Alocation $h^{1}$ leaves mutually beneficial trading opportunities, as well as a smaller subset of the contract curve as a new core. As soon as the individuals realize this, within this new core, it may again be that an efficient allocation is reached in one step through market clearing prices. It is at least equally hikely, however, that another: intermediate step is made at some other price ratio, depending again on the view of the individuals, their patience, and the nature of the bargaining process. Also, it may be that an intermediary caries out the price adjustment process, and takes a fee in
neturn.

Crucial, in any case, is that once trade takes place, the origmal Walrasian equilibrium $W$ is no longer among the possible equilibria. As a consequence, in this example, by engaging with mutual consent in a partially rationed trade, individual 2 has secured a larger share of the total enclowments in the final equilibrium than he would have However, although she may deduce that pricesidual 1 may, of course, anticipate this. is no way she can know this for sure. That prices are likely to change in her favor, there 
importantly, the price dynamics is unspecified. Therefore, her willingness to engage into trade $h^{1}$ initially depends on her beliefs about the matter. That is, on the way she perceives the economy and foresees its development over time.

This conclusion is only fortifed if indeed a third, intemediary party is involved in the establishment of trade proposals, and this party requires part of the available resources in returm for its coordinating activities. For example, this intermediary may buy cheap from one individual and sell expensive to the other, without them knowing this. Such entrepreneurial behavior would modify Figure 1.I importantly. It would introduce two different price vectors. Moreover, in each trading round, it involves a modification of the shape of the Edgeworth-Bowley box, due to the fact that the endowments to be split between the two individuals decrease in varying proportionsthus reducing the total size of the box Obviously, this will have an infuence on the contract set and the core, which will both be different upon each intermediate trade. Also, each new allocation after trade will have one or more new Walrasian equilibria.

The point of this little example therefore is that even when a Walrasian equilibrium exists and is unique, the value of commodities as expressed in their eventual equilibrium prices depends crucially on the out-of-equilibrium path by which an equjlibrium is reached-provided it is reached at all. The same holds for the distribution of wealth. Value and distribution, therefore, are determined by out-of-equilibrium behavior. They are path-dependent. Out-of-equlibrium behavior, in turn, is governed by the perceptions of the trading situation at hand, and any information that may become available along the trading path. It depends on what trading parties perceive to be wise offers to make or accept, as well as on the influence of a third party. The larger the economy in terms of individuals and commodities, the heftier the task of understancling markets and price changes, and the larger also the importance of perception and information. Without an understanding of their role, there is no particular reason at all to consider any of the allocations in $C^{\prime} C^{\prime}$ as more relevant than another, nor, really, to assign much more relevance to equilibrium allocations over distributions that are not an equilibrium.

\subsection{Some Conceptual Issues}

Despite the fact that economics experienced trouble developing a widely accepted theory of the ont-of-equilibrium dynamics, insights, as well as smaller and larger con tributions to the end of obtaining such a theory, are plentiful. They have respectively been had and made in several smaller intellectual schools and a variety of disciplines, and have found their way into a literature that is either not very wiclely considered, or largely detached from out-of-equilibrium research.

This literature consists of contributions of members of largely forgotien schools of thought, such as the Stockholm and the Austrian schools of thought; socialist market planning theory; neglected early reflections of general equilibrium theorists; analyses in an appendix of a peculiarly un-associated, yet large and to out-of-equilibrium analyses highly relevant, literature on general equilibrium theory with quantity constraints-.that is generally thought of as macroeconomics; extensions on a literature on trading 
process that cane at an inappropriate time, when rational expectations theory was widely athered to; occasional models in search and game theory; and recent work on learning. Particularly, also, important insights were offered by eminent individual scholars.

Developments stretch out over a long period of time, in which substantial progress was made in equilibrium analysis as well. As a result, there is some conceptual and semantic divergence associated with the subject issues-to which a loss of attention for many of them can be traced back. It is important, therefore, to settle on nomenclature before going into the relevance of out-of-equilibrium theory and then its history.

\subsubsection{General Equilibrium}

An economy is commonly understood as a group of individuals with subjective needs and, due to the innate scarcity of resources, limited means to fulfill these needs-in which the means can be put to alternative uses. ${ }^{6}$ The problem the indiwiduals face is, through interaction with one another and through production, to each form a plan that serves individual well-being given the individual possibilities best, and that, on top of that, is such that all plans are mutually consistent in such a way that they can all be carried out to the full, preferably such that al scarce resources are applied fully and efficiently.

The analysis of the first part of this fundamental problem, the formation of individual plans, is generally taken to be well captured by individual utility maximization under feasibility constraints, particularly a restriction on budget, and given the information of opportunities available to the individual. That is, individuals seek to do what they subjectively perceive to be optimal.

The second part of the problem, the tuning of individual plans to make them mutually compatible in an efficient way given the structure of the economy, is much more complicated. It involves the varionsly intertwined infuences that the actions of each one individual have on potentially all the others. This coordination is taken by some to be well done by govemment, by others through a system of market prices, and by many through some combination of these two alternatives. In either view, the institutional structure of an economy is instrumental in providing the individuals peopling it with signals, prices or others, that help them formulating their private plans, and possibly adjust them if necessary. A general equilibrium is a situation where these signals are such that individually rational plans are mutually compatible, need no further adjustment, and can all be carried out fully.

\footnotetext{
Writing on their onganiation is scarce. The few sureys that identifed some relationships datue Hack some time, whe somewat obscurely pubhshed and went themselpes largely unnoticed-much as the informod Hsich and Mangum (1986), which identifes common themes microm and marom conomics, the rather pointless Hamouda and Towley (1988), which combinedly discusses subilty theory and a merocomomic liberature on expectations, or the more interesting High (1990), which relates ability and seach theory to Anstian market prosess theory. An importand early axepton

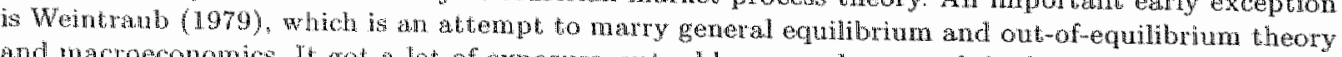
and macroconomics. If got a lot of exposure, yet addresses only part of the literature.

6 Full recognition of this now generally accepted definition of economic scienca is due to Lionel Robbins, on whom more in the nest chupter. Of. Robbing (1935).
} 
Different authors subscribed to this informal definition of general equilibrium. Hayek expressed the following in 1936 in Economics and Knowledge.

"It appears that the concept of equilibrium merely means that the foresight of the different members of the society is in a special sense correct. It must be correct in the sense that every person's plan is based on the expectation of just those actions of other people which those other people intend to perform and that all these plans are based on the expectation of the same set of external facts, so that under certain conditions nobody will have any reason to change his plans." (Hayek, 1949, p.38)

In his 1973 inaugural lecture at Cambridge titled On the Notion of Equabrim in Economics, which was a sharp reaction to criticism on the model of general equilibrium, particularly Kaldor's 1972 paper "The Irrelevance of Equilibrium Economics," Hahn-who had then just published the authoritative 1971 text General Competitre Analysis on general equilibrium theory with Kenneth Arrow commented on several applications of the term equilibrium before his time as follows:

"[A] central theme runs throughout many of these usages, namely the singling out of those states in which the intended actions of rational economic agents are mutually consistent and can therefore be implemented." (Hahn, $1973, \mathrm{p}, 2)$

It is this theme that is formalized in present day definitions of equilibrium. To give just two regular examples, the concept of a Nash-equilibrium shows equal roots in this definition from Fudenberg and Tirole (1995):

"A Nash equilibrium is a profle of strategies such that each player's strategy is an optimal response to the other players' strategies." (op.cit., p.11)

Similarly, a Walrasian equilibrium is discussed by Mas-Colell et al. (1995), as follows.

"At a market equilibrium where consumers take prices as given, markets sthould clear. That is, the consmoers should be able to fulfill their desired purchases and sales of commodities at the going market prices." (op.cit., pp. 518-9.)

\subsubsection{Out-of-Equilibrium, or Disequilibrium}

With the concept of general equilibrium thus understood, that of positions out-ofequilibrium follows straightforwardly. An economy is out-of-equilibrium if the plans of at least one individual cannot be carried out as planned, due to incompatibility with those of the others. In other words, out-of equilibrium is associated with nonclearing markets, that is, excess demand, excess supply, or both of some commodities, and consequently, with disappointment. Out-of-equilibrium theory studies behavion in case plans come out unfulfilled, and are thus in need of adjustment.

The first semantic issue to be dealt with rises here. So far, apart from the title, the term 'out-of-equilibrium theory' has been used for this studies' subject matter. Yet, 
most contributors to the literature, as could be read from several of the quotations given above, apply the term 'disequilibrium'-which features also in the title of this book. Disequilibrium as used by the authors quoted has the same meaning as was given to out-of-equilibrium above. Yet, there are various others who have used the term disequilibrium differently.

For example, Jean-Pascal Benassy in his book The Economics of Market Disequilibrum, published in 1982, was not concerned with out-of-equilibrium behavior at all. Instead, the book presents his important work of many years in the existence and efficiency properties of general equilibrium in general equilibrium models with fixed prices and monopolistic competition - also called 'Keynesian-" or 'K-equilibria'.? These equilibria are not disequilibria. They are equilibria in the very same sense as set out above. Individuals in the model are aware of the fact that some prices are exogenously fixed, that some markets are characterized by irremovable types of imperfect competition, or that they will otherwise face quantity constraints. They modify their plans in the light of this information, however, by taking the imperfections and the consequential rationing schemes into consideration. The existence is studied then of allocations for which these plans are mutually consistent. These general equilibria may not be the Walrasian equilibria, they may not be in the core, and consequently they may not be and generally are not-'first-best' efficient, but they are equilibria in the sense that all individual plans match.

Disequilibrium is a misnomer for these allocations. They are better referred to as general imperfect markets equilibria-where imperfections are defined as a deviation from the model of perfect competition. ${ }^{8}$ Consequently, in the following out-ofequilibrium and clisequilibrium theory can and will be used interchangeably for the subject matter of this book: theory on situations where individual plans do not match.

Frequently, the type of equilibrium analysis with market imperfections also misnamed disequilibrium analysis is referred to as non-WaIrasian equilibrium analysise.g., Varian (1977) and also Fisher (1983). It is important to note, however, that although imperfect market, equilibria certainly are non-Walrasian, perfect market equilibria are not necessarily Walrasian. Walrasian equilibria are, as set out in the simple example given in the previous section, very special competitive equilibria, namely core allocations that relate to any given initial allocation through a single vector of relative prices. Hence, proper disequilibrium analysis will, since it concerns the question how this price vector comes about, generally also be concerned with convergence on nonWalrasian equilibria, even when the latter are competitive. Non-Walrasian equilibrium

"It is an issue of some debate whether Koynes" argument in The General Theory that situations of involuntary unemployment, can be persistent is best understood as the equilibrium argument for Which it is generally taken, or as a disequilibrium argument. Lundberg (1937) has already been noted to consider Keynes' analysis an equilibrim theory, and this is the way particularly Benassy has advanced it -see Chapter 5. The question rises then, however, to what extent rationing on labour supply is involuntary, as in equilibrum all foreseen and real cationing is incorporated in the individuals 'plans. Patimkin (1969) held that Keynes' should be understood from a disequilibrium perspective- $c f$. op.cot., p.338. See on this issue also Iwai (1981).

\& Other examples of misnomers of this kind are Varan (1975), Chapter 8 in Drèze (1991), and Maddan (1992). The literature on general imperfect markets equilibrinm will be discussed in Chapter 5. 
analysis, therefore, is not an entirely appropriate name for the analysis of imperfect markets equilibria either, since non-Walrasian yet competitive equilibria can well arise in perfectly competitive models.

A different semantic issue is the following. In the presence of rationing, both in equilibrium and outside of it, it is of importance to make a distinction between notional and effective transactions - terms applied already in the example above. The former refers to planned transactions, desired by individuals given their preferences and the opportunities and information that they have. It is with their notional clemand and supply that houselolds and firms turn to the market. There, they discover the extent to which notional transactions can be carried out. That is, the extent to which they match with one another. When plans do not match completely, effective demand and supply, that is, the demand and supplied actually carried out at the end of the trading day, is different from notional demand.

Again, a difference in terminology should be noted here. Benassy (1982) refers to effective demand for planned demand derived under constraints on expected rationingon top of the budget and technology constraints. 'Market transactions" in his teminology then are the result of a rationing scheme applied to "effective demands". In the following, however, the term notional applies to any desired price-quantity combination that follows from utility or profit maximization under any system of constraints.

A further semantic issue, that is often used when arguments against the need to consider out-of-equilibrium behavior are advanced, is that any disequilibrium in one model is an equilibrium in a differenty formulated model. In other words, by specifying the model properly and to the occasion, all that is to be understood is its equilibrim behavior. Hence, there is no sense in distinguishing theoretically between equilibrium and disequilibrium in any one particular model. ${ }^{10}$ Plans that do not match from one perspective, are matching plans that were never planned to match from another perspective. When you want to understand certain behavior, make sure to formulate a model that displays it as equilibrium behavior and study its properties.

One unequivocal formulation of this view is by Metcalf:

"Separations of equilibria from disequilibria] are not as sharp a set of distinctions as might at first sight appear, since one can tum any disequilibrium model into an equilibrium equivalent and vice versa by a suitable definition of the information sets and perceptions of ... agents." (Metcalf (1988), p.561)

This certainly is a valid observation. Yet, refusing to make such a separation in any given case sacrifices an important and helpful analytical distinction, and for no particularly good reason. This can be made clear with Metcalf's terminology. The equilibria of any given model are defined with respect to the principals of that model. In general equilibrium theory, these are the privately known initial endowments of commodities, the individual preferences and available production techniques. On information

Of. Benassy (1982), p.28.

11 Hahn, in his respectiful contribution On General Equaldorizm and Stability to Sammelson's liber amicorm published in 1983 , attributes this view to Samuelson. Of. op.rit., p.33. 
on other issues, such as prices, or the preferences and techniques available to others, various assumptions can be made. Generally, the former are public knowledge, and the latter two are not. Given this information structure, a general equilibrium is identified in the above sense, that is as a dissemination of information that allows for the formulation of independent yet mutually compatible plans-minimally information on prices. With it follows a meaning for disequilibrium situations.

Out-of-equilibrium behavior is concerned with changes in plans resulting from changes in the information sets of the various individuals. It seeks to understand the characteristics of an economy in which such changes in plans culminate in their mutual compatibinty preferably efficiently. Renaming such processes sequences of moving equilibria in different underlying economies, instead of disequilibrium adjustments, does not change the fact that they require understanding. It just muddles up the terminology. Moteover, it poses the question which sequence of economies is underneath the process that led to equilibrium in any equilibrium model that helps explain the disechnkbrim wa the original model. Out-of-equilibrium theory does not run into this semantie guidssand.

\subsubsection{General Disequilibrium Analysis}

It is important to note that disequilibrium theory is theory only really meaningfully done in the setting of general equilibrium models-as opposed to models of partial equilibrim. That is, out-of-equilibrium issues are to be studied in models with mutual interdependency of potentially all individual plans. It is here that the problems of mismatch are largest, and most complicated. In some sense, partial equilibrium theory is general equilibrium theory in which a large amount of spill-over effects is exogenously excluded. Hence, to find characteristic aspects of out-of-equilibrium behavior in a partial equilibrium model has little or no implications for models of general equilibrium. Likewise does, for example, a lack of stability in partial equilibrium models not have straightforward implications for general equilibrium theory, as the partial fixation may well be its cause. In fact, the point of general equilibrium theory, as argued above, is to show mutual compatibility when actions and their consequences are related. Therefore, the challenge to show under what conditions this is relevant should be taken up within general equilibrium theory.

The example given in the previous section of the relevance of out-of-equilibrium behavior for understanding value and distribution is one from general equilibrium theory. To drive home the argument that this is the appropriate setting, consider a well-known partial analysis, offered in the so-called 'cobweb model'. This model was developed in response to empirical findings in the 1920's and 1930's that agricultural prices and incomes displayed fluctuations over the years. ${ }^{11}$

In a partial supply and demand framework, as illustrated below in Figure 1.2, the argument was made that each year, when decisions on agricultural production were to be taken, farmers would be guided by the prices that ruled in the previous season. If an initial production $q_{0}$-as drawn, the previous equilibrium quantity before an 
exogenous demand shock - was sold at prices $p_{0}$, farmers would plan to grow a harvest $q_{1}$ in response. This, however, would then drive down prices to $p_{1}$ in that year, which would result in plans $q_{2}$. These would in turn come out at unexpectedly high prices in an ongoing process.

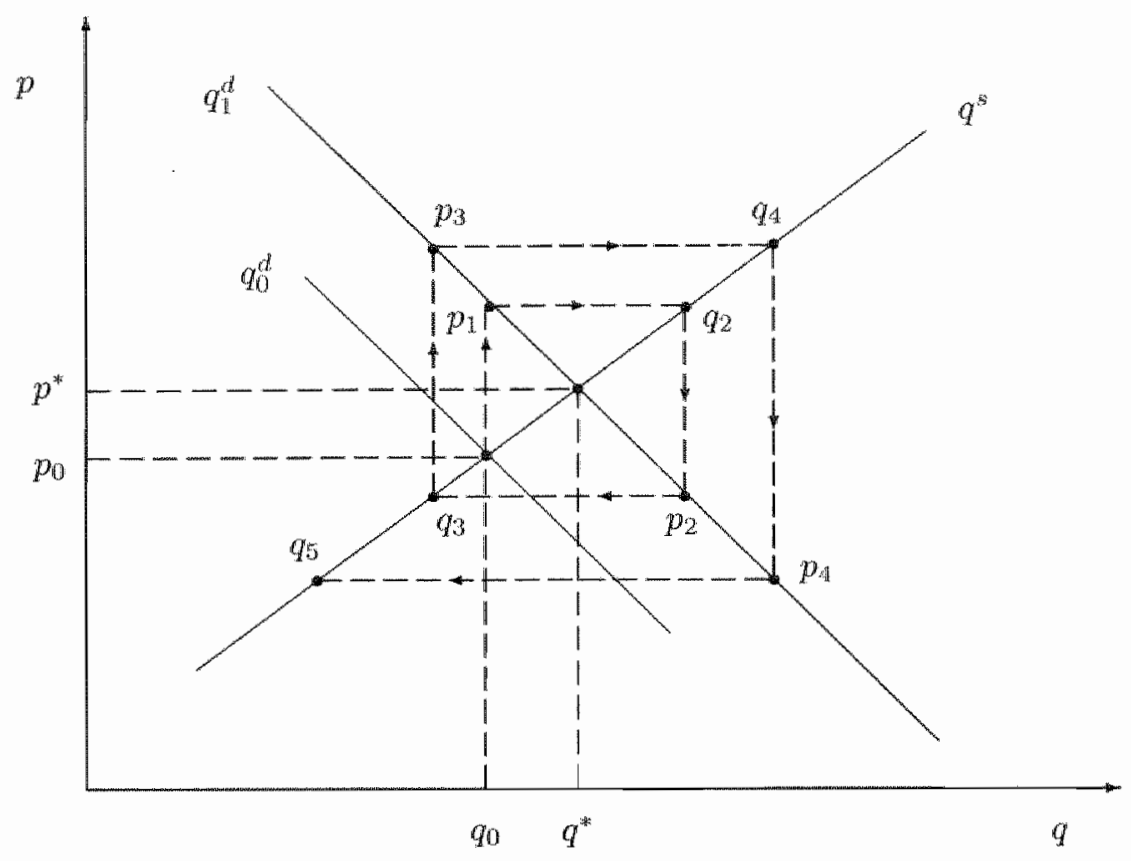

Figure 1.2 The cobweb model as a partial out-of-equilibrium theory.

Naturally, this line of thought leads to conchisions on the persistence of out - of equilibrium that go at the relative slopes of the supply and demand functions. On this a literature developed that concluded that convergence to equilibrium results when demand is elastic relative to supply, divergence would result if supply is elastic relative to demand, and constant cycles would result in the case of equal elasticities. ${ }^{12}$

The idea that issues of disequilibrium and stability boil down to the elasticities of supply and demand has been persistent. Yet, the cobweb model presupposes crucial elements of a rather rudimentary theory of disequilibrium. For one thing, supply and demand are constant over the years, and not influenced by the transactions on this particular market, which apparently take place at disequilibrium prices. Also, the adjustment of prices upon each harvest is taken to be very quick, without offering an explanation for this. That is, each supply of agricultural product is fully matched by

$12 C f$. Kaldor (1972) and Schultz (1938). The latter proposed that stability would be helped by farmers predicting the effect, and adjusting quantities conservatively. 
demand through the adjustment of prices. Also, of course, farmers are not taken to be sufficiently organized to understand they exert an influence on prices.

More importantly for the case in point, however, is the fact that the analysis does not reckon with spill-over effects into and from other markets. In the first year, when farmers earn unexpectedly high incomes due to the exogenous increase in demand at given supply, they face an increase in spending power. This they will exercise on other markets. As a result, demand rises in these markets as well-although the initial rise in demand for agricultural products must have its repercussions in terms of demand falls in other market, which illustrates the point equally well. This implies that prices in other markets rise. At least two different effects can be expected. Those who sell in these other markets see an increase in income similar to that of the farmers. Those who buy, however, see their incomes decrease. Both have an effect on the demand for agricultural products, yet in opposite directions, and the dominating effect can not easily be determined. A back-swing of demand for agricultural products will help establish equilibrium in that market. An additional out-swing will further disequilibrate it. Moreover, changes in the elasticity of demand have their effect-and thus disqualify stability results that rely on these. And these remarks concern only the effects through the demand side of the market. Changes in supply are equally likely. Clearly, nothing straightforward can be said on these important effects in a partial model. Disequilibrium analysis requires a general equilibrium perspective instead. ${ }^{13}$

\subsubsection{Information and Expectations}

In disequilibrium behavior, a central role is played by information. In the two-individual exchange problem given in Section 1.1, the decision to accept or reject a trade offer is guided by the ability to foresee the consequences of such a decision--or in the absence thereof, by the expectations of the consequences-and hence by information had on the specifics of the economy. Likewise, in the cobweb model of the previous subsection, the fact that farmers are apparentiy tuable to level their income over the years reveals their inability to see through the structure of supply and demand and escape its grip. In both examples, subjectively rational decisions may not be objectively rational as a result of less than full information on the side of the decision makers.

In fact, the absence of full information on the economic environment in which individual's make their choices is essential for a meaningful theory of out-of-equilibrium behavior. Failure to see this has led to confusion about the importance of disequilibrium analysis. This is well illustrated by the question of stability as presented in the textbook Cournot duopoly model. ${ }^{14}$ Apart from the fact that the model offers a partial analysis only, the stability issue in this setting is generally meaningless due to the abundance of available information.

Consider the version of the Cournot duopoly model illustrated in Figure 1.3. Two firms serve the demand for a commodity - which is assumed to be linear. Both deter13 In lact laker developments in global stabity theory by Hicks and Sammelsom departed from
this observation on the cobveb model. Cf. Chapter 3 .

O Co Gobons $(1992), 0.14-21$ 
mine the quantity they will offer for sale independently, after which prices establish that clear the market. Both frms have full knowledge of the specification of the demand function, their own cost function, as well as that of their respective rivals - both firms generally are identically operating at constant marginal costs. Each firm is taken to maximize profits under the behavioral assumption that the quantity the other firm offers is independent of its own quantity. This results in two reaction functions, the intersection of which-under the given specifications a single point-satisfies both optimal strategies simultaneously such that no frm has an incentive to deviate, and is therefore a Nash equilibrium.

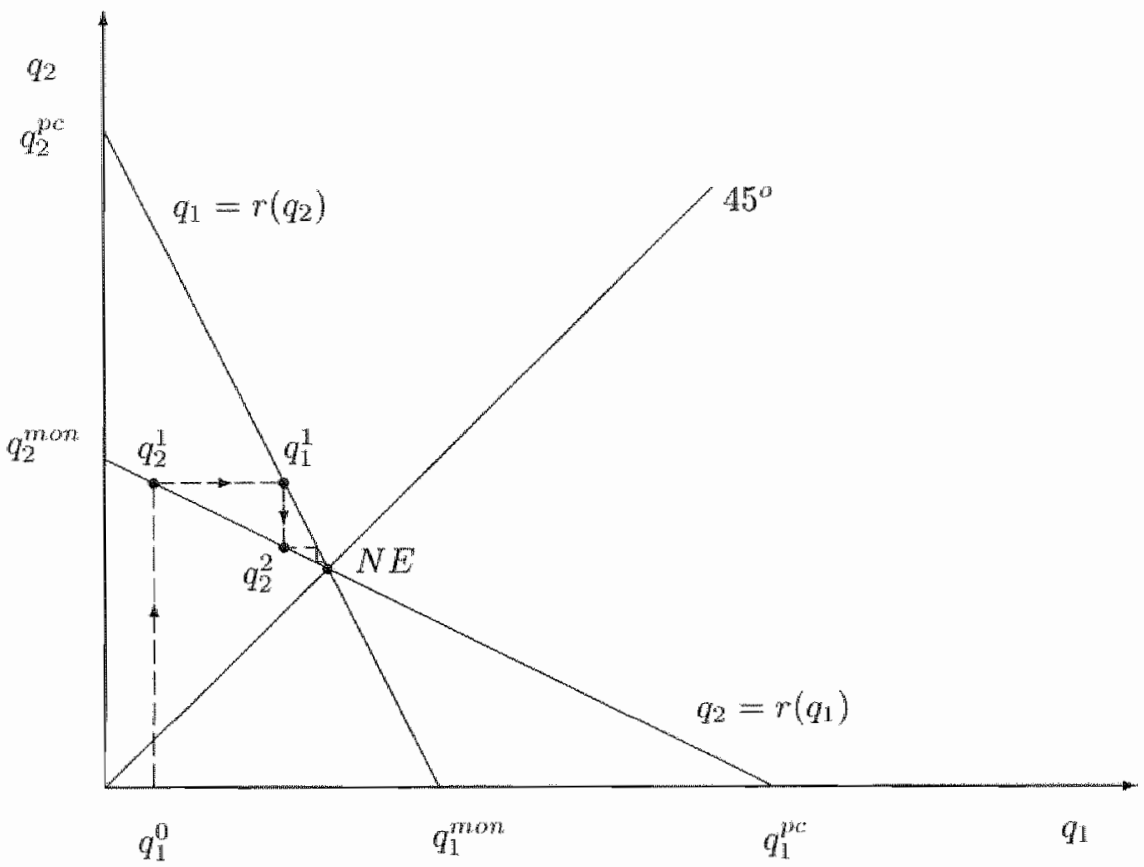

Figure 1.3 The inrelevance of stability analysis in the Cournot duopoly model.

The stability issue in this model has some history. In fact, Augustin Cournot himself discussed it in his original exposition. For an arbitrary quantity produced by any one of the firms, the argument goes, the other firm reacts according to its reaction function. The first firm then produces its best reply, and so forth. This reasouing is illustrated in the figure by a dotted line. Whether convergence on a Nash equilibrimm takes place-. as drawn-maturally depends on the relative slopes of the reaction functions. An early formal approach to that effect has been developed in the classical sequence of references Theocharis (1959-1960), Fisher (1961), and Hahn (1962c). The consecutive articles consider the stability problem for a general number of frms, and derive the sufficient condition under the adjustment process described that for neither firm marginal costs 
should fall faster (if at all) than demand, and that each firm's marginal revenue should fall were the other firms to expand their output. Fudenberg and Tirole (1995) present the more straightforward condition for the duopoly case, which is that the product of the absolute values of the slopes of the reaction functions be strictly smaller than one. $^{15}$

The point is, however, that this type of disequilibrium analysis makes litile sense. Given the knowledge of the market they operate in assumed in the determination of the reaction curves, and given the fact that it concerns a one-period, simultaneous moves model, neither firm has, upon a little reflection, any incentive to produce anything but the Nash equilibrium quantity - after all, this is what the definition of a Nash equilibrium says. Consequently, upon calculating their own and their rival's reactions, each firm will promptly choose to produce its part of the Nash equilibrium output. The adjustment process drawn in Figure 1.3 and substantiated with the groping story is at odds with the model. The stability conditions are meaningless. ${ }^{16}$

The upshot of this critique is that a meaningful disequilibrium theory departs from a model in which individuals do not have all relevant information-and form expectations instead. In models that involve many firms and consumers, this is not an heroic assumption. Less than full, information can take at least three forms. First, individuals can be taken to have incomplete information. That is, they may not have insight into all the specifics of the structural specification of the economy in which they operate. They may, for example, not know the private preferences of their neighbors. Second, people can be assumed to have imperfect information. That is, they may fail to have all knowledge of the past behavior of others- or themselves for that matter. They may, in other words, not know the full history that led up to their present situation, including, perhaps, lack of memory of their own past actions. Finally, individuals can lack perfect foresight. That is, they may not have full information on all future exogenous changes and consequently, may not be able to predict the future perfectly.

All three of these types of less than full information establish a difference between the objective state of affairs on which information can be had, and the subjective knowledge available. In the two-person exchange problem of Section 1.1, perfect foresight is not an issue, as there are no exogenous events, both individuals have incomplete information, as they do not know each other"s offer curves. They conld and could not

15 Op.cit., p.24. The subject is an issue of both theoretical and ampirical research still. Cf. Seade (1980) and Dowmer (1992).

If Cf. Friedman (1983), Chupter 2. The same is true here if firms have less than full knowledge, but expectations that are common knowledge. Whenever firms know the reactions of all other firms, the best thing to do is produce the Nast equilibrim ontput. It should be noted, however, that ingeneral the $\mathbb{N}$ as equilibrim is not necessarily played if players hold wonjectures abont heir opponents" play that are rasonable in the sense that they can be rutionalized as expected play against the other players" conjectured play. In general, common knowledge of conjectured play and rationality lead only to rationahability and not to $\mathbb{N a s h}$ equilibrium. Cf. Bermeim (1984) and Pearce (1984), who

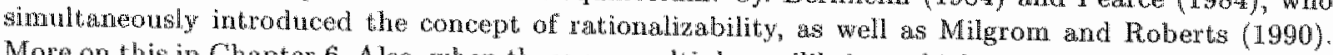
Mose on this in Chapter 6. Also, when there are multiple equilibria which can exaly happen for more general specifoations of denand and costs-this conclusion is weakened. Then there will generally be wontict of interest anong the frms over the Nash equibrium to play, and some selpotion mechanism is requared. Here a disequilibrinm thery of the type described has a role to play. 
have imperfect information. In the cobweb model above, farmers have no perfect foresight into the exogenous demand shock, they lack complete insight into the market relations, as well as perfect information on the behavior of other farmers, as they are communicated only market prices.

Finally, it should be noted that although less than full information is a prerequisite for a theory of disequilibrium, it can also be dealt with purely in an equilibrim manner. Moreover, equilibrium does not necessarily imply full information. In fact, general equilibrium theory has been able to incorporate uncertainty and expectations very elegantly into its main results. ${ }^{17}$

\subsubsection{Equilibrium as a Rest-Point}

The notion of an equilibrium as an identifiable situation in which plans match has long been tangled up with the more dynamic concept of an equilibrium as a position of no further change, or rest. Smith gave every reason to do so. After identifying 'natural prices', associated with generally acceptable rates of 'normal' profits, that were argued to be the outcome of a process of 'free competition', he wrote:

"The natural price ... is, as it were, the central price, to which the prices of all commodities are continually gravitating. Different accidents may sometimes keep them suspended a good deal above it, and sometimes force them down even somewhat below it. But whatever may be the obstacles which hinder them for settling in this centre of response and continuance, they are constantly tending towards it." (Smith, 1979, p.75)

What is offered here is a rudimentary insight into out-of-equilibrium behavior of economies-an insight later on embodied in the metaphor of the invisible hand, discussed above. The same is true for Ragner Frisch's definition of disequilibrium in his very influential paper On the Notion of Equilibrium and Disequilibrium, written in a hotel room over night after a discussion on the subject with, anong others, Tjalling Koopmans and Jan Tinbergen, and presented the next day. It reads:

"[When] no tendency to change exists ... the system may ... be said "to be in equilibrium." Otherwise it may be said to be in "disequilibrium." In the latter case the system would, if left to itself, change its configuration as time goes on." (Frisch, 1936, pp.101-2)

To substantiate either of these claims requires an actual theory on out-of-equilibrium dynamics. The point here is that the idea of an equilibrium as a situation of fully compatible plans is not inconsistent with that of equilibrium as a rest-point of some disequilibrium process. Quite to the contrary, indeed. Tibor Scitovsky, for example, in his praised book on welfare economics, first published in 1952, wrote:

"The word 'equilibrium' means a state of rest. A person is in equilibrium when he regards his actual behavior as the best possible under the circumstances and feels no urge to change his behavior as long as circumstances 
remain unchanged. The same is true of the equilibrium of a frm. A market, or an economy, or any other group of persons and frms, is in equilibrium. when none of its members feels impelled to change his behavior. For a group to be in an equilibrium, therefore, all its members must be in equilibrium; and the equilibrium behavior of each member must be compatible with the equilibrium behavior of all the other members." (Scitovsky, 1963, $p p, 230-1)$

Understanding equilibria as rest-points of disequilibrium adjustment provides a very useful perspective on questions of disequilibrium. For one thing, only out-ofequilibrium dynamics that is played out fully if and only if prices equal competitive equilibriun prices-comparable to Smith's 'natural prices'-would be able to capture the applied notion of "free competition". In general, however, there is no particularly good reason to impose such a constraint on disequilibrium theory. In fact, it will be argued there lis sufficient reason not to do so. As a consequence, the rest-points of selected disequilibrium dynamics can become the equilibria of interest.

\subsubsection{Statics and Dynamics}

A term applied already several times is dynamics. There are various ways in which the concept of dynamics is understood, and the subject is as potentially puzzling as that of equilibrium. John Stuart Mill wrote in 1843 in his two volumes methodological investigation A System of Logic, Ratiocinative and Inductive:

"Social Dynamics is the theory of Society considered in a state of progressive movement; while Social Statics is the theory of consensus ... existing among the different parts of the social organism ...." (op.cit., p.508)

If consensus is read as equilibrium in the above meaning, to Mill dynamics was something related to the absence of it. "That is, dynamics to Mill belongs to the realm of disequilibrium analysis.

To Walras, the founding father of microeconomics, however, dymamic theory was primarily theory involving changes in the underlying fundamentals of the economy, i.e., changes in preferences, technology or commodities. He understood dynamics, therefore, mainly as changes over sequences of moving equilibria that consequently
are temporary. 18

Yet, Walras also left the following beautiful dynamic picture at the end of his book Elements of Pure Economics. ${ }^{19}$

"[The market is like a lake agitated by the wind, where the water is incessantly seeking its level without ever reaching it." (op.cit, p.380)

Of. Walras $(1954)$, p.318.

Elements d'comorne poltigute pure was published in five editions, the first in 1874 , the last cdution definitine in 1926. Almost wntil his death in 1910 Walras reedited his life's work. All quotes Whate. 
Here, clearly there is a dynamics imvolved that is similar to Mill's.

Finally, Hicks, to whom the full introduction of dynamics into the economics is often attributed, consictered a theory dynamic when it involves dated commodities which can apply to both dynamics over disequilibria and over series of changing equilibria, each corresponding to slightly changed fundamentals. ${ }^{20}$

With the help of the analytical distinction between equilbrium and disequilibrim made above, an analogous clistinction between equilibrium and disequilibrim dynamics can be made, which is closest to Hicks'. Essentially there are three different types of dynamics to be identified. First, there is the dynamics of intertemporal choice models. These include, for instance, general equilibrium models with dated commodities and overlapping generations. In these models the equilibria of individual planning problems involving different time periods are considered. The analysis focuses on sequences of equilibria in the sense of compatible plans that stretch over time. These planning problems can be complicated, for instance when endownents change over time, either in a foreseen way or by means of exogenous shocks, or when there is a clear time preference. Their study applies methods of dynamic optimization, resulting in equilibrium time-paths with associated equilibrium price vectors-particular ones of which, typically those that display constant price ratio's and allocations, are commonly referred to as steady-states. In equilibrium dynamics, the influence of shocks is considered by comparing equilibrium time-paths. ${ }^{21}$

The second type of dynamics is diseguilibrium dymamics. It concerns the behavior of economic magnitudes over different stages in which plans do not match-everything else remaining constant. In most cases this is done with an interest in processes directing the economy towards an equilibrim. In those cases the dynamics is modelled to understand the equilibrating processes, or convergence processes at work. Hence, it is disequilibrim dynamics which provides the structure for studies into market mechanisms.

As already said, general disequilibrium dynamics is studied in general equilibrium models. These can be equilibrium models that do not involve dated commodities, as well as dynamic equilibrium models. The latter make a third type of dynamics possible. Dynamic equilibrium models supplemented by disequilibrium dynamic mecharisms allow for a description of the behavior of the system when there are small disturbances: from the equilibrium time-path. These combined infuences of the passing of time quicky introduce difficult problems. For instance, the question what happens when individuals anticipate on future developments of the disequilibrium processes, and tailor their plans accordingly. Furthermore, in such models, it is hard to separate the instantaneous infuence of exogenous shocks on the equilibrium time path-which is generally not immediately reached from the accommodating effect of the adjustment: process by which a steady-state path is re-established.

\footnotetext{
20 Of Hicks (1939), p.115, hrsi published in 1939. To Hicks, it meant particularly sequences of temporary intertemporal equilibria, as he had little eye for disequilibrium as defined here-as axet out in Chapter 3.

21. The equiburium analysis of decisions involving tirne is the dominant approach in theory. $C$ f Mas-Colell et al. (1995), Chapter 20.
} 


\subsubsection{Time, Distance, and Speed of Adjustment}

Closely associated with the issue of statics and dynamics is that of time. Particularly of interest for out-of-equilibrium analysis is the time it takes to adjust plans relative to the time over which plans stretch. In a simple model in which planning has no time dimension, an equilibrium is of relevance if the plans thus defined become compatible before any changes in the underlying structure have modified them. Such changes are assumed to be absent, yet, the relevance of that assumption is closely tied up with the speed of adjustment.

In a dynamic equilibrium model, however, the values of fundamentals change over time. Preferences for example change, or endowments. Similarly, as time unfolds, the dates of commodities can well go past. Even though these changes are anticipated, it depends on the relative speed of adjustment of the disequilibrium process specifiedor the anticipation thereof-whether these changes take place while the economy is already in equilibrium or still in disequilibrium. This matters, and is well formulated by Heinrich von Stackelberg in his textbook The Theory of the Market Economy, the English translation of which was published in 1952 :

"[I]n reality there is certainly no long-period equilibrium position, for before a current process of adjustment has come to an end the data have changed once again and a new compensatory process begun, which in turn will be interrupted before it has resolved itself, because in the meantime there has been yet another change in data; thus the actual economy is always in a state of transition and the long-period equilibrium is never established." (op.cit., pp.156-7) ${ }^{22}$

In fact, the concern with stability issues in the 1930's derived mainly from the potentially disharmonious interplay of adjustments to intermediate exogenous and endogenous changes in different markets that were thought to cause business cycles. This holds for Eugen Böhm-Bawerk and Hayek in the Austrian school of thought, as well as for Lundberg, an exponent of the Stockholm school. ${ }^{23}$ The latter wrote: ${ }^{24}$

"If the adaptation [of the economy] to given changes in the data takes place at all, it must actually be happening within a certain period of time which can not be discarded or eliminated, unless it is shown that nothing of relevance to the system occurs during this time. This implies on the one hand, that new changes in the data do not set in before complete adaptation has had time to take place; on the other, that the adaptation process itself does not influence the fundanental conditions of equilibrium." (Lundberg, 1937, pp.2-3)

In their writings, these authors devoted much attention to the definition of "unit periods', periods of a length in accordance with time taken by the adjustment processes

22 This long run-short run distinction was introduced by Alfred Marshall to deal with disequilibrimm issues as temporary phenomena. $C f$. Marshall (1920), pp.313-5.

23 Of. Keesing (1939), Cllapter 7 , particularly pages 150 - 1 .

2. To Lundberg, this was an important argument to consider disequilibrium issues in a general equilibrium context (ibid.). 
as well as changes in the underlying data. ${ }^{25}$ Modern economic theory, however, has very bittle to say on speeds of adjustment. This is a direct consequence of its lack of attention for disequilibrium issues in general. Yet, it has also to do with the fact that a theory of speed of adjustment requires a concept of 'distance" between equilibrium and disequilibrium, and more importanty of 'size' of the steps with which any movement towards or away from equilibrium is foreseen. These are difficult matters. The extent to which plans do not match can be understood in different ways. Quite naturally perhaps, 'distance' is captured by combining the aggregate excess demands at a given disequilibrium price vector. Yet changes in distance thus defined over time require some idea about business activity against disequilibrium prices. Is that in kilograms, lots or bulk, and how regularly? Particularly problematic in this respect is the fact that, in general equilibrim theory, there is no particular unit of account for commodities. This leaves the matter of speed of adjustment largely unfounded. ${ }^{26}$

The focus on equilibrium has led to an almost exclusive focus on disequilibrium be havior that has no influence on the plans of individuals. That is, adjust,ment processes, if modelled at, all, are considered to be neutral and instantaneous. It is sometimes said that these processes operate "outside of time," in the sense that any of the changes proposed in the adjustment process only materializes when those exact changes are found that match all plans simultaneously. The reason for this is quite obvious: allowing, in addition to exogenous changes to the fundamentals of the underlying economy, endogenous changes related to out-of-equilibrim behavior greatly complicates matters.

\subsubsection{Convergence and Stability}

Disequilibrim dynamics raises questions of convergence and stability. Several times already these terms appeared above, without properly specifying them. Traditionally, to the extent that they have been considered, the disequilibrium dynamics properties of modem general equilibrium models have been studied in an onganized fashion in a discipline called stability analysis. Stability analysis bas seen different concepts of stability and it is of importance to consider them briefy. ${ }^{27}$

The frst concept of stability is that of local stability. An equilibrium is locally stable if, when slightly perturbed, there is a return to it or a neighborhood of it. Naturally, a study of this requires an identification of the equilibrium of which the local stability is studied, as well as an explicit model of the disequilibrium responses to a slight purturbation.

A more general type of stability analysis is global stability analysis. Global stability analysis is concerned with two types of questions. One is whether, for all initial prices

25 Cf. op.cit. p.47 and p.187.

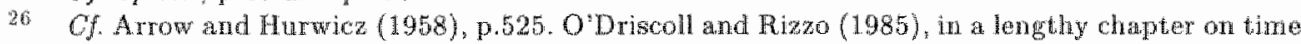
in economics, points to various issues here addressed in a dwell on the difference between so-culled "Newtonian time" and 'real time" that reflects a refusal to accept abstract theory. An earlier Anstrian exposition on time is offered in Shachle (1957, 1961).

27 Of. Newman (1959) and Newman (1961). For a more forma approacli cf. Hahn (1982b) or Takayame (1985), Section $3 \mathrm{H}$. 
in a certain set, convergence of the specified disequilibrium adjustment process takes place on a particular equilibrium. This is the global stability analysis of equilibria. As it identifies regions of initial prices for which there is convergence of the specified disequilibrium adjustment process on equilibrium, this type of global stability analysis can be thought of as local stability analysis for very large perturbations.

The other question, particularly relevant for general equilibrium models with several equilibria, concerns the identification of regions of initial values for which the dynamic process would converge to some one of the equibria. That is, the question of global stability of the dynamic process, also called system stability. Naturally, in case of a wnique and fixed equilibrium and only then - these questions are identical. It is also important to note that the formen, global stability of equilibria, only has meaning if those equilibria are independent of the adjustment process, that is, if the adjustment process is neutral-which is assumed in close to all stability literature. Yet, the global stability of dynamic processes explicitly allows for path-dependency of equilibrium.

The notion of stability as convergence to equilibrium corresponds to the mathematical concept of asymptotic stability, introduced by Samuelson with the definition of the problem. It requires that every motion of the system starting sufficiently near to an equilibrium or a set of equilibria converges to that equilibrium or that set as the time that has elapsed increases. Asymptotic stability is equivalent to what Samuelson called 'Stability of the Furst Kind'. Asymptotically stable equilibria are what he referred to as "truly dynamically stable" equilibria.

A less stringent concept of stability is stability in the sense of Lyapounov. A system and its equilibrium are considered Lyapounow stable if, when perturbed slightly from its equilibrium, all the subsequent motion remains close to the original equilibrium, without necessarily converging to it. Lyapounov stability therefore does not require a. return to equilibrium. It only excludes an explosion of the system. Lyapounov stability corresponds to Samuelson"s stability of the second kind. In Hahn's 1982 overview of stability analysis a system is defined as stable if all its equilibria are Lyapounov stable.

In Figure 1.4 the various concepts of stability are illustrated. ${ }^{28}$ Within the innercircle, a process starting at $x_{0}$ is stable if it remains in the area $S$, and unstable if it develops outside of the boundary of $S$. The process is asymptotically stable if it converges to equilibrium $x^{*}$. If all possible adjustment paths from a certain set of initial allocations converge to $x^{* *}$, then $x^{*}$ is said to be globally asymptotically stable in that set.

Another stability concept that has played an important role in the literature is quasi-stability. It is more demanding than Lyapounow stability, yet less stringent than global stability. A process is said to be quasi-stable if every limit point of the time path of the adjustment variable(s) is a rest point of the process. The difference between global stability and quasi-stability is that a process can be quasi-stable, yet converge to no rest-point in particular. It allows, therefore, for rest-points that are not isolated. Ir Figure 1.4 a quasi-stable adjustment from $x_{0}^{\prime}$ to the inner-circle is drawn. Quasistability plays an important role in the Second Method of Lyapounov for prowing

2s Based on Salle and Lefschetz (1961). 
stability, which has been very important in the study of stability-and has to be separated from Lyapounov stability.

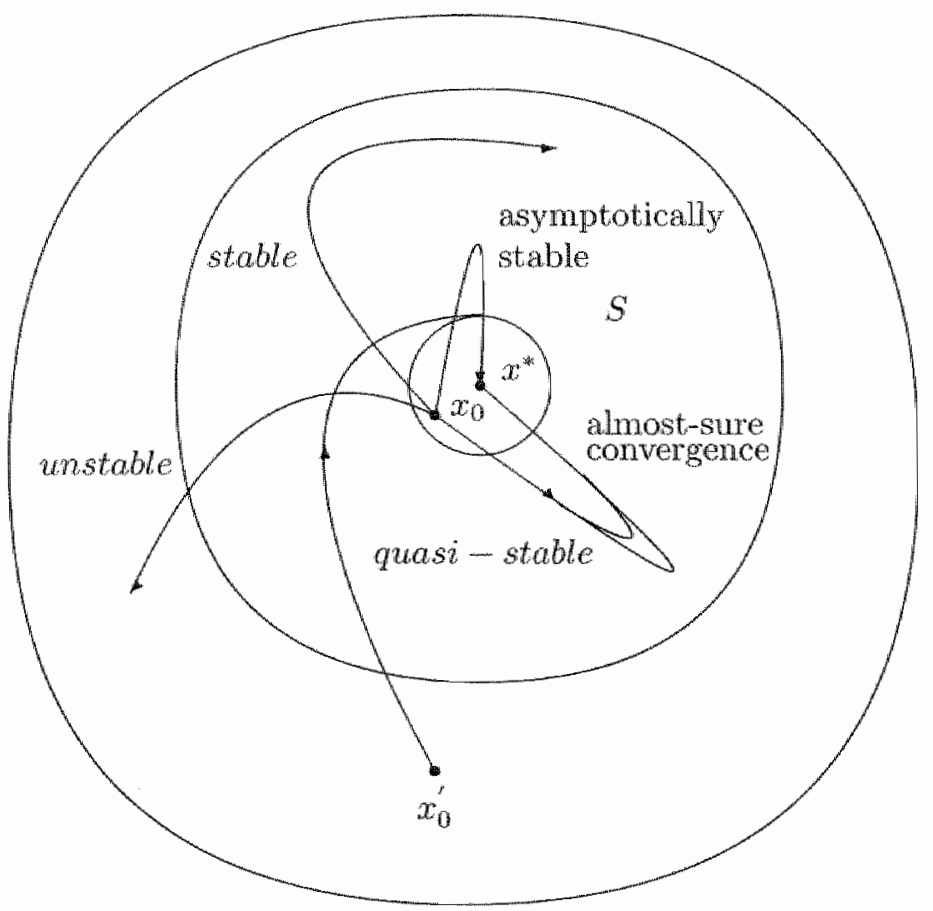

Figure 1.4 Some stability concepts illustrated.

Finally, it is of importance to introduce the concept of convergence in probability, or: "almost sure convergence". A disequilibrium process converges almost surely if for any given initial allocation, the set of paths that converge to an equilibrium has neasure one in the set of all possible paths developing from that initial allocation. That means that of all possible developments according to the disequilibrium theory, almost all will converge. In Figure 1.4 , the process starting at $x_{0}$ and potentially developing according to the paths drawn from there converges almost surely, as only a single path does not end in equilibrium, whereas all othen possible developments do. Convergence in probability is a concept reserved for processes. Yet, an adjustment process can converge 'almost surely" from any initial allocation to one and the same equilibrium, as drawn in the figure. 


\subsection{The Need for Disequilibrium Theory}

After having addressed some of the conceptual and semantic issues surrounding the study of disequilibrium processes, and having brushed upon several arguments for its relevance, it is important to stress the need for it in a more organized fashion. At least six different arguments can be made for an in-depth analysis of the out-ofequilibrium behavion of economies. They all have theoretical, as well as important political ramifications.

A first argument remains closest to the mainstrean view that general equilibria are of central importance to analysis, leaving disequilibrium analysis as a side-issue. This view is based on the idea that economies are always in equilibrium, or instantly, or at least very rapidy, adjust to one. As a result, it is argued that it suffices to restrict attention to positions of equilibrium only. Disequilibrium situations are simply denied any relevance. In Reder (1982) this approach is called "Tight Prior Equilibrium", and associated with the Chicago school of thought ${ }^{29}$

One way of granting the view that economies are close to always in equilibrim is to assume that all individuals posses all information necessary for them to each individwally identify the equilibria comesponding to any given situation of their society, and to realize they cannot do better than do what they would do in equilibrium. For that to be possible, information on all relevant data such as the complete distribution of endowments of resources over all individuals, their preferences and production techniques would need to be common knowledge. This seens a rather strong assumption. In fact, in general equilibrium models, it is plainly unacceptably strong.

Another, closely related, argument is that although individuals have limited amount of information such that they are not able to each individually solve the coordination problems between them explicitly, prices are a sufficient statistic for guiding them in wanting only what is mutually consistent with the plans of all others. Moreover, market processes are swift and take care of establishing these prices very quickly, so that persistent positions outside of equilibrium are non-existent and hence need no special attention.

Clearly, it is true that equilibrium prices, if they exist and once they are established, have the property that they coordinate plans. Also, competition is Jikely to help the spread of information through prices. In fact, this is fully in line with the view of those quoted above who take disequilibrium theory seriously-particularly, the idea that prices convey information is associated with Hayek (1937). Any justification of the argument that such happens very quickly, however, rests on a theory of out-ofequilibrium behavior, and this provides the argument for studying it. It necessarily relies on two underlying properties of disequilibrim behavior.

The first is that such dynamics is globally asymptotically stable, leading the economy to the center of attention, equilibrium. The second is that such converging dynamics is quick, particularly relative to other changes to the economy, such as in its underlying structural parameters. Trust in the smooth and quick convergence of outof-equilibrium behavior to any one equilibrim assumes the existence of an adjustment

29 of op.cit., pr.11. 
process with very high speeds of adjustment. Research into disequilibrium behavior is of prime importance to substantiate such implicit theory, and corroborate, or possibly falsify ideas on its reliability. Without it, the Tight Prior Equilibrium view amounts to trust in an assumption, a belief, that is. Such camnot be considered a particularly strong argument for the relevance of equilibrium economics. Disequilibrium theory, in other words, is necessary as a foundation of equilibrium economics if the latter is to have any claim of prominence. 30

A brief discussion of rational expectations theory is appropriate here ${ }^{31}$ The rational expectations approach takes a stance similar to Tight Prior Equilibrium -and it is no coincidence that it is of Chicago origin. It argues that people's expectations, specifically as to the behavior of prices, will never be structurally false. For this to be true, however, obviously it is necessary for all individuals to have a clear knowledge of the structure of the economy. Muth (1961) first introduced rational expectations theory as a reply to the literature on mechanistic adjustments outside of equilibrium of the type staged in the cobweb model discussed above, and with an argument of that kind. That is, it posed the question why the individuals peopling an economy should not have the same information as the economists studying it. Even when unsight in the structure of the economy is at some point expected with individuals-although this is a very strong assumption indeed - to have an understanding of the parametric specifications of all relevant issues is really unacceptably strong. In fact, general equilibrium theory has succeeded in moving quite some distance awray from that necessity, seeking general assumptions on data for the existence of equilibria with quite desirable properties. ${ }^{32}$

If rational expectations theory is just the hidden assumption that all indiwiduals possess all relevant information to calculate all equilibrium prices, it is the old "Tight Prior Equilibrium story. If it is a theory of rational action given all the information available to an individual, it is certainly the first step in a satisfactory theory of disequilibrium behawior, wich then considers changes in the information available.

A second argument rests on a point of view which is quite orthogonal to that of the mainstream. 'This view is that disequilibria, and especially the processes of partially matched plans and their subsequent adjustment that run over situations of disequilibrium, are an appropriate description of reality, and provide a better understanding of economics than an equilibrium perspective-ruling out that latter as meaningful. Economists working in the Austrian tradition approach economic phenomena in this way. ${ }^{33}$ One of their founding fathers, Ludwig won Mises stood with his Human Ac-

\footnotetext{
Jo One regularly referred to result for which this is trut and important is the Coase thoorem-of. Mas-Cotall et al. (1995), pp.357-8.

il. More on this subject in Chapter 6 .

32 That is not to say that the amonnt of infomation ind widuals have in equilbrim on future prices on state-contingent makets is still staggering in general equibrum models that involwe thime and uncertanty. proticnlarly in models with imperfections such as imcomplete markets. Vet, the rational expectations approach pushes the level of sophistication to a limit. Cf. Hirstaller and Riley $(1992)$, Section 6.3
}

33 And so did those of the Stockholm school. Cf. Lundberg (1937), which opens as follows:

"The ultimate purpose of all economic theory is to analyse changes in economic life with respect to time." (op.cht., p.1) 
tion, first published in 1949, together with Samuelson's Foundations, at the basis of the important junction in economic thinking in the late 1940's between this view and the previously discussed, neo-classical approach - a junction which involved a debate on several methodological issues, such as the appropriateness of mathematics to economic analysis, but importantly also the issue of equilibrium versus disequilibrium. Von Mises wrote:

"We want first to analyze the tendency, prevaling in every action, toward the establishment of an evenly rotating economy; in doing so, we must always take into account that this tendency can never attain its goal in a universe not perfectly rigid and immutable, that is, in a universe that is living and not dead. Secondly, we must comprehend in what respects the conditions of a living world in which there is action differ from those of a rigid world. This we can discover only by the argument a contrario provided by the image of a rigid economy." (von Mises, 1963, p.250)

Naturally, the view that disequilibrium processes are of prime interest over equilibria calls for attention to the former. Austrian economics has provided important insights into elements of their understanding. One that has been developed particularly by Israel Kirzner, is that the entrepreneurial behavior of individuals in disequilibrium is likely to constitute a drive towards equilibrium. By exploiting the profit opportunities that exists, for instance, due to an uneven availability of particular information, such as the specific knowledge that some commodity can be bought cheap somewhere, and sold expensive elsewhere, entrepreneurs reveal these 'holes in the market', thus opening them up for competition. One consequence of this is that profits are not at all necessarily a bad. They are, instead, instrumental in equilibrating the economy.

An opposing Austrian disequilibrium view, associated with the work of Schumpeter, stresses that there are individual incentives that work towards destabilizing equilibria and the obstruction of convergence. As it can be profitable to exploit disequilibria for some, the possibility of creating new profit opportunities may well work against convergence on competitive equilibrium. ${ }^{34}$ A precise model, or a comprehensive consensus on which of these two effects is likely to dominate, lacks. Only a substantive theory can illuminate these issues, and confront the Austrian view with that of Tight Prior Equilibrium.

A third argument for out-of-equilibrium economics rises from an essential equilibrium property of general equilibrium models, the existence of multiple equilibria. It is valid even if no interest is taken in the adjustment process as such, and its swift working is relied upon. The presence of multiple equilibria is commonplace in general equilibrim models - as they are, in fact, in partial equilibrium models. Generally, for any given initial allocation, preferences and production techniques allow for several allocations where plans match. Obviously, when there are several possible equilibria that are in some sense isolated, a globally asymptotically stable adjustment process

34. The equilbriating, or somalled Kirznerian, entrepreneur is staged in firmer (1973), which aso oflers a discussion on the Schumpeterian entepreneur who disequibrates through "ateative destruction", process Schumpeter envisioned to undermine capitalism in Schumpeter (p974). 
converges on a particular one. Possibly a different one for different starting prices, maybe not. Essential is that in equilibrium models with multiple equilibria, any stable adjustment process can by definition not be neutral: it selects one of the equilibria. The final equilibrium, in other words, is path-or history-dependent. Only a study of the adjustment process, therefore, can shed light on the relevance of any one particular equilibrivm. 35

Two types of path-dependency are worth distinguishing here. The first is most traditional. It results from non-uniqueness of Walrasian equilibrium. Uniqueness of Walrasian equilibrium in general equilibrium models of perfect competition is only guaranteed under extremely strong conditions on preferences and production techniques. Assuming these conditions to apply is totally unnecessary from the perspective of research that aims at establishing the existence of equilibrium. Moreover, it greatly reduces the generality of its insights. In the case of several Walrasian equilibria, a converging adjustment process that is neutral in the sense that it does not change the set of equilibria corresponding to the initial allocation, singles out one Walrasian equilibrium.

In the example of Section 1.1, this type of path-dependency of the eventual Walrasian equilibrium was illustrated. Consider again Figure 1.1. As set ont, a Walrasian equilibrium is a vector of relative prices that constitute the budget constraint for both individuals on which, apart from their respective initial endowments, lies an allocation in. the core which is the optimal choice for both at the given prices. The price ratio $-\frac{\mu_{1}}{p a}$ and endowments $X^{0}$ thus support the Walrasian equilibrium $W$. There is no particular reason, however, why there should be only one such vector of relative prices. In fact, there are many-in regular economies a finite and odd number of locally isolated ones. ${ }^{36}$ Which one is relevant is a mater of disequilibrium theory.

The upshot of this insight is, of course, that the presence of multiple Walrasian equilibria does not constitute a problem in a model that offers an understanding of outof-equilibrim dynamics. Asymptotic convergence implies uniqueness of the relevant equilibrium. The point is, however, that comparative statics withont a disequilibrium story offers insufficient argument for considering upon some exogenoms change, any one particular equilibrium over another.

This is even more pressing in a second type of path-dependency. There is no particular reason other than perhaps some deriving from sociology of science that will be considered later--to assume that what happens out-of-equilibrium has no infuence on the equilibria of the model in the way neutrality was defined above. In fact, all allocations in the core share the property that they represent matching plans that are individually (weakly) preferred over the initial allocation. Hence, it is possible to think of an adjustment process that ends in any particular one of these core allocations. Not ali may be equally likely some may need to be ordained-but that is a matter of disequilibrim theory.

$3:$ Recently, Halin stressed the need to do out-of-equilibrim research to substantate equilibrium analysis when equilibrie are history dependent in Hahn (1991). Other references to hinstory dependency of equilibrium are Fisher (1960) and Krugman (1991).

36 Cf. Debreu (1970), Dierker (1972) and Dierker and Dierker (1972). 
Ta Figure 1.1 again, this second type of path-dependency of equilibrium was illustrated by the fact that out-of equilibrium trade up to $h^{1}$ excluded the Walrasian equilibrium $W$ from the core. Once the two individuals are at $h^{1}$ they reconsider their options, and trade again. In fact, the allocation at $h^{1}$ can be seen as a new initial allocation which refines new lens. Within it, any allocation could be the result of the next trade, ever reducing the set of potential next trades. Several steps of a simillar nature would have a converging adjustment process eventually zoom in on any one particular allocation in the initial core. Hence, the entire set of infinitely many equilibria indicated by $C C$ are all potential equilibria of some adjustment process. ${ }^{37}$ Consequently, the equilibrium of a full out-of-equilibrium story is totally depending on that story. Path-dependency of equilibria, therefore, is an essential feature of general equilibrium models, even if the Walrasian equilibrium of the model is unique.

In fact, there is a type of folk theorem in general equilibrim analysis that any allocation in the core is the equilibrium of a properly specified reasonable disequilibrium process. 38 This insight currently lacks a full proof for economies involving production. Yet, quite some progress has been made in a literature on 'accessibility of equilibria' in exchange economies, a term coined by Stephen Schecter. Schectex (1977) shows that under standard assumptions in an exchange economy any allocation in the core can be connected to the initial allocation defining the core through a finite series of voluntary trades that, consequently, are Pareto improvements.

The meat of this paper has been presented in various possible economic interpretations, in wich specific behavioral assumptions are made that give rise to sensible price paths, and a controller governs the access to the market. This way, it is shown that in an economy with a changing unique price vector, imposed rationing of plans can direct the economy to any particular core allocation. More recent examples are Champsaur and Comet (1990) and Bottazzi (1994). Although most of this literature derives from that on plamning procedures, one interpretation of its findings is indeed that all core allocations of an economy associated with the initial endowment are potential market clearing equilibria of that economy. Again, the relevance of one core allocation over another is intimately tied up with questions on the relevance of one out-of-equilibrium process over another, and therefore calls for disequilibrium theory.

The importance of the insight that all equilibrium analysis requires a disequilibrium analysis is also well illustrated by means of the second fundamental theorem of welfare economics. This theorem states that any Pareto efficient allocation is a Walrasian equilibrium to the proper initial endowment. ${ }^{39}$ It is widely considered to be one of general equilibrium theory's most important insights. By properly changing the initial distribution of commodities, any for whatever reason socially desirable efficient

It These are typicaly not isolated. Yet, in the final step from a disequilibrimallocation to the eventhal equilibrim, one of possibly several isolated equilibria is selected, provided the economy is regutar. Afterall, the property that Walrasian equibuia are locally isolated holds then in the core as defined by the lastly obtained disequilibrium allocation.

38 Essentially, the insight that each core allocation can be the outcome of a bargaming process derives from Edgeworth (1967), originally published in 1881 . Again, refrence to Newman (1965) is applopriate, especially pages $61-4$.

(2) Cf. Mas-Colell at. (1995), Ghapter 16. 
allocation can be established as an equilibrium by a competitive economy. Yet, reliance on this result for policy advice implies reliance on an unspecified adjustment process that is neutral in both of the senses in which it was just made clear it cannot be assumed to be. It is unclear that the targeted Walrasian equilibrium will be reached if others correspond to the established initial allocation as well. More importantly, generally none of these, but quite another equilibrium, will be reached by an out-of-equilibrium theory that involves inreversible trades in the process that make equilibrium path-dependent. ${ }^{40}$

The implications for comparative statics of the insight given above is considerable. In fact, comparative statics is quite meaningless unless accompanied by general disequilibrium theory. Similarly questionable is the relevance of the large literature on computational algorithms. Here, the quest is for methods by which the predetermined equilibria of a model are found efficiently and for any initial situation. It rose from the work by Herbert Scarf - which is in turn associated with the history of outof-equilibrium theory that is considered later on. Computational algorithms are not presented as representations of plausible disequilibrium behavior of individual traders. They are admittedly external processes to equilibrium models. Given the fact that the equilibria of the primitives of any such model are importantly determined by the outof-equilibrium dynamics that is to accompany it, the meaning of these initial equilibria is quite relative, and so is computing them. Particularly again, for the purpose of comparative statics, it can be quite misleading. At best, it shows that some converging dynamics exists. Whether it, or any of its rest-points has much relevance is at least doubtful.

All these remarks on the relevance of strict equilibrium analysis when equilibria are path-dependent are further fortified by a fourth argument in favor of the study of out-of-equilibrium behavior for its own sake. This argument rests on an even stronger form of path-dependency, that easily rises in reasonable out-of-equilibrium processes, referred to as 'hysteresis'. Whereas the second form of path-dependency discussed above leads to the conclusion that all core allocations are potential rest-points of some adjustment process, these effects change on top of that the set of core allocations on which any converging process zooms in. It results from changes to the endowments of the economy over the period of adjustment, resulting from disequilibrium consumption or production decisions. Consequently, it is intimately tied up with the questions on the speed of adjustment addressed above.

In the example in Figure 1.1, suppose that after trade has been carried out up to $h^{1}$, both consumers eat half of their endowments-endowments could also be partly perishable. With commodities thus used up, the size and shape of the EdgeworthBowley box changes. The box becomes smaller-flatter and longer or narrower and higher. In any event, the indifference curves of both individual will be differently positioned, and consequently, so will the core. The consequence is that all types of equilibria, Walrasian or not, will be different. Only a deep understanding of whether: and to what extent these types of disequilibrium phenomena are important, relative

40 The inportance of multiple equilbria and the absence of global stability results for the interpretations of the second fundamental theorem of welfare economics is stressed in Bryant (1994). 
to the speed of adjustment that can be expected, can give insight into the importance of these effects. It is, therefore, a matter of ont-of-equilibrium theory.

Apart from justification of traditional equilibrium theory, as a way to understand actual economic phenomenon that are of an out-of-equilibrim nature, and as a means to select between multiple or path-dependent equilibria, that may also be subject to intermediate changes in total endowments, there is a fifth reason to take the out-ofequilibrium properties of economic models seriously. It derives from an often made empirical statement that real economies display a fair amount of 'stability', and that therefore no disequilibrium analysis is necessary to understand them.

It is indeed true that the prices of certain commodities, such as bread, do not fuctuate very much over a few days, weeks or even months. Some "stability" is observed in them. Yet, the study of out-of-equilibrium behavior is not necessarily a study of chaotic or widely fuctuating price behavior. In fact, it is quite different from that. Disequilibrium theory considers whether there exist movements towards new equilibria if previous ones are disturbed, what the natwre of these movements is, and what influence they have on the equilibrium eventually reached. This is all the more relevant if economies are fairly ordered.

Also, it is a mistake to associate relatively constant, prices, or for that matter any other constant variable, with equilibrium. Just as it is not right to think of price fuctuations necessarily as disequilibrium phenomena, as in a dynamic equilibrium model, price differences over time, and particularly also fuctuations, can well reflect foresen changes in the underlying preferences, techniques or endowments, so is it erroneous to think that prices cannot be constant in disequilibrinm. In fact, it may very well be that plans camnot adjust to match because of the stickiness of some prices-this is not to be confused with equilibrium theory with fixed prices, as discussed above. The two are very difficult to disentangle empirically. Neither of them is evident.

Moreover, even if indeed real economies are stable on an invariable equilibrium, this does not reduce the walue of out-of-equilibrium behavior. Quite to the contrary. If the actual economies that are meant to be understood by means of theoretical models inhibit strong stability properties, and converge quickly on a new equilibrium when disturbed, then so need these models. So far-and gain this will be substantiated later on-few satisfactory stability results have been obtained in general equilibrium models, both of perfect competition and of imperfect competition. There have been found quite a few negative results, however, pointing to the impossibility of global convergence results on the given foundations of these models. The consequence of this may very well be that economic models that can provide plausible and converging out-of-equilibrium analyses need different fundamentals. Conditions that guarantee stability of general equilibrium models can be very helpful in completing these models and understanding isstes of equilibrium. Such conditions may be found on the level of individual preferences and opportunities. However, they may also wery well have to do with the structure of economies, that is, with the organization of markets. Particularly, it may well be that perfect competition is not a market structure that can assure flexible adjustment to changes in the parameters of the economy. Stability may well require positions of market power. In this respect, out-of-equilibrium analysis, has an important role to play in the modification of equilibrium theory and its welfare analysis. 
A suxth and last-yet truly not least-argument for the study of disequilibrium is the fact that several important economic phenomena are just better understood from a disequilibrium perspective than with equilibrium analysis. Obvions examples are the existence of money and economic profits. For both there is no role in a general equilibrium with perfect competition. Therefore, alternative equilibrium theries have been constructed, which rely on market imperfections, such as the presence of transaction costs that trade through money can lower, or scale economies. The same is true for the presence of powerful firms and intermediaries, or the existence of a natural rate of unemployment. Also, the steep recent growth in trade on the world-wide-web, and the decrease in prices that can be observed to come with it, are well understood as disequilibrium phenomena.

Understanding these issues in that way has, in turn, important implications for possible policy towards them. Monetary policy, for example, is different when price changes are seen as disequilibrium adjustments rather than measured as mere inflation. Particularly also, antitrust policy advice is importantly different when the role of profits in stimulating disequilibrium adjustment towards equilibrium is recognized. That is, from a disequilibrium perspective, profts need not be a bad per se.

In fact, this difference in perspective forms an organizing principle in the ideas on antritrust policy and associated theory in the Chicago and Harvard schools of thought in industrial organization. Initial concerns with the need to keep competitive processes in societies in check using government intervention, as for example expressed by Clark (1940), found strong criticism by Chicago economists, that stressed the self-stabilizing nature of competition. In key subjects such as limit and predatory pricing, vertical restraints and tying, time and again the core of the argument of either side rests on a belief in the smooth workings of competitive markets, respectively a lack thereof. ${ }^{4}$

In all, there seems sufficient justification to seriously consider the existing knowledge of out-of-equilibrium processes, its successes and failures, to learn from them, and see if perhaps they require modification. That is, to consider what Franklin Fisher posed as the "key question of stability analysis":

"In an economy made up of agents that understand that they are in dis.m equilibrium, and perceive and act on profit; opportunities, does the action of those agents lead the economy to converge to equilibrium, and if so, to what sort of equilibrium?" (Fisher, 1999, p.27)

This book provides a critical reflection on the existing literature on out-of-equilibrium theory, identifies alternative routes, and travels some distance along them.

\subsection{Outline of the Book}

The aim of this book is to revive interests into working towards an understanding of disequilibrium behavior in a general equilibrium setting largely in two ways: a critical

11 For a survey on the Chicago school see Reder (1982), referred to earlier. For an outspoken Chicago contribution to the debate see Bork (1995). Martin (1994) uses the dichotomy to lively present the main body of industrial organization theory. 
reflection and a substantial contribution. As noted above, a unifying approach to the literature on this subject largely lacks. Yet, the problems of disequilibrium research look different with a more complete overview of existing knowledge. Its organization, namely, reveals many correspondences that help to develop a more satisfactory theory of out-of-equilibrium behavior than offered in mainstream stability theory. It may revive learning on this central open research problem in economics. To provide an organization of existing knowledge as well as a unifying approach is the aim of the first part of this book. It thus categorizes elements of a theory of disequilibrium.

To that end, the first part of the book is organized as follows. The next chapter steps back and presents methodological considerations that will help to understand the organization of research in theoretical economics, general equilibrium theory, and especially the place of disequilibrium analysis therein. Also, these considerations allow for the identification of growth of knowledge. Chapter 3 reviews the literature on disequilibrium known as stability theory. This literature is closest to general equilibrium theory, yet did not deliver very many insights into the working of markets outside of equilibrium. In fact, it developed in a direction away from that objective. In Chapter 4 , this state of affairs is considered. Applying the organizational concepts supplied in Chapter 2, it defines the disequilibrium research program. Subsequently, the chapter identifies the program's main problem, and suggests a key change of approach to obtain a more satisfactory theory on out-of-equilibrium behavior the need for which is then apparent.

This approach then is fleshed out in the remainder of the book. Chapter 5 presents the first concept for a more satisfactory theory of disequilibrium behavior, the ability of some individuals in the economy to make trading proposals. For that, a structure of monopolistic competition in a general equilibrium context is required. The literature on this subject is considered in the chapter. Chapter 6 discusses insights into a second element of disequilibrium behavior, the modification of trade proposals, resulting from changes in the perception of trading possibilities and market relations. It ends with the possibilities offered for modelling these in a recent literature on learning. Chapter 7 addresses an important issue in disequilibrium research, the question how disequilibrium processes influence the nature of equilibrium. It is argued that lack of acknowledgment of a trade-off between stability and efficiency has led astray from considering full blown disequilibrium processes. They have, in other words, traditionally been geared towards competitive equilibrium. In Chapter 8 , all elements for a theory of disequilibrium from all three literatures are combined into a rudimentary model of out-of-equilibrium behavior, suggested to revive learning of disequilibrium behavior. Apart from an extensive apparatus necessary for that, the chapter offers a global asymptotic stability result, that closely relates to existing knowledge, particularly the so-called Fisher process-despite its relative seniority the state-of-the-art in disequilibrium research today. Chapter 9 concludes with some directions for further research. 


\section{2}

\section{Economics as a Science}

Conveyed history is teleological. That is, any story is necessarily constructed. It is told from a certain perspective that guides the selection and the ordering of the elements presented with a view to the story's ending. Acknowledgement of this is of some importance. The direction given to current and future developments, namely, is largely deternined by the history that those who give direction subscribe to. Moreover, the direction eventually taken depends importantly on who share what history.

The next chapter presents a history of thought. It surveys a number of theories and models that over time appeared in print in economic science. All relate to the question, introduced in the previous chapter, what happens when an economy is not in equilibrium. The history is meant to illustrate a line of development, that subsequently is commented on and extrapolated in later chapters of the book. It differs importantly from the history of theory concerned with this question that is commonly adhered to, and thus offers new ways of appraisal.

In order to be able to identify a line of development in thought and comment on it, there are at least two requirements. First, it is necessary to organize the wide variety of ideas encountered in the literature. This allows for a main story line. Second, there is a need for clear criteria for the identification of progress, or the lack thereof. These enable the determination of a theory's or model's contribution to the growth of knowledge sought for in the story.

Philosophy of science supplies means to these ends. This chapter briefly rewiews the methodological debate on how science develops, and applies the insights that can be had from this debate to economics. It is concluded that from its early development, in empirical apriorism, the predominant methodology in economics has been consistent with the general consensus in epistemology, the Lakatosian methodology of scientific research programs. The methodology of scientific research programs then is used to describe the present program of mainstream economics and some of its advancement; 
particularly general equilibrium theory. The aim is to make the standards explicit by which theories and models in later chapters of the book have been selected, are presented and evaluated.

The chapter is organized as follows. The first section discusses the relationship between empirical observations and theory. It is argued that the latter necessarily precedes the former-although this is not without its problems. In sections 2.2 and 2.3 , ways suggested to deal with these problems in respectively the work of Karl Popper and that of Imre Lakatos are presented. Section 2.3 also offers some later refinements of Lakatos" framework. In Section 2.4 empirical apriorism is discussed and shown to have propagated a method similar to that arrived at by Lakatos. Subsequently, in Section 2.5 , a set of core propositions widely adhered to in economics is defined, and its influence illustrated. Closest to this hard core is general equilibrium theory, the appropriate context for a study of disequilibrium behavior.

\subsection{Inductivism versus Deductivism}

The central tension in the construction of knowledge lies between empirical observations and universal conditions. Empirical observations are specific statements about a particular state of affairs that obtains in a particular place and at a particular moment in time. Universal conditions, on the other hand, are universally true conditional statements that logically relate particular conditions to singular statements, or conclusions. That is, by application of an elementary logical argument, a universal condition allows the derivation of singular statements from specified particular conditions. ${ }^{1}$

A universal conclition is universally true in the sense that it applies whenever the specification of the particular conditions holds. That is, it seeks to describe a general principle behind a larger body of phenomena. Ideally, these phenomena make potential empirical observations, such that whenever its particular conditions are fully specified to the occasion, a universal condition produces a singular statement that matches relevant observations. Generally, however, empirical observations are related to several universal conditions operating simultaneously. Then the singular statements of theories, which are systems of universal conditions that relate in a logically consistent way, can confront observations. An illustration of the logical structure of a theory consisting of $n+1$ universal conditions, applied to specified particular conditions to unravel into a singular statement, is given in Figure 2.1 below.

Philosophy of science developed from the question of what serves as the appropriate basis for the generalization laid down in a universal condition or a theory. Initially two opposing views on this question were put forward. According to one, the formulation of universal conditions or theories arises from sufficiently large bodies of empirical observations, carefully collected under documented particular conditions, by generalizing their common features. The other view holds the opposite, that is, that the formula-

1 The terminology used here differs in several respects from that of the various authors referred to below-just as terminology difers between them. Yet, it awes to Maks (1981). For an introduction into logic and the structure of theories see Grayling (1997). 
tion of a theory is largely independent of, and precedes the systematic collection of the empirical obserwations it is required to match whenever the particular conditions apply.

\begin{tabular}{ll} 
Universal Condition 1 & If $x_{1}$ then $y_{1}$ \\
$\ldots$ & $\ldots$ \\
Universal Condition $n$ & If $\mathfrak{x}_{n}$ then $y_{n}$ \\
Universal Condition $n+1$ & If $\left(y_{1}, \ldots y_{n}\right)$ then $z$ \\
Particular Conditions & $\left(x_{1,}, \ldots, x_{n}\right)$ \\
\hline Singular Statement & $z$
\end{tabular}

Figure 2.1 An illustration of the structure of theories.

When the sciences re-emerged from the shackles of religion in the early 17 th century, emphasis on the former, inductivistic, method for arriving at general statements was pioneered by Francis Bacon. ${ }^{2}$ Bacon wanted to free science from the authority of the church that was based on dictums, largely unwerifable or, if not, untouchable. In order to do so-and attempting not to fall back on Aristotelian metaphysics-Bacon proceeded to fight established prejudgments, or 'Idols' as he called them, and approach the study of reality with an open mind. To Bacon, any theorizing is to be preceded by a period in which large amounts of facts on all phenomena to be explained are carefully gathered under a wide variety of circumstances. Only after a large and reliable body of facts has thus been collected are universal conditions and theories to be derived from them inductively. Any other way would only lead to unclarity:

"The syllogism consists of propositions, propositions of words; words are the signs of notions. If therefore, the notions (which form the basis of the whole) be confused and carelessly abstracted from things, there is no solidity in the superstructure. Our only hope, then, is in genuine induction." (op.cit., pp.107-8)

Alhough formulated carefully and in a rather long-winded manner, Bacon firmly believed this to be the case.

However appealing as inductivism may be, it presents a mumber of difficulties. A first fundamental problem rises from the question which observations are to serve as the starting point in the construction of knowledge. Since there really is an infinite number of things about which empirical statements could potentially be made, there has to be some selection. That is, what counts as an observation needs to be carefully defined. Moreover, to know what counts as a relevant observation is a prerequisite for collecting manageable sets of observations. The other way around, any particular empirical observation only has meaning when the categorization that applies to it is known. "The more complex the phenomena in which a general principle is sought for",

Cf. Bacon (1952), originally published in 1620 .

i A consequence of this problem is that human perception de facto is lknowledge-dependent. Its validity shows nicely in the well-known drawing that is, when seen with the right eyes, instend of the face of Sigmumd Freud, a lewd lady. Chamers (1999) stresses this point, and how it obstructs the inductivistic method (op.cat., pp.14-8). 
the more prominent these problems are. Both play roles in the inductivist program where it calls for a 'large' body of observations, collected under a 'wide variety' of circumstances, without being too precise about what is 'large' or 'wide' or a "variety".

A different and later acknowledged problem with inductivism is the so-called induction problem, first raised by David Hume in the 18 th century. ${ }^{4}$ When deriving a singular statement under specified particular conditions from a theory, a logically valid argument is made-provided it is done correctly. Deduction thus preserves in the singular statements any truth present in the theory. "The method of induction, however, amounts to an attempt to do the reverse: on the basis of a number of singular empirical statements, a universal condition is proposed. However true these statements may be, there is no logical guarantee that truth is preserved in the universal condition thus obtained. The empirical statements, namely, necessarily correspond only to a finite body of specified particular conditions, whereas a universal condition is bound to apply whenever the particular conditions hold. Since the number of potential, yet unknown, violations of the induced universal condition is infinite, and the number of empirical statements used in the induction finite, the likellihood that any theory arrived at by the method of induction is valid is nil..$^{5}$

Around the same time Bacon propagated the inductive method in England, Rene Descartes, largely in The Netherlands, developed an opposing method to construct knowledge, from the first difficulty raised above. ${ }^{6}$ Descartes noted that observing does not just involve the senses, but also reasoning based on ideas vested in the mind. With the same objective as Bacon-to free science from the dogmatic orthodoxies of the church-Descartes stressed critical reflection and introspection as sources of knowledge. To him, there was only certain truth in universal conditions that are clear and distinct to the consciousness. That is, there exist 'Innate Ideas', ideas that hold necessarily, independent of experience. It is a futile exercise to attempt to distillate truth from laborious empirical work. Instead, only reason can reveal appropriate theories. Descartes wrote:

"Reason does not insist that whatever we see or imagine thus is a truth, but it tells us clearly that all our ideas or notions must have some foundation of truth." (op.cit., p.54)

Clearly, cleductivism, as the latter method is referred to, steers free from both the practical and the logical problems of inductivism. By having theory precede observation, a basis for a meaningful categorization of observations is provided, and the induction problem avoided. Yet, deductivism presents its own problems. Particularly, it is leaves largely unexplained how introspective knowledge relates to reality. As a consequence, it is for example unclear how one person's introspective truth compares with that of another. Modern philosophy of science has concerned itself with these issues.

4. Cf. Hume (1978), Book 3 , originally published in 1740 .

5 Of some farne is the induction problem around Christmas time, observed by Bertrand Russell, of the turkey that induced from a limited number of observations the universal condition it was fed at 9.00 am each morning. Cf. Chalmers (1999), pp.43-5.

(: Cf. Descartes (1952), originally published in 1637 


\subsection{Falsificationism and Quasi-Induction}

The most infuential and eminent contemporary philosopher of science, Karl Popper, started constructing his view on epistemology from the induction problem, and partjcularly the demand made by the inductivistic logical-positivists in the 1920's that scientific theories are to be verifiable by observation. ${ }^{7}$ Popper pointed out that the induction problem implies that the verification of any universal condition or theory by empirical observations, however rumerous, is impossible. Nevertheless, any particular observation has the potential to refute, or falsify a theory when it does not match its singular statements. On this insight, Popper constructed his methodology of falsificationism.

Any theory, universal condition, or singular statement should only be accepted as true in the sense that it has not been proven false--that is, as long as it has not. The latter is done by the occurrence of events explicitly excluded by a singular statement deduced from the theory. In order to be open to falsification, therefore, a singular statement should posit the existence of observable facts that can be tested by empirical observation. The extent to which refutable singular statements can be derived from a theory, i.e. the number of potential falsifiers, determines the empirical content of a theory.

Based on the performance of their singular statements in tests, theories are said to be false, or not yet false. Theories are said to be more or less corroborated, depending on the amount of empirical tests the singular statements stood up against. Corroboration camnot provide any quantifiable measure of truth, however, by the same logic that renders the likelihood of truth in any induced condition nil. Important for both is the necessity of some inter-subjective agreement among related researchers about the nature and occurrence of falsifying and corroborating observations.

His negativistic deductivistic approach to the relationship between theory and empirical observation allowed Popper to set science apart from non-science, as well as to identify growth of knowledge. To Popper, a discipline deserves the predicate "science" if its theories have empirical content. That is, its universal conditions and theories need to be able to produce falsifiable singular statements. Progress is only possible in a science thus defined, since it is driven by the falsification of singular statements, that time and again necessitates the modification of theory.

Hence, instead of cautiously corroborating theory distilled from empirics-which is what the inductivistic method amounts to when it goes beyond the stage of collecting data- to Popper science progresses, deliberately provoked by trial and error, over a series of clear and best daring conjectures and their refutation. In that, the origin of conjectured singular statements can vary. Metaphysical universal conditions, which by their nature cannot itself be refuted, can certainly serve as antecedents in their conjunction, or part thereof. As long as they have some testable implications, theories

7 The confrontations between Popper and Rudoph Carnap, a prominent logical-positivist, in the som-called 'Vienna-circle' in the 1920's gained some farne in philosophy of scionce. Cf. Redman (1991), Chapter 4. 
have empirical content. In fact, Popper is convinced that scientific discoveries are impossible without metaphysical cormitments. ${ }^{8}$

What type of modification of theory reflects growth of knowledge is explained in Chapter 10 of Popper's Conjectures and Refutations, first published in 1963. The modified theory needs firstly to proceed from "some simple, new and powerful, unifying idea," secondly to have "new and testable consequences," and thirdly to be able to "pass some new, and severe, tests." The second and the third requirement relate directly to increases in empirical content. The second excludes the introduction of so-called ad hoc changes of refuted theories. It asks for the modified theory to have empirical content in excess, and independent, of the test that led to the falsification. The third requirement demands some empirical success, or corroboration, in indepenclent tests.

The first demand concerns the logical content of theories. It requires that new theory, or modifications to theory, are able to make "some connection or relation between hitherto unconnected things (...) of facts (...), or new "theoretical entities"," striving at theories that "describe the structural properties of the world." 10 Popper acknowledges that this first condition presents some important difficulties. Since they escape direct falsifialbility, the precise nature of progressive modifications to a theory that consists of several not independently testable universal conditions is not obvious.

In The Logic of Scientific Discovery, first published 1959, Popper does shed some light on how systems of universal conditions should develop however, by means of the concept of quasi-induction. Quasi-induction is a process representing growth of knowledge over successive corroborated theories of ever higher levels of universality, that are ever better testable, and ever contain the old, corroborated theory as a special case. The theories of ever higher universality gradually encapsulate the metaphysical statements that inspired the less universal proponents, in the sense that theories previously non-falsifiable become the falsifiable conjectures of others. Popper provides the following beautiful analogy.

"To obtain a picture or model of this quasi-inductive evolution of science, the various ideas and hypotheses might be visualized as particles suspended in a fluid. Testable science is the precipitation of these particles at the bottom of the vessel: they settle down in layers (of universality). The thickness of the deposit grows with the number af layers, every new layer corresponding to a theory more universal than the one beneath it. As the result of this process ideas previously floating in higher metaphysical regions may sometimes be reached by the growth of science, and thus make contact with it, and setitle." (Popper, 1959, p.277-8)

To Popper, science thus progresses through the simultaneous enlargement of both the logical and the empirical content of theories-where the former ultimately serves to facilitate the latter. Both are suggested by the confrontation with empirical observations of singular statements deduced from prior theory. Although, therefore, theory

Cf. Popper (1959), p.85 or Popper (1963), Chapter 11

Op.cit, pp $240-2$.

Op.cit, p.241. 
necessarily precedes systematic obserwation, empirical observation should be exploited to inspire new theoretical insight and new logical connections between universal conditions. A more explicit account than Popper's of how such is done is given in the methodology of Imre Lakatos, one of Popper"s most influential students. It is subject: of the next section.

\subsection{Methodology of Scientific Research Programs}

An important fundamental issue that rises in falsificationism is that once a singular statement derived from a theory that involves metaphysical or not independently testable universal conditions is agreed among scientists to have been falsified, there is a logical problem to determine which of the unversal conditions in the theory, or which of the particular conditions specified to arrive at the singular statement, is faulty. In relation to this, the point is often raised that falsificationism is inadequate on historical grounds. That is, there are examples of theories that individual scientists or small groups of them adhered to despite the apparent and commonly agreed upon falsification of their singular statements. In several of these cases, the apparent falsification. later turned out to have been based on false grounds. This fruitful dogmatic adherence to in hindsight fertile ideas in fact occurred in several of the major contributions to the growth of knowledge."

Observing this, Thomas Kuhn gave an influential sociological description of the process of science based on the concept of paradigms, which he intended as an attack on Popper's philosophy of falsificationism. ${ }^{12}$ According to Kuhn, paradigms are generally recognized scientific achievements that for a time provide derived model problems to a community of practitioners. Normal science is performed within vested paradigms which are exempt from falsification. Revolutionary science, on the other hand, brings about paradigm-shifts, i.e., changes from an old to a new paradigm. The latter only occur very rarely, and in response to persistent refutations of derived statements, or unsolvable logical puzzles. In Kuhn's observation, paradigm-shift were 'Gestalt switches', comparable to religious conversions. Consequently, there exist no rational grounds for the comparison of different paradigms-that Kuhn therefore said are incommensurable.

In formulating a more rational reconstruction of the process of science, Lakatos? methodology of scientific research programs both attermpted to incorporate Kuhn's observations, and maintain the solid Popperian criteria for the growth of knowledge. ${ }^{13}$ The methodology of scientific research programs provides insight into the question how

1 Chatmers (1999) makes both points in Chapher 7 as criticism to Popperm the furst is linown as

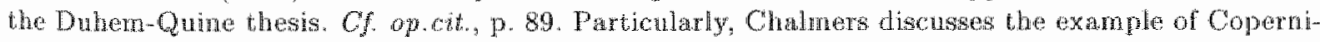
cus, whose theory that the earth turns was originaly thought to hawe been refuted by the fact that stones, when droped from a tower, do not fall way from the base of the tower, whach was believed to be a valid singular statement of the theory-which, of coune, it later was found not to be, beceuse it neglected the loorizontal motion of the stone while dropping it.

12 Cf. the extended second edtion, Kunn (1970).

13 Of. Lakatos (1970). 
to deal with complexes of theories and metaphysical statements when derived singular statements have been falsified. The central idea is that all parts of such complexes are not on par. Some are more important than others to groups of scientists, and it is the less important ones that are to accommodate refutations.

The defining principles of a research program are its so-called hard core propositions. This is a set of universal conditions and basic principles, that are taken to be irrefutable by the members of the scientific community in question. Therefore, the hard core is shielded from falsification as a matter of convention-or by its nature if it concerns accepted non-testable universal or metaphysical conditions. This is enabled by surrounding it with a protective belt, containing auxiliary conditions and hypotheses, ceteris paribus clauses and specific premisses. A theory of a research program is a combination of its hard core and a particular materialization of its protective belt. Not the hard core but the protective belt is adjusted or replaced if a particular singular statement of a program is falsified.

The shelter thus provided by the protective belt, allows research around the hard core space to develop in relative autonomy, and counter apparent anomalies. To that end, their scientific research program directs researchers that work in it by methodological rules. A so-called positive heuristic guides them to certain, for the program relevant questions. Particularly it indicates the way in which the protective belt should be modified and sophisticated in case of refutation of singular statements. A negative heuristic rules out certain research as irrelevant, or non-scientific typically research that starts from deviations from any of the hard core propositions.

Growth of knowledge within programs occurs when changes to the protective belt explain away apparent empirical refutations of earlier singular statements of the program. This type of progress Lakatos refers to as progressive theoretical problem shifts. The positive heuristic guides this type of problem shifts. Lakatos reads:

"A 'model' is a set of initial conditions which one knows is bound to be replaced during the further development of the programme, and one even knows, more or less, how. This shows once more how irrelevant 'refutations' of any specific variant are in a research programme: their existence is fully expected, the positive heuristic is there as the strategy both for predicting (producing) and digesting them. Indeed, if the positive heuristic is clearly spelt out, the difficulties of the programme are mathematical rather than empirical." (op.cit., p.136, note deleted)

Ideally, progressive problem shifts also generate new and independently testable singular statements. Yet, increases in empirical content should not be required with every modification of the protective belt. Only at certain intervals should there be an increase in potentially falsifiable statements, referred to as intermittently progressive empirical problem shifts.

Although Lakatos focussed attention in his work primarily on the development of programs around their hard cores, he did recognize that growth of knowledge can also be had in progressive changes in the logical structure of the hard core itself. Yet, such developments are importantly more unwieldy than those of the protective belt. Lakatos writes on this: 
"The actual hard core of a programme does not actually emerge fully armed like Athene from the head of Zeus. It develops slowly, by a long, preliminary process of trial and error." (op.cit., p.133n4)

The combined processes of swift protective belt, and gradual hard core modifications, both with increased logical and empurical content, is referred to as hardening the hard cone". "Programs that cannot deliver any of these types of growth, and instead explain novel facts and anomalies at the cost of ever decreasing logical and empirical content, on by means of ad hoc adaptations, in time should and will be abandoned. Such programs are said to be degenerative.

On the basis of these notions, programs can be compared. A program will be modified or rejected in fawor of a rival program, if the modified or rival program is better able to anticipate novel anxiliary hypotheses and novel events to be observed, as well as better able to explain its apparent refutations in the course of its development. This is measured in the program's heuristic power. Knowledge grows when the heuristic power of a program increases within or over research programs. The former takes place in a progressive research program, the latter when degenerative programs are rejected for others. A mature science is a science which applies a research program that has a respectable heuristic power. ${ }^{15}$

An interesting dynamical extension of the defence mechanisms at work in progressive research programs is provided by Joseph Remenyi. ${ }^{16}$ To him, the protective belt. surrounding a hard come is organized. It is divided into a pure theory protective belt and an applied theory protective belt. The former is nearest to the core. In both belts various separate yet intimate sub-disciplines, each with their own set of universal conditions sheltered from falsification, are located. These little hard cores of the sub-disciplines of a research program are referred to as demimcores. They share the hard core principles, but each have their own additional demi-core principles.

Sub-disciplines around demi-cores serve primarily to celebrate and protect the hard core of the program. The genesis of a new demi-core is spurred by the positive heuristic of the hard core-occasionally supplemented by signals from other sub-disciplines. It encourages the development of legitimate sub-disciplines in the protective belt, concerned with subjects to which the hard core propositions can successfully be applied, central questions of the discipline, or theoretical puzzles the solution of which can warrant the hard cone principles. A special element in the latter heuristic is the socalled bravado impulse, particularly operating in the pure theory protective belt. It encourages the formulation of new theories which directly protect the hard core from apparent theatening inconsistencies or anomalies by explaining their validity. ${ }^{17}$

Each sub-discipline is organized like a little research program, $i e$, according to Lakatos' methodology of scientific research programs, but on a micro-level. That is,

\footnotetext{
14 loid.

15 Op.cit. ppi $133-4$

16. Of Remenyi (1979).

It These threats are discovered by researchers who have a policing function-called the 'owersight principle?-and a number of academic and institutional disciplinary measures at their disposal, such as control over journalis, money, reputations and career tracks. $C$ f. op.cit, pp.51-2. Here Remenyi seems to get carried away a little.
} 
demi-cores ideally develop over progressive problem shifts, continuously theoretical and intermittently empirical, and disappear by the persistent refutation of their singular statements that can only be saved in a degenerative way. However, a demi-core is more easily rejected than the hard core, since it is more open to refutation. Its additional propositions are not strictly dogmatically adhered to, which makes criticizing them a legitimate subject of scientific research. As a consequence, logical inconsistencies among demi-core and hard core propositions within a sub-discipline undermine the latter sooner than the main program. Demimcores display more wolatile dymamics than the hard oore. They die out, disappear as separate disciplines, lie dormant for long periods to reemerge again, merge, or are taken up by other disciplines.

In this respect holds that the further away from the hard core-i.e, the more applied a sub-discipline the more contact there is with reality, and therefore the easier abandoned the sub-discipline is on the basis of falsifications. Consequently, growth of knowledge is found here merely in excess empirical content. Closer to the hard core, theories are more fundamental to the program and less prone to empirical contact, so that growth of knowledge is found particularly in increases in logical content.

Although Lakatos' reappraisal of the role of metaphysical statements has been criticized as leading astray of Popper"s firm criterion of falsifiability, and the extent to which he managed to free the judgement of scientific progress from the influence of articles of faith and popularity stressed by Kuhn questioned, the methodology of scientific research programs provides handles on Popper's quasi-induction, the DuhemQuine thesis, as well as Kuhn's observations. ${ }^{18}$ The methodology may not provide the definite solution to the central problem of philosophy of science-which by its nature most likely evades a solution altogether -it certainly has provided a useful mainstream consensus. As such, it offers a useful visual structure for an understanding of the organization of economic science, as well as means to identify progressive economic research. Both are sought after in this chapter.

\subsection{Empirical Apriorism}

The foundations of current methodology in economic science were laid in a body of epistenological principles referred to as empirical, apriorism. It is a form of deductivism that allows for a meaningful confrontation of singular statements with empirical observations. Contributors to its development in the second half of the 19 th and the early 20 th century where John Stuart Mill, Carl Menger and Lionel Robbims. ${ }^{19}$

In his On the Defnition of Political Economy; and On the Method of Investigation Proper to It, first published in 1836, Mill argued that the nature of the object of study

is Pudman (1991), that propagates a nave form of falsifrationism, stresses the critiquas mentioned very forcefully, a $g$. in Chapter 4.

10 Im Maks (1980) empirical apriorism is presented as the predomintant methodology in economics, a state of andir which apphuded. In Blang (1980), Chapter 4 , it is pitied for having hindered a. in Bhag's view, potentally meaningfil use of falsificationism in economics. The present exposition owes importartty to Maks (1980), Chapter 1, "The Compatibility of Aprionism, Popper"s Philosophy of Science and Applied Demand Analysis." 
in the social sciences is such that a method of andysis different to that appropriate for the natural sciences is required. To Mill, social phenomena are importantly determined by a rery complex interplay of human motives, that can never fully be known. Yet, an abstract knowledge of them can be acquired through introspection, substantiated by global empirical observation. This abstract knowledge forms the fundamental axioms of the particular social science, as Mill referred to them. Mill writes:

"The materials of this knowledge every one can principally collect within himsel; with reasonable consideration of the differences, of which experience discloses to him the existence, between himself and other people." (Mill, 1844, p.149)

According to Mill, each social science should specialize attention to very few specific human motives only. For economic science he proposed the single notive to acquire wealth through known means. ${ }^{20}$ This fundanental axiom of economics, combined with various auxiliary hypotheses that make it applicable to specific classes of circumstances, provides a basis for the deduction of singular statements. Mill writes forcefully on this somcalled concrete deductive method, or method à prion:

"[W]e go further than to affirm that the method a priori is a legitimate mode of philosophical investigation in the moral sciences: we contend that it is the only mode. We affirm that the method a posterioni or that of specific experience [i.e., the inductivistic method, see op.cot.., p. 14.3], is altogether inefficacious in those sciences, as a means of arriving at any considerable body of valuable truth; though it admits of being usefully applied in aid of the method $a$ prom, and even forms an indispensable supplement to it." (op.cit., p.146)

The aid of the $a$ posterion nethod, also referred to as the inverse-deductive method, firstly consists of sharpening the auxiliary hypotheses necessary to derive singular statements in combination with the fundamental axioms in particular aftairs. Secondly, it can indicate that a situation at hand cannot be understood by the application of the particular science alone. These verifications, as Mill called them, of singular statements through an a posteriori confrontation with observations sets aside a theoretical scientist from a practical one. It does not, however, play a role of importance in the discovery of the universal condition(s). ${ }^{21}$

In his attack with his book Untersuchungen iuber die Methode der Socualwissen schaften, published in 1883, on the predominant method of research in the German Historical School, then led by Gustav Schmoller, Menger put an even stronger emplasis on the a priori method as appropriate for the social sciences than Mill did. The German historicists, who were very influential at the time, rejected abstract the ory, insisting instead on observing and recording "real history in its infinitely wide variety'. ${ }^{22}$ Menger countered with the argument that any such empirically obtaned

20 Op.cit, p.13\%.

21 Op.cit, p.155.

22 Of. Pheby (1988), Chapter 1. On the German Historical School and the Methodenstreit see Ekelund and Habert (1990), pp.250-6 and pp.3224. 
regularity can, due to the complex nature of the reality studied in economic science, not be expected to hold without exception. Consequently, there is little use in extensive confrontations of such empirical laws, as he referred to them, with observations.

So-called exact laws, derived in the exact theoretical sciences, on the other hand, do hold with certainty. The exact method is based on strict types that reflect the typical elements of reality as understood to be true through introspection-or "empathisch Verstehen' as Menger referred it. Since they abstract from many aspects of the complex reality that do influence observations, however, they cannot be expected to match empirical observations very well either. According to Menger both empirical regularities that perfectly match exact laws, and exact laws that are fully corroborated by empirical observations are ideal types that are unattainable.

Clearly, Menger's view on the methodology appropriate for the social sciences in general, and political economic in particular, corresponds to Mill's concrete deductive method. Like Mill, Menger also believed economics was to concentrate on a particular motive understood this way, in casu the human desire to satisfy its material needs in complete freedom and with full knowledge of all relevant facts. ${ }^{23}$

Menger's book spawned a debate on method that became known as the Methodenstreit. It would last for several decades. ${ }^{2 / 4}$ Eventually, the influence of the German Historical School diminished to the point of non-existence. At the same time theoretical economics that started from a priori laws gained larger influence. An important role in that development was played by Robbins' An Essay on the Nature and Significance of Economic Science, in first edition published in 1932. The comprehensive work can be seen as the methodological foundation of modern economic science. In it, Robbins defined economics as the science that considers the allocation of scarce resources with alternative uses towards ends that are distinguished in order of importance. This definition was presented in the previous chapter as the central problem of economics. ${ }^{25}$

Importantly different from the views of Mill and Menger, Robbins did not believe that economics should concentrate on any one end in particular. That is, economics does not distinguish itself from other social sciences by the study of the single motive to acquire wealth or material needs. Ends can be of various origin and nature. On the method proper to economics, however, Robbins largely agreed with the views of Mill and Menger. He wrote:

"[T] he nature of economic analysis (...) consists of deductions from al series of postulates, the chief of which are almost universal facts of experience present whenever human activity has an economic aspect, the rest being assumptions of a more limited nature based upon the general features of particular situations or types of situations which the theory is to be used to explain." (Robbins, 1935, p.99-100)

\footnotetext{
230 p.cos, p.78.
}

34 Some argue it is relevant still for an understanding of the disciplinary seperation of economics into macrom and microconomics, the former being inductively, the later deductively inclined. $Q f$ Pheby $(1988)$, pp. 201 .

25 Cf the axtended second edtion, Robbins (1935), pp 10-6. 
The main a priori postulates of economic science to Robbins were that individuals have preferences, as sajd, arranged in an order, that production takes several input factors with diminishing marginal rates of technical substitution, and that there is uncertainty on future scarcities. As examples of assumptions applicable only in particular situations, also called subsidiary postulates, he listed the market structure, the number of market participants, and the state of the law. ${ }^{26}$

Like Mill and Menger, Robbins refers to the complex nature of economic phenomena as the reason for scepticism towards those seeking universal conditions in observations. $^{27}$ Likewise, Robbins also acknowledges that confrontations of theory with reality can be very useful. He states three possible uses. Finst, "realistic investigations" can provide insights into the applicability of theory to particular situations, and be helpful in establishing the relative importance of different effects when making predictions. Second, they can serve to suggest subsidiary postulates that make the theory applicable. And third, such studies may "expose areas where pure theory needs to be reformulated and extended." 28

The first two uses were suggested by Mill-and to a lesser extent by Mengen-as well. The latter is related to the langer scope of pure theory Robbins saw for economics. It is not particularly elaborated upon. Robbins stresses forcefully, however, that it should not be taken as an inductivistic argument:

"The theoretical economist who wishes to safeguard the implications of his theory must be continually "trying out", in the explanation of particular situations, the generalizations he has already achieved. It is in the examination of particular instances that lacunae in the structure of existing theory tend to be revealed.

But this is not in the least to say that solutions of the problems thus presented are themselves to be discovered by the mere multiplication of abservations of divergences of this sort. That is not the function of observations, and the whole history of the various "inductive revolts" shows that all studies based on the expectation have proved utterly fruitless." (op.cit, pp.119-20)

The deductivistic approach taken in empirical apriorism thus grew out of the idea that the subject matter of social sciences is of a particularly complex nature, and hence its study is different from that of other subjects, specifically the subject matter of the natural sciences, requiring a different method. ${ }^{29}$ It is merely a dictum. Yet, it is clearly in line with the methodology of Lakatos, that, as said, was inspired by the logical problems of generalization in physics. Lakatos' recommendation to develop theory around a sheltered hard core is followed in the adherence to non-falsiffable a priori postulates that are known through experience and introspection. Auxiliary

\footnotetext{
26 Op.cit., p.79.

27 Op.cis, p.111.

28 Op.cis., pp.116-26.

29 In modern writing on economic methodology this apparent diffarence is stressed still. Cf. e.g. Kant $(1987)$.
} 
assumptions and hypotheses serve as protective belts. Using them to flesh out a priori universal conditions for application provides empirical content. Particularly the role of empirics described by Robbinis strongly resembles the demand to test conjectures and reply to refutation with modifications to first and foremost auxiliary propositions, but gradually also hard core propositions, that deliver both excess logical and excess empirical content.

Moreover, a progressive theoretical development of the hard core over Mill, Menger and Robbins can be identified. Whereas Mill and Menger defined a specific economic motive the acquisition of material wealth through known means-Robbins left the ends of study open, and accepted perfect foresight and perfect rationality only as approximating assumptions. ${ }^{30}$ Certainly, this modification of the hard core of economics has been progressive, both logically and empirically. It led to the concept of (ordinal) preference structures and utility functions, which include the money motive of Mill and Menger as a special case, and delivered important potential for new and independently testable theories. The methodology of empirical apriorism prescribed all methods to harden the hard core of economics. It put economic science firmly on a track that would allow it to flourish.

\subsection{Economics' Scientific Research Program}

From its foundations, economic science can be understood as having developed according to the methodology of scientific research programs, a justifiable consensus in philosophy of science that recognizes both empirical and logical growth of knowledge. Several authors have made attempts to understand 20 th century economics applying the methodology of scientific research programs, and have proposed hard core and protective belt propositions. ${ }^{31}$ In this section, an organization of 'mainstream' economics is provided that borrows, yet deviates, from all. ${ }^{32}$ It enables a focus on general equilibrium theory, which is background to the subject of this book.

Central to the economic scientific research program are the following ten hard core propositions.

HC 1. Material and immaterial things can be seen as commodities, with a common categorization-including physical characteristics, space, time and state-of-world.

HC 2. Commodities are scarce, and have alternative uses. ${ }^{33}$

HC 3. Commodities can in principle be owned.

On the latter, see Robbins (1935), pp.9344.

H E.g., Latsis (1976), Blaug (1975), Remenyi (1979), Fulton (1984), and Weintraub (1979; 1985).

In footnotes the relation with these references will be specified.

32 Occasionally, mainstream economics is referred to as 'neoclassical economics. This term thas varions poltical comotations-particularly it is associated with the Chicago school of thonght. These have typically cansed the type of conceptual misunderstandings addressed in Chapter 1 . The following concerns positive economic theory, without any specific normative or political aspirations-ils in the association of 'neoclassical' with Samuelson and MTT.

3\% Cf. Remenyi (1979), Hard core proposition 7 and Fulton (1984), Presupposition 1. 
HC 4. Certain commodities can be transformed into certain other commodities by means of relatively constant production techniques.

HC 5. All phenomena that involve human behavior are best understood as the aggregate interrelated consequences of individual action. ${ }^{34}$

HC 6. Individuals have relatively constant preferences over all commodities that are known to hem.

HC 7. Individual behavion is motivated by subjectively perceived private abjectives. 30

HC 8. Individuals engage in transactions whenever they believe they can benefit from them.

HC 9. Conclusions should be drawn only from situations that have no tendency to change, i.e., from equilibria. ${ }^{37}$

HC 10. (Pareto) Efficient allocations are socially desirable ower inefficient allocations, but comparing (Pareto) efficient allocations is a normative exercise, and therefore ontside the realm of science. 38

The first proposition provides a useful way to categonize objects of choice. ${ }^{39}$ HC 2 implies that the use of something by somebody, or a group of people, implies that less use of it is possible by others. ${ }^{10}$ As a consequence, choices affect each other. Scarcity is reflected in a finite number of commodities by the categorization of $\mathrm{HC} 1 . \mathrm{HC} 3$ presupposes a legal structure, or at least some social comvention that assures property is respected. Note that it is certainly not assumed ownership is complete, nor that it should be, but only that it can. By HC 4 production is viewed as transformation, preserving scarcity. Certainly, production techniques can change over time, but unless it is the prime interest of the analysis, changes in technology are not the first sourse of explanation for economic phenomena. HC 5 is referred to as methodological individualism. It excludes arguments based on universal conditions on the behavior of groups - unless described by the behavior of the individuals making up the group. ${ }^{4}$

\footnotetext{
3 Cf. Fulton (1984), Presupposition 3 and Weintrab (1985) HC4.

35 Of Latsis (1976), Fard core proposition 2, Remeny (1979), Hard core propositions 1 and 3 where the later demands that, preferences are monotonic, which is quite special and Weinirab (1985), $\mathrm{HC} 2$

36 Cr. Latsis (1976), Hard core propositions 1 and 3, Remeny (1979), Hard core proposition 2, Fulton (1984), Presuppositions 4, 5, and 6, and Weintraub (1985), HC3 and HC5. All authors presume all 'relevant" knowledge is available to decision makers, without specifying what is relevant. The formulation here is much weaker.

37 Cf Latsis (1976), Hard core proposition 4, Rentenyi (1979), Hard core proposition 6, Fulton (1984), Presupposition 7 , and Weintraub (1985), HC6.

38 Cf. Remenyi (1979), Hand core proposition 5 .

39. It was formally introduced by Debren (1959) and lays at the heart of the so-called conomic imperialism of, e.g., Garry Becker. In nature HC 1 was present in Robbins (1935) aince it is closely related to $\mathrm{HC} 6$ when ends are left open. Note that $\mathrm{HC} 2,4,7$ and 8 were also discussed above to deriwe from Robbins.

4t It includes collective goods when properly understood as club goods. Of Buchanan (1969).

"1) Note $\mathrm{HC} 5$ does certanly not imply participation in a group cannot change individual behavior; such that gromp behavior is in turn infuenced. The nicroeconomic foundation of macroeconomics reffects the wide acceptance of this proposition. $C$. Weintraub (1979).
} 
Hard core proposition 6 states that people can rank all commodities they are asked to. Again, just like with technology, changes in tastes are not taken as the first explanation for observed phenomena. HC 7 states every person attempts to better him- or herself to the best of his or her ability, where the objects of choice are of various nature. It certainly does not imply that people are necessarily egoistic: with the appropriate specification of preferences, it covers altruistic behavior. More generally, the independency of decisions does not imply people are not influenced by others. Yet, it implies that individual decisions are taken independently. With $\mathrm{HC} 3$ and $\mathrm{HC} 6, \mathrm{HC} 7$ has the logical implication that individual behavior can be understood as deriving from the feasibility constrained maximization of subjective utility-which is the meaning of the concept of rationality in economics. ${ }^{42} \mathrm{HC} 8$ considers passing up on acknowledged beneficial transactions irrational. HC 9 states it is of no use to derive insights from transient positions of very short existence-i.e., unstable situations. Instead, focus should be on positions of little or no change-ie., stable equilibria. Finally, HC 10 justifies the Pareto efficiency criterion as the appropriate means to evaluate allocations in positive science.

All these hard core propositions can in principle be criticized, and have been so. In HC 1, for instance, it is problematic whether and how people are to agree on the categorization chosen. Scarcity is sometimes disputed for specific commodities, e.g.t for information, for which the reproduction, contrary to $\mathrm{HC} 4$, can be thought of as different from a transformation. The ownership of certain commodities, such as a column of ocean water, can be difficult to assign or honor. Universal conditions are arguably often better found at group level-as in traditional macroeconomics. People might be thought of as having the liberty to do things that go against their perceived private interests - although this commonly involves a redefinition of their interests. Interesting insights, also, may be had from transitory states. Finally; Pareto efficiency has been argued to be an importantly normative concept. ${ }^{43}$ However interesting some of these critiques are-some also are very uninteresting-they are considered deviant and misdirected research, generally inspired by a lack of understanding of the meaning and aim of the research program.

Around its hard core thus drawn up, the economic scientific research program has two protective belts, the pure theory belt and the applied theory belt, in which its subdisciplines are organized to apply, protect and develop the hard core principles. Each is located according to its distance from the hard core and the empirical boundary of the discipline. Fach has its own demi-core, as well as its own protective belt. A graphical illustration of this situation is given in Figure 2.2 below. ${ }^{4}$

Some sub-programs are closer to the hard core than others. Many examples of sub-disciplines in the applied theory protective belt can be given. Since they do not specifically concerm the argument made in this chapter, however, they are not discussed

42 Profith maximization constrained by production technology is a special case of this, substantiated by $\mathrm{HC} 4$.

43 Of. Hennipman (1995).

44 Based on the general structure in Remenyi $(1979)$, p. 43, Figure 4. Weintraub (1985) also offers a graphical interpretation of the methodology of scientific research programs applied to economics. Cf. op.cat, p. 134, Figure 8.3 . 


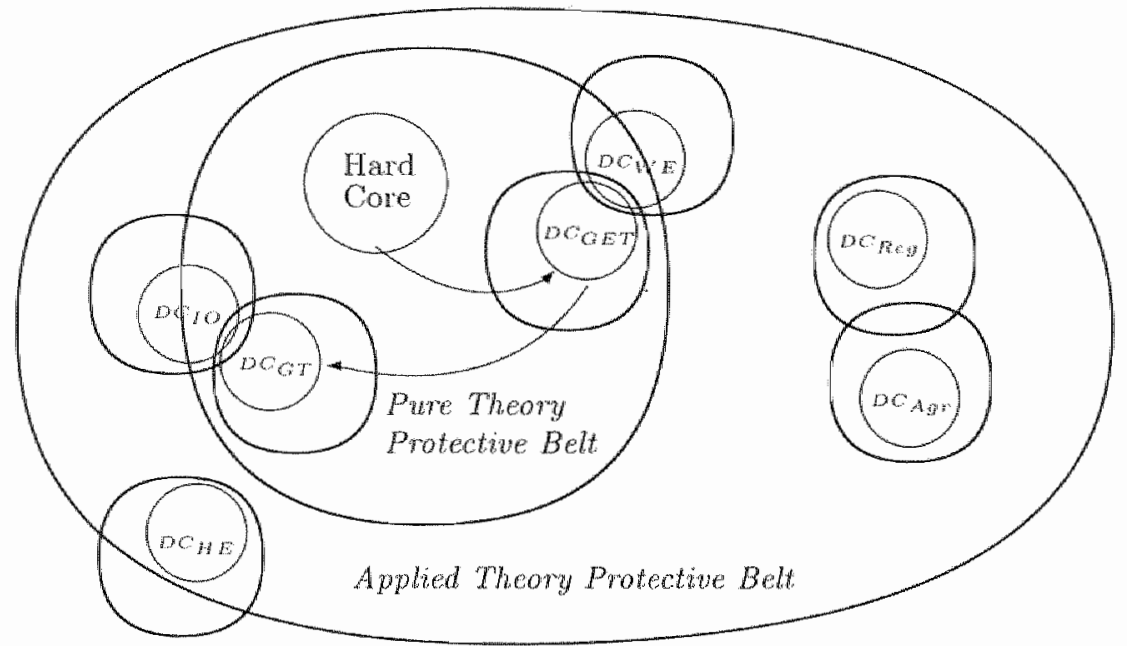

Figure 2.2 The structure of economics" scientific research program.

in any depth. As an example, in Figure 2.2 health economics is drawn in as $D C H E$, with its demi-core propositions just in the belt of the economic program, but some of its protective belt outside. It borrows auxiliary hypotheses to derive its singular statements from the tableau offered by both conomics, and other disciplines, for example political theory or medicine. More fimly inside the applied belt are the related sub-disciplines agricultural economics $\left(D C_{A g r}\right)$ and regional economics $\left(D C_{R}\right)$, that share part of their respective typical belts, such as theory on the influence of weather on crop growth. All these sub-disciplines are able to generate singular statements that relate directly to empirical obserwations. They find very direct application.

Closest to the hard core, sub-disciplines become more abstract and cletached from empinical statements. Very close is the sub-discipline of general equilibrium theory $\left(D C_{G E T}\right)$. Its rise has very directly been inspired by two important elements of the positive heuristic of the hard core of economics-stressed in Figure 2.2 with an arrow.

The first of these is encouragement to provide argument for the central insight of Snith that society is better served by an organization based on free competition, well embedded in a legal infrastructure, than by discretionary goverment intervention, however well meant, as a 'natural law'. Maurice Dobb stated on this:

"What was strikingly new in Smith's "principle of Natural Liberty", which he enuriated as early as 1749, was the empirical assertion that (as Schumpeter paraphrased it) "free interaction of individuals produces not chaos but an orderly pattem that is logically determined"- a pattern which, ac-

A* Th Remenyi (1979) this stated as Hard cone proposition 4. 
cordingly, could be elucidated in rational terms." (Dobb, 1973, p.39, note to Schumpeter"s History of Econamic Analysis deleted).

That a society without explicit coordinating institutions was doomed to end in chaos was a regularly advanced argument in the 18 th century, against which first Mandeville and then Smith objected wh ideas that ultimately led to the development of the ideat extreme offered in the general equilibrimm model of perfect competition. A crucial role in this has been played by Walras' Elements. Early in this book Walras sets out his research objective as follows.

"Tn fact, the whole world can be looked upon as a vast market made up of diverse special mankets where social wealth [i.e., scarce, valuable and exchangeable resources (op.cit, pp.65-7)] is bought and sold. Our task, then, is to discover the laws to which these purchases and sales tend to conform automatically. To this end, we shall suppose that the market is perfectly competitive, just as in pure mechanics we suppose, to start with, that machines are perfectly frictionless." (op.cit. p.84)

In Arrow and Hahn's General Competitive Analysis, published in 1971 and earler referred to in Chapter 1 , theory developed in the 1950's and '60's that made the general equilibrium theory research program come full circle in this respect is consistently presented. The central aim of the program is very well put in the Preface:

"There is by now a long and fainly imposing line of economists from Adam Smith to the present who have sought to show that a decentralized economy motivated by self-interest and guided by price signals would be compatible with a coherent disposition of economic resources that could be regarded, in a well-defined sense, as superior to a large class of possible altenative dispositions. Moreover, the price signals would operate in a way to establish this degree of coherence. (...) The proposition having been put forward and very seriously entertained, it is important to kmow not only whether it is true, but also whether it could be true. A good deal of what follows is concerned with this last question, which seems to us to have considerable chim on the attention of economists." (op.cit., pp.vi-vii)

It is lair to say that this claim for attention was answered with a preoccupation of theorists with general equilibrium that led to major advances in general equilibrium theory, but few in out-of-equilibrium theory.

The other important element of the positive hewristic of the economic research program that stimulated the sub-discipline of general equilibrim theory is the enconnagement to formute formal models, based on general principles. "This idea has already been shown to have been present in rudimentay form in empirical apriorism. The fact that it was abie to reach the level it did in general equilibrium theory is widely attributed to Walnas. Methodologically, Walras was in direct line with the aprionists.

16 Thenengi (1979) this captured in Hard cope proposition 8 , and in Fulton (1984) in presuppositions 2 and 9 . 
In Part I of Elements, Walras wrote, after isolating three classes of economic science, "pure science", 'applied science', and 'social ethics', to restrict himself in his book to the frst, the pure science of political economy. For this discipline, Walras had a clear conception of the correct method:

"Pure sciences abstract ideal-type concepts which they define, and on the basis of these definitions they construct a priori the whole framework of their theorems and proofs. (...) Following the same procedure, the pure theory of economics onght to take from experience certain type concepts, like those of exchange, supply, demand, market, capital, income, productive services and product. From these real-type concepts the pure science of economics should then abstract and define ideal-type concepts in terms of which it carries on its reasoning. The retum to reality should not take place until the science is completed and then only with a view to practical applications." (op.cit., p.71)

Wallas' 'method of decreasing abstraction' was pushed to its limit by Debren, who advanced general equilibrium theory importantly. Debreu was educated in the Bourbaki-group, a group of mathematicians that sought for an axiomatic approach on the highest possible level of abstraction. In the introduction of Theory of Value, published in 1959, Debreu set the frame of mind for theoretical economics as follows:

"Allegiance to rigor dictates the axiomatic form of the analysis where the theory, in the strict sense, is logically entirely disconnected from its interpretalions." (op.cit., p.x)

General equilibrium theory thus is a sub-discipline of economics where the positive heuristics, which are clearly spelt ont, present difficulties that are mathematical rather than empirical - to paraphrase Lakatos. Furthest from the disciplinary boundary where contact with empirical observations is made, its function is to establish. intermal consistency of the hard core propositions. The type of growth that can be expected thus is increased miversality of universal conditions and theory, that is, increased logical content, finst in the cemi-core of the sub-discipline and gradually also in the hard core of the program.

There is one central deni-core proposition that is added in general equilibrimm theory to the hard core propositions of the economic program. It is as follows.

$\mathrm{DC}_{G E T}$ The aggregate of all simultaneous choices is to be studied in a closed system.

The essence of this proposition is that included in the analysis should be the origin, direction, and destination of everything in the economy considered. Typically this implies individuals each start with some initial allocation, dividing the total anount of all commodities amongst themselves. They express the denand for commodities they do not have in sufficient number, as well as the supply of any surplus goods, according to their preferences, and restricted by the budget they obtain through the latter, supplemented by the retum on their ownership of shares in the firms. This is generated by frms employed to produce towards the demanded end, and owned fully by the individuals peopling the economy. 
The demi-core of the general equilibrium sub-discipline is surrounded by a protective belt, that contains some of the best-known auxiliary assumptions of economics, those that make up the general equilibrium model of perfect competition. Most prominent amongst them are: people have smooth preferences (e.g., complete, transitive and convex); individuals are (locally) non-satiable; at some finite production level returns to scale are non-increasing-which is really the consequence of scarcity, as unbounded increasing economies of scale imply scarce inputs generate infinite amounts of outputs-; property rights are fully specified; there are no transaction or search costs, hence all relevant public information is known to everybody; the market structure is complete; individuals are sovereign, and not forced in their decisions; nobody has a noticeable influence on the aggregate levels of supply and demand; there is a price system that operates freely and openly, and assigns a unique and publicly known price to each commodity.

It is important to note that none of these conditions in the protective belt is dogmatically adhered to. In fact, close to each and every of these ideal type auxiliary assumptions has been replaced by deviations in various types of general equilibrium models. There is a large literature indeed on so-called second-best models, where the consequences of certain irreparable deviations from the general equilibrium model of perfect competition - that is, first-best-are studied. Typically, it produces results orthogonal in nature to those of the model of perfect competition. There are models of monopolistic competition in general equilibrium, incomplete information and market structures, externalities, as well as search and transaction costs models. All these models produce conclusions that provide insight in the role of the auxiliary assumptions. They allow, in accordance with the positive heuristic of the economic program, explanations for observations that seem to deviate from singular statements. They do not question the demi-core of general equilibrium theory, nor the hard core of economics.

The general equilibrium model of perfect competition is a bench mark model to all the other general equilibrium models. This is due to the answer to the main question posed by the positive heuristic it supplied, as well as its formal elegancy. That is, with its auxiliary assumptions in place, general competitive equilibrium theory has delivered important first-best insights: the existence of Walrasian equilibria, and the first and second fundamental theorem of welfare economics. These form the closure of the line of development from Smith that was argued above to be the basis of its gonesis, as well as a beautiful example of the success that can be had with theoretical work in the normal sciences.

An elaborate and very well written Lakatosian case study on how the demi-cone of the general equilibrium sub-program was hardened over the history of contributions to the problem of the existence of Walrasian equilibria, from Walras to the ArrowDebreu model, is Weintraulb (1985). ${ }^{4}$ To Weintraub, the fact that it was shown that with the hard core propositions all in place, Smith's insights could be true, provided

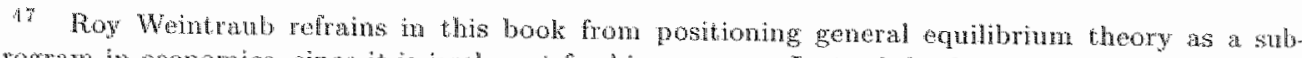
program in conomics, since it is irrelevant for lis purposes. Imstead, he focuses on the development of existence proofs in the ream Wabram scientific neseanch program. 
a very strong argument in their favor. By the end of the 1950 s "the hard core of the neo-Walrasian program was ... no longer problematic". "Weintraub concludes:

"The sequence of papers [on existence] represents a hardening of the hard core of that program. Progress, for this sequence, is a sequence of interpre tations of the terms of the hard core such that (1) each successive interpre tation is manifest in a consistent model, (2) each succssive interpretation contains the interpretation of the predecessor, and (3) each allows a concept uninterpreted by that predecessor to be interpreted." (op.cit. p.117, italics deleted)

It made economics a mature science with a large heuristic power. ${ }^{4}$

Finally, in Figure 2.2 three other examples of sub-disciplines are given. Closely related to general equilibrium theory and applying its insights is welfare economics $\left(D C_{W E}\right)$. In its main structure it shanes the demi-core proposition of general equilibrium theory. It also uses several of its auxiliary assumptions in the protective belt. Welfare economics starts from the fundamental welfare theorems provided by the general equilibrium program, and extends on it with eg., optimal taxation theory, and distribution and property right policies. The singular statements of these theories are closer to empirical observations, so that pant of its protective belt is in the applied belt of the program. Since also partial equilibrim welfare analysis is done, the demi-core of welfare economics is larger than the overlap with that of general equilibrim theory.

The last example then, game theory, is put entirely in the pure theory protective belt and close to the hard core ( $D C_{G T}$ ). Its prime demi-cone proposition is inspired by problems with strategic behavior encountered in the general equilibrium sub-disciplinealso indicated by an arrow. The positive heuristic of general equilibrium theory has stimulated its development. Its characterizing dermi-core proposition reads as follows.

$\mathrm{DC}_{G T}$ Individuals consider the reactions of others to their actions.

Although the positive heuristic of the program calls for the integration of this proposition into the demi-cone of general equilibrium, so far this has proven problematic. Instead, game theory has developed a large amount of partial models, with a variety of insights. Applications of these are particularly made in the sub-discipline of industrial organization ( $D C_{f O}$ ), which shares the demi-core proposition of game theory, applies partial nodels, and has important extensions into the applied protective belt of the program.

Op.cit. p. 113

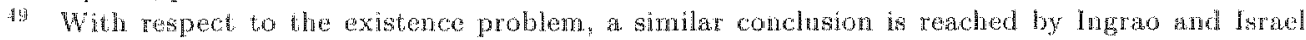
(Mog)), discussed in (llapter 4 .

Whamples of this type of applied theory that is close to the DC Ex include also applicaliona

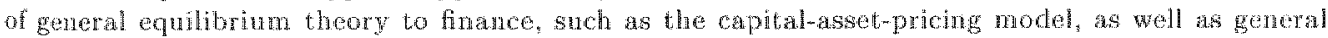
equibritum models used to substantate specific policy proposals.

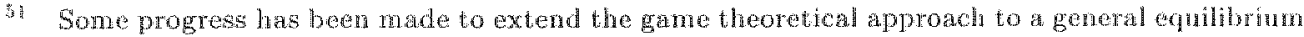
context. Cf. the classic. Shapley and Shubik (1969) and the more recent Dubey (1994). 



\section{A History of Disequilibrium Theory}

Having presented economic theory in general, and general equilibrium theory in particular, as developed into a fairly well organized and mature, yet still progressive scientific research program, the question rises why economic behavior out-of-equilibrium is as poorly understood as claimed in Chapter 1 . Answers to this question are of some relevance if it is agreed that issues of disequilibrium are of the fundamental. importance argued for it. They can point to ways to gain an understanding of these issues.

This chapter presents a history of the mainstream contributions to disequilibrium theory, that is, contributions made in what got known as stability theory in the context of general equilibrium theory. These contributions cover the larger part of existing disequilibrium theory-hence the title of this chapter-and reflect the state of the art. This is not to say that there are no theories on out-of-equilibrim behavior offered elsewhere. What is known through them, however, either amounts more to a number of insights rather than coherent theory, and is by far not as developed as stability theory, or it departs from the material covered in this chapter. To the extent that these contributions are constructive, they will be dealt with later.

The history told in this chapter substantiates the claim that there is insufficient general insight into economies ont-of-equilibrium. There exists no satisfactory theory on stability in economics. It is furthermore shown that from the foundation of the general equilibrium research program, despite high aspiration for it, the setup of diseguilibrium research foreclosed a successful development.

The history of traditional stability theory can be understood in five major steps. Along these, this chapter is organized. The first was taken by Walras. The next section presents his seminal treatment of disequilibrium dynamics and stability in his theory of tatomement. Then, after quite some time, Samuelson took the next step in reaction to Hicks, formalizing Walras' theory as an explicit dynamic system. Section. 3.2 elaborates on Hicks' and Samuelson's conceptions and delimiting representations 
of Walras' theory. Section 3.3 sets out the way in which Arrow, Block and Hurwicz, in a pair of joint papers, accomodated the third major development, from local to global stability analysis. When these events took place, around 1960 , the general frame of mind was overly optimistic with respect to results. That is, global stability results wart thought to be had easily, for merely all general equilibirum models relying on conventional primitive assumptions. The fourth step in the development of stability theory came upon several examples of economies, reasonable by these standards, that wer not globally asymptotically stable at all. Before Section 3.5 addresses the meaning of these counter-xamples of Scart, and their generalization, in Section 3.4 the development of tâtonnement into its modern textbook version is surveyed. Sections 3.6 to 3.8 then discuss subsequent developments up to the present state-of-the-art. Section 3.6 is on some conceptions and results in the theory of computational algorithms. Section 3.7 discusses a literature that seeks to establish conditions necessary for global tatormement stability in heterogeneity in the economy. Section 3.8 presents the consequences of a fith step in global stability research, taken by Hahn, the suggestion to study actual out-of-equilibrium trading process in some detail.

\subsection{Walras' Theory of Tâtonnement}

As he is the founding father of general equilibrim theory, it is appropriate to start a bistory of the disequilibrium research program with the icleas on out-of-equilibriun market dymamics of Walras. These took shape in his theory of tatomnement. To appreciate Walras" theory of tatonnement, the insights into Walras" methodological viewn" offered in Chapter 2 are of relevance. In Elements of Pure Economics, Walras striven: for a theory of political econony, based on ideal type concepts that describe the fur damental principles, or 'laws', operating in an economy. These laws were to be derived from casual observation and a priori reasoning. The latter Walras believed to be furthered particularly by the use of mathematics. The former, casual observation, Walras took from professional traders on the Paris stock exchange.

Begimning with a two-commodity exchange model, Walras built on three "suppositions" that he derived from these observations. Exchange takes place between francs and "3 per" cent Rentes ... payable by the French State". "The first supposition is on equilibrium and equilibrim prices. It says that if the aggregate offer and aggregate demand are equal, which happens at a certoin price level, each broker finds another broke" he can deal with, exchange takes place, the price is "maintained", and the market is in "equilibrium". "By substantiating the concepts of demand and offer, and showing how they both depend on relative prices but in opposing ways, Walras angued that such relative equilibrium prices exist.

Reference to this seminal existence proof as "the theoretical and mathematical solution" is found throughout Elements, were Walras extends from a two-commodit. to an $m$-commodity exchange model, and eventually to an $m$-commodity production

$0 p \cdot r i, 0.84$

Bid. 
economy. As set out in Chapter 2, it has extensively been criticized, elaborated and corrected upon, and eventually found its full current form in the elegant Arrow-DebreuMcKenzie model in the late 1950's.

The other two suppositions consicler the events in case demand and supply differ. This early exposition shows the rudiments of Walras' theory of tatonnement. There fore, the precise text is of interest. Consider the "Second Supposition" which discusses the consequences of aggregate excess demand at a price of 60 francs per rent-the thind concerns the analogous case of excess supply.

"The brokers with orders to buy can no longer find brokers with onders to sell. This is a clear indication that the quatity of three per cents demanded at 60 francs is greater than the quantity offered at that price. Theoretically, irade should come to a hout. Brokers have orders to buy at 60 franes 05 centimes or who have orders to buy at higher prices make bids at 60 francs 05 centimes. They rase the market price.

Two results follow from this bidding: first, those buyers who would have bought at 60 francs but who refuse to buy at 60 francs 05 centimes, withdraw; second, those sellers who are willing to sell at 60 francs 05 centimes but who previously refused to sell at 60 francs, come forward. These buyers and sellers will now give orders to this effect to their brokers if they had not already done so. Then, in consequence of a two-sided movement, the difference between effective demand and effective offer is reduced. If equality between effective offer and effective demand is restored, the rise in price ceases. Otherwise, the price continues to go up ... until affer equals demand. A new stationary state is thus found at a higher price." (op.cit., p.85, editorial note deleted, emphasis added)

These observations on the operation of the stock exchange Walras took to reveal the underlying "general laws of the market"." With an unfavorable reference to, among others, Mill's discussion of the peculiarities of the establishment of value in exchange of particular goods, such as diamonds or Raphael's paintings, Walras says to follow logic's demand to consider the general case betore the special one- "What physicist would deliberately pick cloudy weather for astronomical observations instead of taking advantage of a cloudless night?" "The general law is what is referred to in the rest of the book-for the two-commodity case with direct reference to the stock exchange example on page 106, for the m-commodity case in Lesson 12-as "the law of the establishment of the equilibrium price." For the general equilibrium model it reads:

"When ... equality between effective demand and effective offer of each commodity] is absent, the attainment of equilibrium prices requires a rise in the prices of those commodities the effective demand for which is greater wan the effective offer, and a fall in the prices of those commodities the effective offer of which is greater than the effective demand." (op.cit. p.172, emphasis in original) 
Watras clearly thought of this dynamic behavior of prices not only as "the scientife formulation of what is known in economics of the LAW OF SUPPLY AND DEMAND: but as an accurate description of the central processes working in competivive marhets as well, as he writes the following in closure of the two-commodity case in no uncertain terms.

"We are now in a position to see clearly what the mecharism of market competition is. It is the practical solution, reached through a rise and fall in prices, of the same problem of exchange to which we have just given a theoretical and mathematical solution; but it must be understood that we do not have the slightest idea of substituting one solution for the other. The rapidity and reliability leave no room for improvement. It is a matter of daily experience that even in big markets where there are neither brokers nor auctioneers, the current equilibrium price is determined within a few mimutes, and considerable quantities of merchandise are exchanged at that price within half or three quarters of an hour." (op.cit., p.106)

However, after generalizing his model to an m-commodity exchange model and establishing the mathematical and theoretical solution there as well, Walras posed the following research question to his disecuilibrium theory.

"What must we do in order to prove that the theoretical solution is identically the solution worked out by the market? Our task is simple: we need only show that the upward and dowmward movements of prices solve the system of equations of offer and demand by a process of groping ['par: tatonnement']." (op.cit., p.170, translator notes deleted, emphasis added)

Here a crucial leap in abstraction is revealed. No longer is the market process a system that finds any particular equilibrium in practice. It has turned into a process by which the exact same equilibrium price vector associated with the initial allocation of the theoretical model is found. Hence, the practical and the theoretical solution are now considered substitutes. Important in this respect is also that for the m-commodity model Walras thought of the equilibrium price vector as unique, given the numeraire value "Hence, in the mocommodity model Walras" theory of tatonnement no longer is a theory of out-of-equilibrium behavior. It has become a method to find the alleged unique general equilibrimm-and thereby corroborate its existence. Ironically enough, the 'simple task" Walras put with these implicit assumptions would puzzle disequilibrium theory up untill the present day.

In the theory of tationnement subsequently described for the m-commodity exchange economy, all markets making up the economy are sequentially worked through in at

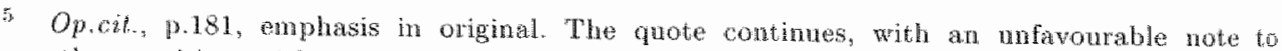
Contruot"s exposition, with:

"This fundarental haw has hitherto been stated either mroneously or in form devoid of meaning." (ibid)

(1) Op.cit., p.200. 
particular order. The price on the first market is fixed at one, i.e, the first commodity serwes as numeraire. One by one the remaining maxkets are bronght into partial equilibrium by an aprioriate price change in accordance with the law of supply and demand, keeping the prices on all other maxkets fixed."

Through general equilibrim price effects, the adjustment of the price in each partial market generally obstructs the previonsly obtained partial equilibria. Walras was fully aware of these effects, which he described in a series of partial indeterminate inequalities. However, he considered them to constitute no serious problen for convergence, arguing that the own price dynamics establishes price changes "invariably in the direction" of partial market equilibrium, whereas the cross-effects are

"... indirect infuences, some in the direction of equality and some in the opposite direction .... so that up to a certain point they cancelled each other out." (op.cit., p.172)

Hence, Walras thought of the tatonnement process as consisting of various rounds of adjustments that would naturally "move [the system] closer and closer to equilibrium" - and eventually find it.s

The theory of tatonmement after the introduction of production, discussed in Lessons 20 and 21 of Walras (1954), is slightly more involved, as Walras observed two important differences with the theory of exchange. First, he realized that the productive transformation of commodities on the basis of disequilibrium prices would change the composition of available commodities, in an essentially irreversible way. As a consequence, he believed the tatomement process would not find the theoretical and mathematical solution corresponding to the initial allocation if production at disequilibrium prices were allowed. Secondly, Walras remarks that production, even at equilibrim, talies time, contrary to exchange.

The latter issue Walras ignored "...pure and simple". The first he solved by the introduction of "tickets". These are notional production levels corresponding to any disequilibrium prices. These production plans are not actually canried out. They are only announced to find out whether there is excess demand or supply for productive services. Accordingly, prices are adjusted sequentially as in the exchange model, where direct price effects from changes in the manufacturing plans can safely be taken to be stronger than minect effects that are "cancelling each other out, more or less," thus moving the system asymptotically "closer to equilibrium". 1"

Some debate rose in subsequent developments of Walras' theory of tatomenent on whether it was meant as at, simultaneous or a sequential adjustment process. Uzawa (1959), for texmple, clains that Walras" summary on page 172 suggests it is simultaneous. Of. oprat, p.182. Also, Hicks, Samuelson, Thlatshi Negishi in a survey article published 1962, and then the discipline at large came to interpret the process ans simutaneous (see text). Cleanly. Walras thought of th as secuential although Inis implicit assumptions to assure mentrality of the process importanty reduce the nueaning of thits astirection.

Ibid. This implicit assumption is now known as diagonal dominance-and not necessarily to be sufficient for global stability. It will be discussed in Section 3.4 .

Op.cit, p. 242 .

10 Op.cit, p.246. 
In a recent litenature on the development of Walras' thought over the consecutwe editions of Etements, it is argued that Walras theory of tatonnement was originally much richer than the version in the fifh translated edition." Especially, this is true for the tatonnement procese in the theory of proctuction involving capital. That is, before the fourth edition, Walras allowed for production and trade at disequilibrium prices-sometines, following Hicks, rather pejoratively called 'false tracle'. The equilibrating process consisted really of geveral mechanisms operating simultaneously, to equilibrate the capital markets, the markets for manufactured goods, and the original exchange system, in all allowing for trade along the path. Only in the fourth edition are tickets introduced in this theory, to solve the problems of path-dependency Walras saw in these complex production processes - as can be read from the preface of that edition. included in Jafe"s translation. Donald Waker and Jan van Daal go as far as to conchdu that Walras, already in the autumn of his life, spoiled his lifework with these changes. that are qualified as "made ... in an imperfect way, unsystematically and slovenly here and there" 12

Much earlier, in 1956, Don Patinkin made similar observations on Walras' changes to his theory of tâtonnement. ${ }^{13}$ He noted that, since Waras apparently understood the path-dependency of equilibria in the processes of production, he did not make his theory "logically watertight", since he did not apply the same logic-that, is, that trade at disequilibrim prices in the exchange model also imply a path-dependency of the equilibrium, and hence do generally not have the market process reach the exact same equilibrium that corresponds to the initial allocation to the theory of exchange. Patimkin conchuded that Walras was not primarily interested in describing the actual disequilibrium path an economy takes, but instead wanted to corroborate the existence of equilibrium. Implicitly, that is, Walras assumed the absence of trade at disequilibrium prices or recontracting, which is logically equivalent. ${ }^{4}$

Several puzzles on the history of thought solve with the view that Walras himself struggled with the theory of tatommement, meant it as a complex theory of disequilibrium behavior, but eventually settled in the edition that became the basis for subsequent developments for a neutral process that would find the assumed unique equilibrim price. An important first one is that on the famous Walrasian auctionect with which modern versions of the tatomement theory are invariably presented. In fact, in Elements there is no mention of an auctioneer as a secretary of the market,

\footnotetext{
It Cf. Walker (1996) and Daal (2000).

12 Cf. Daal (2000), in which a lecture on that thesis by Walker is favorably discussed.

1. Cf. "Note B. Walras" Theory of Thtontement" pp.531-40 in Patinkin (1969).

1. Walker connters this by arguing that the Paris stock exchange at the time had as a general trading rule that no trade at diswuilibrum prices in the day were allowed. Hence, Walras' theory of thonnement in the exchange model was a correct representation of that process. This is a puzzle. Firstly, ass can be read from the quote on his observations given above on the Paris Stock Excjange trade at disequibrium prices did take place, and "comes to a halt" when exhansted. Moreover, since Whlas clearly believed his theory to apply also to all other exchange markets, it remains an omissien he dicl not discuss recontracting explicitly. Co. Walker (1996), pp.267-8.
} 
except for the quotation given above where his, her, or its existence is said to be irrelevant for establishing equilibrium. ${ }^{15}$

Although, then, Walras does not explicitly appoint a particular person or institution responsible for the establishment of each successive proportionally unique price vector, the occasionally uses the term 'crying', for instance when he starts the iteration process described above:

"Let $p / b, p / c, p / d, \ldots$ of $(B),(C)$, (D) $\ldots$ in terms of $(A)$ be the $m-1$ prices cried in this way [i.e., in relative terms], at random." (op.cit., $\mathrm{p}$. 169, emphasis added)

This crying out of ratio's must be done by somebody. It cloes not seem to be the trading individuals, since they are price takers, as earlier assumed and reflected by their passive disequilibrium behavior. It seems to be an impartial non-trader, but his or her incentives are unclear. The same kind of questions can be raised to the theory of production where the information in tickets needs to be collected and used somewhere and by someone. Walras (1954) provides insufficient chues to settle these issues. However, the notion of the auctioneer as a fictitious player calling prices is a necessary condition for his alleged proof of identity between the theoretical solution to his general equilibrium model, and the practical solution found "par tatomement."

Another issue concems the difference between global and local stability. Clearly, Walras" theory of tatomement is a theory of global asymptotic stability of the process. However, by assuming a unique equilibrium, the global stability of his system implied the local stability of that mique equilibrium, in the sense that the economy returns to the equilibrium for all perturbations, large and small. The generally held view on Walras" theory of tatomement is that, although it is at best "rather clumsy, "it is "essentially" the first discussion of stability known. ${ }^{16}$ For this specific reference is made to Lesson 7 of Walras (1954), where the actual term 'stability' appears. Interestingly enough, however, to Walras the theory of tatonnement was, although associated with it, explicitly different from his conception of stability.

In Lesson 7, in a graphical analysis of the existence of equilibrum for the two commodity exchange model, the problem of multiple isolated equilibria resulting from multiple crossings of the supply and demand curves is addressed. Walras discusses the relative significance of these equilibria by means of a stability analysis. Although it rests upon a version of the tathonnement theory, it is clearly not equivalent to it. Consider the treatment of a stable equilibrium.

"T To the right of the point of equilibrium, the offer of the commodity in question is greater than the demand for it, which must result in a fall in price, that is, in a return to the point of equilibrium... [T]o the left of the point of equilibrium, the demand for the commadity is greater than its offer, which must result in a rise in price, that is, in a movement towards

15. According to Fisher, the Walrasian auctioneer most likely was an invention of Schumpeter that, through his teachings at Harvand in the late $1930^{\prime}$ 's, got introduced into the literature by Samueson (private commanications).

16 Arrow and Habn (1971), p.4. 
the point of equilibrium. Such an equilibrium is exactly similar to that of a suspended body of which the center of gravity lies directly beneath the point of suspension, so that if this center of gravity were displaced from the vertical line beneath the point of suspension, it would antomatically return to its original position through the force of gravitation. This equilibrium is, therefore, stable" (op.cit., pp. 109-12)

This discussion of stability as a local property of equilibria, however, precedes the full formulation of the theory of tatonnement in a multi-market setting, in which it does not return. Moreover, after this short exposition, Walras explicitly assumed the problem of multiple equilibria away, and since to Walras stability analysis was meaningful in the distinction between various possible equilibria, by that after Lesson 7 the study of local stability is exchuded. It is this that accounts for the fact that after the introduction of the tatomement theory for a multi-market exchange and production economy, the term 'stability' no longer appears in Elements. And it is the subtlety of this distinction that would be overlooked in subsequent developments.

Walras' theory of tâtonnement is a very rich theory of disequilibrium market processes. Initially presented as a realistic description of the market process, however, over the course of Elements and its various editions, its abstraction amounted to a nettral computation method, relied upon to find, by-passing possible path-dependency of equilibrium, the unique price vector that equilibrated the general equilibrium model. This necessitated both the absence of trade at disequilibrium prices as well as the presence of an auctioneer-type institution that collects aggregate information and adjusts prices accordingly. Although it would have been more in line with Walras' method of decreasing abstraction to move away again from these implicit assumptions, it was particularly these elements that would find their way into modern economics.

\subsection{The Hicks-Samuelson Dispute on "Truly Dynamic Stability'}

The infuence of Walras" Elements was not immediate. To the extent that it was read in French, it was generally considered overly formal, and not appreciated for the abstract framework of general equilibrium it offered. ${ }^{17}$ Instrumental in raising an interest in general equilibrium theory among Anglo-American theorists was Hicks' Value and Capital, that first appeared in 1939. At the time, Hicks was a member of the soucalled 'Robbins circle" at the London School of Economics. This group around Robbins-. who came to LSE in 1929, shortly after Hicks-included among others Hayek, who came to London from Austria in 1931. Hayek had then already developed a theory of intertenporal equilibrium, published in 1928, which involved dated commodities, to explain interest.

17 Hicks (1939) refers in this respect to Marshall. Cf. op.cit. pp.2-3. In the note in Patinkin (1969) refared to above, Patinkin argues that particularly the theory of tatonnement was advanced littlo wntil Samnelson due to a critical review of Elements by Edgeworth. 
Hayek's ideas on equilibrium and disequilibrium have already been presented in Chapter 1. It is interesting to note that Robbins expressed a similarly clearly disentangled notion of statics and disequilibrium dynamics in his Essays on the Noture os Sagnificance of Economic Science. After explaining the method of comparative statics, Robbins wrote:

"But we may go beyond this. Not only may we compare two final states of equilibrium assuming given variations, we may also endeavor to trace out the path actually followed by different parts of the system if at state of disequilibrium is given. (...) [ $]$ n doing all this we make no assumption that final equilibrium is necessary. We assume that there are operative in different parts of the system certain tendencies which make for the restoration of an equilibrium in respect to certain limited points of reference." (op.cit., pp. 101-2)

On Robbin's instigation, Hicks studied and lectured on general equilibrium theory. He used his knowledge of German, French and Italian to read the original works of von Mises, Walras and Vilfredo Pareto on which Value and Capital draws importantly. ${ }^{18}$ More contemporary influences in Hicks' thought came, apart from Hayek, through Swedish economists Gumar Myrdal and Erik Lindahl. The latter were in the so-called Stockholm school of thought, that flourished for roughly a decade between 1927 and 1937. Hicks reviewed Myrdal's work and Lindahl had visited LSE in 1934 and 1935. In the Stockholm sckool had developed-partly based on Gustav von Cassel's extension of Walras' work laid down in 1918 in Theoretische Sozialokonomie, partly also on Hayek's 1928 paper-quite extensive ideas on the role of expectations in intertemporal choice models. Particularly, it was recognized that for an intertemporal equilibrium to remain over time, the expectations on which it was ex ante based, should never be disappointed ex post. ${ }^{19}$

Value and Capital develops, on the basis of these elements, a rigorous theory of temporary intertemporal general equilibrium. In this structure, individuals form expectations on future states and form their demand and offers accordingly. Markets then open once a week, on 'Monday', to clear at equilibrium prices. This happens instantaneously. Events during the rest of the week may alter expectations and hence disqualify the established equilibrium as such, but since markets are closed, these surprises or disappointments have no immediate influence on trade. Only when, on the basis of adapted plans, the next Monday markets clear again, a new temporary intertemporal equilibrium is established. On the process by which this clearing takes place, the book is silent. In hindsight, Hicks said on this-referring to the fact that Keynes had focussed on money as the factor obstructing equilibrium:

"While Keynes had relegated the whole theory of production and prices to equilibrium theorists, I tried to keep production in time, just leaving

1. Cf. Witteloostuiju and Maks (1989)

19 A fuil rudimentary theory of disequilibrium acljustment of expectations in a temporary intertemporal equilibrium model was eventually given in Lundberg (1937). I.ts impacet has been weak. It will be discussed more extensively in Chapter 6 . 
prices to be determined in an equilibrium manner. I wanted, that is, to go further than Keynes, keeping closer to Lindahl. But I could only do so by an artificial device, my "week", which was such that all prices could be fixed up in what would now be called a 'neo-Walrasian' or "neo-classical" manner, on the "Monday"; then, on the basis of these predetemined prices, production in time conld proceed. (...) I have become abundantly conscious how artificial it was. Much too much had to happen on that "Monday"!" (Hicks, 1975, p.290) 20

Clexrly, Value and Capital develops a theory of equilibrium dynamics. Yet, it offers a chapter on disequilibrium as well, Chapter' X. Here Hicks identified as a 'perfect: equilibrium' an intertemporal equilibrium in which all expectations come true, and hence no price adjustments are necessary to make all plans meet every Monday. As possible causes of disequilibrium, situations where "... expectations are cheated, and plans go astray," he discusses price-expectations that ane inconsistent, plans that are inconsistent, or false perceptions of preferences and production processes. ${ }^{21}$ Yet, these disequilibria result from the fact that no temporary equilibria exist, respectively due to discrete expectations, or false individual perceptions, which are the first and thind cause, or for other reasons, which is the second cause. These are not disequilibria due to continuous plans that rely on price signals that need adjustment. If, in other words, temporary equilibria exist, they are found on Monday in an unexplained way. ${ }^{22}$

In Chapter $V$. Hicks (1939) also addresses the problem of the stability of equilibria in a general equilibrium system. To Hicks an equilibrium is stable if a "... slight movement away from the equilibrium position ... set[s] up forces tending to restore equilibrium". 2.3 Hence, Hicks was concerned with the local stability analysis Walras paid attention to only in the two commodity case, and not with an explication of the theory of tatomement. But like Walras, the dynamics behind the stability properties of equilibria was sought for in the relationship between aggregate excess demand and the behavior of prices, as Hicks writes for the two goods case:
"[T] stability condition is that a fall in the price should increase the excess demand -that the excess demand curve, if we like to put it that way, should be dowaward sloping." (op.cit., p.63)

Consequenty, Hoks correctly thought he superseded Walras' stability analysis by "... break $[$ ing] some altogether new ground..." in studying the local stability of equi-

20 Later on in his life, Hicks observed about the entire Robbins circle:

\footnotetext{
"We seened, at the starts, to share a common wiewpoint, or even, one might say, a common faith. (...) The faith in question was a belief in the free market, or "pricemechanism'- that a competitive system, free of all "interferences"... would easily find an 'equilibrimn'", (Hicks, 1982, p.3)
}

21 Op.citi, pp. $132-4$

22 Hicks also discusses expectations that are "probably" tather than "definite". These continuous expectations give rise to "... a type of Imperfect Fquilitinm rather than of disequilibrium" (bad.). 
libria in a multi-market exchange setting. ${ }^{24}$ For that analysis he developed the concept of 'perfect stability', that would come under heavy attack from Samuelson. A system is perfectly stable in the Hicksian sense if, most generally,

"... a rise in the price of $\mathrm{X}$ will make supply greater than demand, (a) all other prices given, (b) allowing for the price of $Y$ being adjusted to maintain equilibrium in the $Y$-market, (c) allowing for the prices of $Y$ and $\mathrm{Z}$ being adjusted, and so on, until all prices have been adjusted." (op.cit., p.66n)

Although at first sight this comes close to the sophisticated sequential adjustment described in WaIras' theory of tatonnement, it is importantly different. Hicks developed a general equilibrim analysis of local stability, not a study of the convergence of the system, and he was fully aware of this distinction. ${ }^{25}$

By formulating the stability analysis in the above way, the study of local stability conditions focuses on the level of total derivatives of aggregate excess demand at equilibrium, which need to be negative for the own, and zero for the cross total effects. This led Hicks to the well-known condition of alternating signs of the left-hand upper principal minors of the Jacobian matrix of the system of aggregate excess demand evaluated at the equilibrium price vector, that got known as the Jacobian being 'Hicksian'. A sufficient condition for it is quasi-negative definiteness of the Jacobian at equilibrium prices, which in tum necessitates that it is of full rank and that it is symmetric. Symmetry of the income effects over all consumers suffices for symmetry of the Jacobian-since substitution effects are unconditionally symmetric. This amounts to parallel Engel curves for all consumers at the equilibrium allocation, and is a strong condition. ${ }^{26}$ However, it is not necessary for the Jacobian to be symmetric, and hence certainly not for it to be Hicksian. Appropriate cancelling out of the individual income effects can provicle the Hicksian property for the aggregate excess demand system.

Hicks (1939) discusses at, some length the composition of aggregate excess demand and supply in order to give body to his stability condition, and to conchude that it seized at the income effects in a fairly acceptable way:

"It cannot $\ldots$ be proved a priori that a system of multiple exchange is necessarily stable. But the conditions of stability are quite easy conditions,

\footnotetext{
2u Mid.

25 This ahow for instance from the motiwation with which Hicks introduces perfect stability. Discussing causes of instability it reads:
}

"[l] the first condition only being price movemant in the direction of excess demand on bach separate market, holding all other prices fixed is not satisfind, the tendency to moxe away from equilibrium will be checked in the end, thongh not direty id will be checked throwgh repercussions in other markets, not by the working of the $X$-market alone. It is easy to see that in such a case as this the estabtshnent of an exwabrum price-sustem is gorng to be an awhward business; but once equilibrinm is rearled, it whl

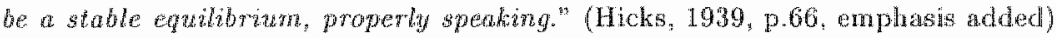

26 Note that it is, however, not as strong as assuming Gormall indirect utility furetions-3.

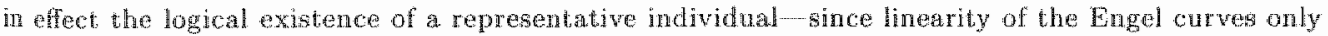
needs to hold locally around the equilibriur state. Of. Mas-Collell at. (1995), pp.19-20. 
so that it is quite reasonable to assume that they will be satisfied in almost any system with which we are likely to be concemed. The only possible whimate source of instability is strong asymmetry in the income effects. A moderate degree of substitutability among the bulk of commodities will be sufficient to prevent this cause being effective." (op.cht. p.73)

Finaly, only after his exposition of local stability of general equilibria, does Hicks shorty discuss "the economic laws" deducible, provided a system is perfectly stable. He conctudes that "... it does appear that an increase in demand for a particular good (or group of goods) is most likely to have an upward effect upon prices in general" "2 Nowhere, however, does Hicks (1939) claim to have provided a theory of tatonnement, or, for that matter, a theory of the market process. ${ }^{28}$

It can thus be argued that Hicks had some notion of local price dynamics in mind when he developed the concept perfect stability. However, there is no explicit account of it. This made it open to criticism from Samuelson who, with a firm background in dynamic systems theory, attacked Hicks" stability analysis soon after Value and Capital was published. ${ }^{29}$ Over a number of publications which preceded their bundling in Foundations in 1947 by almost ten years, Samuelson. claimed to have superseded Hicks' stability insights by showing that they were neither necessary nor sufficient for what he termed "truly dynamic stability".

Like Hicks, Samuelson was primarily interested in comparative statics. His approach explicitly consisted of deriving theoretical conclusions from a combination of maximizing behavior on the part of consumers and producers, and what he called the "correspondence principle" on the local direction of a particular equilibrium of a system resulting from small perturbations in its exogenous variables. The correspondence principle consists of the idea that deriving theorems in comparative statics is "intimately tied up with" the problem of the local stability of equilibria, i.e, given the existence of a new equilibrim and the direction in which it is to be searched for, upon changes in the data, the new equilibrium is likely to be found. 30 Hence, to Samuelson the correspondence principle provides a local device for equilibrium selection.

As a consequence, it is a historical emor to name and apply the Hicksian conditions for perfect stability as local stability conditions, and to associate Samuelson's dynamics with global stability theory. Samuelson approached the dualiby of statics and dynamics he reintroduced clearly from the side of statics, and for local purposes only. He wrote on this:

\footnotetext{
27 Op.cit., p.75.
}

2* Alfred Marshall had considored stability primarily as a local concept as well. Cf. Marshall (1920). p.287. In this respect, another historical puzale is worth seting. It concerns the customary clifference between Walrasian and Marblallian stability. The former is generally taken to be stability based on the adjustment of prices, the latter of quantities. Equilibria or said to be Walrasian or Marshallian stable, both, ether or netther. Of. Quirk and Saposnik (1968), pp.149-52 or Takayama (1985), pp 296-9. This schism rests on a misinterpretation, attributable to Hicks. Cf. Hicks (1946). pp.61-2. Both Walras and Marshall recogmized both types of adjustment. Cf. Davies (1963)

29) For an extensive history on Samuelson's Harvard education, social ties and research incentives, see Weintranb (1991).

30 Sammelson $(1963) \times 1.258$ 
The equations of comparative statics are ... a special case of the general dynamic analysis. They can indeed be discussed abstracting completely from dynamical analysis. (...) But the problem of stability of equilibrium cannot be discussed except with reference to dynamical considerations. however implicit and rudimentary. We find ourselves confronted with this paradox: in order for the comparative-static analysis to yield fruitful results, we must frst develop a theory of dynamics." (Samuelson, 1941, p. 102, notes deleted) ${ }^{31}$

Whereas he distinguishes "stability in the small" from "stability in the Large" wat various places in Foundations, attention is strictly limited to the fomer over the latter. "This is stressed again in a note to the above text:

"The point made here is not to be confused with the commonplace criticism of comparative statics that it does not do what it is not amed to do, namely describe the transition path between equilibria." (ibid)

With this context provided, consider Samuelson's introduction of methods of differential calculus in stability analysis. It is widely taken to represent Walras" tătonnement theory rigorously. Samuelson (1963) never refers to it as such, and all the later references to Walras are to the latter's conditions for stability of equilibria in the two-commodity case only. Of special interest are both the exact formulation, and the single paix of reflections on its possible economic interpretation. For the two commodity case-in which the process actually generates Hicksian concitions as a result of the obvious symmetry of a scalar it reads:

"In the literary explanations of the process by which supply and demand are equated, the assumption is usually made that if at any price demand exceeds supply, price will rise; if supply exceeds demand, price will fall. Luet us state this more precisely as follows:

$$
\begin{aligned}
& \frac{d p}{d t}=H\left(q_{D}-q_{S}\right)=H[D(p, \alpha)-S(p)] \\
& \text { where } H(0)=0, \text { and } H^{\prime}>0 . "(o p \cdot c \lambda t, p .263)^{31}
\end{aligned}
$$

The analysis then immediately proceeds with a study of a linear approximation around the equilibrium state.

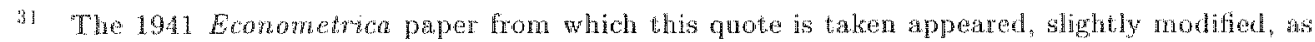
Gimper TX of Sammelson $(2963)$.

32 An important influence here is Frisch (1935) that explicity introduces systens of diferential

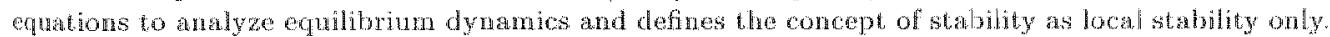

37 The reating of Samuehon forms the soil for Weintrab's intrigning trace of the origin of the

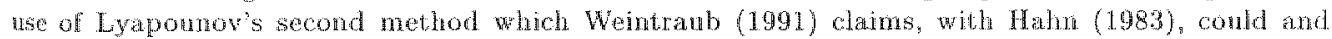
shond have been in fowndatons to save the discipline ten years, if only savinelson would have appreciated French. Strictly speaking Samuelson"s discussion preceded the ganses of Arow and Hurwicz (1958) and Arrow, Block and Hurwice (1959) by almost twenty years. Yot, Samnelsons interest in disequilibrinm issucs was local omly. 
Credit is given to Wallas in the multimarket case, where the economic interpreta tion is extended no further than the following remarks:

"To test the necessity or sufficiency of these criteria fof Hicks" perfect stability] in terms of a more fundamental definition of stability of equilibrium let us make a natural generalization of the Walrasian conditions of the following form: the price of any good will fall if its supply exceeds its demand, these each being regarded as functions of all prices.

Mathematically,

$$
\begin{aligned}
\dot{p}_{i} & =-H_{i}\left(q_{S}^{i}-q_{D}^{i}\right) \\
& =-H_{i}\left[q_{S}^{i}\left(p_{1}, \ldots, p_{n 2}\right)-q_{D}^{i}\left(p_{1}, \ldots, p_{n 2}\right)\right] \\
& =H_{i}^{i} \sum_{j=1}^{n} a_{i j}^{0}\left(p_{j}-p_{j}^{0}\right)+\ldots
\end{aligned}
$$

where

$$
0=q_{S}^{i}\left(p_{1}, \ldots, p_{n}\right)-q_{D}^{i}\left(p_{1}, \ldots, p_{n}\right)=-q_{i}\left(p_{1}, \ldots, p_{n}\right)
$$

represents statistical equations of supply and demand, $a_{i j}^{0}$ represents the partial derivative of $q_{i}$ with respect to the $j t h$ price evaluated at the equilibrium set of prices. In general, $a_{i j}^{o} \neq a_{j i}^{0}$. (op.cit., p. 270, emphasis in original, note and equation numbers deleted)

At least four things are important to note about these texts. First, the final righthand side parts of the first equation of the last quote, as well as the second requation of that quote, clearly validate the statement that Samuelson had a local interest only in truly dynamic stability, which he called "perfect stability of the first kind in the small". Second, supply and demand are a function of prices only, i.e, commodity holdings are not included, and hence their development was not taken to be a part of the dymamic process. "Third, price dymamics is explicitly represented by a function of aggregate excess, or market excess demand. The aggregation process of which these functions are a result is not considered a topic. ${ }^{36}$ The fourth observation is that, unlike in the analyses of Wadras and Hicks, prices are thought of as moving simultaneously on all markets.

By studying a linear approximation of the above system of differential equations that was to represent price dynamics close to equilibrium, stiability conditions focus on the Jacobian of the aggregate excess demand system again. For stability of the first kind in the small, Samuelson applied a general mathematical result on the stability of linear systems of differential equations that derives naturally from the explicit solutions

\footnotetext{
wio Op.cti, pp.261-2.
}

30 In fact, only in an accompanying note does Samelson address the issue that "the general supply and demand function is the aggregate stpply and demand, and that there is an individial demand antanglement behnd these aggregations, in which there is an important role for incomat edects, as stressed by Hicks $(1939)$. 
of their homogeneous parts, which can be expressed as linear combinations of the elements of their sets of fundamental solutions, which generally consist of exponential functions of the time variable premultiplied by the respective eigenvalues. It states that the real parts of the eigenvalues of the Jacobian evaluated at the equilibrimin are all negative, and implies either straight asymptotic convergence or damped oscillation. ${ }^{3}$

For the m-commodity case, Samuelson then concluded that the Jacobian matrix being Hicksian was neither necessary nor sufficient for it to have negative real parts of the eigenvalues, that "W] hy any system should be expected to possess perfect stability, or why any economist should be interested in this property is by no means clear, "and that consequently "[i]n principle the Hicks procedure is clearly wrong". 38

Hicks' reaction to Samuelson's allegations came in an additional note to the second. edition of Value and Capital. Hicks explains he followed the traditional approach of Waras and Marshall that assumed that equilibria are fairly quickly reestablished upon perturbations. As a result he did not feel the need for explicit dymamics. Hicks praised Samuelson for introducing "... heavier mathematical artillery ..." that is "... perhaps more acceptable to mathematicians". 39 At the same time, however, Hicks felt that something was missing in Samuelson"s approach, that he thought of as being present in his own. He wrote:

"[T]he discussion of stability remained timeless, at least in the following sense: that I assumed the process of adjustment to temporary equilibrium to be completed within a short period (a 'weels') [obviously, this should be a 'day'], while I neglected the movement of prices within the week, so that my economic system covld be thought of as taking up a series of temporary equilibria. (...) [I]t is now quite evident that I oversimplified [my dynamic theory]. But in so doing I did leave myself free to make some progress with the less mechanical parts expectations and so on. I still feel that this procedure has its uses, and I should be sorry to abandon it altogether in favou of a pure concentration on mechanism. (...) [F]or the understanding of the economic system we need something more, something which does refer back, in the last resort, to the behaviour of people and the notives of their conduct." (op.cit, pp.336-7)

Hicks thus clearly thought of his sequential partial process as having more economic content than Samuelson's mechanics. This view was widely shared, and an extensive literature rose on the relationship between the Hicksian and the Samuelsonian conditions for local stability, the latter taken to be methodically sound, the former with some intuitive economic meaning. ${ }^{40}$ At least four important links were established

For systems of diference equations a closely related theory states that be abolute walnes of the eigenvalues ane all to be smaller tham one.

Op.cis. p.273.

Op.cit p.336.

4n Takayam (1985) clearly takes this vew, and devotes much effort to setung ont the relationship. Takayma smphasizes that Samuelson's truy dynanic stabiby superseded Hicks" perfuct stability by refring to Samuelson's specifoation of price dyamics as a function of aggragate excess demand as "the fudamental assumption of stability analysis" (op.cit. p.315-). 
there. The first, given by Samueison himself, is that symmetry of the Jacobian of the linearized truly dynamically stable system evaluated at the equilibrium price vector suffices for it being quasi-negative definite, and therefore renders the Hicksian and Samuelsonian conditions equivalent. Symmetry, as said however, is unnecessarily strong for the Jacobian to be Hicksian. The second, due to Metzler (1945), states that if the system is locally stable regardless of the values of the speeds of adjustment, the Jacobian necessarily is Hicksian. This result is of interest in models with instantaneous adjustment or perfect divisibility of goods, in which the speeds of adjustment are arbitrary, since they vary with the units of measurement--as observed by Arrow and Hurwicz (1958). The third link, also due to Metzler (1945), holds that if the Jacobian of the linearized system evaluated at the equilibrium price vector satisfies gross-substitutability in the aggregate, i.e., if all its off-diagonal elements are positive, the Hicksian and Samuelsonian conditions coincide - which was the inspiration of much research on gross-substitutability in the 1950 's, particularly that of Hahn and Negishi, who independently established that gross-substitutability implies the Hicks condition.

The fourth was established by Danie McFadden. His 1968 contribution to Hicks" Liber Amicorum provides a conclusive study on the relationship between Hicks' intuition and Samuelson's apparatus. It is based on a result that in the context considered says that the combination of a diagonal matrix of speeds of adjustment and the Jacobian of the linearized aggregate excess demand system at equilibrium is stable in the Samuelsonian sense i.e, has eigenvalues with negative real parts - if the absolute value of all the ratio's of speeds of adjustment for markets $j$ and $j-1$ are bounded by a positive constant, and the ratio of the left-hand upper principle minors $j$ and $j-1$ premultiplied by the speed of adjustment in market $j$ is negative. This result enabled McFadden to reconstruct Hicks' analysis for perfect stability using explicit: dynamics. ${ }^{11}$ The crux of the analysis is that, unlike Hicks' original setup, markets are sequentially partially equilibrated in an order dictated by the respective speeds of adjustment of their price dynamics. That is, first the market with the highest speed of adjustment finds an equilibrium. This adjustment process is a function of, but does not exert an infuence on, the prices in all other markets, since they are relatively constant. Then the market with the second highest speed equilibrates. For this process the first market is quick enough to stay in equilibrium even though the second market moves, and the other markets are slow enough for them not to influence the second market dynamics. Consequently, this partial process is not a function of the first market's price. Then the third, for which the first and second are quick, and the rest slow, is equilibrated, and this process is contimued until the general equilibrium system is in its locally stable rest-point.

By modifying the definition of perfect stability through the ranking of markets in decreasing order of their speeds of adjustment, excess demand for every market is effectively a function of its own price and the constant prices of the slower narkets

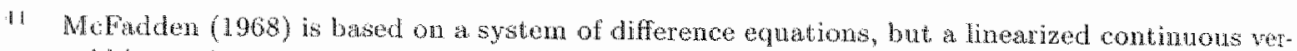

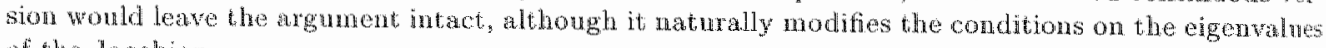
of the Hacolian. 
only, given the 'quicker' markets remain in equilibrim-Nolfadden (1968) speaks in this respect of the "compensated excess demand" on a manket. "Granted this, it is readily assumed that each price must partially adjust in the direction of the compensated excess demand on its market-just as in the Walrasian stability analysis where spill-over effects were absent by construction. This yields the condition that the Jacobian of (compensated) aggregate excess demand is Hicksian. Prowided local continuous differentiability of compensated excess demand at equilibrium, and nonzero upper left-hand principal minors of the Jacobian, McFadden (1968) shows that a Hicksian .Jacobian suffices for true dymamic stability. Hence, with the modification of ranking the markets, for a class of dynamic processes Hicks may have envisioned when he wote Value and Capital, the Hicksian local stability conditions are sufficient for dynamic stability, the practice of studying Hicksian matrices is justified, and Samuelson's conclusion on the meaning of Hicks' analysis is shown to be overly harsh.

To summanize, the following. Hicks developed an extension of Walras" local stability analysis, having no pretensions to be a theory of global convergence, and studied meaningful local stability conditions on wealth effects-that is, essentially on individual preferences. Sammelson formulated explicitly the local dynamics that had been implicit in the earlier analyses, and provided the mathematically sound conditions on the Jacobian of aggregate excess denand at equilibrium prices necessary and sufficient to mender it locally stable, that is stable in a linear approximation around the equilibrim state. Although for any given Jacobian Hicks' stability conditions are generally neither necessary nor sufficient for the Samuelsonian ones, they are sufficient for at least one possible dynamic interpretation of Hicks' notion of local stability. Funthermore, effectively the Hicksian conditions are of some interest if interpretations on the level of the data of general equilbrim models is required beyond the strong assumption of gross-substitutability. If anything, these conclusions show the importance of a careful and explicit analysis of the underlying market dynamics. However, the subsequent analysis of disequilibrium and stability would develop in an altogether different direction, away from much meaning given to the out-of-eguilibrimm process.

\subsection{Global Stability Theory}

Originally intending to break the chain of papers considering the relationship between Hicksian and Samuelsonian stability conditions and instead study the question whethor the local stability conditions of Hicks and Samuelson would hold under a given set of assumptions on the structure of a competitive general equilibrium nodel, in a pair of papers in Econometrica, Arrow, Block and Hurwicz would first facilitate and then make the important shift from local to global stability analysis. From Samuelson, Arrow, Block, and Hurwicz took that conditions on out-of-equilibrium behavior requires the formulation of

"... a fomal dynanic model whose characteristics reflect the nature of the competitive process." (Arrow, Hurwicz, 1958, p.523)

Op.cit. p.3.3. 
To that end, with reference to Samuelson (1947), they stated:

"From among the many possible versions of the market process we have chosen two particular ones, here labelled, respectively, (A) the anstantaneous adjustment process, and (B) the lagged adjustment process. The instantaneous process is well-known and is of particular interest because it is close to the formulations of Walrae, Hicks, and many other writers, and because (comparatively) a great deal is known about it. (...) [O]ur main emphasis is on the instantaneous process defined below." (op.cit., p.524. note deleted)

It is an autonomous system of simultaneous ordinary differential equations, as follows. For each commodity $j$ its price $p_{j}$ changes over time by a function given as

$$
\frac{d p_{j}}{d t}=k_{j} f_{j}\left(p_{1}, \ldots, p_{m}\right), \quad k_{j}>0, \quad(j=1, \ldots, m)
$$

in which $f$ is the aggregate excess (net) demand function for the $j$ th commodity, and $k_{j}$ the speed of adjustment which, by a suitable choice of the units of measurement, can be nomalized to one, and hence eliminated from the notation. 43

In this system, an equilibrium is a rest-point in which $\frac{d p_{j}}{d t}=0$ for all $j$. Arrow and Hurwicz (1958) sets out the concepts of stability briefly introduced here in Chapter 1. An equilibrium is asymptotically stable if a solution of the system of differential equations for a certain vector $p_{0}$ converges towards it in the limit as $t$ goes to infinity It is locally asymptotically stable if it is asymptotically stable for vectors $p_{0}$ restrinted to a neighborhood around the rest-point. It is unstable if such a neighborhood does not exist, and it is globally asymptotically stable if it includes all price vectors the static structure of the model allows for-generally the positive real numbers, or the wnitsimplex upon normalization. Finally, by construction any equilibrium that is globally stable, is also locally stable, but the converse is not true, since equilibria are generaly not unique.

In the companion article Arrow, Block, and Hurwicz (1959), it is then realized that the system as a whole can asymptotically converge to any of its equilibriaalso a generalization to price dynamics as a sign-preserving function of aggregate excess demand is introduced, thus arriving at Samuelson's structure. If such is the case for all possible price vectors, the system is said to be globally asymptotically stable. This final transition from local stability analysis to global stability analysis and the accompanying nove to the study of globally stable systems is one of the major esrly steps in the development of stability analysis. It reintroduced the high ambitions Walras had for the theory of tatonnement, that both Hicks and Samuelson stayed away from. However, the analysis also took over Walras' implicit assumption that the tatonnement process is neutral. Prices are assumed to be unique, one for every conmodity, they are changed by some unexplained auctioneer-type institution.

4it of op.ch, p.52r. This process, as well as those to follow, are presented in the original notation. 
without there being any trade at disequilibrim prices, and all individuals take prices as given. Consequently, the equilibria as rest points of this process are equivalent to the Walrasian equilibria of the competitive model. Strikingly, hitile or no discussion of these crucial issues associated with the choice of disequilibrium dymamics is offered.

The various cases in which stability on the basis of the dynamic process of Arrow, Block and Hurwicz is found still count among the major results on tatonmement stability. A general equilibrim model with no trade in any commodity at a unique aquilibrium is found to reach that equilibrin's price vector globally, and as a corollary economies with identical preferences and endowments over all individuals, as well as economies that start out in Pareto efficient states are globally stable. Satisfaction of the weak axion of revealed preferences by the aggregate excess demand functionsessentially that is, aggregate demand behaves as individual clemand, which boils down to assuming a representative individual renders the equilibrium price vector unique and globally stable. A two-commodity economy with a unique equilibrimm is shown to be globally stable in the absence of complementarity between the goods, and satisfaction of global gross-substitutability by the aggregate excess clemand functions--that is, that at every price level the aggregate excess demand for each commodity increases (decreases) if the price of any other commodity increases (decreases) and, of course, decreases (increases) if the price of the commodity increases (decreases)-generates a mique and globally stable equilibrium. Finally, global stability is established for a system for which the Jacobian matrix of the system of aggregate excess demand functions satisfies diagonal dominance for every price vector-that is, that the (weighted) sum of of-diagonal elenents is smaller in absolute terms than the (likewise premultiplied) diagonal element. 14

Instrumental in obtaining these results has been the then for economics newly discovered second method of Lyapounov-that actually stems from the end of the 19th century. This method allows for by-passing the analysis of the solution of the actual dynamic system-which is Lyapounov's first method-when it is hard to find, if one can identify a so-called Lyapounov function. This is anction of some variable associated with the state wariables of the system that monotonically decreases to a constant value, associated with a rest-point of the system. If such a function exists, than, no matter what the actual behavion of the system is, it will asymptotically converge to that rest-point.

Just like the method of linear approximation around an equilibrim state does locally, Lyapounov's second method constructs a summarizing function of the state variables of a system of (non-linear) equations. Both methods dodge a study of the explicit solution of the actual system, which is rarely avalable, but the scond method of Lyapounow has several major advantages over the method of linearization around the equilibrum state. First, it by passes the often painstaking actual linearization at the system's equilibria. Second, it is decisive in systems for which linearization provides. ambignons stability results, and third and foremost, it extends to any arbitrary region.

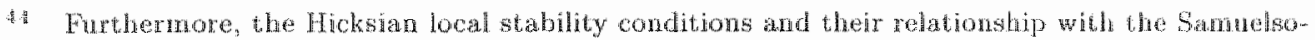
naw ones are reproduced for vanishing income effects and a negative definite Jucobian of the aggregate excess demand system evaluated at the equilibrm price vector, and generalized to quasi-nogative definiteness of the Jacobian. 
around the equilibrim positions of a system and hence allows for an analysis of the global stability properties of the system and its equilibria. ${ }^{45}$

The second method of Lyapounov carries with it all the aspirations of generality sought for in the general equilibrium research program. After its fairly late discovery by the discipline, it was embraced, and it still forms the core of its major stability proofs. The development of global stability theory up to the present day can be read as a series of models constructed within the boundaries set by the conditions necessary for the existence of a Lyapounor function. ${ }^{46}$ And not only in economic theory did Lyapounov's method Houmish. Luenberger (1979) praises it as

"... the most powerful device for the analysis of nonlinear systems-its power being derived from its simplicity, its generality, and its Hexibility." (op.cit., pp. 319-20) 17

However sophisticated its methods, applied to the price adjustment process of Airow, Block, and Hurwicz, global asymptotic stability requires assumptions that restrict the interplay of individual substitution and incone effects greatly, up to the point that ic becomes possible to describe aggregate behavior as if it were that of a representative individual. On this state of affairs, the conventional view is well captured by the following conclusion in Fisher ( 1983 ).
"[I] nteresting necessary conditions for stability were clearly not to be had; and sufficient conditions for stability appeared to involve wildly restrictive conditions on individual (or aggregate) demand." (op.cit., p.27)

Nevertheless, Arrow, Block, and Hurwicz conjectured some fairly bold conclusions at the time. In fact, they concluded on the study of disequilibrium and stability in the same optimistic spirit with which Walras had considered it a simple task" and Samuelson its inelevance 'a matter of the crudest probability calculation':

"It should be emphasized that because of the fragnentary nature of the present study, no general assertions about the stability of the system under

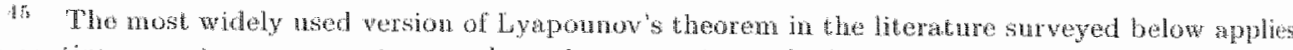

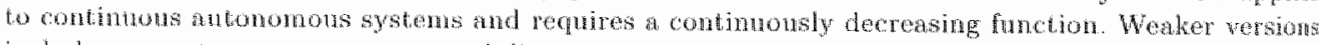

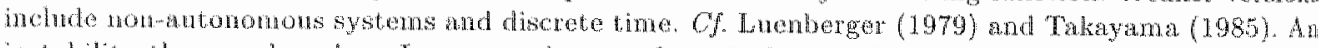

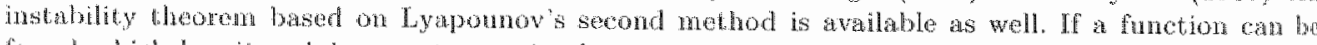

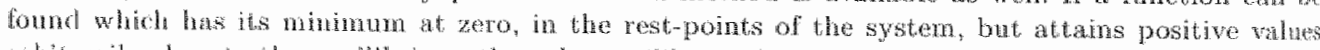

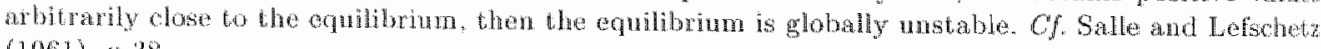
$(1961), 1.38$

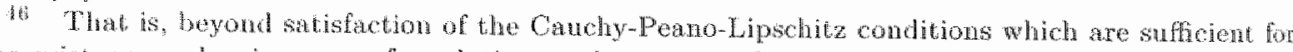
the exhtence and unigueness of a solution to the system. Cf. Takayama, 1985, pp.303-6.

4. A large part of Weintrab (1991) is dowoted to an extensive overven of the history of Luan pormov"s second method in modern Anglo-American dyamie systems analysis. In it on crucial roto

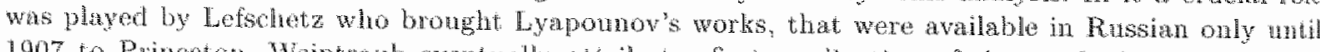

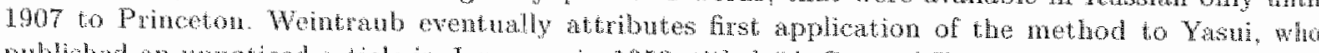

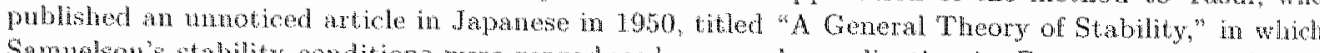

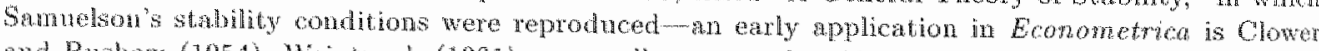

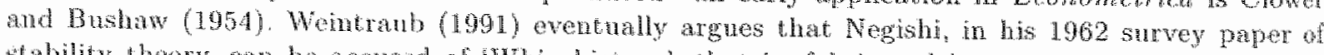
stability theory, com be accused of 'Whig history", that is, fabricated lastony writen in hindsight Patholarly, Wointrab holds hat Negish gawe too much credit to Alais in this respect. 
competition can as yet be made. It is conceivable, for instance, that (outside the class of situations here treated) an example of unstable unique competitive equilibrium may be found. On the other hand, none of the results so far obtained contradicts the proposition that under perfect competition, with the customary assumptions as to convexity, etc., the system. specified is always stable. If the latter proposition turns out to be true, Samuelson's "correspondence principle" would then provide no information that could not be deduced from micro economic considerations under competition, at least, for the particular class of adjustment processes considered. At the moment, however, the question remains open." (Arrow, Hurwicz, 1958, p.530)

The first optimistic conjecture was soom proven false by several counter-examples of Scarf, that will be discussed in Section 3.5. The second conjecture is of special interest here. It shows the confidence the authors had in their dynamics representing the actual dynamies of economies far axay from equilibrium-or "competition," as they repeatedly referred to it. Samuelson's aspirations of the correspondence principle were only locall. To judge it globally reveals a faith in its appropriateness as a representation of out-ofequilibrium that only Walnas may have had out of mawareness of its limitations. ${ }^{48}$

Moreover, various contributions to the widely referred to 1959 Stanford Symposium on Mathematical Methods in the Social Sciences, edited by Arrow and published under that title in 1960, reveal the discipline's frame of mind. In the opening article, "PriceQuantiby Adjustments in Multiple Markets with Rising Demands," Arrow presents a multimarket model in which prices and quantities move simultaneously, and the demand for engineers and scientists rises at the same time, resulting in complicated and interesting dymamics. Nevertheless, "[i]t is assumed that the price on each market obeys the law of supply and demand," $i, e$, rise in the presence on excess demand, fall with excess supply-for "more of which" reference is made to Samuelson (1947)." Also both Richard McKenzie and Michio Morishima postulate wersions of the above price dynamics straightorwandly in their papers on the study of disequilibrium dynamics-that will be considered in the next section. ${ }^{50}$

It appears that the generality of prices changing according to the law of supply and demand, thus establishing a Walrasian equilibrim, supported by the circunventing second method of Lyapounov, allowed for sheering off a further study of the intricacies

H On various occasions this conviction can be observed ith the two articles. For instance, the

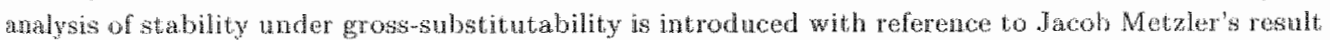

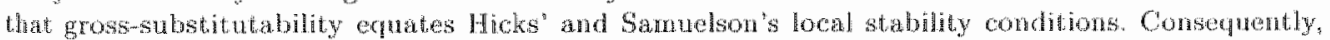
the guestions arrow and Hnrwioz (1958) set ont to answa is "... if there would bo stability (necessarily

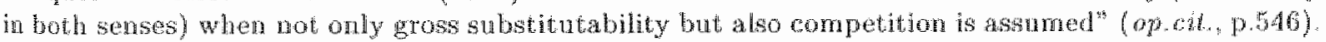
Agin the purzung conception of the meaning of dynamics used by the authors shows trom this interpretiation.

sis C. Arrow 1960 ). p.4.

Th It shond be noted that. Arrow has his application of the law of supply and demand come with a Dute to the lack of foundation for th, as well as a reference to Arrow (1959), discussedextensively in Chapter 4 . 
of the working of markets. The known logically unsound elements of the absence of disequilibrim considerations, and the presence of an auctioneer were taken on faitl for the sake of the attainment of a higher goa: 'general' economic theories, in which stability conditions could be studied on the level of preferences, production techniques, and endowments through dymamics entirely disconnected from its interpretation. Iroticaly enough, as it would fail to delivar satisfactory stability results, this route would lead away from that goal and, although successive steps were undertaken to clothe the mathematics in economic theory, disequilibrium theory still suffers from having taken it.

\subsection{The Subsequent Development of the Theory of Tâtonnement}

With the newly discovered techniques to obtain global stability results, a host of publications was generated. The first contributions concenned what becane known as the theory of tatomement. The development of the concept of the auctioneer, which is inherent to Walras' theory of totonmement, was taken up in Uzawa (1959). It is an early application of the second method, of Lyapounov to obtain quasi-stability.

Quasi-stability is a concept strictly reserved for the analysis of global asymptotic stability of systems and their solutions-as opposed to equilibria. It makes use of a modification of Lyapounow's second method, clamed by Hirofumi Uzawa in a survey paper of stability results, Uzawa (1961)--to a then forthcoming version of which Uzawa (1959) refers. It gave rise to a specific and much applied method for proving global stability, known as 'Uzawa's proof strategy". It is less demanding than prowing global stability directly, in that it allows a larger class of potential Lyapounov functions. A process can be quasi-stable, have many possibly infinitely many-equilibria, but. newertheless not converge to any specific one of them. Essentially, the requirement of a unique minimum of the Lyapounov function is traded for lower boundedness, which allows its application to sets oll" equilibria.

Key to the appreciation of guasi-stability are two straightorward but important results. The first is that if a dynamic system is quasi-stable and its solutions remain in a compret set, then the solutions converge over time to a set of rest-points of the system. The second is that if, on top of a system being quasimstable and its solutions remaining in a compact set, either the rest points of the system are locally isolated-which includes the special case in which the system has a mique equilibrium or the rest-point of a particular solution is unique, then the system is globally stable and the isolated equilibria locally-and for a unique equilibrium, globally-stable. ${ }^{52}$

if Cf Fisher (1983). Appendix. Both the dohition of quasi-stability and the Lyaponov theoren

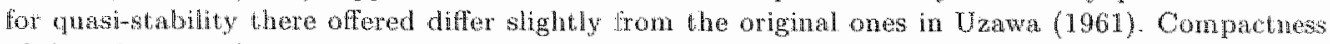
of the solutions of the system is not inctuded in the definition of quasi-stability. Furthermore, Uzane (1961) orignally presented the theorem with upper and lower bounds on the lyapounow functur.

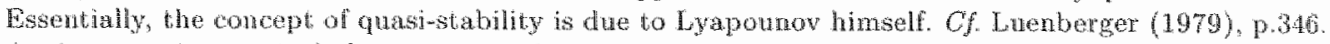
Again atengions to inchle systems wh the properties mentioned in note 45 are known.

3. See for the prools of this chein of results the mathematical appendix an fisher $(1983)$. 
The strategy of proof that derived from these constructions typically consists of three parts. The first part is establishing quasi-stability by finding a Lyapounov function. The second part is demonstrating compactmess of the solution paths, and the third showing that the equilibria of the system are isolated-or all the same. Debreu (1970) provides general results with respect to the latter for regular economies, that is provided some differentiability conditions are satisfied-which is so for an open set of economies of full measure. Compactness of the state space is usually readily provided for-provided issues such as disequilibrium consumption and production that alter the commodity space are ignored-which reduces the core of stability proofs to coming up with a dyapounov function-which is not an easy task.

As noted before, Uzawa (1959) starts with the claim that Walras" theory of tatonnement was ambignous in that Walras was unclear about whether his process was taking place in a simultaneous or sequential fashion over the various markets, and, moreover, lacked a satisfactory answer to the stability problem at least the former of those allegations is not quite true. Uzawa then states that he will show that the problem to determine an equilibrium in a general multi-market commodity exchange nodel, will rigorously be solved by "the Walras' tatonnement process". "That Uzawa, influenced by Patinkin's 1956 note from which he started, thought of this process as a method to find equilibrium rather than a description of the market process-for which, again, Walras certainly gave every reason-is clear from the following lengthy quote.

"Let. us interpret the competitive exchange economy as a game [in] which $R$ indiwiduals and a fictitinous player, say a Secretary of Market, play according to the following rules:

(i) Secretary of Market announces a price vector.

(ii) Each individual submits to Secretary of Market a 'ticket' on which the quantity of demand and supply by the indiviclual according to the announced price vector is described.

(iii) Secretary of Market calculates the quantity of aggregate excess demands from the tickets submitted to him by the individuals.

(iv) Secretary of Market announces a new price vector such that prices of commodities which have positive excess demand will rise, and prices of commodities which have a negative excess demand ... will fall. Moves (ii) and (iii) are repeated at the new equilibrium price vector." (op.cit., p.184)

Both for a system in which prices of commodities are groped at according to the above structure in a simultaneous way, and one in which the groping is sequential, quasi-stability is proved. For the simultaneous case the price dymanics is represented by

$$
p_{i}(t+1)=\max \left\{0, p_{i}(t)+f_{i}(t)\right\}, \quad t=1,2, \ldots \text { and } i=1, \ldots, n \text {, }
$$


in which $f_{i}(t)$ is the aggregate excess demand in market $i$. The distance function fo Euclidean spaces

$$
\Phi(p)=\frac{1}{2} \sum_{i=1}^{n}\left(p_{i}-\bar{p}_{i}\right)^{2}
$$

in which $\bar{p}_{i}$ is the equilibrium price level of commodity $i$, is shown to be a Lyapouno function for the system, in case aggregate excess demand satisfes the weak axion o revealed preferences, for which both quasi- and global stability are established.

For the sequential case, which comes closest to Walras $p_{j}(t+1)$ is determined st as to satisfy the relation that

$$
z_{j}\left[p_{1}(t+1), \ldots p_{j}(t+1), p_{j+1}(t), \ldots, p_{z}(t)\right] \begin{cases}=0, & \text { if } p_{j}(t+1)>0 \\ \leq 0, & \text { if } p_{j}(t+1)=0\end{cases}
$$

where $t=1,2, \ldots$ and $j=1, \ldots, n$. For this system a function $\Phi(p)$ that satisfies

$$
\frac{\partial \Phi}{\partial t}=-\lambda_{j}(p) z_{j}(p), \quad j=1, \ldots, n
$$

is studied, in which $\lambda_{j}(p)$ is some positive valued function. $\Phi(p)$ is a Lyapounon function for the system in case of gross-substitutability and in case of the existenct of community preferences, that is if aggregate excess demand satisfies the axiom a revealed preferences.

Walras' own conditions for convergence seem to differ somewhat from Uzawa's. How. ever, the assumption on the behavior of cross-price effects Walras trusted to guarantex convergence was shown by McKenzie (1960), already referred to above, to amount to the condition that the own price effects on the aggregate excess demand of commodi. ties are larger than the sum of the cross-price effects, independent of the directior of the latter. That is, that there exists some positively weighted sum of the absoluti values of the off-diagonal elements in each row of the Jacobian matrix of the system of aggregate excess demand functions that is smaller than the respective positively weighted absolute values of the diagonal elements the real value of which was in variably, but unnecessarily, taken to be negative by Walras (1954). This condition is known as diagonal dominance. McKenzie (1960) shows it is sufficient for local asymptotic stability in linearized Samuelsonian systems of differential equations representing price dynamics, and since gross-substitutability implies diagonal dominance, it suffice for global stability of the Arrow, Block and Humica type as well. ${ }^{5.5}$

Finally, the other paper in Arrow (1960) referred to in the previous section, the one by Morishima, is also of interest here. In this paper, titled "A Reconsideration of the Walras-Cassel-Leontief Model of Generad, Equilibrium," Morishima defines a

\footnotetext{
T. 6 . op.cit, p.st and page 186, respectively.

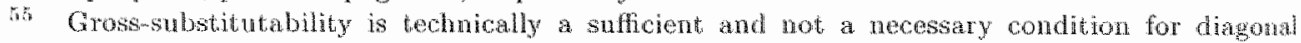
dominance, bu since the literatume seens to provide no modungful axmples of acomonios that satisfy diagonal domingnce and not also gross-substitutability, they are practically identical. Cf. Halu (1982b), p.759. Jaffs (1967) agres with Metaler (1945) that "Waluas" mind was sot in whe mold" of gross-rubstitutes.
} 
theory of tatonnement for a general equilibrium model with exchange and production. In it, exchange nor production takes place outside of equilibrium. Production takes place on the basis of linear technologies. Yet, the analysis extends importanty over the exchange model of Uzawa (1959). The paper builds towards dymanics in which simulaneously with prices changing in the direction of aggregate excess demand, the ticketed output of each commodity increases (decreases) when the price of that comnodity exceeds (or falls short of) its costs of production. ${ }^{50}$ Under the assumption that aggregate excess demand satisfies the weak axion of revealed preferences, and assuming the existence of a solution to the adjustment process, a Lyapounov function that sums the Euclidian distances of input and output prices from their (mique) equilibrim values, and output from its equilibrium level, is shown to exist, so that the model is globally stable on its unique Walrasian equilibrium.

Morishima's model is further extended to general production functions, and related to the text of Walras" Elements, in Mas-Colell (1986). The dynamics is similar to that of Morishima (1960), yet more explicit. Adjusted are prices $p$ and produced outputs $x$, as follows in vector notation

$$
\begin{aligned}
& \dot{p}=K(F(p, \widehat{y}(p, x))-y(p, x)), \text { and } \\
& \dot{x}=Q\left(p_{M}-c(p, x)\right),
\end{aligned}
$$

where $F(\cdot)$ is aggregate demand based on prices and the total of cost minimizing production which together determine profits, which is income $y(\cdot)$ is aggregate supply, $p_{M}$ is the vector of output prices, $c(\cdot)$ is the vector of marginal costs at the minimum costs procluction plan, and $K$ and $Q$ are positive diagonal matrices of speeds of adjustment. The same assumption that no trade or production outside of equilibrium takes place is made. ${ }^{57}$

Andren Mas-Colell focuses attention on the local stability of this system around equilibrium states, and derives several results. On global stability he is very brief, and no results are offered. This is due to the fact that Mas-Colell does not attribute much meaning to the dynamics specified, as he writes:

It is important to keep in mind ... that the global andysis is nore difficult to interpret than the local. In the fust place, the farther we are from equilibrium the less confidence we can have in precisely formulated dymanic laws. In the second place, the tatonnement [sic] dynamics is not a real system taking place in real time. (...) The point is that either the tatomement works by taking us to the equilibrium and then we have a theory or it does not and then we don't." (op.cit., p.63)

To Mas-Colell, as to Samuelsom, tatomement is a plausible model of the behavior of competitive market only very close to equilibrim. Otherwise, it is merely andhod to find equilibria as it is to Uzawa. Yet, Mas-Colell had knowledge of developments in the 1960 's and ' 70 's. 
None of the global asymptotic stability results obtained for the theory of taton nement is very surprising. They mimic the Arrow, Block and Hurwicz $(1958 ; 1959$ conditions, and quasi-stability is proved under assumptions sufficient for unique equi libria only. The value of the articles, particularly of Uzawa and Morishima, is in the explication of the process conceived to be behind the law of supply and demand Clearly, even admitting the logical necessity of signaling through tickets in the als sence of disequilibrium trade, and the presence of a secretary of market, it seem to have distanced itself from the "empirical solution" Walras observed on the Pari Stock Exchange. Nevertheless, it was taken as such, and as an appropriate represen tation of actual market processes. Uzawa's account, generally in differential form, stil dominates the textbook representation of the theory of tatonnement-and the whol account of market dynamies for that matter. .5

\subsection{Scarf's Counter-examples and their Generalization}

In the early development of global asymptotic stability of tâtonnement, in accor dance with the optimistic proposition of Arrow, Block and Hurwicz, progress wa expected to be had from superseding the gross-substitutability and weak axiom o revealed preferences in the aggregate cases, and establishing global stability gener ally for economies satisfying the relatively mild conventional conditions on preference and production techniques known to be necessary and sufficient for the existence 0 equilibria. Soon, however, in 1960, Scarf published constructed examples of a class a exchange economies that are conventional, yet globally unstable for the tatomemen process. This showed that such expectations were likely to be in vain.

The crux of Scarf's examples, which were formulated for a three by three economy with a unique equilibrium price vector, lies in the direction of aggregate excess deman changes upon price changes. If for at least one good aggregate excess demand goes uf with the commodity's price in equilibrium, the equilibrium is locally unstable applying the tatonnement price dynamics, in that the Jacobian of aggregate excess demanc around the equilibrium state has at least one eigenvalue with a positive real part. Scarf found that for preferences with sufficiently strong income effects over substitution effects, sufficient preference of two commodities over the other in a cyclical way acrosi the individuals so that each consumer derives utility from a different combination o the goods, and sufficiently skewed initial holdings, such is the case. Moreover, witt a proper condition bounding them away from zero, prices will converge to a cyck instead, so that the unique equilibrium is globally asymptotically unstable. Thest examples showed that stability conditions were not to be had from the conventionat

Ss. Examples me Varian (1984) and Mas-Colen at al. (1995). A role of major importance in th: sething of manstrean view is played by Negishi (1962), an early closure of the heydays of stabilit research.

"it In lact, Scart developed a Lyaponow function by taking a Taylor approximation of the Eu chlean distance between abitrary price vectors and the unicue equilibrimm price vector, and showe

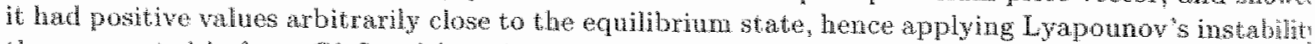
theorem noted before. Of. Scal (1960), pp $166-7$. 
continuity, differentiability, strict convexity, and monotonicity assumptions. They were only to be found by introducing additional assumptions on the relationship between income and substitution effects. 60

In the days of high expectations when Scarf's examples came out, this result shattered global stability research-and, therefore, disequilibrium research at the time. It forcefully showed that Walras" task was indeed not very simple. "The impact was widely felt, tempered optimism and made research in global stability theory largely come to a still. It is now known that Scarf's counter-examples are in no way special. In a series of articles published in the early 1970's Sonnenschein, Debreu, and Mantel showed that for any real-valued function of positive prices, that is homogeneous of degree zero and satisfies Walras" law, an economy with any finite number of individuals equal or larger than the number of commodities exists, for which that function is the aggregate excess demand function. ${ }^{2}$ That is, to any aggregate excess demand function that does not satisfy conditions that guarantee global stability of the tatonnement dynamics-like those producing Scarf's cycles-there corresponds a structure of conventional preferences, production techniques and endowments that generates that aggregate excess demand function. Consequently, the set of economies with aggregate excess demand functions for which for the tatonnement price process a Lyapounow function exists is small compared to the set of all economies. In a regular economy, therefore, in order to have global asymptotic stability results for the price dynamics sofar taken to represent market processes, additional restrictions on aggregate excess demand are inescapable. If, in other words, it is believed that the law of supply and demand is a sufficient representation of the market mechanism, the market mechanism cannot be relied upon to stabilize the economy.

The road to general and neutral convergence results pointed out by Walras, paved by Samuelson, and taken by the late 1950's global stability literature thus ended here. To many, this was, and still is, considered also the end of the disequilibrium research. Yet, the road ended at a junction. Three further main directions of development were taken, that, although based on seminal 1960's contributions, picked up particularly in the 1970 's and early ' 80 's. One retained the assumption of no trade and production outside of equilibrium, as well as the assumption that prices are adjusted by an auctioner-type institution, and inquires what that auctioneer needs to do supplementary to, or instead of, following the Samuelsonian equations to find equilibrium pricess. This computational algorithm approach is discussed in the next section. It preserves neutrality of the disequilibrium adjustment process. The second research direction sought to ground the strong assumptions found to be sufficient for global stability of the tatomment process in specific characteristics of the underlying econony. This so-called distributional approach is discussed in Section 3.7. The third direction of inquiry broke the relationship between the 'theoretical' and the 'practical' solutions of Walras. It considers the organization of markets outside of equilibrium. These trading

60. Gale (1963) simplifies Scarf's examples to a structure with only two individuals and three comnodities, and clearly shows how the instability results derive from the dominarice of the income effects over the substitution effects-referred to as the "Giffen paradox."

41 Col. Hands (1984) on the impact of Scarf's examples.

a2 References are Sonnenschein (1972), Sonnenschein (1973), Debreu (1974), and Mantel (1976). 
processes keep the law of supply and demand in place. They are subject of Section 3.8 .

\subsection{Computational Algorithms}

In 1973, the same Scarf who earlier broke global stability research on the basis of the law of supply and demand, published, in cooperation with Terje Hansen, a book, titled The Computation of Economic Equlibria, which defined a research discipline that strives for computational algorithms with which to find quick and efficiently equilibrium prices for arbitrary imitial conditions in ever larger models. ${ }^{6}$ All of the research in this progressive program essentially relates to a computational method introduced in Scarf (1967). The method is based on a subdivision of the price simplex in a finite grid of small sized sub-simplices, each with its vertices labelled according to a signing wule related to aggregate excess demand at those prices -e.g., all vertices of a sub-simplex have the label of the commodity in largest aggregate excess demand. There then is a sub-simplex that holds the equilibrium price vector and that has vertices all differently labelled, referred to as it being completely labelled one of the arts is to find the appropriate grid-size to indeed capture the equilibrium price vector in a completely labelled sub-simplex.

In the thus prepared price space, Scarf's algorithm amounts to the following. Starting in a corner of the price simplex, sub-simplices are visited until a completely labelled one is found. This is done by moving from an incomplete labelled sub-simplex, which has at least one label double, to an adjacent sub-simplex, in a direction away from the double vertex and towards a vertex with the required label. As a consequence, eacli sub-simplex is characterized by only one 'entrance' and one 'exit', and never more than one of either. A completely labelled sub-simplex only has an 'entrance'. When the process enters such a sub-simplex, it is subsequently searched for the equilibriusi price vector. As a result, it is impossible for the process to cycle. That would mean, namely, to enter the same sub-simplices severall times. To start such a cycle is only possible through an exit into a previously visited sub-simplex that was neither the previous entrance into that sub-simplex, nor be exit. This implies that only from a sub-simplex with at least three "doors", a cycle can start, and those do not exist. Since also it is impossible to leave the total price simplex, the process must converge to at

is The computational approach offers, apart from methods to find equilibria in specific modets

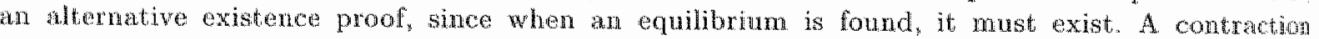
mapping used to proot the existence of axed point in an early existence proof strategy in Uxara (1962a) was introduced withont any attempt to give it an interpuetation as a description of ont or

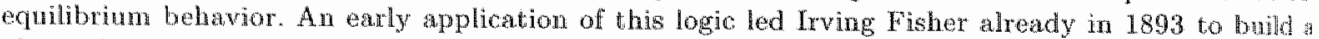
physical computational device in which watr reaches Walresian equibrium levels in a simple general equilbrim model of exchuge-also without much claim to descriptive relevance. For a descripticn illustrated with pictures of the Fishermachine, see Fisher (1925). 
equilibrium. ${ }^{64}$ Showing the existence of a properly labelled subdivision as describedwhich relies on Walras' law - establishes the existence of a globally stable algorithm.

Many important extensions and improvements on the original processes based on Scarf's method were made in order to generalize it. Particularly, it was made possible to initiate the algorithm from arbitrary starting prices, and not just one of its comers. Also, various labelling methods were applied in attempt to make the process more efficient, and hence able to find equilibria in larger models. Also, an extensive literature rose on making these algorithms readily applicable, not only to general equilibrium models with perfect competition, but to a variety of theoretical and applied, general and partial equilibrium models with assumptions of imperfect competition, missing markets, and game theoretical elements. ${ }^{65}$

From the beginning of its development, the implementation of these types of computational algorithms has closely been tied up with a socialist central planning perspective on general equilibrium theory. In a survey in Scarf (1989), no mention is made of Walras intentions to describe the actual working of markets to determine the theoretical solution -neither, for that matter, of the passible interpretation of the theory of tatonnement as a computational algorithm. Instead, Scarf stresses the need to base politics on comparative statics analysis. He quotes Enrico Barone, who understood in "The Ministry of Production in a Socialist Econorny" the Walrasian model as an adlequate description of an ideal economic system, provided supplemented by an appropriate income distribution, yet, in 1908, when the article was published, pointed to the impossibility due to computational complexity to determine the situation of "maximum collective welfare ... on paper" ${ }^{66}$ Scarf, however, optimistically reports:

"At the present moment, some 20 years after the introduction and continued refinement of fixed-point computational techniques, I have in my possession a small floppy disk with a computer program which will routinely solve-on a personal computer-for equilibrium prices and activity levels in a Walrasian model in which the number of variables is in the order of 1.00. (The authors of the program suggest that examples with 300 variables can be accommodated on a mainframe computer.)" (ibid.)

and undoubtedly, today the number of variables is importantly larger than ten years ago. In that respect, over the years many have pimned faith in socialism on increasess in computational power of modern computers. ${ }^{67}$

In the context of understanding disequilibrium behavior, however, the computen tional algorithm approach is better understood in line with a 'Gedanken experiment'

(if Fon a formal specification of this simplistic explanation see Kehoe (1991), Section 2. Intorestingly enough, this survey paper presents tatonnement processes as rather clumsy methods for computing equilibria that are "popular in practice" (op, cit., p.2068). Similarly, Gerard wan der Laan and Dolf 'Talman's 1987 survey of the computation literature reads Walras' theory of tatonnement as a "little advanced" algorithm (op.cit, p.85).

the On these various subjects, as well as extensive references, see Herings (1998).

bi Barkne, quoted by Scarf (1989) p.90.

or E.g. Lange (1936, 1967) and Goodwin (1951). The argument was often made in the somalled callculation debate', on which more in Chapter 6 . 
in Arrow and Hahn (1971). After discussing the relatively unsatisfactory state of: fairs in the 1960's in tatonnement stability theory, Arrow and Hahn opened a secti titled 'Some Other Anctioneer's Rules' with the following quote:

"We have seen that it is by no means true that, in all situations, the two rules we have examined [both sign-preserving functions of aggregate excess demand, both studied in a context without disequilibrium trade, one with, the other without prices being expressed in terms of a numéraire] will be successful in seeking an equilibrium for the economy. If, for the moment, we think of the auctioneer as a planner who is seeking the equilitrium by trial and error and forget all about simulating market procedures, it is reasonable to enquire whether there is some other rule that would lead to an equilibrium whatever the fine properties of the excess-demand functions might be." (op.cit., pp. 302-3, emphasis added)

The section then proposes the following price dynamics, in vector notation

$$
\dot{\mathbf{P}}=\mathbf{J}(\mathbf{P})^{-1} \mathbf{z}(\mathbf{P}),
$$

in which $\mathbf{P}$ is the price vector, $\mathbf{J}(\mathbf{P})$ the Jacobian matrix and $\mathbf{z}(\mathbf{P})$ the vector aggregate excess demand, both evaluated at $\mathbf{P}$. Without additional conditions on t aggregate excess demand functions, yet introducing the fairly restrictive assumpti that the inverse of the Jacobian exists for all prices, this process is shown to be globat successful in finding an equilibrium. ${ }^{\text {ti }}$

It should be clear, however, that this price adjustment algorithm demands qu some information on the side of the auctioneer that he or she is not very likely have. No longer does it suffice to have the auctioneer adjust prices in the direction the absolute difference in the plans revealed to him at every single price vector. $N_{1}$ each price is a function of the direction of aggregate excess demand change upon pri change, and of those changes in all markets simultaneously. Although the informats requirement is less than perfect knowledge of aggregate excess demand--which be the disequilibrium question altogether-it is very close to it.

Negligence of consideration whether the proposed algorithms might be econonaical interesting kept the literature on computational algorithms on this track. General Stephen Smale is associated with the study of global stability with the global Newt method. This algorithm is introduced in Smale (1976c) in vector notation, as follow

$$
D f(x) \frac{d x}{d t}=-\lambda f(x),
$$

where $x$ is the vector of prices, $f(x)$ is aggregate excess demand, $D f(x)$ is its Jacolis matrix, and the function $\lambda=\operatorname{sign}\|D f(x)\|{ }^{69} \mathrm{It}$ is found successful in establishit equilibrium under slightly milder restrictions than the algorithm of Arrow and Ha above, as it relaxes the need for existence of the inverse Jacobian for all prices, at 
trades ifor restrictions on the initial price vectors. Compared to that algorithm, it elminates the (one would say for the auctioneer relatively minor) problem of inverting of the Jacobian of aggregate excess demand. Clearly, this does not reduce the anount of information necessary.

The contributions to economics of Smale, who as a mathematician occasionally excused himself as an outsider, are quite remarkable indeed. In 1973 and 1974 he published in the Jownal of Mathematical Economics, a sequel in six parts, titled "Global Analysis and Economics," and then the number, in which he proposed a reconstruction of generail equilibrim theory from its foundations. Then, all in 1976 , he published some four papers on disequilibrinm issues. They reveal that Smale was drawn to the study of stability by a dissatisfaction with existing explanations of outof-equibrim behavior. For example, in Smale (1976a), he wrote:

"I would like to give some reasons why I feel equilibrium theory is far from satisfactory. For one thing the theory has not successfully confronted the question, "How is equilibrium reached?" Dymamic considerations would seem necessary to resolve this problem." (op.cet., p. 289)

It is questionable, however, whether Smale's own analyses really served that purpose. Apart from the global Newton process, is the global asymptotic stability of a process with trade at disequilibrium prices considered in Smale (1976b). This process and the results obtamed for it, however, are essentially identical to those of Hahn and Negishi (1962), discussed in the next section.

The global Newton method requires the auctionger to know in what direction equilibrim is to be found. That the same applies to the Scart algorithm becomes clear once one realizes that the method of Smale, when appropriately started near a corner in the price simplex, behaves like Scarf's algorithm when applied to a subdivision of the pricesimplex with infinitesimally small grid size. The Smale algorithm, in other words, is the limit of a sequence of Scarf processes with ever increasing precision. As a consequence, both are open to the negative results of Saari and Simon (1978), that show that at least the auctioneer needs to include in his price adjustment the partial derivatives that is, the Jacobian-of the aggregate demand functions of the given economy at all prices. Hence, there is no bope for finding any rule for an auctioneer leading a tatomnement process that relies on less knowledge of the underlying econony than necessary for the global Newton methods. ${ }^{70}$ 'This makes Uzawa's secretary' of market quite an omniscient planner. If anything, it shows that if one wants to retain equality between the 'theoretical' and the "practical' solution, one must give up the law of supply and demand, and instead rely on hardly economically justifiable price patterns. " 1

One of the more recent and quite successful continuous algorithms is that of wan der Laan and Talman (1987). According to this process, that can start from any

\footnotetext{
See also Willams (1985) and Saari and Williams (1986).

"In Herings (1998) it is argued, on the basis of the relationship between Scarf's and Snate's algorthms there set out, that Scarf's algorithm has the same "natural interpretation as price aljustment processess" as Smale's has. This is at least contested by the quote from Arrow and Hain (1971) given in the text.
} 
interior initial price vector $\left(v_{1}, \ldots, v_{n}\right)$ in the $n$-dimensional unit-simplex, pricos ate set relative to initial price prices, as follows.

$$
\begin{array}{rlrl}
\frac{p_{i}}{v_{i}} & =\min _{h} \frac{p_{h}}{v_{h}} & & \text { if } z_{i}(p)<0 \\
\min _{h=} \frac{p_{h}}{v_{h}} \leq \frac{p_{i}}{v_{i}} \leq \max _{h} \frac{p_{h}}{v_{h}} & \text { if } z_{i}(p)=0 \\
\frac{p_{i}}{v_{i}}=\max _{h} \frac{p_{h}}{v_{h}} & \text { if } z_{i}(p)>0
\end{array}
$$

where $z_{i}(p)$ is aggregate excess demand of commodity $i^{72}$ By employing results hom the literature on manifolds with generalized boundary, Herings (1997) shows that this process converges generically under standard assumptions on excess demand. Yet, it telies on a particular feature new to auctioneer models, a memory of initial prices, whin helps to identify cycling. Even though, as also established in Herings (1997), the van der Laan and Talman process closely tracks tatomement under gross-substitutabiling it remains questionable for what reason other than the property that it converges an auctioneer would follow it.

However interesting the literature on computational algorithms may be, it fully and explicitly broke with the idea that disequilibrium theory is to study the convergent behavior of markets, that was, with all the twists observed cbove, at least the intention of Walras, Hicks, Samuelson, and Arrow, Block and Hurwicz. It is, therefore, no surprise that the approach was umable to provide insights into the behawior of markets ont-ofequilibrium. Nevertheless, the computation approach attracted considerable attention. So did the approach discussed next.

\subsection{The Distributional Approach}

The strict adherence to the Samuelsonian formulation of competitive price dynamics that became the focus of attention in global tatomement stability research had led to assumptions on aggregate characteristics of economies, particularly on the sys tem of aggregate excess demand, for which the Sonnenschein-Debren-Mantel result shatered all hope for further general foundation in individual characteristics. Ye: Hicks, and after him also Arrow and Hahn, had already indicated that problematic income-efects-the main source of instability results conld well level out in the asgregate, provided the individuals peopling the economy are sufficiently different. In the so-called distributional approach, this idea of establishing levels of heterogeneity that deliver well-behaved aggregate (excess) demand was further pursued. The prime motivator of this dine of research has been Wernen Hildenbrand. Surely, one of his main motivations was to substantiate tatomement stability.

An important underlying assumption in the indeterminacy result of Sonnenschein, Debreu and Mantel, is that the characteristics of the individuals in an econony can be chosen arbitrarily. That is, preferences and incomes are left largely unconditionedapart from the relatively weak conditions necessary for the existence of competitive

72 Op.cit, p.103. 
equilibrium, discussed earlier in Chapter 2 , and the demand that individuals act rationally and do not violate their budget constraints. The distributional approach seoks to narrow this very broad category, yet leave it as wide as possible. In Hildenbrand (1983), a seminal contribution to this research, the shape of the conditional distribution of the income, or expenditure, of individuals is qualified. That is, it is assumed that each conditional income distribution has a continuous non-increasing density with a bounded support. Roughly, that is, higher incomes are abserved with lower frequencies. Although this cannot generally be corroborated empirically, Hildenbrand showed by way of example that it is at least possible to find desirable aggregate characteristics in this approach. A survey of the state of affairs in this line of approach is Hildenbrand (1994).

In Grandmont (1987), Jean-Michel Grandmont showed that Hildenbrand's result could also be obtained by placing conditions on the distribution of preferences over the space of consumers" characteristics, rather than on income, using homothetic transformations - a type of affine transformation. In this approach, preferences are transfomed in that way by a parameter that is distributed in a qualified shape.

Yet another opening for introducing heterogeneity is on revealled behavior itself. That is, by assuming at least some individuals do not behave rationally. Garry Becker pursued this line of thought in Becker (1962) in an attempt to show that individual irrationality does not necessarily lead to "pathological" aggregate behavior. In that article, Becker shows that in the absence of rationality, but assuming that individuals are restricted by their budget constraints, choosing on these constraints randomly from a uniform distribution retums relatively nice market demand. In Grandmont (1992), this idea is taken up to show that the desired properties of aggregate excess demand can also be obtained without assuming rationality, by conditionally randomizing over choices. ${ }^{73}$

The distributional approach clearly relates to a line of development pointed out by some of the early contributors to disequilibrium theory. Moreover, it is a line of research that still is being followed. Yet, despite its quite interesting findings and its strong inherent critique to representative agents models, with which macroeconomics is often said to have been 'micro-founded'-narrowing the aggregation problem down by restricting the starting characteristics allowed, only to justify aggregate conditions that came as a big disappointment at the time, undeniably has the flavor of continuing on a false route only because it was once chosen. ${ }^{74}$ Particularly, this is questionable as there also is a third way, taken in a literature on trading processes, which holds more promise than the relatively little attention it got might signal.

\footnotetext{
73 A recent contribution in the distributional approach is Quin (1997).

7. Grandmont (1992) goes as far as conchding that the representative agent models aro mislonding, heconse individual characteristics middle out in the aggregate. Cf. op.cif, p.33.
} 


\subsection{Trading Processes}

As the heydays of research in tâtonnement ended, two major developments in diss quilibrium theory were led, respectively by Hahn and Uzawa, that held promise for more fuitful disequilibrium research. In two separate directions, Hahm-soon joined by Negish-and Uzawa started more explicit studies of stability conditions on the underlying out-of-equilibrium trading patterns-instead of on either individual endow ments, preferences and technology, or aggregate excess demand. Hence, with these respective initiatives, besides the one leading to computational algorithms, two other roads led away from the junction after the global failure of tatomement.

Both pointed to the need to flesh out market dynamics by studying out-of-equilibrium trade effects. Along the one, so-called Edgeworth-processes involve coalition fomation and barter processes, intentionally with neither a unique price vector, nor an auctioneer. Along the other, progress has been made in models with more or less onganized disequilibrim trade at unique disequilibrium prices. Because of the fact that trade at disequilibrium prices changes the endowments, and thereby the subsequent demand and supply, equilibria of both these types of out-of-equilibrium models depend importantly on the path of trade taken. Therefore, in the literature, they are often grouped as non-tatonnement processes. Yet; they involve more than just the presence of disequilibrium tracle, and are therefore better referred to as 'trading processes'.

Remarkably, the manuscripts of all of the seminal articles on both approaches were received by the respective journals in the beginning of May 1960 , and all but one were published in 1962. Moreover, there are mutual acknowledgments of helpful discussion and occasional cross-references extended, generally to differently titled working papers. As a result, it is hard to determine precedence. The single paper not published in 1962 was Negishi's "On the Formation of Prices," which appeared in the January 1961 issue of International Economic Review. In the May 1962 issue of Intemational Economic Review, both Hahn's "On the Stability of Pure Exchange Equilibrium" and Uzawa's "On the Stability of Edgeworth's Barter Process" were published. Finally then, the July 1962 issue of Econometrica had Hahn and Negishi's conclusive "A Theorem on Non-Tatonnement Stability," combining their earlier, independently written papers.

Nevertheless, it is Hahn who deserves credit for being the first to reconsider the Samuelsonian specification of disequilibrium behavior. In a brief and unattached article, also in 1962, in Review of Economic Studies, titled "A Stable Adjustment Process for a Competitive Economy" Hahn proposed an odd price adjustment process in which the price of commodity 8 changes proportionally to its present value, as follows.

$$
\frac{\dot{P}_{i}}{P_{i}}=\frac{X_{i}}{D_{i}}
$$

where $X_{i}$ is aggregate excess demand, and $D_{i}$ aggregate demand for commodity $i^{7}$

i5 Op.cit., p.63. It is interesting to note that again Scarf had the insight, as he wrote in his 1960 . article:

"Another possible interpretation is that the price adjustment mechanism above is not conrect." (op.cit. p. 1.60) 
Of course, it can be argued that setting up this process is little different from the computational algorithm approach. Yet, Hahn offered a justification.

"One rationalization is obvious: if the excess demand is small (in absolute
value), relatively to the total demand, the "error" appears small and mer-
charts do not change prices very much -in the reverse they do. But we
may also interpret. [it] to mean that the "error" is $X$ and that the speed of
adjustment, which is variable here, is $\frac{1}{D_{i}}$." (ibsd.)

This process is subsequently argued to globally stabilize both exchange and production economies, without specific assumptions on aggregate excess demand-and without requiring trade at disequilibrium prices, which it does not-by showing that the sum of prices times demand is a Lyapounow function for the system. ${ }^{76}$

Since furthermore Negishi, in his survey article-also published 1962 -referred to his own work with Hahn as the "Hahn-process", the fundamental insight to restrict the actual disequilibrium processes themselves, most certainly stems from Haln. Essentially, therefore, he stood at the basis of both trading process developments. In this section, first the "Edgeworth-process", so dubbed by Uzawa, and then the Hahn-process is discussed, both with contemporary extensions.

\subsubsection{The Edgeworth-Process and Extensions}

Uzawa's interest in clothing the dynamics of Arrow, Block, and Hurwicz in history of thought showed in his 1959 article on Walras" intentions. Uzawa was also the first to attempt to capture Edgeworth's concurrent theory of convergence in contemporary mathematics. Reviewing Walras' Etements, Edgeworth had considered the theory of tatonnement cumbersome. ${ }^{77}$ In Mathematical Psychics, published in 1881, he offered an alternative theory, in which the market process rests on sequence of disequilibrium transactions of individual traders, driven by their incentives to better their position. It has been subject of at least as much controversy as the theory of tatonnement.

Ambiguity exists particularly on the concept of recontracting. ${ }^{3}$ One way to take its meaning is that contracts previously made are no longer enforceable when a new round of contracting announces itself, so that the process does not involve actual trade, but rather a sequence of proposed trades, that is, offers and counteroffers, of which only the final one is binding. Edgeworth gives reason for yet another interpretation. The term recontracting is introduced in Edgeworth (1967) as follows.

\footnotetext{
76 Op,co, p.64. Hah"s result later turned ont to be false, cf. Kagawar and Kuga (1980) which has an example of an economy in which the process cycles. It clearly is at odds with the SonnenscheinDebren Mates result. Yet, this does not diminish the importance of Hahn seminal atempt in move awa from tadional tatomement in this articte.

77 For an extensive discussion on how Edgeworth wrongly condernned Walras theory of thitonnement see Walker (1987)

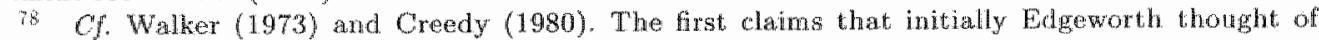
recontracting as trade proposals, wheras in his later work he deweloped it as irrevocable transactions, and bemce initiated non-tatomement theory. The second paper essentally holds the oposite.
} 
"Ts it peace or is it war?" asks the lover of "Maud", of the economic competition, and answers hastily: It is both, pax and pact between contractors during contract, war, when some of the contractors whow the consent of others recontract. Thus an auctioneer having been in contact with the last bidder (to sell at such a price if no higher bid) recontracts with a higher bidder. So a landlord on expiry of lease recontracts, if may be, with a new tenank." (op.cit. p.17)

Here, 'without the consent of "can be interpretated as 'independently of', "without informing with" others. 'This interpretation is supported by the fact that the landlord only then recontracts, after the previous lease expired. In fact, therefore, recontracting of a different commodity, namely recently available housing takes place, as opposed to recontracting of a previously sold commodity. In a later paper, however, it reads.

"The barter process] need not be supposed to take up a long period; rather the contrary, since the disposition and circumstances of the parties are assumed to remain throughout constant. But it is supposed that agreements are renewed or varied many times. A 'final settlement' is not reached unti] the market has hit upon a set of agreements which camot be varied with vantage to all recontracting parties." (Edgeworth, 1967, pp.313-4)

Naturally, recontracting understood as inconsequential trade implies that the disequilibrium trading process is really of no infuence, when compared to the assumption of absence of trade at disequilibrium prices. In other words, recontracting renders the Edgeworth-process neutral- like the tatonnement process. ${ }^{79}$ Yet, recontracting can also be laken to imply a series of enforceable property right changes through dise quilibrium that do have an influence on distributions. Urawa (1962b) takes the latter interpretation, and consequently presents a non-neutral process. As a result, the equilibrium of his model, if reached, is depending on the "path of bartering," as Uzawa refers to it. The paper spells it out, as follows.

"Edgeworth's barter process consists of successive barters between individuals according to their preferences and budgetary constraints. At each stage of the barter process, each individual transacts whenever he becomes better ofl by trading; and, in the competitive case, the quantity of a commodity in the exchange for the unit quantity of a standard commodity rises or falls according to whether or not the aggregate demand for that commodity exceeds the excess supply." (op.cit, p.21.9)

A transaction rule transforms a particular distribution of commodities into another under the restriction that every transaction must weakly improve the situation of

\footnotetext{
Th Another way of reducing the path-dependency of equilibra that comes with nom-tatonnemen

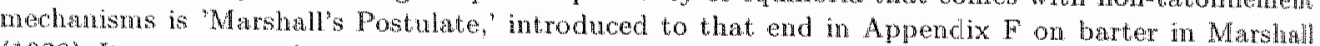
(1920). It amonnts to the assumption of constant marginal ntility of one commodity typically thoner. This reduces the indeterminatieness of the barter process with one dimension. Of. op.crt. pe.6.3.4, Hicks (1946), pp. 127-9, and Nerman (1965), p.81.
} 
all indiwiduals, and strictly that of at least one, until an equilibrimm is reached. To capture this Uzawa (1962b) has the prices of commodities change simultaneously, and as function of aggregate excess demand. In all, the dynamics is represented by the fallowing set of differential equations.

$$
\begin{aligned}
& \dot{p}_{i}=\rho_{i}\left(x_{i}-y_{i}\right), \quad i=1, \ldots, n, \text { and } \\
& y^{s}=\sigma\left(z^{*}-y^{s}\right), \quad s=1, \ldots, S .
\end{aligned}
$$

in which $\rho_{i}$ and $\sigma_{i}$ are positive rates of adjustment, $x_{i}$ is aggregate demand, $y_{i}$ aggregate supply, $z^{s}$ the vector of amounts of commodities individual $s$ is granted by the market through a distribution system, which is a function of the demand of the individual, and hence of prices and income, and $y^{s}$ is a vector of amounts of goods in possession of individual $s$-which is crucially assumed to be positive for all commodities throughout the process. The precise nature of the distribution system is specified no further than that new bundles must weally increase utility over that deriyed from each old bundle, and at every stage everything is fully distributed. ${ }^{80}$

Uzawa presents a global asymptotic stability proof for this process, as well as for: a difference version, by showing that the sum of the individual utilities increasing monotone through disequilibrium, and is bounded by the equilibrium utility levels, so that its negative is a Lyapounov function. Furthemore, convergence is shown to take place on a Pareto efficient allocation. This stability result is the article's main message. It does not rely on tătomement-type stability conditions, i.e., on the existence of a consistent aggregate preference structure. However, as the endowment structure only changes out-of-equilibrium if trade is at nobody's expense, and in at least somebody's interest, it is no surprise that over trade the sum of the individual utility levels increases. Global asymptotic stability of the process is readily derived.

Moreover, since the final equilibrium is path-dependent and consequently unique, if convergence takes place, it takes place essentially irrespective of the behavior of prices. Whatever rule the secretary of market follows to change the price lovel by, every now and then he is likely to announce values that allow for trade. Asymptotically, this suffices for global convergence. Due to the fact that neither consumption, nor production takes place outside of equilibrium, the absence of trade at any other price vector, simply preserves the value of the Lyapounov function. Although, therefore, Utawa's approach allows for a relaxation of the strong global stability conditions of the tâtonnemeut, mechanism, and makes some leeway in grounding individual interaction and trading, still the prime responsibility for the rise of trade opportunities is with an anctioneer-type institution. As a result, Uzawa's Edgeworth-process provides little insight in the actual trading process, nor in what way characteristics of the rest-points of the trading dynamics depend on it.

Further work has been more specific about disequilibrium trade, by looking at coalition formation. The basic idea of three important subsequent contributions to the understanding of the Edgeworth barter process is to study convergence in probability of equilibrim allocations on the basis of the probabilities of coalitions being formed and

sit Op.ro, pp.226-7. 
offers being made, and derive stability results in terms of "almost sure" convergence. That is, global asymptotic convergence to an equilibrium is shown for all possible solution paths of the disequilibrium process, but a subset of measure zero.

A seminal article that takes this approach, yet couples it with the more regular interpretation of Edgeworth's recontracting as a sequence of trade proposals that do not materialize outside of equilibrium, is Jerry Green, "The Stability of Edgeworth's Recontracting Process," Econometrica, 1974. A series of Pareto efficient trade proposals is studied, which are succeedingly blocked by counter-proposals of coalitions formed out of the individuals peopling the economy that can gain by doing so. At each stage an old proposal is on the table. A particular coalition is picked out of all possible coalitions that can come up with a counter-proposal that betters its members position over their situation in the present proposal.

Each possible coalition is selected with a certain probability-which Green (1974) does not make dependent on the potential blocking proposals of potential coalitions, but on the set of possible coalitions only. Within that coalition, from the set of possible blocking proposals, a Pareto efficient one is taken and proposed, with a probability depending on the size of the set. Individuals excluded from the coalition at hand are assumed to pick a trade proposal in the set of Pareto efficient allocations for themselves, although in general those will not be superior to the proposal present. Consequently, individual aspirations to utility levels can go down. Since the core allocations for the economy are the only Pareto efficient allocations that cannot be blocked, it is shown under a number of assumptions, and over an exhaustive series of possible cases, that eventually the process generates a proposal in the core with probability one. That is, Green's process converges almost surely to a competitive equilibrium proposal that is subsequently executed.

In the same train of thought, two articles by Leonid Hurwicz, Roy Radner and Stanley Reiter, "A Stochastic Decentralized Resource Allocation Process, Part I" and "Part II", both in Econometrica in 1975 present, in many varieties, a model in which individual traders make offers from their sets of potentially utility increasing trades, according to some probability distribution. Here, however, if bids match, trade actually takes place. After such trades, the situation is reconsidered, and new bids are formulated, until the sets of potentially utility increasing trades are disjoint. Under the assumption that Pareto improving bids have a positive probability outside of equilibrium, it is shown that the bidding process converges almost surely to a Pareto efficient allocation as time goes by. Hence, the process is globally asymptotically stable on a path-dependent core allocation.

Finally, Daniel Graham and Roy Weintraub, "On Convergence to Pareto Allocattions" in Review of Economic Studies, 1975, combines disequilibrium trade with coalition formation in the sense of Green (1974), and studies the effect of the costs of 'inter-agent communication' in the process of the formation of Pareto improving blocking proposals. The conclusion is that communication costs obstruct the attainment of small Pareto improving blockages, for which the gain does not exceed the costs. Given that those blockages are assigned zero probability, convergence results similar to those of Green (1974) are obtained under the assumption that the magnitude of potential Pareto improvements is positively related to the probability of that improvement being established. In the absence of communication costs, positive probability on even 
the smallest Pareto improving trade proposal assures almost sure convergence on a Pareto efficient equilibrium. ${ }^{81}$

In the results found in these three models, the crucial factor responsible for convergence is in a rather straightforward convergence property of probability distributions defined over shrinking sets. At each draw from a distribution, the drawn allocation leaves a smaller support, until it eventually consists of only one point, that will get all probability mass. This is true both with and without recontracting. In the absence of recontracting, the path-dependency behind the Uzawa-Lyapounow function is active on top of this. In Green (1974), the history of trade proposals, although they are recontractable, steers the process to the eventual equilibrium in a non-deterministic way.

Once matches of potential trades are made, the updating of probability distributions is quite natural. However, in the actual matching of individual trade proposals, a form of coordination is needed. Pareto efficient blocking proposals of subsets of the total of traders arise with a certain probability, and are matched by Pareto efficient propasals of the traders not in the coalition. The actual trade process is in arriving from the individual desire to trade to Pareto efficient proposals on any particular level, and that is not considered. As a consequence, the disequilibrium problem is shifted from an economy wide problem to an internal coalition problem. Especially since eventually the coalition is to include all individuals, this is different from solving it. Green (1974) refers for the processes inside coalitions to Hurwicz, Radner and Reiter (1975). Although there is an individual drive to form coalitions, their solution eventually also appeals to central coordination, this time in matching the individual bids formulated.

Another problem with the Edgeworth-process is found in studies of the information requirements of coalition formation in the absence of a unique price vector. Madden (1975) shows that the size of coalitions is bounded above by the number of commodities in the economy, and that if every individual possesses a strictly positive amount of every good, convergence over coalition formation need only involve coalitions of two indriduals at a time. Yet, Fisher (1989) generalizes these results, and shows that the information requirements on preferences and endowments on the side of all individwals in order to come to coalitions in which all members increase their utility levels are indeed restrictively severe, especially when compounded trades are required, $x_{\text {. }} e_{\text {; }}$ chains of indirect trades, which only weakly increase utility, but are carried out with a view to a final strongly preferred trade. ${ }^{82}$ As a result, particularly with no further insights into the trading processes offered, Pareto-improving proposals may very well never arise.

The fact that each and every trade requires the individuals involwed to at least not decrease their instantaneous utility levels by engaging into iti, not only poses at serious coordination problem, it also largely rules ont arbitrage. After all, individualis

\footnotetext{
\& C. Graham, Jacobson and Weintrab (1972).

32 Cf. Madden (1976). On a reaction to similar earlier critiques on the Edgeworth Process by Fisher see Madden (1978). Tsai (1993) presents an impossibility theorem on coalition formation involying many individuals by showing the problem is Nondeterministic Polynomial (or NP)-Hard. substantiating this claim.
} 
involved in arbitrage over disequilibrium prices may well face decreases in utility when things tum out differently than expected. Although entrepreneurial arbitrage is geard towards increasing expected utility ex ante, ex post actual utility may well be decreased by it. The Edgeworth-process thus leaves no room for modelling arbitrage, an essental element of disequilibrium behavior.

The Edgeworth-process, particularly when interpreted as sequences of irrevocable trades, identifies elements of an acceptable theory of out-of-equilibrium behavior. It has a place for rational offers and counter offers by individual traders. However, a focus on global asymptotic stability results led Uzawa to neglect how these proposals take shape. Moreover, he retained an auctioneer to set prices in a traditional manner. Later developments moved away from this, applying a different strategy of proof, and established almost sure convergence of possible sequences of either blocking trading-coalitions. Out of the many possible coalitions, and the many possible trades among them, one is drawn every step in the sequence. This requires a coordinating institution, the task of which grows exponentially in the number of traders, and prob. ably over its head. In all, this type of trading processes relies on individuals finding the trading opportunity that exist between them, and thus zoom in on the cores How they do so remains largely un-illumimated.

\subsubsection{The Hahn-Process and Extensions}

Hahn observed in the early 1960's that the way of modelling market dymamics in tatomement theory had not led to interesting results. He first explicitly proposed to instead enhance stability analysis by considering more specifically what happens outside of equilibrium in "On the Stability of a Pure Exchange Economy" as follows.

"[I] $\mathrm{f}$... some arbitrary prices are called, it is reasonable to postulate that some exchange will take place at these prices provided at least one individual gains and no individual loses thereby. (...) This suggests the following idea: If we argue that a tatomement takes place, i.e. no exchange, if and only if no individual can 'gain' by exchanging at the called prices withont. some other individual 'losing", then this condition itself may help to determine whether the tatomement process is stable. As it turns out, it does." (op.cat, p.207)

In the Hahn-process that developed out of this idea, trade taking place at disequilibrium prices is combined with an anctioneer who changes prices. The two processes altemate. As long as individuals can gain from trading, they will engage in disequilibrium trades. As soon as trading stops, prices change as a, function of aggregate excess demand, until new trading opportunities arise. The structure of the proof of global asymptotic stability in the early articles by Hahn is rather longwinded-and has later been corrected upon. ${ }^{81}$ After, at Stanford, Hahn had combined forces with

R3 On equivalene between bater equibria and Wahsian equilibrit when the number of raders moreses seo Debreu and Sarf (1963). Auman (1964), and Hildenbrand and Kirman (1976)

84 An early correction on the concept of "dominance" used in the proof is by Morishima. (1962). This concept was no longer used in Hahn and Negishi (1962). 
Negish, - who published a very elegant proof in Negishi (1961a) the Hahn-process was laid down in full in Hahn and Negishi's Econometrica article "A Theorem on Non-Tatonnement."

Prices change according to Samuelsonian specification of the law of supply and demand, after all trade at current prices has taken place. The infuence of the latier at. disequilibrium prices on the endowment structure is captured in a system of differential equations as well. Together, the following system describes the market dynamics in the Hahn-process.

$$
\begin{aligned}
\dot{p}(t) & =K z(t), \text { and } \\
\dot{\bar{x}}_{\alpha}(t) & =F_{\alpha}(p(t), \bar{x}(t)),
\end{aligned}
$$

where $K$ is a diagonal matrix with positive diagonal elements, $z(t)$ is the vector of aggregate demand, $\bar{x}_{\alpha}$ is the vector of possessions of individual $\alpha$, trade in which is captured by $F_{\alpha}(\cdot)$, an single-valued continuous functional. 85

Several assumptions are made on the system-which, naturally, is assmmed to have a solution. Price adjustment starts only after all potential exchanges, in all markets, have been traded out. This implies several assumptions on $F_{\alpha}($.$) . After on a certain$ market, all possibilities are exhausted on a "first come first served" basis, some plans may be "overfulfilled." This occurs becanse some individuals may be forced to spill over to other markets in order to satisfy their budget constraints. The latter is captured by the assumption that at all times the sum over all trades must equal zero - that is, the total amount of commodities is constant, and also that, quite acceptably, at any price vector, indiwidual wealth is not affected by trade-known as 'quid pro quo' or 'no swindling' - which says that at each moment of trade, each individual will accept a trade if and only if the exchange takes place against equal value, given the ruling price vector.

Most essential, however, is the assumption that markets are sufficiently organized for all partners with trades among themselves to find each other. As a result, every individual excess demand for each commodity is, after all trade has settled, of the same sign as the aggregate excess demand for that cormodity. If not, individuals with opposing desires neet and trade. Formerly, this 'orderly markets' or "Hahn assumption', states that right before prices change,

$$
z_{\alpha j}(t) \sum_{\alpha=1}^{m} z_{\alpha j} \geq 0 \text { for all } j
$$

where $z_{\alpha j}$ is the aggregate demand of individual $\alpha$ for commodity $j$, and there are $m$ individuals.

To appreciate the importance of both the quid pro quo and particularly the orderly markets assumption, a sketch of the proof of global asymptotic stability of the Hahnprocess is instructive. It is based on the following function

$$
V(t)=\sum_{\alpha=1}^{m} u_{\alpha}\left(x_{\alpha}\left(p(t), \bar{x}_{\alpha}(t)\right)\right)
$$

Op.cit, p. 465 
where $u_{a}(v)$ is a standard utility function representing individual preferences. The os sential thing to note is that $V(t)$ is not the sum of realized utility, but of aspired nitiny at a certain price vector; .e., it is the sum of indirect or 'target' utility. Differentiahing $V(t)$ with respect to time, returns

$$
\frac{d V}{d t}=\sum_{a=1}^{T n_{i}}\left(\sum_{j=1}^{n} \frac{\partial u_{\alpha x}}{\partial p_{j}} \frac{\partial p_{j}}{\partial t}+\sum_{j=1}^{n} \frac{\partial u_{\alpha}}{\partial \bar{x}_{\alpha j}} \frac{\partial \bar{x}_{\alpha j}}{\partial t}\right)
$$

Since each individual demand is the result of utility maximization given prices and endowments, utility changes optimally, i.e, according to marginal changes in the constramed maximization problem given in the Lagrangian $L_{\alpha}=w_{\alpha}\left(x_{\alpha}(t)\right)^{-}$ $\lambda_{\alpha} p(t)\left(x_{\alpha}(t)-\bar{x}_{\alpha}(t)\right)$. Hence, upon some substitution

$$
\frac{d V}{d t}=\sum_{\alpha=1}^{m}\left(\sum_{j=1}^{n}-\lambda_{\alpha}\left(x_{\alpha}(t)-\bar{x}_{\alpha}(t)\right) \frac{\partial p_{j}}{\partial t}+\sum_{j=1}^{n} \lambda_{\alpha} p(t) \frac{\partial \bar{x}_{\alpha j}}{\partial t}\right)
$$

Now $V(t)$ can feature as a Lyapounow function if it is declining through disequilibrium to its minimum in equilibrium. Here the assumptions come in. The first is the quid pro quo assumption, $i e^{2}, \sum_{j=1}^{n} p(t) \frac{\partial \bar{x}_{a j}}{\partial t}=0.86$ Substituting $z_{\alpha j}$ for individual $\alpha$ 's excess demand of commodity $j$, and using what is assumed on price acjustment, it reduces the equation to

$$
\frac{d V}{d t}=\sum_{\alpha=1}^{m}-\lambda_{\alpha} \sum_{j=1}^{n} z_{\alpha j}(t) k_{j} z_{j}\left(p_{1}(t), \ldots, p_{n}(t)\right)
$$

Since commodities are scarce and utility non-satiated, the individual buchet constraints are binding, i.e., $\lambda_{x}>0$ for all $i$. Furthermore, $k_{j}>0$ for all $j$-if not normalized to one. Hence, the function is declining. Monotonicity can be found now in the relationship between individual and aggregate excess demand. If the two are of equal sign, $V(t)$ is a suitable Lyapounov function and quasi-stability can be proved.

Hence, the orderly market assumption on rationing is central to the convergence of the Hahn-process. It is also quite restrictive, and runs into the same type of problen detected in the Edgeworth barter processes, that is, that some coordinating dewice is required. Yet, problems are somewhat smaller here. Since all individuals take the centrally quoted prices as their yardstick, the Hahn assumption is satisfied through sufficient bilateral trades. Therefore, the information requirements of coalition formation are dropped. A problem of compounded trade is equally present, however. It is not guaranteed that any two individuals with advantageous trades between them are

\footnotetext{
Sit In fact, qud pro guo alone suffices to show that any nom thtonnement model satisfying in will be stabe nuder the sane conditions as its tatonnement, equivalent, since althongh indivat excess demands change with partial trades, the distribution of wealth does not, and consequenty the

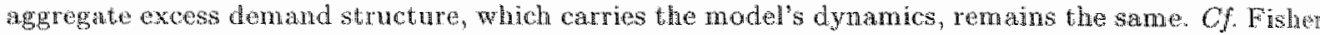
(1983). Of comse, this only reveals the shortcomings of tatonnement.
} 
able to exploit these, because they may not both be in possession of something that has walue for the other in exchange. ${ }^{87}$

To circumvent this problem, Arrow and Hahn (1971), in their coverage of the Hahnprocess, introduce the so-called "positive cash assumption', i.e., the assumption that no individual ever runs out of cash to express his demands through, since in the case of abundance of money all exchange is direct. This requirement certainly explains a role for money. Yet, mismatches and the inability to carry out plans to the full are essential aspects of a serious disequilibrium theory.

Both the Edgeworth-process and the Hahn-process thus imply a coordinating device to regulate trade out-of-equilibrium. Moreover, for the behavior of prices outof-equilibrium, both rely on an auctioneer-type institution. The essential difference between the processes is in the degree of organization of the market. In the Edgeworthprocess there is no explicit organization, in the Hahn-process there is a high level of organization required. In neither process, the questions how this organization comes about is very extensively treated.

A similar orthogonality is found in the strategy of proof with which stability results are obtained. Essentially, the difference there is in the Lyapounov function used. For the Edgeworth-process, this is the sum of direct utility, resulting from actual trades. For the Halm-process it is indirect utility, resulting from potential trades that never came through. With these different functions Uzawa (1962b) and Hahn and Negishi (1962) present quasi-stability results without the strong conditions required for tatonnement stability. In return, however, as in the Uzawa case, stability of the Hahn process rests an irreversibility effect in the disequilibrium trade pattern. The value of the Lyapounow function is preserved at ary price movement away from equilibrium, since no trading opportunities will arise, and declines as soon as prices are obtained which do cast up profitable trades for some parties.

Through the nature of its Lyapounov function, however, the Hahn-process does offer more opportunities to introduce extensions in the disequilibrium behavior of indiwiduals than the Edgeworth-process does. Falling target utility is the result of the fact that people see the prices of the commodities they planned on buying, but could not due to insufficient supply, going up, and the prices of the commodities they in vainly planned to sell going down. Not finding a trading partner fast, in other words, implies a loss of potential utility, or disappointment. As a consequence, the type of behavior that would potentially obstruct the proof of convergence is behavior that increases target utility. This means that the process leaves room for disequilibrimm actions that are in hindsight suboptimal, as well as speculations with disappointing ontcomes. Fisher (1983) summarizes this idea as follows:

"[P]rofit for firms or utilities for households can never be higher given the restrictions imposed by irreversible actions than they would be could those actions be undone at will. It is therefore not hard to show that target profits for frms and target utilities for households are still declining out of equilibrium; indeed, the declining utility and profit feature of the

47 This critique was forst formulated to general equilibuin theory by Chower in Chower (1965). See also Patinkin (1969). Abraham and Whittaker (1989) make it more exllensively. 
Hahn Process makes it particularly adaptable to the case of disequilibrium consumption and production." (op.cit, p.42).

In a series of extensions on the Hahn-process in the 1970's, Fisher exploited these degrees of freedom. In Econometrica appeared "The Hahn Process With Firms but No Praduction," published 1974 , and "A Non-Tatonnement Model with Production and Consumption," in 1976, and in 1978, in The Review of Economic Studies, "Quantity Constraints, Spillovers and the Halan Process." 88 In the 1974 article, it is shown that firms, when they refrain from production out-of-equilibrium such as households do not consume outside of equilibrium in such models, face falling target profits during the price adjustment process. The consequential decline in expected income from profits strengthens the fall of the sum of indirect utility over all individuals, which thus serves as a Lyapounov function to establish global asymptotic stability of the Hahn-process still. In Fisher (1976) production and consumption outside of equilibrium are allowed within the Hahn-process assumptions. As a Lyapounov function serves then the sum of target utility over individuals plus the sum of target profits over firms in disequilibrium, and global asymptotic stability is derived. Finally, Fisher (1978) establishes that when individuals are quantity constrained in their transactions on certain markets, and the spill-over effects thereof ane taken into consideration, that then the Hahn-process still converges globally, either on an imperfect market equilibrium, or, when constraints are falsely perceived, possibly on a core allocation. ${ }^{89}$

These extensions certainly show the power of the Hahn-process. Yet, they bring no relief from the stringent aspects of it, noted above. It remains un-illuminated how transactions outside of equilibrium come about, how prices change, and particularly also, why individuals, in light of the apparent dynamics of markets, do not behave as to take advance of it. In none of the trading processes a satisfactory treatment of these issues is offered. From the 'simple task' of Walras took off a series of contributions, none of which were able to perform it well. Even though the trading processes evade the impact of the for tattonnement theory negative Sonnenschein-Debreu-Mantel, as well as the Saari-Simon results, and even though they at least were contrary to Samuelson's, Hicks', and the computational algorithm approach -intended again to shed light on the dynamics of out-of-equilibrium market behawior, they left many fundamental questions open.

ss Both eqrier and later papers in disequilibrium beharior have a difereat approach, and will bo dischesed an Chapter 5 .

39) In Cisher (1983) Chapter 3 , the state of affurs with respect to the Hahn-process is set out. self-cont abined. 


\section{On a Homunculus Explanation in Economic Theory}

In recent years, various scholars have found in stability theory case studies in the methodology and sociology of science. Examples are Hands $(1984,1994)$, Ingrao and Israel (1990), and Weintraub (1991) referred to in the previous chapter. Stability theory makes a good subject for such studies indeed, for several reasons: its main and best known novelties date back quite some time, it has been reviewed extensively and comprehensively, it applies fairly insightful mathematical tools, with which it offers a limited amount of transparent strategies of proof, it was once prolific, but, suddenly abandoned after the Scarf examples and their generalization, hardly any research is currently in progress, and the subject attracted surprisingly many of conomics' best minds, of which many have later on expressed themselves in negative ways on both the knowledge on stability produced, and that to be expected.

The tenor of these studies is invariable negative. The results obtained in stability theory are judged meagre, relying on assumptions that are hardly justifiable, and were never able to reach the level of generality that those on equilibrium properties in general equilibrim models did. Research attention has shifted to other problems, and hardly a soul works on extensions of the theory anymore. It is concluded that stability research makes a perfect example of a research program that degenerated in the Lakatosian sense, in the 1970's at the latest, with which the matter is left.

Of the studies referred to, Hands (1984) uses Scarf's 1960 contribution to illustrate the importance of counter-examples in the progress of science. Ingrao and Israel (1990) claims that stability theory was unappealing because it was not as general as equilibrium theory-a case in sociology of science built almost exclusively on the observation that Debreu stayed away from stability analysis. Weintraub's study is different. Although, as explained in the introduction, Weintraub set out to show the degeneration of stability research, the book instead offers a study into the influence of literature surveys on mainstream opinion-with Negishi's 1962's survey article on precedence of 
Lyapounov's second method as case in point. Yet Hands (1994), which is an extensive survey of Weintraub's constructivistic argument, seeks again to conclude on stability theory's failure.

All these studies contain intriguing stories and touch upon valuable insights. Yet: none of them goes far past the impact of the Sonnenschein-Debreu-Mantel result. Only Ingrao and Israel (1990), that after a very brief and incomplete discussion peculiarly enough concludes in the closing pages that "... the literature on non-tattonnement seems to have led above all to strictly mathematical developments comnected at the ontside with problems of economic planming" (op.cit, p.354, note deleted). More importantly, none of them is very constructive."

The conclusion that global stability research has long ago degenerated as a program substantiates popular opinion that the study of disequilibrium and stability is dead without hope for resurrection. Yet, as extensively argued in Chapter 1, the questions asked in disequilibrium theory are of fundamental importance both to economics in general and general equilibrium theory in particular, and they are still largely open. Therefore, these contemporary methodological case studies cannot be allowed to windicate common understanding that equilibrium analysis suffices. Instead, their negative conclusions on past progress should-where they have merit-be taken to point to ways to revive the disequilibrium research program into a progressive one again.

The history presented in Chapter 3, which had a negative tone as well, was to show that the poor state of affairs in disequilibrium theory was largely due to the fact that stability theory started on the wrong footing. This argument will be driven home in this chapter by means of the organizing principles presented in Chapter 1 . It will clear the way for a progressive problem-shift which the rest of the book extends.

The chapter is organized in four sections. Section 4.1. locates stability theory in the general equilibrium research program, and identifies its main problem. Section 4.2 introduces a concept that captures the heart of the matter at hand in out-ofequilibrium theory, that of homunculus explanations, and lays out how stability theory offered just that. Section 4.3 addresses some very early replies to the Samnelsonian approach to price adjustment. These point to elements of monopolistic competition and imperfect information for a more satisfactory theory of disequilibrium. Section

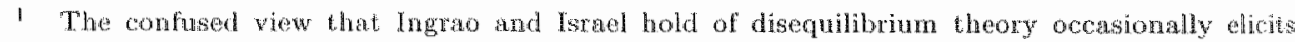

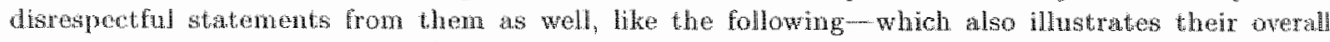
opinion and mon amganent. Debreu's stayng awdy from stabulity issues.

\footnotetext{
'Sonnenschein's papex justifies those, like Debreu, who had never been convinced of the possibilities of achering significant results in the field of stability and had had nothing to do with it. It also divides those who had worked in the field into two groups: those concerued only to moum the loss of global stability and those who see that no progress is possible in that direction and so a change is called for. The nost lucid and representative exponent of the first group is F.H. Hahn, who is still repeating today that: at theory of gemeral equilibxim lacking a satisfactory theory of the "invisible hand" is like a mutilated body, whont however concealing the difficulties involved in achieving satisfactory analytio resuls. The anthor to express the attitude of the second group most clearly ... is Herbert Scarf." (op.cit., p.347, a lengthy note deleted)
} 
4,4 tackles a final obstacle in the way out of the problems of disequilibrium theory, its alleged ad hoc nature.

\subsection{The Disequilibrium Research Program}

The picture painted in the previous chapters is sketched as follows. The research program of economios is well orgamized, around a consistent hard core. It is mature, yet progressive. Closest to its hard core is its theoretical core, general equilibrium theory. The general equilibrium sub-program adds an extra demi-core proposition to the hard-core propositions of economics, which is that choices are to be studied in a closed system, in which the interrelation between markets is fully acknowledged. This is the setup sought for to study out-of-equilibrium behavior. The encouragenent to general equilibrium theorists provided by the positive hewistic of the research program of economics is to formulate logically consistent models with a relatively high level of abstraction, that give body to Smith's insight that societies based on free competition can well be orderly.

Stability theory has been tailored to that effect. Its pure theory was cleveloped in a theoretical general equilibrium setting of perfect competition, where it lhas mainly served the purpose of corroborating equilibrium analysis. To Walras, the theory of tatonnement, although based on observations, essentially was a means to appreciate the existence of equilibrium. Even if initially he was interested in studying the intricacies of market processes, Walras postponed such analysis over successive edition of Elements, and constructed tatomement to make sure the process would find no other than the presumed unique general equilibrium, either with or without production. After Samulson explicated the formulation necessary for that, Arrow, Block and Hurwicz made disequilibrium analysis fully supplementary to equilibrium theory. The processes studied are constructed to have solely predetermined, generally Walrasian, equilibria as their rest-points. There is no return to a more detailed description of masket processes. Quite to the contrary: the same is true for the computational algorithms spproach-where there is much more application to other types of market structures than perfect competition, as well as partial applications. And although trading processes do consider an influence of the adjustment process on the eventual equilibrim, they as well are primarily concerned with establishing swift convergence to core allocations. At best, disequilibrium analysis has been considered a second-order problem of little consequence. The advancement of equilibrium theory has been given priority in theoretical wonk. It is widely agreed that the stability of economic systems can safely be assumed for the sake of concentrating on equilibrium.

Remenyi (1979) identifies a clear principle in the Lakatosian methodological framework, that is operating in the research program of economics to the advancement of both the initial postponement of disequilibrium issues and the later service role of stability analysis. It is the heuristic of the bravado impulse, introduced in Chapter 2. Remenyi states on it:

"In economics [the bravado inapulse] has led ecomomists to poffer a range of scenario's-"stories" to explain, for example, the self-equilibrating. 
mecharism or the choice of "predicted" price and allocation decisions." (op.cit. $\mathbb{p} .36)$

The position of disequilibrium research in stability theory can thus be understoud as an auxiliary sub-sub-program with a demi-demi-core in the protective belt of the demi-core of general equilibrium research. It is to shield the sub-discipline of general equilibrium theory, and is illustrated in Figure 4.1, that is to be understood as a specified detail, lifted from Figure 2.2 in Chapter 2.

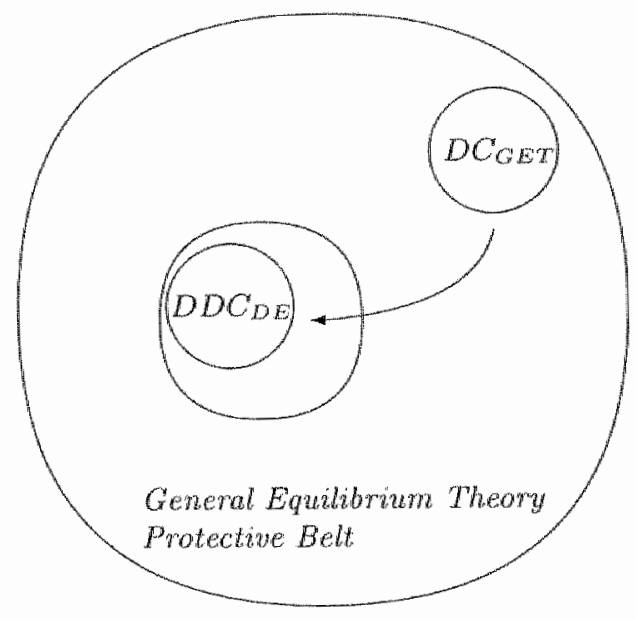

Figure 4. Disequilibrim research in general equilibrium theory.

The deni-demi-core of the disequilibrium research program is in the protechive bet of the general equilibrium research program. Its propositions are the following.

DDC 1. Commodity prices are the primary public signals on which individuals base their. plans.

DDC 2. Each commodity has a unique price at any given time.

DDC 3. Prices change according to the law of supply and demand.

DDC 4. Economies equilibrate sufficiently quickly to leave the fundamentals unchanged.

The first proposition is straightorward. It is generally prices that are taken to equilibrate economies through the effect they have on individual plans. Proposition DDC 2, which says that each specified vector of physical characteristics, location: time, and state of the world, as a unique price, is quite essential. It presupposes a level of organization of markets, which is not obvious. Yet, it is assumed in all global 
stability theory considered. The same is true for DDC 3. Prices are taken to change in the direction of aggregate excess demand, which is referred to as the law of supply and demand. Finally, adjustment processes, whether they allow trade at disequilibrium prices or not, are assumed not to allow time to pass in which the numbers of individuals or firms, preferences or production techniques change.

The prime positive heuristic that comes with these propositions is to formulate price adjustment processes that converge globally asymptotically to the equilibrium associated with the initial allocation of the model-or any of those when there are several. That is, to construct neutral adjustment processes that do not involve any other changes outside of equilibrium than to prices, and thus do not affect the equilibria of the model.

Clearly, the disequilibrium research program so delineated left ample room for a fortification of the existence results with which the general equilibrium sub-program was so successful in answering to the positive heuristic of the neoclassical program. Yet, at the same time it importantly hindered the development of insight into behavior outof-equilibrium, essentially in two ways. Firstly, and most obviously, the demi-demi-core setup and positive heuristic of the disequilibrium research program simply suppressed an interest in specifying meaningful out-of-equilibrium behavior. It has already been argued that such theory has to explain prices and their behavior, is likely to require important modifications of equilibrium theory.

Secondly, as the program was unable to deliver interesting results, disequilibrium research was soon deemed to be uninteresting, and the opinion became widely shared that it had failed. First, Samuelson's correspondence principle, i.e, the idea that important characteristics of equilibrium could be understood by studying the conditions necessary for stiability of out-of-equilibrium processes, was deemed a failure. Arrow and Hahn (1971) alleady stated that because only sufficient conditions - and very stringent ones-for local stability of the Samuelsonian dynamics were to be found,

\section{"... the correspondence principle "isn"t."." (op.cit., p.321)}

Soon, as illustrated by the studies referred to in the introduction of this chapter, this became a common belief for all stability theory related research. Naturally, few people would still work on out-of-equilibrium theory, thus indeed halting its progress. "This is the state of affairs today.

The argument that the heuristic of economics has led to the failure of global stability theory is all the more acceptable, once it is realized that the single way out of the deadend developments of the theory of tatonnement considered in the literature led via more detail to the trading processes outside of equilibrium. It involved a direct break with the economic research program. Trading processes come with path-dependent equilibria. That is, they converge on other than the Walrasian equilibria, and hence are not neutral. This goes against the ruling positive heuristic, yet turned out to generate interesting stability results, and thus temporarily revived the disequilibrium research program. Lakatos recognized this phenomenon:

"[I]t occasionally happens that when a research programme gets into a degenerative phase, a little revolution or a creative shift in its positive heuristic may push it forward again. It is better therefore to separate the 
'hard core' from the more flexible metaphysical principles expressing the positive heuristic." (Lakatos, 1970, p.137)

The approach, however, found few followers, most certainly because it is in conflict with arrived methodology.

The understanding of out-of-equilibrium behavior remained low, even with the influence of out-of-equilibrium trade accounted for. The prime reason for this is more fundamental. It derives from a methodological dichotomy between the study of equilibria and that of disequilibria. Whereas the former is based on methodological individualism, the latter is not. The research program of economics prescribes that the aggregate behavior of economies is to be studied on the basis of individual choicespreferably subjectively rational individual choices. Yet, the disequilibrium program relies for an understanding of the behavior of markets on aggregate excess demand, which has insufficient relation to individual behavior. Price behavior, therefore, is denied an underpinning in rational individual action.

In the terminology of the methodology of scientific research programs, DDC 3 is in conflict with $\mathrm{HC} 5$, that all phenomena are best understood as the aggregate in terrelated consequences of individual action. And it is clear from the SonnenscheinDebreu-Mantel result that they cannot be married. It is for this reason that an appeal to some entity outside of the model-particularly that of the auctioneer-is necessary. As such, stability theory offers little defence to general equilibrium theory. To put it a little charged, the disequilibrium research program has been a non-starter from its foundations. Inflicting the law of supply and demand on it has restrained economic theory. This straightjacket of the program foreclosed interesting disequilibrium theory, and thereby held the seeds of its failure. Inescapably, economics offers a homunculus approach to its central research problem.

\subsection{A Homunculus Explanation}

In the cognitive sciences, understanding the human mind has presented major diffculties. From the second half of the 18th century up until far into the 19th, if not the $20 \mathrm{th}$, century, the concept of human thought as a structured system of ideas was explained by a model in which a male-type master of ceremonies was seated in the brain and orchestrated thinking. Theories of the memory likewise postulated a little human librarian in the head, who would deliver from his archives forgone observations and thoughts at the request of his thinking master. In the picture below, taken from an old text book on the working of the human brain, a complete office of these litte men takes in signals from the senses and coordinates appropriate action in the brain headquarters--which is situated in the cerebrum. ${ }^{2}$

Of course, the librarian, on any of these little men in the figure, all need themselves to come equipped with their own little brains and memories. Following the explanation concept, therefore, all would need their own office workers, that in turn require

2 Precise source unknown. 


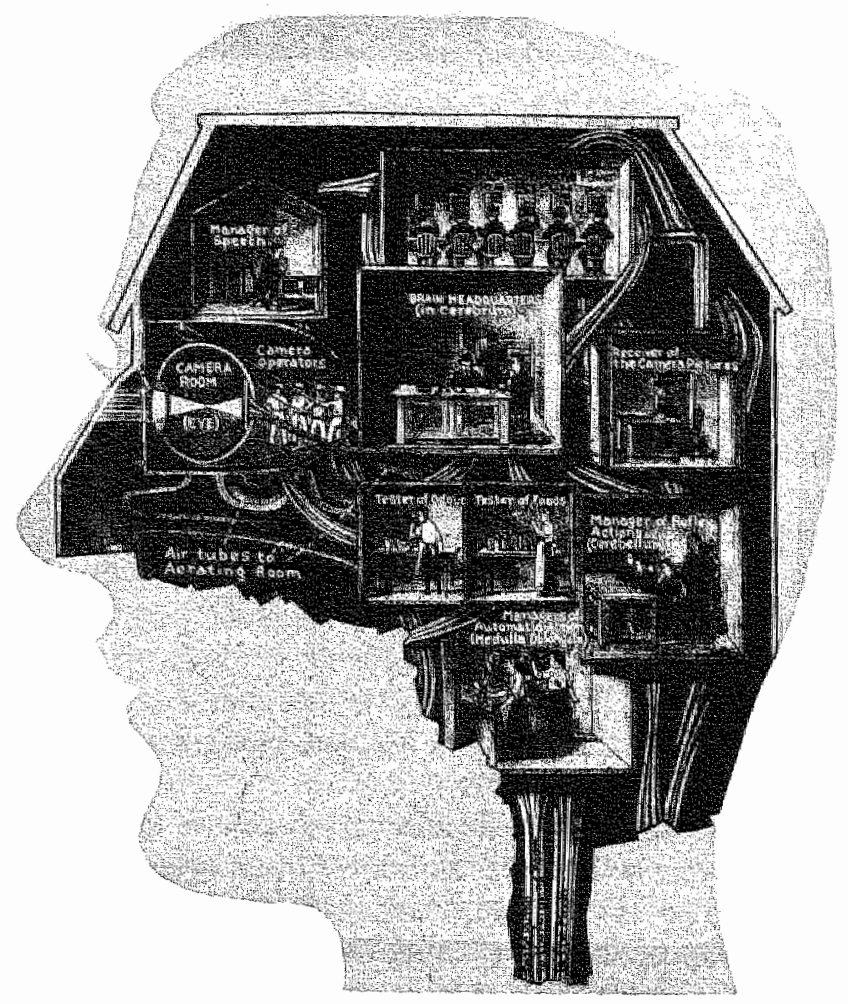

Figure $4.2 \mathrm{~A}$ homunculus explanation of the human mind.

assistant librarians and staff. That this infinite regress meant that really no theory of the mind was offered at all was first observed by David Hume in his A Theatise of

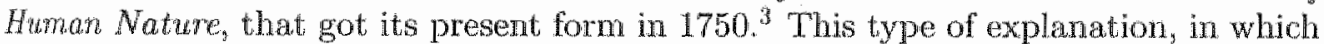
what is meant to be explained is really imposed as a metaphor on a higher level of abstraction, is referned to as a "homunculus explanation". Today, in psychology it is generally ridiculed.

In economics the auctioneer is a homunculus, and theories that rely on the auctioneer for coordination offer homunculus explanations. What is meant to be explained, that, is, the coordination of individually made plans through a structure of freely operating makets, is actually imposed, literally personified by a little man, whose function is to collect information on the demands and offers of the individuals peopling the economy, to combine this information, and to use it to signal new terms of trade, on which then-

3 For a dischssion of the role of homunculus explanations in the cogritiwe scicnces set Dennet $(1081)$

4. Yet, the remants of these old theories are still present today. People are still comtortable with the concept of a "conscience", for instance, "telling" them what is right and wrong. Also, in

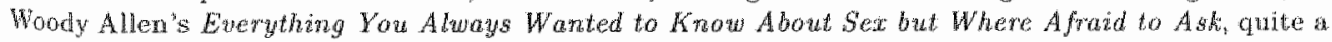
sticcessful hominculus explanation is offered for some trouble associated wath a Manhutara sex life. 
irrespective of the patterns of trade to perform the necessary calculations again, wnt: equilibrium is reached.

The invisible hand of economic's homunculus was born with the Walrasian theory of tatonnement. His alleged behavior was formalized by Samuelson, made responsible for establishing global stability by Arrow, Block and Hurwicz, was given a face as "sw retary of market" by Uzawe, and various different rules to go by in the computationat algorithm approach -in which its inherent break with descriptive economics is find and clean. It remained central in the distributional approach, as well as responsible for occasional price adjustments in both types of trading processes - the Edgeworthprocess and the Hahn-process-and where necessary it was on top of that entrusted with bringing potential trading partners together.

The homunculus is inherent to the methodological prescriptions of the disequilib rium research program in its present form. It was silently accepted as the appropriate representation of the market process for the generality of its formulation. Yet, if is this appeal to an unexplained onder, to explain order, applied in various models, and time and again justified with reference to the invisible hand or the law of supply and demand, that brought stability theory where it is today. It is at the heart of the irmpar. of the Sonnenschein-Debreu-Mantel results, and key to disequilibrium theory's alleged failure.

Understanding the history of disequilibrium research in this way sheds new light: on the common understanding that the disequilibrium research program has degenerated beyond hope of revival. This view is correct for the program as it stands. Ye, the problems are of the program's own making. It thus is easily understood that disequilibrium research is better advanced with a different foundation. Recognition of the hard core-demi-demi-core conflict between HC 5 and DDC 3 allows for a way out of this situation, and thereby for a revival of the disequilibrium research program. The conflict that exists in this logical inconsistency is best resolved by abolishing $\mathrm{HC}$ 9 - that conclusions should be drawn only from equilibria-and replacing it by the requirement that equilibrium theory is corroborated by out-of-equilibrium analysis on the rise and relevance of equilibrium. Such would imply growth of knowledge by Lakatosian criteria. It will harden the hard core of economic research.

\subsection{Early Reflections on the Homunculus}

"The key to solving the problems of disequilibrium research is thus in resolving the conflict between methodological individualism and the homunculus explanation of onta of-equilibrium adjustments. At about the same time that economic theory adopted the

5 An interesting ase in point, here is an infuential artiche by David Gale, published in 1955 . the article is thed "The Law of Supply and Demand" but develops an existence proof of equibrin instead. Hence, the title is quite bady dhosen, to say the least. Occasionaly, still convenient mapping to develop fxed point argments are associated with the opexation of the market process -.....9., Border. (1985), Chapter 20 .

(1) Fisher (1983) drans this conclusion on the literature on tatonnement. Cf. op.cit. p.98. Tle point here is that it holds for all disequilibrium research up to the present. 
homunculus for global stability analysis, methodological observations of this purport were, in fact, made, and forcefully expressed by major and connected theorists.

In a largely unnoticed early article that appeared in 1955 in the Pakistan Economic Journal, and was titled "Competition, Monopoly, and the Theory of Price," Robert Clower considered the possibilities monopolistic competition open up for an understanding of out-of-equilibrium price adjustments. In the article, Clower set out to show that

"... the gulf separating accepted modern theories of competitive and non" competitive price determination can be bridged from either side. The basic problem is to construct the approaches to the "bridge", for the gulf itself is largely illusory." (op.cit., p.219)

The 'approaches' consist of the idea that in a competitive market, "the marketee (whether "he" is a person; a committee, or a mechanical device)" needs to make estimations of the supply and demand relations in order to establish equilibrium prices, and revise them if they turn out to have been wrong, and that the same is true for firms in monopolistic competition, who then each individually bear this responsibility. ${ }^{7}$ The observation led Clower to conclude that:

"The idea that there is something fundamentally different about a monopoly and a competitive market is therefore mistaken. It is a mere illusion which follows from the failure to recognize that the marketee function must be undertaken by some economic unit in every market. Heretofore this fact has not been recognized in monopoly theory because it has been supposed that the monopolist knows the form of the "true" demand curve; the masketee function (i.e. stock adjustment) does simply not exist in this case. And the marketee function has not been recognized in the case of pure competition because the statical problem of the determination of current price has not been analyzed with sufficient care." (op.cit., p.225)

In his Three Essays on the State of Economic Science, published in 1957, Koopmans surveyed the relationship between economic reasoning and mathematical models. In the third essay, titled "The Interaction of Tools and Problems in Economics," he argued that available mathematical methods influence-and especially also impoverish-.economic analysis. Koopmans thus came to question the mechanical character of price adjustments described by the Samuelsonian equations:

"The various assumptions that have been used to describe the adjustment of price or quantity in a commodity market clearly show their parentage in the laws of the physical sciences. If, for instance, the net rate of increase in the price is assumed to be proportional to the excess demand over supply, whose behavior is thereby expressed? And how is that behavior motivated? And is the alternative hypothesis, that the rate of increase in supply is proportional to the excess demand price over supply price any 
more plausible, or any better traceable to behavior notivation?" (op.cit., p. 179 , two notes deleted)

In a supplementary note, Koopmans also provided brief answers to these questions. To him price changes described by differential equations of aggregate excess demand lacked a "clear connection with economic motivation," and suffered from a "difficulty of definition," and "accessibility to observation".

Interestingly enough, Arrow--instrumental in advancing the homunculus by setting the Samuelsonian price adjustment equations at center stage in global stability theory and the widely shared optimism about thus explaining the global stability of competitive markets -made similar methodological obserwations towards the end of the 1950 's. Moreover, he suggested an altemative route similar to Clower's, and travelled some distance along it. In a contemporary short and literary essay titled "Toward a Theory of Price Adjustment," published in 1959, Arrow stated more forcefully and with reference of indebtedness to the original 1952 edition of Scitovsky (1963)-the text squared brackets replaces reference to equations:

"The Law of Suppy and Demand may be a useful basis for interpreting some empirical phenomena, particularly the conrse of prices in markets subject to rapid changes in supply and demand conditions, although in fact few such applications have been made; however, the Law is not on the same logical level as the hypotheses underlying [aggregate supply and demand as a function of prices]. It is not explained whose decision it is to change prices in accordance with [aggregate excess demand]. Each individual participant: in the economy is supposed to take prices as given and detemined his choices as to purchase and sales accordingly; there is no one left over whose job it is to make decisions on price." (op.cit, p.43)

The essence of this 'Arrow-critique' is that the axioms of choice under perfect competition do not allow for a theory of price adjustment with which they are logically consistent. Hence, the need for a homunculus. As a way out of this problem, Arrow pointed for a theory of disequilibrium to elements of imperfect competition outside of equilibrium. For only individuals with some ability to infuence prices can possibly change them. Hence, some form of 'local monopoly' on the side of either suppliers or' buyers-or both - is required, at least outside of equilibriurn. The study of disequilibrium thus requires a theory of monopolistic competition among 'market makers' in a general equilibrium context. ${ }^{2}$

What is more, to have a theory of disequilibrium adjustment, Arrow recognizod it is detrimental that monopalistically competing narket makers have less than full knowledge of the market relations in the economy, as well as local monopoly powar. Should they have perfect insight into the economy, Arrow argued, little adjustment. would be necessary, and a general equilibrium with imperfect competition readily

Ibid.

9) Hor this, Arrow makes reference to Triffin (1940), where an extension of earlier partial analses or imporfect competition to general equlibrium seting is adrocated as well. 
established. 10 Since the two go comfortably together-imperfect information is indeed a source of monopoly power on the side of the informed over the uninformed to Arrow they were typical disequibrium phenomena, in which price and quantity adjustments should be founded. He concluded:

"In disequilibrium, the market consists of a number of monopolists facing a number of monopsonists. The most general picture is that of a shifting set of bilateral monopolies. (...) In general, though, it is reasonable to suppose that if the selling side of the market is more concentrated than the buying side, the main force in changing prices will be the monopolistic behavior of the sellers. The buyers would find little possibility of exerting their individual monopsonistic powers because there are so many for each seller. Similarly, if the buying side of the market is the more concentrated ... the dymamics will come from that side. (...) Thus the dynamics of prices may be affected by the structure of the market even in cases where there are sufficient numbers in the market to instare reasonably competitive behavior at equilibrium." (op.cit., p.47)

The last remark - that in equilibrium again perfect competition prevails - is somewhat puzhling. In fact, with a possible seat of price adjustments now identified, it unleashed another yet associated problem upon the few who followed Arrow's program, namely the need to explain how monopolistic positions erode over the convergence of the disequilibrim process. More on this is said in Chapter 7 . In the next two chapters, respectively an inquiry is made of what the literature has to offer on both elements of disequilbrium theory, monopolistic competition in a general equilibrium context, and impenfect information, expectations, and learning.

\subsection{Exemplifying Theory}

Apart from neutrality of out-of-equilibrium belwvior, it is clear now that also the kind of generality sought for in the law of supply and demand should be abandoned. Only by grounding the behavior outside of equilibrium in the fundamentals of general equilibrium theory, particularly in the structure and progress of individually available information and the competitive stmcture of markets, can meaningful disequilibrium theory be developed. An often made argument against this is that the result of such a move away from 'generality", implies that disequilibrim theory becomes merely concerned with ad hoc examples.

In the introduction of his survey on stability theory in the 1982 edition of the Hondbook of Mathematical Economics, Hahn stated that the knowledge then, which, as said, is largely all there is still, had this natur-in passing noting directions for improvernents.

10 Arrow refers in this respect to Lange (1944) in which a seminal price adjuanent process of at fully informed monopolist is discussed. More on this in the next chapter. 
"The conclusion of the ensuing survey will be this: a great deal of skilled and sophisticated work has gone into the study of progress by which an economy covid attain an equilibrium. Some of the (mainly) technical work will surely remain valuable in the future. But the whole subject has a distressing ad hoc aspect. There is at present no satisfactory axiomatic foundation on which to build a theory of learning, of adjusting to errors and delay of times in each of these. It may be that in some intrinsic sense such a theory is impossible. But without it this branch of the subject can aspire to no more than the study of a series of suggestive examples." (Hahn, $1982, \mathbf{p} .747)$

Ingrao and Israel make the unavalability of 'general results' the centre of their case against stability theory. With reference to the aspiration of Debreu, quoted in Chapter 2, to develop an axiomatic theory dictated by a love for rigor, and logically entirely disconnected from its interpretation, they boldly counten Hahn's reflections in a 198 . precursor of their 1990 book, as follows.

"[W] do not hesitate to take the final step, namely, say that 'such a theory is impossible' and that this theory 'can aspire to be no more than the study of a series of examples." (Ingrao and Israel, 1985b, p.121)

In his later writings and public appearances, Halm's conclusive thoughts on the question whether a founding theory of disequilibrium behavior can or can not be had is not easily distilled. His statements vary from very pessimistic ones, where the pioblem is considered solely a theoretical one and, to put it mildy, no solid ground for a career in economics, to very optimistic opinions, where rational expectations theory is strongly condemned, and a large and rigorous collection of models is expected wery shortly. 11

Yet, expectations as to what level of generality theory of disequilibrim behavior may boil down to are quite irvelevant here. After all, Debren's dictum is not watertight. The choices for the axioms of regular economies the monograph discusses are plainly violations of it. They were sought out with a clear eye to acceptable properties of preferences, production techniques, and the resulting properties of demand, supply and equilibrim. Generality, to put it differently, is not an obviously definable concept. It is a consensus among scholars in a researcin program. And a consensus basted on individual perceptions of the world.

This should not come as a surprise. The central debate in philosophy of science that sprang from the orthogonal positions of Bacon and Descartes, as set out on Chapter 2 , shows that the relationship of theory and reality is a difficul one, yet existent. Meaningtul theory cannot be constructed without a confrontation with yeality, not can reality be understood without theory. Walras understood this. He considered his frictionless economy in the main part of Elements only as a start, and was ready to move from abstract theory to a confrontation with reality in his method of decreasing. abstraction, once theory had been well developed. Debreu broke with this idea. The

it C. Hahn ( 19826$)$. 
result is an unworkable consensus of required generality that stands in the way of a meaningful theory of disequilibrium. Fact remains namely that out-of-equilibrium behavior is to be understood, not in the least to corroborate equilibrium theory, and that such understanding is not to be had from the type of assumption so far considered to be acceptably general. To quote a recent popular explanation of economic dynamics to mathematicians in Notices of the American. Mathematical Society by Donald Saari:

"Maybe the economists' longtime goal of a universal price mechanism is an impossible dream." (Saari, 1995, p.226)

It is time to consider systematically the elements of the allemative to universal theory, a workable exemplifying theory of disequilibrium. 



\section{Market Makers in Competition}

A meaningful theory of disequilibrium requires that certain individuals can act as market makers. For that to be possible, these individuals need to have a certain amount, of influence on markets-real or imagined. In other words, some distance has to be taken from the model of perfect competition. Theory on economic order in markets when competition is structurally different from perfect is at least as old as that on perfect competition. After all, Walras, following a method of decreasing abstraction, only started his lifelong analyses with the perfectly competitive markets. In Elements, the relevance of deviations from this perfect model are time and again acknowledged. Likewise, monopoly and oligopoly models of Cournot, originally published in 1838, date back much further--and were in fact an important influence on Walras. They were commented and extended upon by Bertrand, who countered Cournot's work in 1883, and Edgeworth, discussed already in Chapter 3. In the early 1930's, an intluential academic quarrel between Joan Robinson and Edward Chamberlin would lead to a spur in the development of this type of models.

At the time, it was widely recognized that competition among firms is not as described in the model of perfect competition, where each individual is a price taker with no demand at higher prices-and all at lower-but rather such that especially firms have a noticeable control over the markets they serve, represented by a slight, particularly downward rigidity in their demand as a function of price. In that sense, competition among them is 'imperfect'. Particularly Chamberlin emphasized that this market power results primarily from product differentiation. That is, each firm offers its own slightly unique products, which are modestly imperfectly substitutable. Chamberlin discussed at length the difference between 'imperfect' competition, which could be any kind of deviation from perfect competition-which he referred to as "pure" 
competition and monopolistic competition, essentially arguing that the latter is: special and most acceptable case of the former."

As a result of the view that imperfect competition, rather than perfect competition, was a characteristic of real markets, and therefore of consequence to theory, mterest centered on the implications of the structural conditions of monopolistic competition for the theory of value. That is, the studies are first and foremost concerned with the nature of monopolistic equilibrium. In a note to the first chapter on perfect competstion, Chamberlin observed:

"The lacts of life remain; movements towards and fluctuations about equilibrium characteristically leave a trail of actual prices behind, which may not be revised, but which are final. Markets are, in fact, more or less imw perfect. How is this chain of actual prices related to the equilibrium price, and how does the amount sold under fluctuating prices compare with the equilibrim amount? The simple conclusion that actual results will "tend" towards equilibrium is hardly warranted." (op.cit., p.27)

Yet, the potential of monopolistic competition in a general equilibrium context to explain disequilibrium price dynamics, later recognized by Clower and Arrow, is not developed in the book. Instead Chamberlin's theory is an equilibrium theory. In a partial setup it develops the idea that in regular markets with first increasing and then decreasing returns to scalle, firms that experience the slopes of the demand they serve to be slightly different from zero, competition drives the profits down to zero in the sense that for any commodity it forces the individual firm-specific demand curve towards the average cost curve, until the two touch. As the latter is convex, production and trade is less than under perfect competition, and prices different from marginal costs-and hence the allocations are inefficient. ${ }^{2}$

The equilibrium perspective is also that of Arrow's reference, Triffin (1940). Newertheless, the "monopolistic competition revolution", as Samuelson referred to the wide impact the development had in its time, certainly held the promise to shed light on disequilibrium dynamics." In this chapter, the modern development of monopolistic competition in the context of general equilibrium theory is considered that started in the early 1960 's of an important paper by Negishi. It is a survey in search of further progress in individually rational disequilibrium behavior.

The chapter is organized as follows. In the next section, a note is made on the rationality of the traditional firm objective to maximize profits. Section 5.2 discusses the so-called 'Lange-conjecture', which is the idea that monopolistically conpeting firms always clear the market. Section 5.3 sets out the seminal model of monopolistic competition in general equilibrium of Negishi. In that model, firms hold subjective beliefs on the market structure. In Section 5.4 a subsequent debate on the need to found firm behavion in the true demand and supply curves they face is discussed. It.

1 Both Robinson and Chamberlin published their respective books on imperfect competition first in 1933. Ghamberlin later took great pains to differentiate his contribution from Robinson's. Of. Chamberlin (1946), Preface to the Fith Fdition and Chapter IX.

2 See on the efficincy properties of monopolistically competitive equilibria Demsetz (1959, 1989 )

i) Cf. Samuetson $(1963)$. 
concludes that particularly models that allow subjective conjectures are of relevance to disequilibrium research. The progress had in the subjective demand approach is presented in Section 5.5. An important role in played by Benassy, who established existence for a very general model. Section 5.6 concludes.

\subsection{A Note on the Rationality of Profit Maximization}

A defining characteristic of general equilibrium theory is that the ownership of frms is in the hands of the individuals peopling the economy. Since these individuals are also the consumers of the products the firms produce, it is not necessarily optimal for all shareholders that their firms maximize profits. An individual that holds a small position in a particular firm from which he or she orders a relatively large share of his or her consumption, may be better off with lower sales prices at the expense of a smaller profit. Individuals are, in other words, not that much interested in money, but in what that money can buy them. Potentially, therefore, there is a conflict of interests among the owners of a firm.

In equilibrium models of perfect competition, this problem is negligible, since there either profits at equilibrium are equall to zero, or when they are not profit maximization is in the interest of the shareholders as long as markets are complete." In. equilibrium analysis of imperfect competition, however, it is present-and it always is in disequilibrium analysis. In these analyses, profit maximization as a behavioral as sumption on firms in fact dodges a crucial coordination problem among shareholders, the description of company objectives from individual shareholder preferences. This is in flagrant conflict with methodological individualism set center stage in the critique of the disequilibrium research program in the previous chapter.

Several ways to circumvent the problem have been proposed in the literature. One obwious and quite manatisfactory approach is to assume individuals have preferences only for money. ${ }^{5}$ The problem goes away more naturally when each firm is owned by a single individual. A variant of this is a structure in which it is not commonly owned producers that set prices, but dealers wo own shops in which they buy and sell commodities, and who only themselwes consume out of their own profit " An early discussion in Koplin (1963) seeks to identify conditions on the relationship between the holdings of stock in a particular frm and the share of that firms product in the consumption vector. One way to obtain this is to assume that fims are sufficiently small.

Related to this is a rather remarkable setup presented by Hart (1985), referred to as the "island structure" 7 In this structure, firms are scattered over a number of small islands, and owned by the inhabitants of the various islands. Inhabitants only shop on their own island. Since a small fraction of the firms on the island is owned by the

Cf. Magill and Quinzil (1996), p.337.

Hart (1985) defends this on pages 109-110.

4. This 'dealer-stucture' is set up in Fisher (1972), discussed in the next chapter.

- An earlier application of this construction is given in Phelps (1970). 
inhabitants, wealth effects are negligible. ${ }^{\$}$ A different approach is to endogenize the ownership structure of firms. In the standard Arrow-Debreu model there is no need for a market for shares. Its introduction in models of imperfect competition, however, may relief conflicts of interest as individuals take up positions to avoid them. Of course, the establishment of stock prices requires a theory of disequilibrium. Generally, in general equilibrium models with imperfect competition, the problem is assumed to be of minor relevance. Yet, it illustrates the difficulties in reaching consensus on models with imperfect competition characteristic of the literature.

\subsection{The Lange-Conjecture}

An early and influential explicit account of the role of monopolistic competition in disequilibrium is Lange (1944)-referred to in Arrow (1959). In this monograph, titled Price Flexibility and Employment, Lange gave a succinct and approving account of Hicks' general equilibrium theory and some of its policy implications. In an appendix, the stability conditions of Hicks and Samuelson, and some of their relations, are set out conscientiously and with the esteem with which they were first received.

Both in the body of the book and in the appendix, Oskar Lange relates monopolistic competition to general equilibrium. In the text, he stated the following on monopolistic competition-it would play an important role in subsequent developments as the Lange-conjecture.

"The nature of economic equilibrium, as well as of disequilibrium, in a monopolistic or monopsonistic market differs from that in a perfectly competitive markets. In the latter, disequilibrium consists in excess demand or excess supply. Monopolistic supply, however, is always equal to the demand for the good in question and monopsonistic demand is always equal to supply. A monopolistic or monopsonistic market is in equilibrium when the quantity sold and bought is such that it maximizes the profit of the monopolist or monopsonist. In this case, there is no tendency to change either price or quantity." (op.cit., pp35-6)

The idea is easily illustrated by the use of a standard partial equilibrium model of monopoly behavior, depicted in Figure 5.1 below.

For any given demand function and given costs, based on the supply functions of inputs, a monopolistically competing supplier of a uniquely differentiated product. maximizes profits at a price at which it can just sell the optimal quantity establishing equality of marginal costs and marginal revenue. Hence, the chosen supply of any given monopolistically competing firm is a single offer on the demand curve that by construction clears the market - that is, as far as capacity allows for it, a subject of later concern. The same is true for any chosen demand on monopsonistically exploited supply. The profit that can be had maximally in this notional transaction is represented by the area $c p_{b} p_{s} c^{\prime}$. 


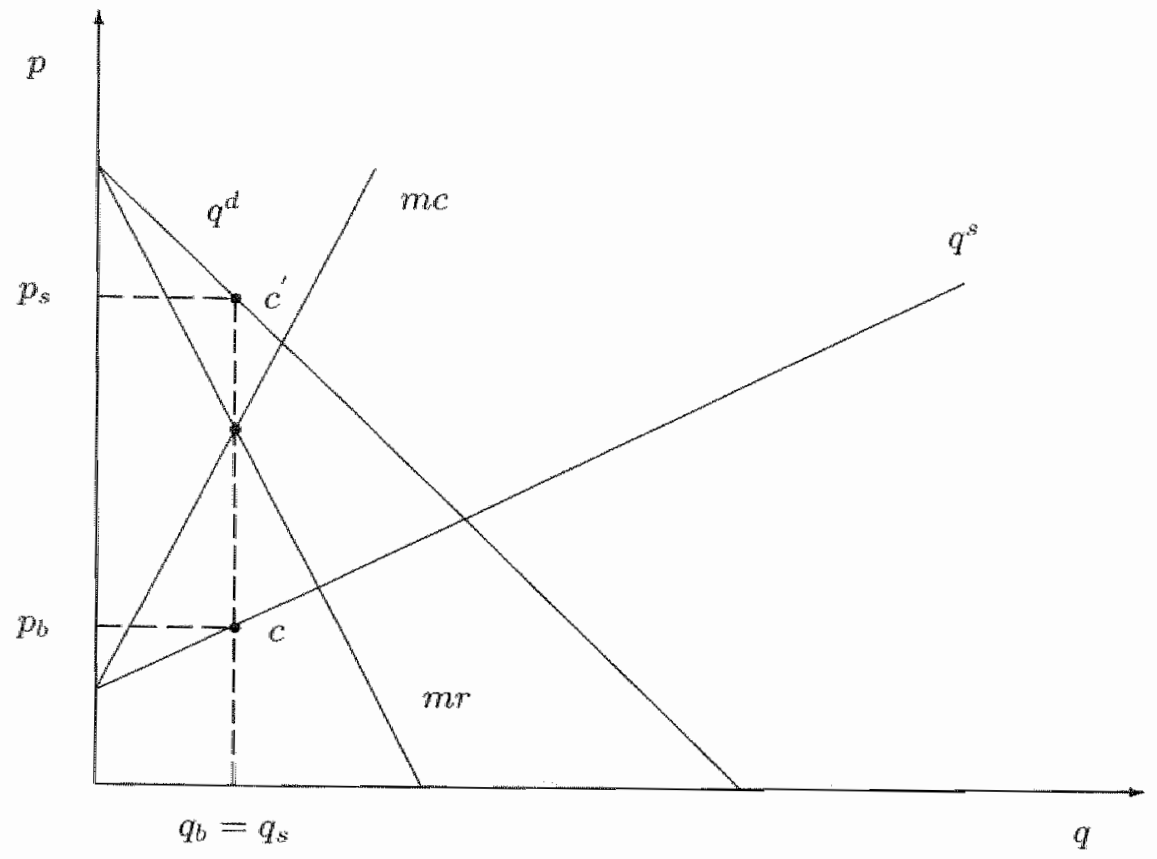

Figure 5.1 The Lange-conjecture ilhstrated for a monopsonistically buying and monopolistically selling firm.

Despite the fact that equilibrating its markets is in each monopolistically competing firm's hands, the quote from Lange continues with a discussion of what will happen if nevertheless firms face inequality between notional and effective sales or purchases:

"Disequilibrium occurs in a monopolistic or monopsonistic market when the quantity sold and bought differs from the equilibrium amount. When a monopolist sells more than the equilibrim amount, he will restrict his supply and raise his price. The reverse happens when he sells less than the equilibrium amount. (...) When a monopsonist buys more than the equilibrimm amount, he will restrict his demand and lower his price. The reverse happens when he buys less then the equilibrium anount. (...) Thus monopolistic underrestriction and monopsonistic overrestriction perform the function of excess demand under perfect competition, while monopolistic overrestriction and monopsonistic underrestriction perform the function of excess supply." (ibid.)

In the accompanying appendix, the mathematical form of this idea bolls down to each price setter adjusting the price of its commodity $r$ over time according to the 
following equation.

$$
\frac{\partial p_{r}}{\partial t}=F_{r}\left(\frac{\partial U_{r}}{\partial p_{r}}\right)
$$

where $U_{r}$ is the profit of the firm monopolistically offering or buying commodity $r$, and $F_{r}$ is a sign-preserving function which is zero when its argument is zero. ${ }^{9}$ Prices thus established are argued to render monopolistically competitive equilibria locally stable, for which the dynamics satisfies both Samuelson's and Hicks' conditions. Fact remains, however, that there is a tension in the two parts of Lange's analysis. It would lead to quite some confusion in the literature.

\subsection{Monopolistic Competition and General Equilibrium}

In "Monopolistic Competition and General Equilibrium," published in the Revieu of Econornic Studies in 1961 , Negishi formulated a rigorous general equilibrium model of imperfect competition that still is widely considered an excellent reference on the subject. ${ }^{10}$ The study states to answer to Triffin (1940) by integrating imperfect compe tition into the Arrow-Debreu model. No reference is made to the potential of monopolistic competition theory to shed light on behavior outside of equilibrium. Nevertheless. a note acknowledges a debt to Arrow, Clower, Hurwicz and Uzawa. Moreover, as one of very few in the field, the article offers, next to an existence result, a stability analysis. Also, the setup of Negishi became the starting point of an interesting discussion on the appropriateness of subjective, as opposed to objective demand functions, which is subject of the next subsection. In all, there is sufficient reason to consider it in some detail.

Negish (1961b) considers a regular production economy with $m$ commodities, indexed $j=1, \ldots, m, n$ consumers, $i=1, \ldots, n$, and $r$ firms, $k=1, \ldots, r$. The preferences of consumers are represented by utility functions defined over de consumption vectors $x_{i}$, for which $x_{i j} \geq 0$. The functions $u_{i}\left(x_{i}\right)$ are continuous, monotonic and strictly quasi-concave. Furthermore, consumers have initial endowments $\bar{x}_{i}, \bar{x}_{i j} \geq 0$. Each firm $k$ masters a technology with which it can produce in a production set $Y_{n}$. The vector $y$ : depicts a feasible combination chosen. There is free disposal, firms can sit idle and the production sets $Y_{k}$ are assumed to be convex and bounded from above. Furthermore, $y_{k j}>0$ represents commodity $j$ as an output, $y_{k j}<0$ as an input. The assumptions allow efficient production to be represented by concave transformation functions.

The economy is characterized by an exogenously determined and given mixed competitive structure. That is, the set of all privately owned firms consists of two subsets one containing $r^{\prime}$ firms in perfect competition and referred to as $R^{1}$, and a set $R^{2}$, with size $r-r^{\prime}$, consisting of firms which are in monopolistic competition. "The commodities

9. Op.cit. p. 107. Arrow (1959) introduces $F$, whereas Langes discussion of this is literary, and identifies the adjustment process as a gradient method. Cf op.cit., p.44.

10 E.g., in the sureys Hart (1985), p.101 and Benassy (1991), p. 2025. 
for which a frm $k \in R^{2}$ dominates the market are collected in a set $y^{k}$. Commodities that are in none of the sets $J^{k}$ are offered competitively and collected in $J^{0}$.

The firms in $R^{2}$ are separated from each other, i.e.s

$$
J^{k} \cap J^{k^{\prime}}=\emptyset \text { for any }\left(k, k^{\prime}\right) \in R^{2}, k \neq k^{\prime} .
$$

This structure implies that the market for each and every commodity is dominated by a single firm. Hence, firms do not directly confront each other strategically in bilateral monopolies or any other oligopolistic setting. Then, since one and the same commodity can simultaneously be supplied or demanded by a monopolist and several fims in perfect competition, a commodity is demanded or supplied either by one frm in a monopoly (or monopsomy) with or without several price taking competitors, or by one or many firms in perfect competition. Also, each particular frm either sells one or more commodities in perfectly competitive markets, or one or more commodities in monopolistically organized markets, but is never active is both types of markets$R^{1}$ and $R^{2}$ are disjoint. The structure thus allows for monopolistic competition as in Chamberlin's "large group case," that is many firms all with small local monopoly power, as well as for a structure with a dominant firm surrounded by a competitive finge. 11

To Negishi, no one in the economy can be expected to have complete insight in all manket relations. Therefore, before effective values of comsumption, production and prices are established, parties need to form expectations on prices, which in turn fom notional decisions. In the following; these expectations are denoted by an asterisk, as $x_{2}^{*}, y_{k}^{*}$, and $p^{*}$, respectively. Prices, once established are collected in a vector $p$, with $p_{j} \geq 0$. Prices are unique and consumers take them as given. They maximize utility on the basis of future prices, from which notional demand curves follow. Firms have expectations on the firm-specific demand they face for their outputs, as well as on the firm-specific supply functions for their inputs. These are, in accordance with assumptioms on preferences and technology, taken to be single-valued and contimuous, and writen inversely as

$$
p_{j}^{*}=X_{k j}^{*}\left(y_{k j}^{*} \mid p_{;} \sum_{i=1}^{n} x_{i j}-\sum_{k^{*} \neq k}^{n} y_{k+j}\right) .
$$

That is, the price firm $k$ expects to sell (buy) commodity $j$ for is a function of the expected own sales (purchases), and the present state of the market given by the current price vector, and current firm-specific demand (supply), which is all consumer demand for commodity $j$ minus (plus) the gross supply (demand) of all other firms that offer it.

It is important to note that decomposing current own demand and supply relations faced as done here already assumes the presence of quite some knowledge of both total matket demand and supply, and the demand of the commodity under consideration

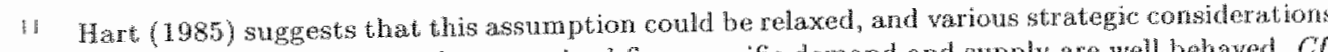
hought behind the assumption that percened fimasecific demand and supply are well behaved. $C f$ ap.e.t., P. TO5 
currently served by competitors. Several later presentations of the model have modified the setup on this point. Negish (1972) discusses the 1961 model initially on the basis of

$$
p_{j}^{* k}=X_{k, j}^{*}\left(y_{k}^{* s} \| p, y_{k}\right)
$$

that is, expected demand as a function only of all current firm specific data, which recognizes spill-overs in market simultaneously served by one and the same firm. ${ }^{2}$ Hukukane Nikaido represented Negishi's model as

$$
p_{j}^{*}=X_{k j}^{*}\left(y_{k}^{*} \mid p, y\right)
$$

in which $y=\left(y_{1}, \ldots, y_{r}\right)$, thus taking the current production of all firms into ac count. ${ }^{13}$ Finally, in his discussion of Negishi's 1961 model, Oliver Hart generalized the subjective demand function to

$$
p_{j}^{*}=X_{k j}^{*}\left(y_{k}^{*} \mid p, \omega\right)
$$

where $\omega=\left(\left(x_{1}, \ldots, x_{n}\right),\left(y_{1}, \ldots, y_{r}\right)\right)$, so that expected demand for commodity $j$ is a function of all current consumption levels and all current production levels of al] firms and all commodities. ${ }^{14}$ The representations of Nikaido and Hart clearly involve much more information on the side of the firms than Negishi originally intended.

In the general structure for expectations thus provided, Negishi (1961b) introduces several further specifications. Firstly, it is assumed that expected demand functions are at all times consistent with the observed state of the economy, i.e., if expected sales coincide with realized sales, the effective demand is identical to the expected demand, put formally as

$$
p_{j}=X_{k, j}^{*}\left(y_{k, j}^{*} \mid p, \sum_{i=1}^{n_{k}} x_{i, j}-\sum_{k^{\prime} \neq k_{k}}^{r} y_{k^{\prime} j}\right) \text { if } y_{k j}^{*}=\sum_{i=1}^{n}\left(x_{i j}-\bar{x}_{i j}\right)-\sum_{k^{\prime} \neq k}^{r} y_{k^{\prime} j} .
$$

Note that this adds the information requirement that the total initial endowments, $\sum_{i=1}^{i k} \bar{x}_{i, j}$, are public knowledge or zero for produced goods. This is not necessary to determine prices, for which gross demand and supply suffice. Nevertheless, the consistency requirement is mild.

Secondly, and much more restrictively, it is assumed that demand and supply are perceived as linear and decreasing with respect to expected sales:

$$
\begin{gathered}
p_{j}^{* k}=a_{k j j}\left(p, \sum_{i=1}^{n} x_{i j}-\sum_{k^{\prime} \neq k^{\prime}}^{r} y_{k^{\prime} j}\right) y_{k j}^{*}+b_{k j}\left(p, \sum_{i=1}^{n} x_{i j}-\sum_{k^{\prime} \neq k}^{r} y_{k^{\prime} j}\right), \text { with } \\
a_{k j}\left(p, \sum_{i=1}^{n} x_{i j}-\sum_{k^{\prime} \neq k^{\prime}}^{r} y_{k^{\prime} j}\right)<0 .
\end{gathered}
$$

Op.cit, p. 106

Nikaido $(1975)$, pp.69-70.

Hart (1985), pp.I02-4 
This assumption is hardly innocuous. Apart from the fact that it introduces an arbitray functional form that has no obvious relationship to the true firm-specific demand, it makes explicit that in the individual choice problems of the firms the effects of the presence of competitors are ignored by assuming their choices to be constant and independent of the own actions.

With competitive structure and perceptions thus delineated, and aggregate excess demand of commodity $j$ defined as

$$
z_{j} \equiv \sum_{i=1}^{n}\left(x_{i j}-\bar{x}_{i j}\right)-\sum_{k=1}^{r} y_{k j}
$$

an equilibrium in this economy is characterized as follows. ${ }^{15}$

Definition 5.1 (General Monopolistically Competitive Equilibrium) A set of vectors $\left(p, x_{i}, y_{k}\right)$ forms an equilibrium if:

(i) $x_{i}$ maximizes $u_{i}\left(x_{i}\right)$ subject to

$$
\sum_{j=1}^{m} p_{j} x_{i j} \leq \sum_{j=1}^{m} p_{j} \bar{x}_{i j}+\sum_{k=1}^{r} \lambda_{k i} \sum_{j=1}^{m} p_{j} y_{k j}
$$

where $\lambda_{d}$ is individual $i^{\prime} s$ share in the profit of firm $k$;

(ii) $y_{k}, k \in R^{1}$, maximizes

$$
\sum_{j=1}^{m} p_{j} y_{k_{j}} \text { subject to } y_{k} \in Y_{k}
$$

(mi) $y_{k}=y_{k}^{*}, k \in R^{2}$, maximizes

$$
\sum_{j \in J^{k}}^{m}\left(a_{j} y_{k j}^{*}+b_{j}\right) y_{k j}^{*}+\sum_{j \notin J^{k}}^{m} p_{j} y_{k j}^{*} \text { subject to } y_{k}^{*} \in Y_{k}
$$

(to) for all $j$,

$$
\sum_{i=1}^{n_{i}} x_{i j} \leq \sum_{i=1}^{n} \bar{x}_{i j}+\sum_{k=1}^{r} y_{k j} \text { and } p_{j} z_{j}=0
$$

Conditions (i) and (ii) guarantee all consumers, as well as all firms operating in pertectly competitive markets can carry out their respective individually optimal plans at to them given prices. Condition (iw) requires that prices in the monopolistically competitive sector are such that at equilibrium firms puerceive maximum profit. To close the economy, condition (iv) imposes feasibility and Walras" law.

The article delivers a concise proof of the existence of equilibria thus ciefined. It is of no special concern here other than that the concavity of the quadratic profit

1. Alapted from Negishi (1961b), p.197. 
functions of the monopolistically competing firms plays an essential role. That is, it is essential for the proof that the compounded profit function is quasi-concave. The linear conjectures on firm-specific supply and demand with negative own-price effects are sufficient for this - and so is an extension Negishi makes to kinked demand funcions, consisting of two linear parts, that reflect downward rigidity of prices, another subject that concermed Negishi, e.g., in Negishi (1979). It should be clear, however, that the specification here is not necessary. ${ }^{16}$

The market structure rules out the case where two firms simultaneously have a monopolistic power over the same commodity. The possibility of a single firm possessing monopoly power over the sales of several of the commodities collected in $J^{k}$ is there, however. Negishi (1972) considers this possibility by establishing a more general existence proof on the basis of expected demand as a function of the firm's full production vector introduced above. The interdependence of demand functions arises especially in case of product differentiation within firms, under the heading of which it is presented. Negishi (1972) generalizes the linear version of the inverse demand and supply systems to one in which the demand and supply systems read

$$
p_{j}^{*}=\sum_{j^{\prime} \in J^{k}}^{m} A_{j j^{\prime}}^{k}\left(p, y_{k}\right) y_{k j^{*}}^{*}+B_{j}^{k}\left(p, y_{k}\right),
$$

where the former critical existence condition which guarantees (local) concavity of the profit function, $a_{k j}\left(p, \sum_{i=\mathbb{I}}^{n} x_{i j}-\sum_{k^{\prime} \neq k}^{r} y_{k^{\prime} j}\right)<0$, is replaced by the demand that the matrices $A^{k}$, which are the Jacobians of the inverse demand systems with dimensions determined by the number of commodities in $J^{k}$, are negative semi-definite. Note that this system reduces to the original one if changes in the quantity of a commodity are not perceived to have an influence on prices faced in other markets, i.e., $A_{j j^{\prime}}^{k}=0$ for all $j \neq j^{\prime}$, which is equivalent to $\frac{\partial p_{j}^{*}}{\partial y_{j^{\prime}}}=0$ for $j, j^{\prime} \in J^{k}$ and $j \neq j^{t} .{ }^{17}$

As said, apart from existence Negishi (1961b) offers a singular study of the stability of the general equilibrium model of monopolistic competition it develops-an analysis usually not considered in the surveys. ${ }^{18}$ The interesting features of that analysis lie in the out-of-equilibrium process upon which its stability characteristics depend. The contemporary view on the appropriate description of this, set out in Chapter 3 , is well expressed by Negishi's introduction of the price dynamics:

"As is well-known, in the perfectly competitive market the price goes up and down according to the excess demand. But in the monopolistically competitive market, the excess demand is always zero by definition (see

lt For the complete existence proof see Negishi $(1961 \mathrm{~b})$, pp. 197-8, and for a discussion of at Hat (1985), D.194. In the nex subsection existence issues rebted to perceptions are addressed more extensively.

is Op.cit., p.111.

18 One of few critiques on Negishis stablity analysis is Nikaido (1975), which, in this respect, rather misplaced. It anounts to Nikaldo disapproving of the presence still of a competitive sector. which is tine but misses the point, More on his contribution hn the next subsection. 
Lange, 1944) and what makes the prices go up and down is the profit of the firm which dictates the market." (op.cit, p.199)

The following system of differential equations captures this to Negishi recall that $J^{0}$ is the set of commodities solely perfectly competitively traded in.

$$
\frac{\partial p_{j}}{\partial t}= \begin{cases}v_{j} z_{j} & \text { for all } j \in J^{0} \\ v_{j}\left(\bar{p}_{j}-p_{j}\right) & \text { for all } j \notin J^{0}\end{cases}
$$

where $v_{j}>0$ is a commodity specific constant representing a speed of adjustment, and $\bar{p}_{j}$ is the price of the $j$-th commodity which is perceived to assure maximum profit for the dominating firm $k$ in its monopolistically competitive market. For commodities that are perfectly competitively traded, that is, prices follow the Samuelsonian equations. Commodities monopolistically supplied or demanded adjust for the monopolistic party to establish maximum profits.

Hence, for products sold under perfectly competitive conditions only, still an auctioneer-type institution is responsible for the price changes. Certainly, this is unsatisfactory. Yet, it comes with the mixed competitive structure, which Negishi wants as a combination of the Arrow-Debreu model with imperfect competition. Monopolistically sold commodities, on the contrary, grope to their equilibrium prices by a feed-back mechanism that is a discontinuous version of the gradient process in Lange (1944) set ont above.

Here the problens in the combination of the Lange-conjecture and Lange's proposal for monopolistic price adjustment already hinted upon above shine through. The Lange conjecture is really valid only under the assumption of full and correct information of the demand and cost structure. Since in the Negishimodel the firmspecific demand and supply functions on which monopolists base their decisions are subjectively perceived relations, as opposed to objectively true functions-which are set up so as to differ importantly-the price-quantity combinations set will only clear the market intentionally. If expected demand (supply) and effective demand (supply) differ, marginal retums differ from their expected values, and quantity decisions ent ante perceived as profit maximizing, are no longer optimal in hindsight.

As a result of this logic, the tarige-conjecture and the adjustment of monopolistic prices to their perceived profit maximizing levels are inconsistent. Since according to the fomer, finms are continuously able to establish prices at the level they perceive to be profit maximizing, there is no reason for $\bar{p}_{j}$ and $p_{j}$ to differ at any one time. A firm will want to establish its determined expected profit maximizing price at once, an not in infinitely small steps in its direction, especially not if it was aware of the fact that hose steps hold pace with the revelation of new information concening the market structure.

Negish clearly struggled with the issue. A more acceptable dynamics outside of equilibrium is in fact likely to be found in changes in $\bar{p}_{j}$, resulting from changes in the perception of firm-specific supply and demand-which raises questions of continuity addressed later. Consequently, either adherence is made to the Lange-conjecture and no disequilibrim analysis is necessary since the economy is in equilibrium, or the liangeconjecture is identifed as false in disequilibrium, and a theory of meaningful out- 
of-equilibrium price adjustment of monopolistically competing firms is constructedwhich does have room for excess demand. ${ }^{19}$

Finally, apart from the unspecified dynamics which establish the eventual trading prices, there is unclarity resulting from the mixed economy structure. Since commodities can simultaneously be supplied or demanded by price taking and price setting firms, it is unclear which of the two influences on the price level is decisive if both market forces work on the commodity price. Naturally, competitive firms could be expected to undercut the prices of the monopolistic suppliers. Yet, they are price takers, and will therefore generally enjoy a profit at going monopolistically set levels. No discussion of these issues is offered, however.

Profits and their distribution outside of equilibrium also raise difficulties in the construction of the proof of asymptotic stability of the combined adjustment processes. Here Negishi needed to assume that aggregate excess demand $z_{j}$ for competitively offered goods, and the perceived profit-maximizing prices $\bar{p}_{j}$ of monopolistically supplied commodities are both functions of prices only, the first being homogeneons of degree zero, the second of degree one. This assumption seems innocuous-after all, all notional values are clirected by prices only. Yet, it is unduly restrictive. Outside of equilibrium, notional and effective plans do not match. Consequently, realized profits, which in turn appear in the budgets of consumers, are determined, not only by prices, but by effective production and sales plans as well. ${ }^{20}$ Therefore, in fact, this assumption acts to exclude disequilibrium redistributions in quite the same manner disequilibrium trade is excluded in tâtonnement.

Keeping out profit distribution effects by assuming that wealth distributions are given prevents the system from rumning into income effects via profits which generally obstruct global stability-just as the assumption of gross-substitutability, to be made next, serves this purpose for income effects in price changes given returns on shares. Were a distribution of profits over the disequilibrium process allowed, demand functions would likely shift in ways which lead the steady price convergence in an opposites direction, thereby obstructing the monotonicity of the Lyapounov function. Negishi justifies the assumption as follows.

"[It] is satisfied if we assume that participants in a monopolistically competitive market other than the monopolistic firm consist of perfectly competitive firms and consumers, who get their income from their initial holdings and from the profit of perfectly competitive firms, but not from the profit of monopolistically competitive firms." (op.cit., p.200)

19 Apart from the conchision that Negish was unaware of the logical difficulties with Ifange (1944) on which he rolied, it is possible that he saw effective prices as flexibly adjusting, so as to allevatat any wxess demand at notional prices, once quantities are stablished out side of equilibrium. In such a structur, the expected profit maximizing price devates from the price established on the matket, and can therefore serve as a disequilibrium measure, as ine stucture above. Yet, it is clear that this interpretation demands a supplementary type of price adjustment not considered in the dymanios specified.

20 Another way of saymg this is that generally Walras' law does not hold outside of equilibrium when individuals have momplete and imperfect information. Of. Fisher (1983), Chapter 7 . 
So the profits of the single monopolist maximally active in each market are reserved instead of distributed.

The next, more familiar assumption to establish global stability Negishi needed is the traditional strong condition that excess demand functions satisfy gross-substitutability, i.e. $\frac{\partial x_{j^{\prime}}}{\partial p_{j}}>0$, for all $j^{\prime} \neq j$. In addition, a second assumption states that $\frac{\partial \bar{p}_{j}}{\partial p_{y^{\prime}}}>0$ for all commodities $j^{\prime}$ monopolistically determined and $j^{\prime} \neq j$ and all relevant $k$, i.e., that the perceived profit maximizing price level of a commodity produced under monopolistic competition is positively related to the price levels of all other products.

The latter of these two assumptions is quite plausibly derived from the former, prowided in addition that the slope of the true demand curves is independent of cross price changes, and that marginal costs do not fall. The first of these additional conditions can be interpreted as actual monopolistic power being independent of price changes-which is, although not in this structure in which firms do not compete in monopolistic markets, very restrictive for cross-price changes-while decreasing returms to scale associated with the convex production technologies postulated invoke increasing marginal costs. Under the conditions stated then-actual and perceivedgross-substitutability implies that price increases of substitutes shift the firm specific demand curve to the right, expressed as $\frac{\partial b_{k} j^{r}}{\partial p_{j}}>0$, which, combined with increasing marginal costs, dways leads to higher profit maximizing prices for the commodity mder consideration. Nevertheless, gross-substitutability of aggregate excess demand is unacceptably strong.

With all these assumptions in place, Negishi (1961b) delivers proof of both local and global stability. The first is based on a linear approximation around the equilibrium state, applying Samuelson's stability theorem, which guarantees local stability on the basis of negative real parts of the characteristic roots of the Jacobian for the linearized excess denand system. The latter relies on the lemma that for this economy in case of gross-substitutability, outside equilibrium aggregate excess demand is positive for the price which is relatively lowest to the equilibrium price, and negative for the price relatively highest to the equilibrium price, that can be adapted to the monopolistically competitive part of the price dynamics as the deviation between an equilibrium price and the set price being negative for the relative highest, and positive for the relative lowest price. The lemma is sufficient to establish global stability, applying a result in Arrow et al. (1959). ${ }^{21}$ In that, it is important to note that the crucial, conclitions on the dymamics specified are to ensure that prices move such as to close the naximum gap between any arbitrary set of values and their equilibrium values, given by the maximum Euclidian norm of the price vectors, continuously. What happens in the meantime with quantities is unimportant for the proof of global asymptotic stability.

Clearly, Negishi (1961b) travels quite a distance along the path indicated by Clower and Arrow that monopolistic competition is the appropriate market structure to understand disequilibrium behavior. The model features subjectively rational price setting in a general equilibrium context, and disequilibrium mismatches between notional and effective plans that in turn can lead to adjustments in perception and plans. Although,

21 Op.cit, Theorem I on page 95. 
due to the infuence of Lange, the mechanistic dynamics Negishi came to postulate to imwestigate the stability of this process takes with one hand what it gave with the other, and consequently the stability results found are neagre, the static structure of the model and the existence results make a firm foundation for a more satisfactory theory of disequilibrium. However, the development of the literature would be such that little was ran up on it.

\subsection{On the Objective Demand Approach}

A distinctive feature of the model introduced in Negistai (1961b) is its recognition of the role played by the perceptions of those with a locall monopolistic and monopsonistic influence in the market of the relationship between prices charged and quantites sold, or prices paid and the size of offers. Naturally, such perceptions should have their counterparts in the true state of affairs. The question rises, however, what the extent of their roflection of the true market power that frms have can be. For a distinction needs to be drawn between the knowledge held by a firm, which is subjective, and the objective structure of the economy. Whereas individual decisions are based on subjective knowledge, whether fully or only partially representing the objective structure, the effects of these decisions in the aggregate are eventually determined by the economy's objective structure.

Negishi (1961b) quite radically specializes subjective ideas on the market structure to linear conjectures. In 1972, Negishi stated on this:

"It is wiclely agreed that the only demand (supply) function that is relevant in the theory of monopolistic (monopsonistic) competition is the perceived, imagined or subjective demand (supply) functions which express the expectations of the firm as to the relationship between the price it charges (offers) and the quantity of its output (input) the manket will buy (sell). (..) $[\mathrm{O}]$ we on hardy conceive of any firm being able to observe and take into account all the variables in the system, $i . e$, not only prices but also inputs and outputs of other firms, etc, since even the modern econometric studies can take into account only a few variables. It is most natural to assume that firms respond to some partial equilibrium type of perceived functions." (op.cit., p.107)

In a monograph titled Monopotistic Competition and Effective Demand, published 1975, Nikaido criticized, after crediting Negishi pioneering work, his partial perception as unft to carry a satisfactory general equilibrium theory with imperfect competition. as he wrote:

"Plerceived demand functions embody only fims' subjective perception of the economic sitnation and conjectures as to rival firms' behaviors rather than a direct recognition of the interdependence of frms in the objective sense. A monopolist controls prices or output through the interdependent relations among economic agents in the objective sense even if his decision 
making is bosed on a proft estimate in terms of his perceived demand function. So we are still not completely satisfied with our knowledge about monopolistic competition in the general equilibrium context." (op.cit., p.5)

On the specific perceptions of Negishi's fums in the monopolistically competing sector, Nikaido furthermore very eloquently put the following.

"A firm whose perceived demand function is steeply downward sloping cannot be a powerful monopolist unless it is practically influential and capable of forcing the market price formation to function through the interdependence in the objective sense toward the goal it desires to achieve. A mere Don Quixote need not be a powerful monopolist." (op.cit., p.6)

To Nikaido, the Lange-conjecture implies, instead, the need to study the true demand curves monopolistically competing furms face, and Lange's intentions to characterize general equilibrium "compatible with the circular relation" between forces that detemine "national income" and "the Marxian labor value" can only be served when firm-specific demand and supply are "defined in a clear-cut way". 22 "These loose quotes are to show that Nikaido is in an entirely different frame of mind than Negishi, who sought a comnection with the Arrow-Debreu model. Nikaido's is a socialistically and computationally inspired example of a quite specific Leontief system, in which the "right" equilibria are to be established.

The wish to increase determination is, of course, well understandable in light of the fact that very many different conjectures can be thought of that can all sustain different equilibria in Negishi's definition. A substantial multiplicity of equilibris is offered, therefore, and many of these equilibria are 'wrong' in the sense that they are based on false beliefs outside of equilibrium that nevertheless find confrnation at equilibrium. Certainly, further determination is likely to come with better informed conjectures.

The two orthogonal positions taken by Negishi and Nikaido, mark in this respect a divide in the literature between the so-called 'subjective demand approach' and the 'objectve demand approach", the latter concerned with models in which demand and supply relations are objectively known to all firms, the former with models where they are not, and subjective beliefs of them have to be entertained instead. The approaches separate developments today. ${ }^{23}$

By assuming perfect insight into the market relations by all parties, the objective demand approach runs into the necessity of providing an explicit account of the firms" strategic considerations of the actions and reactions of others. Negishi leaped this by taking up all infuences on price other than the own quantity into the intercept. Part of the discussion on subjective versus objective dernand, therefore, concerns the complexity in recognized mutual interdependence between market participants, and the possibility to observe others. Traditionally, all firms are taken to determine their

Op.cit. p p. 11-3.

23 Hart's 1985 review covers these particular subjects far more extensively than Benassy's 1991 survey article on imperfect competion. In the following, therefore, reference is mainly made to Hart's account. Still, in both the objective demand approach takes up the larger part by far. 
notional choices simultaneously, without observing the actions of their rivals, and instead to expect either their quantities or prices to remain constant. ${ }^{24}$ These so called Coumot and Bertrand cases are studied next.

The origin of the objective demand model of quantity setting is in Gabszewict and Vial"s 1972 article "Oligopoly "A la Cournot" in a General Equilibrium Analy. sis," written with no reference to the Negishi model-but noted by Nikaido. Yet, the Gabszewica and Vial model is very close to Negishi's. In the model production and exchange decisions are sepaxated. This gives rise to a separation of the commodity space in two subspaces, one consisting of non-produced goods, and one containing produced goods. The former of these are generally held by the consumers and applied by the firms to generate the latter.

Consumers have preferences over all commodities, which are represented by utility functions satisfying the same conditions as in Negishi (1961 b), supplemented by the requirement that utility stricty increases in the non-produced commodities. Consequently, there exists a demand function for each commodity. It is assumed that firm specific demand curves cross the price-axis at some point, which guarantees that firms cannot indefinitely increase their revenue. As before, each firm's sole objective is to maximize profits. Different from the Negishi nodel, however, firms determine quantities in a monopolistic fashion.

Firms' production decisions influence the income of consumers through the distribution of profits. That is, each set of production vectors generates a new "initial' endowment to which either one, many or no exchange equilibria belong. To rule out the latter possibility, the construction of the model includes defining a set $F$, containing all feasible production levels for which a price vector and an allocation exist which maximize the utility of all market participants within their budget restrictions, as well as a separate set of corresponding normalized prices $P(y)$. Some mechanism is assumed to generate a price vector $p(y) \in P(y)$ on the basis of each set of production decisions. This selection dynamics is briefly referred to as embodying the nuaket clearing process. It comes with little discussion, let alone a analysis of stalbility. Prices are subsequently taken as given by all individuals and firms.

Each firm maximizes profits in the knowledge that its actions will generally have an influence on the market price through objective demand and supply. How they come to understand these is not considered. In his general structure each firm $k$ chooses a production plan $y_{k}$ on the basis of rival firms" plams $y_{-k}$, which are taken as givens in a Cournot-like fashion. A Coumot-Nash equilibrium for this model is defined as in Definition 5.1 above, where condition (iv) is dropped, since all firms compete monopolistically, and condition (iti) is replaced by the requirement that

$$
\begin{aligned}
& (\text { ini })^{\prime} p(y)=p, \text { and for all } y_{k}^{\prime} \in Y_{k},\left(y_{-k}, y_{k}^{\prime}\right) \in F \\
& \\
& p\left(y_{-k}, y_{k}\right) y_{k} \geq p\left(y_{-k}, y_{k}^{\prime}\right) y_{k}^{\prime} .
\end{aligned}
$$

24 Given the infotmation available to them, these behavional assumptions are, in act, guite appropriate, as argued in the next subsation. 
In other words, apart from feasibility and optimality for the price-taking consumers, production decisions maximize profit of all firms, given the production strategies of all other firms.

The existence of Cournot-Nash equilibrium is guaranteed under additional restrictions on the sets $F$ and $P(y)$. Furthermore, the solution to the profit maximization on the basis of the price as a function of rival strategies needs to have a unique solution for all firms for all rival strategies. That is, apart from decreasing returns to scale, again the critical condition for existence of an equilibrium boils down to (quasi-) concavity of the profit function, which is now explicitly stated as a function of rival production decisions taken as given. ${ }^{25}$ Despite the constructive contribution of Gabszewicz and Vial (1972), however, numerous examples of non-pathological strategies were found, at the instigation of Roberts and Sonnenschein (1977), which break the existence proof by obstructing compatibility of individual profit maximizing strategies.

Models of price setting on the basis of objective demand are closer to the models of Negishi and Nikaido. Hart (1985) presents a discussion of objective demand based on Hart's own work. It is essentially a Bertrand-like price setting structure, in that firms take other firms" prices as independent of their own actions. Negishi's 1961 setup of a mixed economy is retained. As before, monopolistically producing firms do not: share markets. As in the quantity setting models, production and exchange decisions are separated. Somewhat more strict conditions on preferences and production sets are made. In the former the infuence of non-produced commodities is strengthened, the latter are taken to be strictly convex. Furthermore, the output vector is explicitly bounded.

Objective firm-specific notional demand follows from consumer utility maximization. That is, the demand function faced by the imperfectly competitive firm $k$, producing commodity $j$ and facing only perfectly competitive rivals, can then be written as

$$
y_{k j}=\sum_{i=1}^{n} x_{i j}(p, y)-\sum_{k^{\prime} \in R^{1}}^{r} y_{k^{\prime} j}(p)
$$

in which $y_{k},(p)$ is derived from profit maximization of the competitive, price taking, firms supplying commodity $j{ }^{26}$

On the basis of these demand functions, firms in $R^{2}$ set prices, taking other firms' prices as given. Furthermore, by the same assumption, profits and therefore wealth distributions, are assumed to be given, that is, as before firms do not consider their infuence on the demaind system. Hart argues that the island-structure discussed above provides a justification for the Bertrand assumption, when firms consider rivals as

25 For ar outline of the proot, see Hart (1985), pp.111-2.

20 Observe that this demand reads inversely

$$
p_{j}=X_{k j}\left(y_{k} \| p_{0}\left(\left(x_{1}, \ldots, x_{k j}\right),\left(y_{1}, \ldots, y_{r}\right)\right)\right)
$$

for all $j f^{0}$ "and therefore assumes the same information on signals ats Hat"s interpretation of Neguls wett ont above. The cruchal difference between that and this approach is of course in the assumption made here that $X_{j}(\cdot)$ corresponds to the true demand function for commodity $j$. 
established on different islands, both with respect to the influence of their prices and the distribution of their profits. ${ }^{27}$

A Bertrand-Nash equilibrium for the model is formerly analogous to Definition 5 . above, the important difference being, of course, that firm specific demand and supply is now explicitly derived from the objective clata of the model, and thus corresponds to the true demand and supply. Existence of equilibrium is established on the basis of the additional assumption that the profit maximizing price levels are unique solutions, and that competitively set quantities have an upper limit, reflecting similar problems with existence as present in the Cournot-Nash model. Again, these assumptions are equivalent to assuming (quasi-) concave profit functions, of which sensible violatione are easily constructed. 23

The objective demand approach commences to establish the "true" equilibrium of general equilibrium models with monopolistic competition. Obtaining the existence of general monopolistic competition with objective demand posed an interesting theoretical challenge to which, among others, Gabszewicz, Vial and Hart answered ${ }^{2}$ Yet, the objective demand approach led away from meaningful insights into disequilibrinm behavior for which Clower and Arrow had pointed to it. An important role in this is played again by the Lange-conjecture, taken by Nikaido to mean that information of firms should be full. As argued before, Lange's conjecture is indeed vallid only when information is perfect. Yet, this means it should be dismissed, and not substantiated with informational requirements that stretch the imagination.

On several occasions in Chapter 1 and above, it has been argued that imperfect information is an essential characteristic of disequilibrium. Assuming perfect and full insight into the structure, and knowledge of all the detail of economies not only is unreasonable to ask, it simply begs the question of disequilibrium. Consequently, adherence to a one-on-one correspondence between the objective world and its subjective perception does not allow for a meaningful theory of disequilibrium an insight not had by Lange, nor Nikaido. As such, it is in line with the positive heuristic of economics" research program.

In fact, excluding a meaningful analysis of out-of-equilibrium behavior only limits the possibilities in characterizing equilibrium. As explained before, namely, multiple equilibrium issues rise only in an equilibrium approach. An appropriate model of disequilibrium allows for singling ont one, path-dependent, rest-point, out of possibly many. Consequently, further detemination of models of imperfect competition is likely to be found in considerations regarding behavior outside of equilibrium, rather than in it.

Illustrative in this respect is the fact that the objective demand approach did not succeed in substantially limiting the number of equilibria in models with impertect information, as it set out to do. That is, even though it reduces the number of equilibria resulting from the wide variety of possible perceptions of demand. by furms within the sole consistency condition in the subjective demand approach, objective demand still

2. Op.cil., pp.117-8.

as See for this proof Hart (1985), pp 141-2.

2y Other, including more recent contributions to the objective demand approach are Marschak and Selten (1974), Maskin (1986), Allen and Fllwig (1986), Benassy (1988), and Böhm (1994) 
accommodates a very large number of equilibria, among which the 'true' one does not obviously stand out. 30

Moreover, the objective demand approach has several unattractive features in comparison to the Negishi model. The quantity-setting models impose a rather swift selection of an equilibrium price vector from the many possible. Also, for existence, they require special conditions on the commodity space, as well as preferences, production techniques, and the distribution of profits-stability is not even considered. The same is true for the price-setting models, even though they remain offering an insiglnt into the origin of prices. More importantly, both objective demand approaches run into problems establishing the existence of equilibrium generally. Particularly, discontinuity of the reaction functions is a common problem. Interestingly enough, after establishing some of these, Roberts and Sonnenschein conclude as to the implications Cor future work:

A[n] alternative would be to accept the failure of existence in the model as indicating that equilibrium might well not be achieved in an actual econony in which firms with very complete knowledge of demand conditions behave in the extreme non-cooperative fashion assumed here. (...) [To that end] one might attempt to relax the assumption of full knowledge of the demand conditions. In fact, Negishi"s papers do this in assuming that the firms base their decisions on linear perceived inverse demand curves .... Of conrse, these perceived curves are completely ad hoc, although one might attempt to construct theory to explain them. Within such a theory, however, one would presumably want to allow for learning leading to perceived curves more and more closely approximating the true relationships. In this case, one is confronted again with the original problem of non-existence." (op.cit., p.111)

Few would take up this suggestion. Nevertheless, some further progress was had in the subjective demand approach. It is considered next.

\subsection{Market Makers with Subjective Conjectures}

Important developments in the subjective demand approach were made by Benassy. Athough lis later contributions are mainly to the objective denand approach-which also makes up by fau the larger part of his 1991 survey-Benassy's early work in the 1970 's was on subjectively conjectured demand functions. The core model, also the basis of Chapter 9 of his 1982 book. The Economics of Market Disequilbrium, was in two companion articles in the Review of Economic Studies, the first titled "Neo-Keynesian Disequilibrium Theory in a Monetary Economy," published in 1975, the second titled "The Disequilibrium Approach to Monopolistic Price Setting and General Monopolistic Equilibrium," published 1976. The former takes inspiration from a macroeconomic monetary tradition, that included Clower and Leijonhufvud, and

30 Cf. Hart (1985), pp. 127-30. 
builds on a paper on general equilibrium with perceived quantity constraints later published as Dreze (1975). The latter refers to Arrow (1959), and extends explicity on Negishi (1961b) by the recognition that conjectured demand and supply are in fact price dependent quantity constraints. As such, Benassy's work seminally bridges macrom and microeconomics. 31

In the econony considered, one commodity serves as money. Money is the sole medium of exchange, as well as the standard of value. Its price is equal to one. Furthermore, money generates utility. That is, each individual $i$ 's continuous, quasi-concare and monotonic utility function is $\mu_{i}\left(x_{i}, m_{i}\right)$, over consuraption $x_{i}$ and money $m_{i}$ which is planned to be a positive amount at all times. Note that essentially, this only adds a commodity to Negishi's morlel-although the assumption that all trade rums over money is not innocuous. Each frm $k$ possesses a technology with which it can produce $y_{k}$ in production sets $Y_{k}$. Again, there is free disposal, firms can sit idle and the production sets $Y_{k}$ are convex and bounded from above.

In time, trading processes take place, that are analyzed in quite some detail. That is, prices, once set, are sticky for a period. Quantities, on the other hand, are flexible, in that they adjust to match demand to the extent possible at the ruming prices. The analysis of this requires two different indications for quantities, quantities notionally demanded, written with a tilde as $\widetilde{x}_{i j}$ and $\widetilde{\psi}_{k j}$, and quantities effectively traded, writen with a head as $\widehat{x}_{i j}$ and $\widehat{y}_{k j}$. Since trade takes place against disequilibrium prices, the trading process is generally characterized by differences between notional and effective trades, that is, by rationing.

Rationing gives rise to at least two difficulties that were largely neglected in Negishi (1961b), yet concern Benassy. Firstly, rationing schemes need to be given, representing market processes of searching, meeting, offering, negotiating, and accepting. They embody an organization of markets. Secondly, the possibility of being rationed at going prices should be entertained by individuals. That is, expected rationing will generally influence individual plan formation. 32

The awareness of individuals of the possibility they will be rationed results in expected quantity constraints in each period, indicated by $x_{i j}^{*}$ and $y_{k j}^{*}$, which are maximum amounts believed possible to either buy or sell. These constraints mold the way in which the notional demand is formed. In Benassy (1975), that is, ntility is maximized subject to the budget constraint, supplemented by the requirement that demand and supplies do not exceed perceived constraints-and standard non-negativity con-

31 Benassy (1976) is more general thun Benasy (1975) in various ways. Apant from prioe da pendency of constrants and the explicit accont of price seting that comes with it, the latter is restricted to exchange, while the fomer inchudes production. Yet, Benassy (1975) is more explicit in its analysis of the timing of transactions and plan fomation. The following presents anthesis clasest to Bendsy (1982). Notation is kept as close as possible to Negishi"s, to establish similarities. Finally, it was already noted that Benassy's use of the term disequilibrum is inapproprate- see Chapter 1. In the exposition it is used in the meaning it has here.

32 There is, furthermore, a complicated relationship possible between the awareness of possible rationing and rationing schemes. The complications tising from this are teken out by assuming that rationing schemes ate ron-manilable. Of. Benasy (1982), pp.34-7. 
straints. That is

$$
\begin{aligned}
& \max _{x_{i}, m_{i}} u_{i}\left(x_{i}, m_{i}\right), \text { subject to } \\
& \sum_{j=1}^{m_{m}} p_{j} x_{i j}+m_{i} \leq \sum_{j=1}^{m} p_{j} \bar{x}_{i j}+\sum_{k=1}^{r} \lambda_{k i} \sum_{j=1}^{m} p_{j} y_{k j}+\bar{m}_{i,} \text {, and } \\
& \left|x_{i j}\right| \leq\left|x_{i j}^{*}\right| \text { for all } j .
\end{aligned}
$$

This returns a notional demand $\widetilde{x}_{i j}$ for commodity $j$.

Amalogously, firm $k$ maximizes profits subject to technical possibilities and the condition that

$$
\left|y_{k j}\right| \leq\left|y_{k j}^{* j}\right| \text { for all } j,
$$

from which notional supply $\widetilde{y}_{k j}$ follows.

At any given price vector notional demands and supplies need not necessarily be equal, that is, the economy is generally in disequilibrium. To analyze the consequences of this, the following notation that allows to treat individuals and firms simultaneously as "agents'. Let an index $a=(1, \ldots, n, n+1, \ldots, n+r)$ run over all individuals and firms, and let $\chi_{a j}$ be the net demand of agent $a$ for commodity $j$ when larger than zero, and the net supply when smaller than zero. That is,

$$
\chi_{i, j} \equiv x_{i j}-\bar{x}_{i j} \text { and } \chi_{n+k, j} \equiv-y_{k l,}
$$

where $\bar{x}_{i}$ is the initial endowment of consumer $i$. The top-labels apply as before, i.e., $\tilde{\chi}_{a j}$ is the notional net demand (or supply) of agent $a$, and $\widehat{\chi}_{a j}$ the effective value.

The part of notional plans made effective is determined by rationing rules, captured as follows.

$$
\widehat{\chi}_{a j}=F_{a j}\left(\widetilde{\chi}_{1 j}, \ldots, \widetilde{\chi}_{n+r, j}\right) .
$$

Rationing may be according to a 'first come, first served' rule or some system more complicated, as long as it satisfies the following general conditions-apart from continuity of $F_{a j}(\cdot)$ :

(i) $\sum_{a=1}^{n+r} F_{a j}\left(\widetilde{\chi}_{1 j}, \ldots, \widetilde{\chi}_{n+r, j}\right)=0$,

(ii) $\left|\widehat{\chi}_{a j}\right| \leq\left|\widetilde{x}_{i j}\right|$ and $\hat{\chi}_{a j} \tilde{\chi}_{a j} \geq 0$, and

(iii) iff $\widetilde{\chi}_{a j} \sum_{i=1}^{n+y} \widetilde{\chi}_{i j} \leq 0$ then $\widehat{\chi}_{a j}=\widetilde{\chi}_{a j}$.

Of these, Condition (i) requires the market to clear in terms of effective demand. Condition (ii) states that trade is voluntary, as no agent can be forced to buy or sell more than it planned, nor can an agent be forced to sell what it wants to buy or vice versa. And Condition (iii) says that all agents on the 'short side of the market' realize their notional plans. ${ }^{33}$

"Th: The Latter assumption is, of course, equivalent to that of orderly markets in the Hahn process, discussed in Chapter 3 -as is the idea of flexible quantities within one price period. More on the similarities between the models below. 
Faced with rationed plans, all agents turn to their beliefs on future rationing. If assumed any adjustments thereof follows the continuous process

$$
\chi_{a j}^{*}=G_{a j}\left(\widetilde{x}_{1 j}, \ldots, \widetilde{X}_{n+r j}\right) .
$$

Note that information on effective trades resulting from notional plans suffices to malke perceived constraints adjust according to their discrepancies. Perception changes are taken by Benassy to satisfy the following conditions.

(iv) if $\left|\widehat{x}_{a j}\right| \leq\left|\tilde{x}_{a j}\right|$ then $x_{a j}^{*}=\bar{x}_{a j}$,

(v) if $\widehat{\chi}_{a j}=\tilde{\chi}_{a j}$ then $\left(X_{a j}-\widehat{\chi}_{a j}\right) \tilde{X}_{a j} \geq 0$, and

(vi) if $\widetilde{X}_{a j} \sum_{i=1}^{n+m} \widetilde{x}_{i j}<0$ then $\left(x_{a j}^{*}-\widetilde{\chi}_{a j}\right) \widetilde{X}_{a j}>0$.

The requirement (iv) says that an individual effectively constrained on a market considers that constraint binding in further planning. Conditions $(v)$ and $(v)$ impose the opposite, that is when a commodity was bought weakly or strictly unconstrained, it is believed an equal amount or more of it could, respectively, be reckoned with next.

In Benassy (1975), prices remain fixed and a process of adjustments of percep tions and bence notional denands and supplies is sketched. A $\mathbb{K}$-equilibrium- ' $K$ ' for Keynesian-is defined for any price vector as a notional demands and supplies based on maximization of utility and profit under perceived constraints that comcide with realizes trades, and consequently no longer give reason for adjustment. This definition is, with conjectural demand and supply generally understood, similax to Definition 5.1 above-a more formal comparison will be given below. Yet, it is Important to note that it is beliefs that adjust to establish equilibrium, rather than prices. Existenoe of K-equilibrinm is established by showing that the mapping from previous to new notional demands has a fixed point. ${ }^{34} \mathrm{~K}$-equilibria are generally inefficient, on which Benassy comments:

"The best-known example of these inefficient states is the deflationary Keynesian case: an increase in employment would increase both firms" profts and individual utilities. But unfortunately, the market does not provide any signal for the existence of such profitable trade." (op.cit. p.512.)

In Benassy (1976), the analysis is further extended with a study of price setting. To that end, it is assumed that fims are all competing in a monopolistic fashion thene is no competitive sector. Consequently, all prices other than that for money which is fixed, are set by fims. As in the Negish model, but now for all firms $k^{r}$ and $k^{\prime}$;

$$
f^{k} \sqcap J^{k}=0 \text { for all } k^{\prime} \neq k \text {. }
$$

Hence, each commodity is governed by one and only one firm, which Benassy makes plausible by defining non-monetary commodities by firm, reflecting full product differentiation.

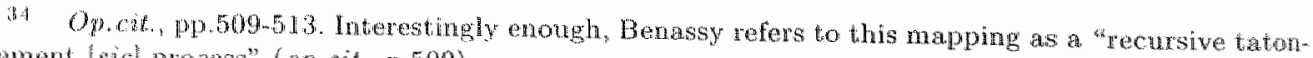
nement $($ sid $)$ promess" (op.eit., p.509). 
The behwior of the monopolistically competing firms explains prices. As in the Negishi model, price setting is based on subjectively conjectured demand and supply curves. The connection is natural, as in fact conjectures to the monopolist are price dependent quantity constraints on its monopolist's planning problem. ${ }^{35}$ As they depend on past information, time, indexed by $t$, is introduced into the notation explicitly. The system of perceived demands of firm $k$ for the products it monopolistically supplies and demands reads:

$$
\left(y_{k j}^{*}(t)\right)_{j \in J k}=X_{k}^{*}\left(p_{k} \mid \widehat{y}_{k}(t-1), p_{k}(t-1), I_{k}(t-1)\right)
$$

that is, demand and supply of each commodity controlled by the firm depend on the current prices, previous sales and the previous prices of all commodities the frm monopolistically offers or buys, and any other information it might have. Demand and supply conjectures are assumed to be consistent with the data of the previous period.

Note that $l_{k}$ can contain the price levels of all other firms, in which case the information available to the firms is equal to the information originally modelled by Negishi 1972). The Negishi 1961. version of the expected demand systern, which is much more convenient, is a special case of the system if changes in price of a commodity are not perceived to have an infuence on the demand or supply constraints faced for any of the other commodities, $i . e$, if $\frac{\partial w_{i j}^{*}}{\partial p_{\beta^{\prime}}}=0$ for $j, j^{\prime} \in j^{k}$ and $j \neq j^{\prime}$-as Benassy soon does. Then,

$$
y_{k j}^{*}(t)=X_{k j}^{*}\left(p_{j} \mid \widehat{y}_{k}(t-1), p_{k}(t-1), I_{k}(t-1)\right),
$$

which is different than the inverse demand of Negishi (1961b) only in that it allows the functional form to be based on additional information.

Given the conjectures on the influence of his price setting behavior on the quantity constraints faced, the monopolist sets prices as to maximize profits. That is, prices and motional quantities are simultaneously established as follows.

$$
\begin{aligned}
& \max _{p_{k, y k}} \sum_{j \in J^{k}}^{m} p_{j} w_{j}+\sum_{j J^{*}} p_{j}^{*}(t) y_{k j} \text {, subject to } \\
& y_{k} \in Y_{k} \text {, } \\
& \left|y_{k j}\right| \leq\left|X_{k j}^{*}\left(p_{j} \mid \bar{Y}_{k}(t-1), p_{k}(t-1), I_{k}(t-1)\right)\right| \text { for all } j \in J^{k} \text {, and } \\
& \left|y_{k j}\right| \leq\left|y_{k j}^{*}\right| \text { for all } j \notin f^{k} \text {. }
\end{aligned}
$$

Finally, to close the model, the expectations on constraints on commodities not under the individual firm's control are assumed to be one period regressive. That is for $f f^{2}$ in the above.

$$
p_{j}^{*}(t)=p_{j}(t-1) \text { and } y_{k j}^{*}(t)=y_{k j}^{*}(t-1) .
$$

Hence, firms do not consider changes in the perceptions of other frms for which, also, they largely lack the information.

\footnotetext{
W5 To consumers, they remain constant, yet Benassy (1976) conclndes with an extension to priceseting consumers. Cf. op. cit., p.79.
} 
Individual profit maximization thus returns the ruling market prices for each period. With these fixed, notional trades play themselves out to the extent allowed by the ordering of markets. That is, the functions $F_{i j}(\cdot)$ subsequently return effective transactions, and in light of that, new perceptions follow from and $G_{i j}(\cdot)$, and hence new prices and new notional trades. An equilibrium is defined as follows.

Definition 5.2 (K-equilibrium) A set of vectors $\left(p, x_{i}, m_{i}, y_{k}\right)$ forms an equilibrim if:

(i) $\left(x_{i}, m_{i}\right)$ is a solution of the utility maximization problem of consimer $i$;

(ii) $\left(p_{k}, y_{k}\right)$ is a solution of the profit maximization problem of firm $k$;

(iii) for all $a$ and all $j$,

$$
\begin{aligned}
& \chi_{a j}=F_{a j}\left(\chi_{1 j}, \ldots, \chi_{n+r, j}\right), \text { and } \\
& \chi_{a j}=G_{a j}\left(\chi_{1 j}, \ldots, \chi_{n+r, j}\right) .
\end{aligned}
$$

Condition (i) and (ii) are straightforward. Condition (iii) requires that plans cone true and beliefs remain the same. An equilibrium, in other words, is a vector of prices and effective demand and supplies, such that all agents see their beliefs confirmed, and consequently, prices settle down at levels where markets are notionally and effectively cleared as perceived profit maximizing-that is, where the Lange-conjecture holds. Again, its resemblance to the definition of monopolistically competitive equilibrium, Definition $5 . \mathbb{1}$, is noteworthy.

The disequilibrium dynamics of the model is thus driven by adaptations of the expected constraints on the basis of observed rationing, information on the own prices and sales, and additional information in the sets $I_{k}$. Benassy breaks this process down into three mappings, two of intra-period adjustments of quantities, and a third of interperiod price adjustment. ${ }^{36}$ The first two are largely empty concepts since instantaneous adjustment to effective demand has been assumed. The price mapping encompasses his contribution to the understanding of disequilibrium behavior.

Benassy (1976) presents an extensive existence proof of the monopolistically com. petitive equilibrium described, which follows the strategy of proof in Debren (1959). That is, it seeks to establish a fixed point of the above mappings. To that end, several assumptions are made on the price process. It is assumed that all prices charged are positive and unique, that sales prices have at all times an upper bound, and purchasing prices a lower bound that is, perceived demand and supply somewhere intersect the price axis, reflecting a perceived limitation of monopolistic powers-that perceived inverse demand curves are contimous in quantities and information, and finally that the information sets $I_{k}$ are continuous in prices and effective demands. ${ }^{37}$

The article does not offer a stability analysis. Benassy's main concern, as a student of Debreu, was with existence. ${ }^{38}$ Towards its close, however, Benassy (1976) acknow edges the lack of attention given to the dynamics of the system, and suggests several

\footnotetext{
3i Op.cit., p.76.

wi Op.cit, p. 77-8.
}

according to the dominant interpretation, with this Benassy is in keeping with Keynes. OH Lundberg (1937), pp.35-8. See also Chapter 1 . 
extensions to that end. The first is to include multiple period information into the madification of perceptions of subjective demand. On this, it suggests:

"This curve could be obtained by any statistical procedure (Bayesian axalysis, regression ...). The shape of the [perceived demand] curve will evidently depend very much on the variables known by the monopolist .... If this information is quite complete, the perceived demand curve may, after a sufficient number of observations, get quite close to the "true demand curve," in particular with respect to elasticity." (op.cit., p.79)

The latter conclusion leaps quite some problems of its own though. Apart from the fact that the Roberts and Sonnenschein results show that full objective information creates existence problems, the 'true demand curves' are changing over the process of false trade by the very actions of the monopolists trying to establish them.

A process in which quantities in prices simultaneously adjusted over time -instead of prices inter-, and quantities intra-period-promised in Benassy (1976) to provide more insight into explicit dynamics, does not. It simply remarks:

"(and the system will actually converge towards it if it is stable" (op.cit., p.521, emphasis added).

Finally, Benassy (1982), in which a transparent exposition of his work on subjective demand is offered, the need to apply estimation of perceived demand and supply is stressed again on several occasions, and some lines for development noted, yet the relationship with the problem of stability is not stressed. Benassy concludes:

"Much work is still needed to construct models of interaction between price making and the learning process of price makers. In any case, a most likely outcome is the realization, at least in the short run, of prices that are not those corresponding to a full Walrasian equilibrium." (op.cit., p.57 $)^{39}$

With the work of Benassy, the subjective demand approach comes full circle with respect to the existence of monopolistically competitive equilibria. In an economy in which the formation of all prices has been decentralized to firms with local monopoly power, acceptably mildly restricted beliefs can support generally matching plans of all individuals and firms. Consequently, the homunculus explanation of the auctioneer who adjusts prices can be left entirely. Prices are the outcome of individually rational behavior. The inconsistency in general equilibrium theory spotted by Arrow can be removed.

\subsection{Individually Rational Prices: A Conclusion}

If one cares to look for it, a substantive literature can be lound on monopolistic competition in general equilibrium context, that can help to answer to Clower, Koopmans and Arrow. This literature extends on two major developments in economics

39. Some progress in this direction is obtained in Sivestre (1977). 
in the 1930's: Keynes' pointing to the absence of spontaneous market clearing and the Jiterature on monopolistic competition, which thus turn out to be related to the problem of disequilibrium. The Negishi model, with Benassy's extensions to all firms monopolistically competing, given the interpretation of Fisher's dealer-structure, of fers a comfortable seat for individually rational disequilibrium behavior. It sets out what is involved in markets being orderly, it substantiates that notional trades can be expressed in money terms, it offers a justification of trade at disequilibrium prices by having individuals expect future rationing, and it has the prices of commodities set by market makers, individually rationally in accordance with perceived profits, and such that markets clear aggregate demand and supply. In all, sufficiently interesting elements for a progressive problem-shift in the disequilibrium research program, one would say.

In the introduction of his 1991 survey, Benassy stated that the "monopolistic competition revolution' was a revolution because

"... it replaced the Walrasian and Marshallian "auctioneers" by explicit price setting agents internal to the economy." (op.cit, p.1999)

This, however, is a little quick. The survey in this chapter makes clear that the main concern has been with establishing existence the of equilibrium prices. An explanation of the rise of such coordinating prices is not complete. The auctioneer is necessary for establishing equilibrium in models of perfect competition. Once prices have taken on equilibrium values, his role is played out. Consequently, replacing it with an equilibrium analysis of monopolistically set prices is of little consequence. Instead, replacing the disequilibrizm analysis is what is called for. Several natural suggestions have been made to follow up on. They concern the way subjective perceptions are formed. For if it is their perceptions of the market position they are in, on which market makers base their prices, it is in changes to these perceptions that adjustment of prices is to be sought for. The next chapter, therefore, turns to theory on information, perceptions, expectations, and learning. 
6

\section{Market Makers in Disequilibrium}

A part from featuring market makers that compete different from perfectly, a meaningfil theory of disequilibrium behavior acknowledges that individuals are generally less than fully informed about the economy in which they operate. In light of the fact that they do not have perfect information, let alone complete insight or even perfect foresight, into economic phenomena and their possible future developments, yet do have to make decisions on trade, consumption, production, and investment, individuals form expectations of the relevant aspects thereof. They do so on the basis of general knowledge and beliefs they deduced from past experiences, acquired data, or learned theories. These form their perception of the world. Necessarily, these perceptions are subjective, and correspond to various degrees to the objective state of affairs. Moreover, over time the relationship between objective and subjective worlds changes, through newly gained experiences, purchased information, or education.

In the theories of monopolistic competition in general equilibrium surveyed in the previous chapter, an essential role is played by subjective perceptions. Existence of general monopolistic equilibrium rests importantly on subjective demand and supply relations, that are only mildly restricted. Yet, monopolistically competitive equilibria are importantly characterized by the expectations of rationing constraints that people (and firms) have, and to which they accommodate their plans. The theories that individuals hold of the economy they live in, in other words, are essential for a theory of economics.

With the acknowledgment of the role of beliefs comes the need to investigate the stability of any particular structure of individually held beliefs. The question of which perceptions can be the stable result of a disequilibrium process of learning is, in fact, of direct importance once the existence of equilibria is established. It helps to identify relevant equilibria among the generally many possible. Obviously, the relevance of equilibria that rest on perceptions that are easily detected as false, have less promi- 
nence than those that find general confirmation. The need therefore rises to identify relevant and less relevant equilibria, or better, the relevant equilibrium among many potential equilibria.

Such identification requires insight into how beliefs are formed and modified through learning from experience, or otherwise. This is were a full disequilibrium theory is to have its foundation. This chapter considers theory on expectations, their disappointment and modification through learning. It is a survey in search of means to substantiate disequilibrium behavior with theory of learning outside of equilibrium.

The chapter is organized as follows. The next section considers seminal ideas on the role of expectations in intertemporal choice that developed in the early 1930's. The way in which they entered general equilibrium theory is considered in Section 6.2. Section 6.3 discusses the rational expectations hypothesis. Section 6.4 presents a literature that sought to classify subjective perceptions, that on conjectural variations. Neither of these approaches helps to understand disequilibrium behavior. In Section 6.5 an early link between Benassy's model of perceived rationing and perception changes, established by Fisher is presented. Full recognition of a crucial element for understanding disequilibrium behavior, the ability of individuall agents to recogrnize that their economy is disharmonious and to take appropriate action is also attributable to him, and taken up in Section 6.6. In Section 6.7 similarly rich ideas in a school of thought with some history, the Austrian school of thought, are set out. In Section 6.8 a recent and large literature on learning is briefly surveyed. This literature considers how beliefs change when expectations are disappointed. It offers tools to constructively model learning im modern economics. Section 6.9 concludes.

\subsection{The Stockholm School of Thought}

The role of individual perceptions and expectations, and their divergence between individuals as well as with the true state of affairs were a concern of Walras. Walras refers to the importance of expectations of future earnings in planning to invest in capital goods. With the minds of individuals on these matters made up, however, he relied on the "law of offer and demand" to establish "rates of net income" to establish equality in the exchange of capital. Similarly, Marshall addressed the role of expectations in the context of investments. ${ }^{1}$ That the influence of expectations on economic activity was much bronder, however, was only fully realized and systematically studied in the early 1930 's. In this, a crucial role was played by ideas that developed in the Stockholm school.

The Stockholm school of thought flourished between approximately 1925 and 1940 . Prominent members were Myrdal, Lindahl, Lundberg and Bertil Ohlin-who coined the school's name in 1937. Although credits to Hayek, Hicks and Samuelson cam be traced in their work, members of the school made seminal contributions to the analysis of intertemporal and temporary equilibrium, as well as to the disentangling of equilibrium and disequilibrium notions.

I Cf. Walras (1954), pp.310-11 and Marshall (1920), pp.292-3. 
The development of thought in the Stockholm School on dynamic theory can both theoretically and chronologically be divided in three stages, centering around equilibrium, disequilibrium and sequence analysis respectively. The foundation of the school was given in Myrdal's 1927 dissertation in Swedish, published in 1932 as The Problen of Price Formation and Change. The core idea of this book is that individuals" anticipations of future stages of the economic system in which they act have a direct influence on the development of that system. It extended on Cassel's 1918 general equilibrium analysis in Theoretische Sozialökonomie, which provided a representation of Walras" original work with which Myrdal felt a discomfort. ${ }^{2}$

Myrdal instigated the introduction of expectations as variables in the formulation of equilibrium models, an idea which was taken over by Lindahl in his development of intertemporal, and later temporary equilibrium. The core notion of the concept of intertemporal equilibrium is that commodities are, among other things, defined by the date of their existence, and hence preferences and production techniques stretch out over time, which gives rise to general equilibria with various equilibrium prices for physically or locationally identical goods, and hence a price for time lapses. As noted in Chapter 3, this insight was stressed as well by Hayek, who used it in a 1928 article to explain interest rates. Both influenced Hicks through the Robbinsian circle at the London School of Economics in the 1930's, who developed the model of intertemporal equilibrium that found its present day form in Debreu (1959).

Although intertemporal equilibrium models include an element of time, by construction their dynamic nature is neutralized in the sense that every present and future aclion of every individual is known before time unfolds. To accommodate for this, lindahl developed the concept of temporary equilibrium, in which changes in the underlying fundamentals of the model--including anticipations of future values-give rise to the need to recalculate equilibrium over time. Inherently, this approach demands the division of time in periods, during which changes are either negligible or collected in order to change the system in the new equilibrium at its intervals. Again, the modern development of this concept includes Hicks' 1939 Value and Capital, in which the monday morning is reserved for recalculation, and eventually culminated in Jean-Michel Grandmont's 1977 Econometrica article "Temponary General Equilibrium Theory."

The equilibrium nature of both the intertemporal and the temporary extensions of the Walras-Cassel general equilibrium model was criticized by founding father Myrdal, and later by Lindahl's student Lundberg, who felt that the study of successive equilibria begged the real dynamic question of the accommodation of equilibrium systems to clianges in the underlying characteristics of the economy, as well as questions of stability. These critiques subsequently developed into the second and most outstanding wontribution to the Stockholm School, the construction of the so-called 'ex ante/ex post calculus', which founded the school's disequilibrium approach.

The centrall idea in the ex ante/ex post calculus, attributed to Myrdal's 1931 Moneiary Equilibrium-so translated in 1939-is that exogenous and falsely anticipated changes in the value of various magnitudes drive a wedge between what ex ante are

2 Cf. Hansson (1987), an anthoritative text on the Stockholm school. 
considered by individuals to be optimal actions, and what ex post Consequenty, peo ple generally want to change their ex ante plans ex post. Analysis should, therefore, focus on conditions under which such changes would eventually accommodate equal. ity between the two. Particularly, such would provide a structure to the study of the behavior of prices among which the rate of interest, which was the focal point of especially Myrdal and Ohlin.

The study of the monday moming processes with ex post/ex anie calculus empha. sized questions conceming the divisiom of weeks. Naturally, the length of a period sws taken best to correspond with the duration of unchanged plans. Yet, it was recognizex that changes in the plans of various individuals overlap, which gives rise to a constant flow of disequilibria and adaptations. Study of such series of either equilibria disequilibria or combinations of the two founded a third pillar of Stockholm thought, sequence analysis. Originally, Lindahl had formulated an equilibrium sequence analy. sis, seminally in an umpublished four pages paper titled Note on the Dynamic Prican Problem. A reactionary disequilibrium sequence analysis was offered at the close of the Stockholm School's heyday's by Lundberg."

Lundberg made his debut in economic theory in 1937 with Studies in the Theory of Economic Expansion. "The monograph substantiates both need and methods for modelling sequences of disequilibria for understanding econonic development. It was received quite well, and got various reviews, among which a highly faxorable one by Lange in Economica. Apart from the extensive and remarkably clear discussion of the need for disequilibrium analysis in a general equilibrium context, and a discussion of the problem of selecting a 'unit period' - to both of which reference was made in Chapter 1, the core of the book consists of a discussion of a rather complicated investment model in which a central role is played by the difference between the timing of production outlays and the availability of returns from investment for consumption. Disharmonious developments of these two concepts over time give rise to series of disequilibria and instability.

Anticipations provide the dynamic causal relationships which give rise to these. In disequilibrim, they are out of tune, so that simultaneously losses and profitexist, under and over the costs of production. ${ }^{\circ}$ On the dyamics of this, Lundberg wrote:

"T) The ultmate aim of the analysis is to investigate to what an extent, and under what conditions, the private undertaking and the individual economic initiative tend toward stable development or not." (op.cit, p.149)

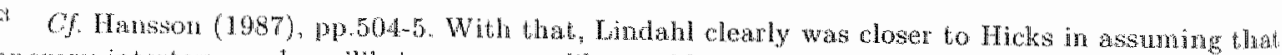

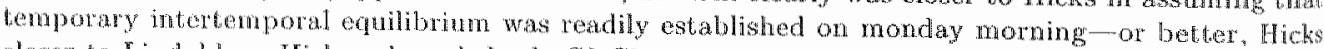
closer to lindshl, as Ficks acknowledged. Cf. Chapter 3.

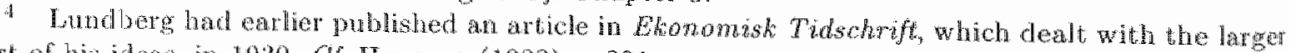
part of his ictas, in 1930. Cf. Hansson (1982), p.221

Davorde at least on the subject matter, as oposed to the presentation, which Large right considered to wathe the book "no easy reading " Of Large (1936), p.247.

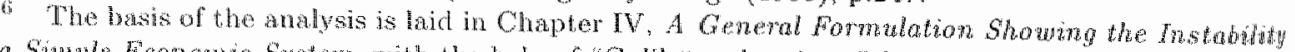

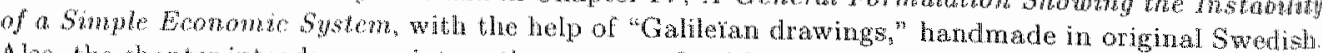

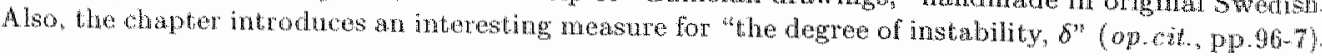


The key to the study of that initiative are investments out of savings. The latter are taken to be an invarialo fraction of total production in each period, i.e., the propensity to save is constant, and hence independent of the interest rate. The determination of the former is Lundberg's object of study, and done on the basis of the ex ante plans behind the investment behavior of market participants, which are in turn based on expected costs. It is here that Lundberg deviates from Keynes' structure, his reference, as he states:

"In order to explain the changes in the capital of the undertaking it is necessary to observe these from the point of view of the plans and operations of the entrepreneurs. Keynes can only calculate the value of the capital at the end of a period as a result of changes during the period in accordance with his definitions of savings and investment. As has been shown above, the construction of a sequence analysis is made impossible by the exclusive use of such ex post items, because this very sequence analysis is to explain, among other things, the actual changes in the value (and amount) of the capilal. If, instead, the planned changes in the amount of the capital of the undertaking in question are taken as the starting point, it means simply a logical continuation of the problem as formulated, when we ask how this investment is planned, i.e., on the basis of what costs." (op.cit., p.153, emphasis in original, note deleted)

The chapter then continues with a classification of various costs which form the basis of investment plans. It is deviations of the real values of these various forms of costs from the ex ante expected costs, which generate over- or under-savings investments, and hence disequilibria. Stable equilibrium will prevail when profits and deficits will be zero and the anticipated optimal plans of the various entrepreneurs are realized "in toto. $"$ "?

To study the global asymptotic stability of the economy, therefore, the causal relationship between realized values and new ex ante planned action reeds to be studied, r.e., the stability matter boils down to matter of expectations. Somewhat stronger, Lundberg states:

"The introduction of expectations can, in a way, be said to mark the stepping stone to dynamic analysis, because they express the connection linking present plans and activities with future events. (...) Total lack of correlation here would mean the complete liquidation of economics as a science." (op.cit., p. 175)

In Chapter VIII, Causal Elements in the System with Special Regand to Determining the Volume of Investments, Lundberg (1937) turns to the specification of expectation formation. Acknowledging that such narrows down his analysis importantly, Lundberg: specialized expectation to be formed by given functions "expressing the reactions by different groups of producers to changes in prices, orders, gains and losses." These

Op.cil., p. 162 
functions are "supposed to express average conditions for these groups, averages which cancel internal differences between firms and producers". 8

In Chapter IX these allow Lundberg to design several numerical sequences, in a series of simulation experiments. It is these simulations Lange (1936) considers to be "the most important part of the book". Their results are presented in various tables and graphs in which the, generally converging, disequilibrium development of precisely specified formal versions of the general model structure laid out above is set out. On the basis of them, an extensive sensitivity analysis of the various dependence relations is made, after which the book closes with a concluding chapter, which re-emphasizes the importance of disequilibrium analysis to the understanding of economic development.

Of conrse, criticism can be directed towards the aggregate and fixed nature of individual expectations applied -as, in fact, to other aspects of the model, like investments, consumption, and especially the specification of the unit period. These methods are rather rudimentary indeed. ${ }^{10}$ However, analyses in aggregates were the common approach at the time. "Instead, Lundberg's book should be seen as far ahead of its time. It is based on a clear definition of equilibrium as a situation where plans match, and its sequence analyses are a full-blown disequilibrium theory, concerned with asymptotic stability issues and carried by expectations, their falsification and adjustment. On the latter, Lundberg concludes:

\begin{abstract}
"In an econornic system with a great number of independent individual producers "the space of expansion" must, therefore, be judged by each producer on the basis of his experience during a past period without definite knowledge of what might be the effect of changed operations during the current period. (...) At the beginning of each period the producer makes a market analysis which tells him the increase (or decrease) in the demand for his product during the period just ended as compared with the estimate gerade termines waresponding revision of plans and operations. The producers when wathe production or bid up the prices on the factors of production, or both, wnit calculated costs, that is the total supply price, have reached the atmit $_{2}$ hetermined by his estimate of future receipts." (op.cit., p. 190)
\end{abstract}

The fundamental problems here raised, and the clear suggestions towards their solution, would be neglected in general equilibrium theory for decades to come.

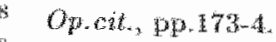

9) Op.cit., pp.24ter.

16) A rather confused critique to Lundberg"s specification of expectations is given in Hansson (1987), who holds that such fixed mexns to form expectations can only offer an equilibrim analysis. This, of course, mudalles up the definition of equilibrium. Cf op, cat., p.505.

11. For that matter, Lundberg is fully aware of these limitations and stresses the possibility to form "sub-groups" with which to break the analysis down to a more accetable micro-level (abid.). 


\subsection{Expectations and General Equilibrium}

Through Hicks, Frisch' Stockholm affiliation, and Samuelson, ideas of the Stockholm School entered into the modern general equilibrium model of intertemporal equilibrim. "These authors, however, put emphasis on the study of intertemporal equilibrium, and consequently on the role of expectations therein-as was set out in Chapter 3 . In equilibrium, expectations are fulfilled, thus making plans match. Equilibrium expectations therefore are invariant, or static. Towards the end of Value and Capital, Hicks did offer a discussion on differences between true price development and its expectation, referred to as the "elasticity of expectations," but it is only to prepare the concept of temporary equilibrium. Expectations do not enter the discussion on 'truly dynamic stability". ${ }^{12}$

Among the first to criticize this-as eloquently as ever-was Halın, who published an article titled "Expectations and Equilibrium" in 1952 in Economic Joumal. Hahn hailed the dynamic theory involving time developed in Samuelson's Foundations as an important development that has led to progress and new insights. Yet, he observed that these theories are rather mechanic and

«... have been characterized by a great deal of formal mathematics and relatively little economics, and nowhere is this more true than in the discussion of dynamic equilibrium and dynamic stability conditions. (...) Especially the role of expectations ..., once the hall-mark of dynamic theory, has been almost entirely neglected." (op.cit., p.802)

The article sets out to discuss the role of expectations proper to a theory of intertemporal equilibrium. To that end, it first elaborates on the correct definition of equilibrium. On this, Hahn remarked:

"Much of what we have to say is as old as, say, the oldest living Swede ...." (ibid.)

yet demanded re-establishment.

A dynamic equilibrium is then described as a situation where plans and expectations that stretch out over time are fulfilled, and hence can go unchanged. A model to that effect is subsequently developed and Hahn takes great pains arguing that equilibrium does not necessarily imply that expectations are constant or routinely formed. Quite the contrary, expectations can take many forms, and moreover, in light of unexpected experiences, they are to change if a new dynamic equilibrium is to be established.

The perspective thus gained, Hahn applied to criticize contemporary writing by Richard Goodwin, Roy Harrod and Hicks. Since it is disappointed expectations and their modification that are characteristics or disequilibrium, and their convergence to harmony with events that is to establish stability, it is here that adjustment processes are to be founded. Stability analysis in multiplier models or cobweb models do nothing of that kind, Hahn observed. They assume equilibrium expectations while deriving 
disequilibrium features. Therefore, Hahn seriously questioned the insight into business cycles these models could provide. ${ }^{13}$ After going through the logic of these models that time and again producers increase supply in response to high prices by too much, and in when prices are low they decrease supply too far, Hahn asked:

"Is it really supposed that modern businessmen or even farmers will not learn from this? Surely before long, when prices rise, the repeated experience of overproduction will induce the individual producers to increase their supply by less than they would otherwise have done, and reduce their supply by less when prices fall.." (op.cit., p.817, note deleted)

And he concluded that learning in the long-run may well stabilize economies that display short-run fluctuations:

"The case which is here pleaded is the importance of a distinction between short-run and long-run stability. A system possessing short-run stability, provided its parameters remain the same, is also likely to possess longrun stability. But the reverse is not true -short run instability does not necessarily imply long-run instability." (op.cit., pp.817-8)

In the model of general equilibrium developed towards the end of the 1950's, the introduction of more sophisticated than naive expectations was taken up-notablyby Arrow, in two early contributions. The first, titled "A Theorem on Expectations and the Stability of Equilibrium," co-authored by Alain Enthovem was published in 1956, the second, co-authored by Marc Nerlove, published as "A Note on Expectations and Stability," in 1958, both in Econometrica.

The 1956 article opens with an observation similar to Hahn's, that stability issues in the general competitive equilibrium models of Hicks (1939) and Samuelson (1941, 1944) are discussed in the context of static expectations only. The article then sets out to study stability under "extrapolative" expectations-where reference is made to a conjecture in Hicks (1939) to the effect that such expectations would generally obstruct temporary equilibrium. ${ }^{14}$

To be more precise, Enthoven and Arrow (1956) considers the local tatomnement stability of a general equilibrium model in which aggregate demand for a commodity is based not only on all current prices, but also on its own expected future price-this setup exclucles 'cross effects' of price expectations, to be studied later. Expectations on future prices are formed in a way captured in the following equation. ${ }^{15}$

$$
p_{j}^{*}=p_{j}+\eta_{j} \frac{\partial p_{j}}{\partial t}, \text { for all } j=1, \ldots, m
$$

in which $\eta_{j}$ is a constant.

Hence, the expected future price is equal to the current price, adjusted for foreseen price dynamics. The latter, $\frac{\partial p_{j}}{\partial t}$, is of the Samuelsomian type, that is, it is a

13 Op.cit. pp.815-7.

14 Op.cit., p.288, particularly note 2.

is Op.cit., p.290- the notation has been altered slightly. 
sign-preserving continuous function of aggregate excess demand-in the following the constants $v_{j}$. Note that in these, expectations play a role again. If $\eta_{j}=0$, current prices are expected to rule in the future. If $\eta_{j}<0$, expected prices lag behind the current ones, which is taken to be "conservative," and for $\eta_{j}>0$ expectations are "extrapolative."

The local stability of the price system thus obtained is analyzed by feeding the price dynamics back into the formation of excess demand, taking the Taylor approximation around an equilibrium where $\frac{\partial p_{j}}{\partial t}=0$ for all $j$, and analyzing the characteristic roots of the Jacobian for that system. The result established is that the equilibrium thus imvestigated is locally stable with these expectations, under the necessary and sufficient condition that the destabilizing effects of especially extrapolative expectations is oflset by sufficient insensitivity of the price adjustment to changes in excess demand, which reads

$$
\frac{1}{v_{j}}>\eta_{j} \frac{\partial z_{j}}{\partial p_{j}^{*}}, \text { for all } j=1, \ldots, m
$$

Hence, the larger the speed of adjustment, the smaller the combined effects of changes in expectations resulting from price changes and the effect of these changes on aggregate excess demand need to be. ${ }^{16}$

Arrow and Nerlove (1958) extends this result by allowing cross-effects of price expectations on excess demand. Moreover, a different form of expectations is introduced, as follows.

$$
\frac{\partial p_{j}^{*}}{\partial t}=\beta_{j}\left(p_{j}-p_{j}^{*}\right), \text { for all } j=1, \ldots, m,
$$

where the $\beta_{j}$ are constants all larger than or equal to zero. ${ }^{17}$

Hence, the expected price changes according to the difference between the current price and the previously formed expectation of that price, that is, adaptively. The assumption that $\beta_{j} \geq 0$ assures that new expectations are formed to close the wedge between expected and realized values.

By applying a strategy identical to that of the 1956 article, Arrow and Nerlove proof that in a system as theirs under adaptive expectations and thatonnement price adjustment, any equilibrium is locally stable if the equivalent system under static expectations is locally stable, independently of the values of the other parameters, as long as $v_{j}>0$ and $\beta_{j} \geq 0$. Hence, adaptive expectations with cross-effects in the formulation of demand has no influence on local stability analysis, as long as expectations are adapted in the direction of past mistakes.

These early analyses are in the local stability tradition of Hicks and Samuelson. Reasoning is set up from the perspective of equilibrium, in which, in fact, expectations have little role to play, as by construction they come out fulfilled. An extension to global stability analysis, however, was soon offered by Arrow and Hurwicz in a 1962 article in the International Economic Review. The article first sets out the Arrow et al.

I op.cit. 299. 
(1959) analysis of global stability of the tâtonnement process without expectations-in its heyday at the time - which is shown to be globally asymptotically stable under gross-substitutability of aggregate excess demand. In the second part of the paper, this analysis is extended by allowing aggregate excess demand to be a function of expected prices, and having expected prices change adaptively, as above. This disequilibrium dynamics is shown to be globally asymptotically stable under gross-substitutability still. $^{18}$

Finally, in keeping with the developments in global stability theory, soon a trading process analysis was offered. Negishi published "The Stability of Exchange and Adaptive Expectations" in 1964 in the International Economic Review. In the article price and expectations dynamics as described above is coupled with trade at disequilibrium prices. The system thus obtained is shown to be globally asymptotically stable as trading processes in which expectations have no role. ${ }^{19}$

However interesting these early results are in showing that the local and global stability results of that time are robust against the introduction of adaptive expectations under acceptable conditions, they are, of course, open to the critique and problems of global stability theory. They rely, in other words, on a homunculus approach again, from which in expectations a departure was sought for. Expectations and their adjustment are supplementary to Samuelsonian price dynamics, and not considered for the substitute they potentially offer. Moreover, these early theories do not address the processes by which expectations are formed and modified very satisfactory, in that they do not offer an explanation for the changes in expectations considered.

\subsection{On the Rational Expectations Hypothesis}

The tension between fixed structurally specified adjustments of expectations in the short-run and long-run modifications thereof, is also the concern of the rational expectations approach. A critique to traditional mechanistic expectations, similar to Hahn's was formulated by Muth in his 1961 Econometrica article "Rational Expectations and the Theory of Price Movements." Muth introduced his paper as follows.

"That expectations of economic variables may be subject to error has, for some time, been recognized as an important part of most explanations of changes in the level of business activity. The "ex ante" analysis of the Stockholm School-although it has created its fair share of confusionis a highly suggestive approach to short-run problems. It has undoubtedly been a major motivation for studies of business expectations and intentions data." (op.cik., p.315)

He believed however that:

"As a systematic theory of fluctuations in markets or in the economy, the approach is limited ... because it does not include an explanation of the 
way expectations are formed. To make dynamic economic models complete, warions expectations formulas have been used. There is, however, little evidence to suggest that the presumed relations bear a resemblance to the way the economy works." (ibid., note deleted.)

In a note, this critique is extended to the modelling of disequilibrium dynamics in tâtonmement stability theory, with reference to Arrow at al. (1959).

As an alternative, Muth proposed the so-called 'rational expectations hypothesis'. It is a radical position in the debate Hahn started-and orthogonal to Hahn's own. The rational expectations hypothesis of Muth holds that the expectations of individwal consumers and firms are essentially the same as the predictions of the relevant economic theory. That is, individuals in a model have perfect objective knowledge of the economy they people. ${ }^{20}$

Muth (1961) stresses that rational expectations thus defined do not necessarily imply that expectations are perfect. To substantiate that claim, the article discusses extensively a variant of the cobweb model with a linear supply and demand funcm tion. Demand is determined, yet in the supply relation an error term appears, that is normally distributed with expected value zero. Various types of expectations are considered in this setup. They lead to different predictions, including cycling of prices and quantities outside of equilibrium. Rational expectations are, however, that these deviations are equal. to zero in expected value. As a consequence, whereas static and adaptive expectations generally send the system off on a disequilibrium adjustment path upon each one of the exogenous shocks, rational expectations do not. Shocks are publicly known to cancel out on average, and are therefore ignored.

Just like the objective demand approach in the literature on monopolistic competition in a general equilibrium context, the rational expectations approach seeks to identify the "true' and 'correct" expectations and equilibria in a model. "These are considered the appropriate 'long-run' equilibria. Just like objective demand, the rational expectations hypothesis thereby begs questions of disequilibrium. Perfect and complete information on the side of all individuals necessarily results in equilibrium behavior. In a partial system with exogenous shocks, the assumption may still amount to an. interesting analysis. In a closed system, however, in which only endogenous instability can exist-that is, in general equilibrium models-it straightforwardly implies that: expectations are perfect, so that there is no room for disequilibrium theory. ${ }^{21}$

\footnotetext{
20 Cf. op.cit, p.316.
}

21 It requires no testimony that the rational expectation approach became wery infuential, and is, in fact, dominant today, particularly in macroeconomic theory and econometrics. It led away from the bype of Keynesian equilibrium analysis offered by, among others, Benassy. See Lucas and Sargent (1981) For a collection of classical papers, and Blanchard and Fischer (1989) for its impact on modern macroeconomics. In the gemeral equilibrium context, results on the existence of rational expectations equilibria were esiablished by Radner $(1972,1979)$. 


\subsection{Conjectural Variations}

The Negish-Benassy literature on monopolistic competition with subjective conjectures is thus re-established as the appropriate framework for a study of individually rational disequilibrium behavior and learning. As there is no objective sense in which these conjectures are correct, the question rises in what sense they can nevertheless be categorized as 'rational' or 'reasonable'. It has been entertained in a literature on conjectural variations, which established some general conditions on firms' considerations concerning rivals' reactions, that is, on perceptions of perceptions.

Conjectures are said to be 'rational', and firms in 'rational conjectural equilibrium:. if no firm can improve its position by choosing a deviation from the equilibrium action, given the expectation it has of the reaction of its opponent, given the expectation the other firms have of the original firm's actions at equilibrium. At a rational conjectural equilibrium, therefore, acting according to the expectations of others, given the own expectations of all rivals' actions given their expectations of its actions, makes each firm better off. ${ }^{22}$ Consequently, it is always better to fulfill the expectations of others, and hence expectations are always correct in the sense that they come true for all.

In the notation of the Negishi model - in the context of which the literature on conjectural variations developed-the requirement of rational conjectures implies a modification of the definition of equilibrium. Recall that in its most general formthat is before Negishi specializes to linear forms-the conjectured inverse firm-specific demand and supply functions in Negishi (1961b) read

$$
p_{j}^{*}=X_{k j}^{*}\left(y_{k j}^{*} \mid I_{k j}\right),
$$

where $I_{k j}=\left(p, \sum_{i=1}^{n} x_{i j}-\sum_{k^{\prime} \neq k}^{r} y_{k^{\prime} j}\right)$ is the information firm $k$ has on prices and gross demand and production of commodity $j$, introduced here for notational convenience. A modification of Definition 5.1 to a general monopolistically competitive rational conjectural equilibrium adds the following condition. ${ }^{23}$

(v) $\left(y_{k, j},\left(y_{k^{\prime} j}\right)_{k^{\prime} \neq k}\right)=\left(y_{k_{j},}^{*},\left(y_{k^{\prime} j}^{*}\right)_{k^{\prime} \neq k}\right)$ such that

$$
y_{k_{j} j}^{*}+\sum_{k^{\prime} \neq k}^{r} y_{k^{\prime} j}^{*}=x_{j}\left(\left(X_{k j}^{*}\left(y_{k, j}^{*} \mid I_{k j}\right)\right)_{j}\right)
$$

and each $y_{k} ; j$ maximizes

$$
\sum_{j \in J^{k^{\prime}}}^{m} X_{k^{\prime} j}^{*}\left(y_{k^{*}, j} \mid\left(X_{k, j}^{*}\left(y_{k_{j}}^{*} \mid I_{k j}\right)\right)_{j}, \sum_{i=1}^{m} x_{i j}-\sum_{k \neq k^{\prime}}^{n^{*}} y_{k, j}\right) y_{k^{\prime} j}+\sum_{j \notin J^{k^{\prime}}} p_{j} y_{k^{\prime}, j},
$$

subject to $y_{k^{\prime}} \in Y_{k^{\prime}}$.

\footnotetext{
2 Cf Hahn (1989a), p.100.

23 This and the rext modification of Definition 5.1 are inspired by Hart's 1985 discussion--which is limited to a partial equilibrium setting. They apply equally to K-equilibria, for general conjectures.
} 
This additional condition states that if a firm $k$ plans on deviating from its status quo production and it conjectures a certain price effect of that deviation, than that conjectured price effect is equal to the real price effect since there exist production plans for all rival firms, which maximize profits for them for the prices they conjecture, given their know ledge of the price firm $k$ conjectures, which clear the market, and which all firms will consequenty choose as best production plans. Since profits are maximized in the equilibrium, however, no fim has an incentive to change production plans, and hence the equilibrium is a rational conjectural equilibrium. As long as each firm acts according to its conjecture-and in equilibrum it would be particularly unwise not to - all conjectures come true and are therefore correct in that sense.

Reasonable conjectures were introduced in Hahn (1977) and Hahn (1978) to weaken the strict requirement of rationality. A reasonable conjecture is one which when acted upon provides the largest profit relative to that obtainable by following a different conjecture, given the conjectures of all other firms. A modification of Definition 5. 1 to genenal monopolistically competitive reasonable conjectural equlibrim adds instead of condition ( $v$ ) above the following.

$(v)^{\prime}$ thene is no $\left(p^{\prime}, y_{k}^{\prime}\right)$ satisfying conditions $(i)$-(iv) such that

$$
\sum_{j=1}^{m} p_{j}^{r} y_{k j}^{\prime}>\sum_{j=1}^{m} p_{j} y_{k j} \text { subject to } y_{k}^{\prime} \in Y_{k}
$$

Hence, for each firm it holds that if all rival frms consolidate their equilibrimm actions, based on their conjectures, it is profit maximizing to follow the private conjecture as well. Since that holds for each firm, each firm will do so. Reasonable conjectures can be conjectures that are incorrect in the sense that the firm that holds them knows they are not correct. That is, that they turn out to be false all the time. Yet, they are reasonable since it is better to stick to them than to deviate.

Both these types of conjectures introduce a different level of information, namely knowledge of the conjectures and reactions of all other decision makers. This is clearly demanding. Note, however, that, even though rational conjectures are oftea referred to as 'correct" the concept-nor that of reasonable conjectures, for that matter-requires that there be correspondence between objective demand and subjectively conjectured demand. Conjectures held by rival firms that do not correspond with reality can be perfectly rational or reasonable, and consequently classified as 'correct', even if they are subjectively known to be objectively false. The only thing that matters is that firms have correct knowledge at ecuilibrium of the conjectures of all others. In that, the requirement that conjectures are reasonable is weaker than that they are rational in that it allows a difference between various subjective truths, as well as between subjective and objective truths.

Out of the many conjectural equilibria that consistency of conjectures leaves, reasonable and rational conjectural equilibria make larger and smaller selections. Yet they both leave open the possibility that outside of equilibrium beliefs may be wildly of the mark. Both, in other words, are equilibrium concepts, within the confines of subjective knowledge. They offer no handles outside of equilibrium, when firms do not have the information to establish conjectural equilibrium. 
To see the importance of this, consider the following, which extends on an example given in Chapter 1 . In a standard Cournot duopoly model with a linear downward sloping demand function and constant marginal costs, either both firms have complete knowledge of demand, as well as of the rival's costs structure, or they do not. If they do, this is model of objective demand. Hence, both frms realize that the best they can do is produce the unique Nash equilibrium quantity, and so they will. At that. equilibrium, the Cournot hypotheses that both firms assume the quantity of the other firm is constant is correct. Hence, the Cournot hypothesis is a rational conjecture-and so is the Cournot bypothesis when frms set quantities. The same is true in the general monopolistically competitive equilibrium models with objective demand discussed in the previous subsection. ${ }^{24}$

When firms do not have full objective information, nor full subjective information, however, they will not be able to establish equilibrium strategies right away, and hence generally set a disequilibrium price. At any particular such price, the Counnot hypothesis is obviously false, as the rival firm will react with a different price. Which one, and how it came to set it is a matter of its beliefs and their modification in the light of disequilibrium evidence. The point is again that only with incomplete information variations from the standard conjectures are meaningful.

The conjectural variations literature, although it acknowledges that the theories that individuals in theories hold matter and shows that conjectures can be different from the objective truth, yet rational, takes a step back from the insight that full information is too much to ask for. It saves equilibrium analysis by assuming full information on a new level, namely information of infomation. The central problem: however, is to consider behavior out of some initial ignorance and to understand if people can ever begin to see the light.

\subsection{Adjusting Conjectures}

Despite the fact that Benassy analyzes existence of monopolistically competitive equilibria only, his work offers a firm structure for insight into true disequilibrium behavior. In fact, Benassy's implicit model of disequilibrium behavior is very close to the Ifalun process discussed in Chapter 3 . That is, trade takes place at disecuilibrium prices, and markets are orderly, in the sense that at each price all trade opportunities are exploited before prices change again. Also, at each price vector quid pro quo is satisfied. Moreover, trade takes place for money only, of which a positive amount in cash is part of the individual planning process, thus founding the positive cash assumption necessary

24 In the diterature on industrial organization this is often muddled up. For example Martin (1904) discusses at length studies in which the wahe of $\alpha_{i}$, defined as

$$
\alpha_{i}=\frac{q_{i}}{q_{-i}} \frac{\partial q_{-i}}{\partial q_{i}}
$$

is estimated as different from zero-which is the Conrnot hypothesis. An interpretation is given to these walues as reflecting cooperative firms $\left(\alpha_{i}=1\right)$ and competitive firms $\left(\alpha_{i}=-1\right)$. Cf. op.cit,
pp.126-9. 
for the Hahn process. The Benassy model is, in other words, a non-tatonnement-or better, trading process-version of the Negishi model. On the one hand, as a, result of this the Benassy model is open to the criticism on trading processes. On the other, a global stability result may well be found in connecting the two. Both lines find early contributions by Fisher at their origin.

The sole reference relating the stability literature to the work of Benassy is an article by Fisher, published in 1978 in Review of Ecomomic Studies and titled "Quantity Constraints, Spillovers and the Hahn Process" "25 It has already briefly been presented in Chapter 3 as an extension of the Hahn-process. In the article, Fisher picked up the research on stability matters in the Negishi model, that had been left for existence. Fisher observed on the work of, among others, Clower, Patinkin, Leijonhufvud, Barro and Grossman and Benassy - to all of whom he refers:

"Despite the fact that the subject is one of disequilibrium behaviour, however, most of the work has concentrated on showing the existence of such non-Walrasian equilibria and relatively little is known about the dynamic stability of adjustment processes in such models. (...) One principle purpose of the present paper, therefore, is to consider a relatively general model of stability under quantity constraints." (op.cit., p.19)

Athough reference is also made to Benassy (1976), the analysis Fisher presents is closest to the first type of $K$-equilibrium presented in the previous chapter. That is, the model of Benassy (1975), in which prices are fixed and only quantities adjust with changes in perceived rationings-which are independent of price. Fisher interprets the sequence of partially rationed effective trades that takes place in the moclel as disequilibrium behavior as similar to the Hahn process.

With this type of trading process, Fisher uses the Samuelsonian adjustment of prices. That is, for each commodity $j$

$$
\frac{\partial p_{j}}{\partial t}=H_{j}\left(\widetilde{z}_{j}\right)
$$

where $\widetilde{z}_{j}$ is the expressed notional aggregate excess denand after at going prices all potential trading opportunities among individuals have been exploited-and $H_{j}$ is a sign-preserving continuous function. With this assumption in place, Fisher shows quasi-stability applying the sum of target utilities as a Lyapoinov function. 26

25 In fact, the relationship between the work of Benasy and Fidner is exenplary for the dichotomy between uncroeconomics and macroecomomics. Botit anthors worked on perceived ationing, both as a result of dissatisfaction with existing general equilibrim theory. Both did so in the same period, and both published extensively in Review of Economic Sudues on their wesults. Both were students of wouding lathers of modem mucroeconomics-Benassy of Debren, and Fisher, although not liverally, of Hallin. Both also had their work at bout the same thme culminate in a book, published at year apart. Newertheles, apart from this one anticle, there are few il any cross references and their wonk is not treated in any tated way-with the notable exception of Hsieh and Mangum (1986). In retaspect. Fisher wtibutes this to "sloppiness". When he made the book, he had forgotten about the 1978 article firiwate comespondence). Yet, it seems the literature on neo-classical synthesis should have picked ap orit

26 Op.cit. 24 . Fon anothen application of the Hahn process where prices are supposed lio follow the Sarnelsonian equation, see Drèze (1991), Chapter 10. 
Although this extends the Hahn process in that it recognizes that when individuals perceive constraints they may not eventually end up in Walrasian equilibrium-Kequilibria are generally inefficient-it is a step back in the study of disequilibriumi without an auctioneer. Yet, it is no surprise that in the first Benassy model, Fisher needs to hark back to Samuelsonian price adjustment, as firms cannot be made responsible for it. ${ }^{27}$ After all, no price adjustment is accounted for in that model. In the full Benassy model, on the other hand, there is no guarantee that prices adjust according to aggregate excess demand, so that the strategy of proof of the Hahn process does not apply. Two earlier seminal contributions by Fisher are considered next, in which price setting is sought for in monopolistic competition, but which struggle with this problem. ${ }^{28}$

In 1972, in Review of Economic Studies, Fisher presented a very early - if not the first-working model upon the observation that a homunculus was offered for price adjustment in "On Price Adjustment without an Auctioneer." 29 The article develops a trading process in an exchange economy with two main features, that extend on Arrow and Hahn (1971). The first is that all trade is in money. The second that there is a social convention on the role that individuals play in the economy. That is, for each commodity either they are 'dealers' in it, who buy and sell, or they are 'customers'. 'This structure gives body to the organization of markets. It is

$$
\begin{aligned}
& \text { "... an attempt at playing Hamlet without the Prince of Norway." (op.cit, } \\
& \text { p.1) }
\end{aligned}
$$

The crucial difference between a dealer and a customer is in their respective roles in the disequilibrium process of meeting and transacting. Dealers are shop owners. They set prices and wait for customers to come by and buy or sell, up to their optimal amounts. Customers search among various shops, but are, as a result of the costs associated with it, bound to search anong a limited number only. They express their wishes and decide whether to accept the offers made. On the basis of their market. experience dealers then adjust their offers for the periods to come.

Several dealers can offer the same physical commodity, and are possibly located near to each other. That is, they compete on price. Customers do not know exactly, however, what dealer offers the best buy. They search among the offers of several dealers and selects the lowest price dealer to come to terms with. Due to the costs involved in this for customers, however, each dealer has a limited local monopoly

\footnotetext{
27 Also, the exposition is likely to have been inspired by Fisher's aim to have the Benassy type of models ond up in Walrasian equilibrimm, despite perceived ratoning. That is, to establish equilibrim where radioning constraints are perceived binding just on, or beyond, the efficient allocation. In fith sense, the Walrastan equilibrim is anong the K-equilibria. In fact, this is the second concern of Fisher (1978), next to the one expressed in the quote given above. It is discussed in Chapter 7 .

28 In his survey of stablity theory. Hahn (1982b) ends with these two early Fisher articles, so that the two research disciplines toud right hare.

29 The article extends on Fisher (1970), which offers a partial prequel. In the same issue of Reangu of Bronomic Strdies was Robert Barro's "A Theory of Monopolistic Price Adjustment, win which a partial equilibrimm model of a monopolist adjusting prices in the light of shocks to demand and ment-costs is conidered. It gained some fame, but does not consider disequilibrium adjustment.
} 
power. It is restricted, however, as customers search among a fairly large group of dealers.

Athough commodities over dealers may be identical in the Debreu-definition, Fisher: assumed that commodities are defined by dealer as well. As a consequence, each dealers, by construction, collects all supply and demand for his commodity in his shop. In that sense, markets are orderly. 30

Depending on the supply and demand monopolistically brought together by the dealers, they set prices, and either end up with unsold stock, or non-satiated customers. In any event, the orderly markets assumption necessary for the Hahn process comes quite naturally. In effect, for each shopkeeper, market excess demand is the shopkeper's excess demand, and it is either zero for the shopkeeper and of the same sign for all customen, or non-zero for the shopkeeper and zero for the customers.

What unfolds is a sequence of trade proposals to the dealers, price being set by them, transactions taking place up to the short side of the market, and new proposals being made from the new state of affairs. Outside of equilibrium, some individuals are rationed. Yet, they never reckon with this ex ante, that is, perceived constraints are not part of the individual planning problans. ${ }^{31}$ Clearly, since markets are orderly and quid pro quo holds naturally, this kind of disequilibrim trade dynamics resembles that in the Hahn process.

Apart from competitive equilibrium, a second type of equilibrium is distinguished for this model; 'quasi-equilibrium'. In both types of equilibrium, markets clear. Yet, whereas in "quasi-equilibrium' a single price is quoted for identical commodities that are only differentiated by dealer, these prices are not necessarily competitive. A substantial part of the paper discusses conditions under which quasi-equilibrium is identical to competitive equilibrium. It involves the requirement that dealers eventually come to perceive that they no longer have market power, not even locally - even when, in fact, they do have it.

The setup thus provided offers a clear structure for rational disequilibrium price adjustment. However, Fisher is led to assume the following.

"Every dealer believes that he faces a flat or almost flat demand curve and names that price which he believes to be the market price. If, after the search procedure just described, he finds a non-zero excess demand for his own wares, then he adjusts his price in the direction indicated by that excess demand." (op.cit., p.2)

The formalization of this is straightforward. Let $p_{j}^{d}$ be the price for commodity $j$ of

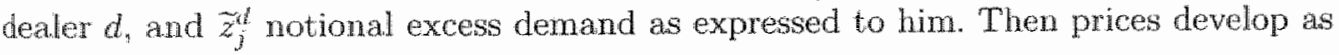

3h Althougly slightly more subtle, this is essentially the same as Benassy's and, for that matter, Negishi's assumption that each commodity is monopolistically traded in by one firm only.

3) Particularly in this respect Fishen (1983) extends the analysis importantly. This will be discussed in the next chapter. 
follows.

$$
\begin{aligned}
& \text { If } p_{j}^{d}>0, \text { or } p_{j}^{d}=0 \text { and } \widetilde{z}_{j}^{d} \geq 0, \text { then } \frac{\partial p_{j}^{d}}{\partial t}=F_{j}^{d}\left(\widetilde{z}_{j}^{d}\right), \text { and } \\
& \text { if } p_{j}^{d}=0 \text { and } \tilde{z}_{j}^{d}<0, \text { then } \frac{\partial p_{j}^{d}}{\partial t}=0,
\end{aligned}
$$

where $F_{j}^{d}$ are continuous and sign-preserving functions. ${ }^{32}$ On the basis of prices adjus ing this way, Figher (1972) presents a stability result on quasi-equilibrium or compe: tive equilibrium, in which the sum of individual target utilities serves as a Lyapom function. ${ }^{35}$

Clearly, the potential of the dealer construction to eliminate the homunculus not exploited with this type of price adjustment. Although supply and demand a reported to a player in the economy, price adjustment modelled is not based on ration behavior. Instead of operating like little auctioneers, dealers would do better exploitir their local market power to gain profits, as soon as they recognize it. Here the difficuli of making individually rational price setting compatible with the law of supply ar demand is irksome. Only the above assumptions guarantee global asymptotic stabili by the Hahn process reasoning.

Fisher (1972) concludes as follows.

"Once we abandon the fictitious auctioneer, the problem becomes richer. In some ways, that richness leads to greater difficulty; in some, I hope this paper shows, it facilitates analysis by making various assumptions relatively more reasonable. In the present model, that seemed true of the Hahn Process Assumption ... and the assumption of non-zero money stocks ... as well as of the nature of the adjustment process itself." (op.cit, p.15)

Yet, in the introduction, the objective problem of dealers is recognized:

"It would clearly be preferable to have clealers recognize that they are in disequilibrium and to adjust their prices in a way explicitly consistent with utility maximization. I have been unable to do this, however." (op.cit, p.2)

Fisher addressed such rational disequilibrium behavior, however, in a sequel articl published in 1973. This analysis is more special, in that the dynamics of a partic market model with monopolistically competing firms is studied. It considers the out come of a pool of competing suppliers of one homogeneous and perishable good-not that homogeneity excludes complicated cross-price effects, and perishability disequi librium income effects through trade at disequilibrium prices. Price adjustment result from a given and known downward sloping demand curve, reflecting invariable loca monopoly power as a result of limited search of consumers.

\section{0 p.ris., p. 7.}

33 Fon an axensive discussion of continuty and boundedness results deriving from the fact tha customers can switid between deaters, and rationing is "urexpected" see op cit. pp.8-10. Thastabilit tesult is on pages 13 and 14 . 
The article seeks to establish conditions under which, when all firms change their prices, at any given prices of the other firms, in the direction of their perceived profit maximizing price, prices converge to values that support a Nash equilibrium. That is, each firm takes, in a Bertrand fashion, the prices af all other suppliers as givens, determines its price $p_{j}^{*}$, and adjusts current price according to

$$
\frac{d p_{j}}{d t}=H_{j}\left(p_{j}^{*}-p_{j}\right)
$$

in which $H_{j}$ is a continuous and sign-preserving function.

This dynamic system is, of course, that of Lange (1944) and Negishi (1961b). The article is, in fact, a global stability analysis of monopolistically competing firms with objective knowledge of demand-in which, important to note, there are no spill-over effects from profits onto demand. It is, therefore, open to the obvious criticism that firms would be more inclined to set prices equal to $p_{j}^{*}$ in one shot. This Fisher counters with reference to adjustment costs. Also, of course, it is cuestionable why firms would not set Nash equilibrium prices immediately, as they have all the relevant knowledge required to do so.

Nevertheless, the conditions for global asymptotic stability are of interest. Where Negishi (1961b) rested with the gross-substitutability assumption, extended with the absexce of income effects through dividend payments, Fisher (1973) seelks for conditions on first principles. The core $i d e a$ is to establish a condition under which each individual firm's true equilibrium price is always in between any previously set price level and the newly perceived profit maximizing price level, and hence there is always an incentive for the individual firm to move in the direction of the system equilibnum. These newly perceived profit maximizing prices are derived from the residual demand curves faced by the individual firms and their marginal costs. Fisher (1973) studies various assumptions on the objective relationship between marginal costs and marginal revenues to establish the desired result.

The central assumption that guarantees the price constellation needed is, that for frms with prices which are low relative to the system equilibrium price, marginal revenues are lower than marginal costs, and hence they have an incentive to decrease output and increase price, whereas firms with a relatively high price face marginal revenues higher than marginal costs, and hence have an incentive to increase quantity and decrease price.

Although eventually this assumption is made for any price vector, it is also found in conditions on the spill-over effects between firm specific demand. The first states that the demand curve of a firm does not shift inward if any other firm increases prices, and does not shift outward if any other firm decreases its price. This boils down to non-negative cross-price effects between firms. The second assumption states that the demand of all firms is inversely related to the absolute price levels, i.e., for all firms demand shifts inward if all prices are increased proportionally, and vice versa for proportional price decreases. This assumption is related to the non-specified existence 
of other goods, and states a negative price effect between those commodities and the one under consideration. ${ }^{34}$

Generally, both assumptions guarantee that the marginal costs of a firm move appropriately with the prices of any other firm. However, no such conclusion can be drawn on the relationship with marginal revenues. Especially the possibility of changes in the elasticity of demand, gives rise to situations where marginal revenue increases with marginal costs in such a way that the profit maximizing point no longer lies in between the boundaries of the relative maximum and the relative minimum price-ie., relative to the system equilibrium price vector - which would provide the profit maximizing firms with an incentive to move away from the system equilibrium.

For firm $j$ the problem is illustrated in Figure 6.1 below.

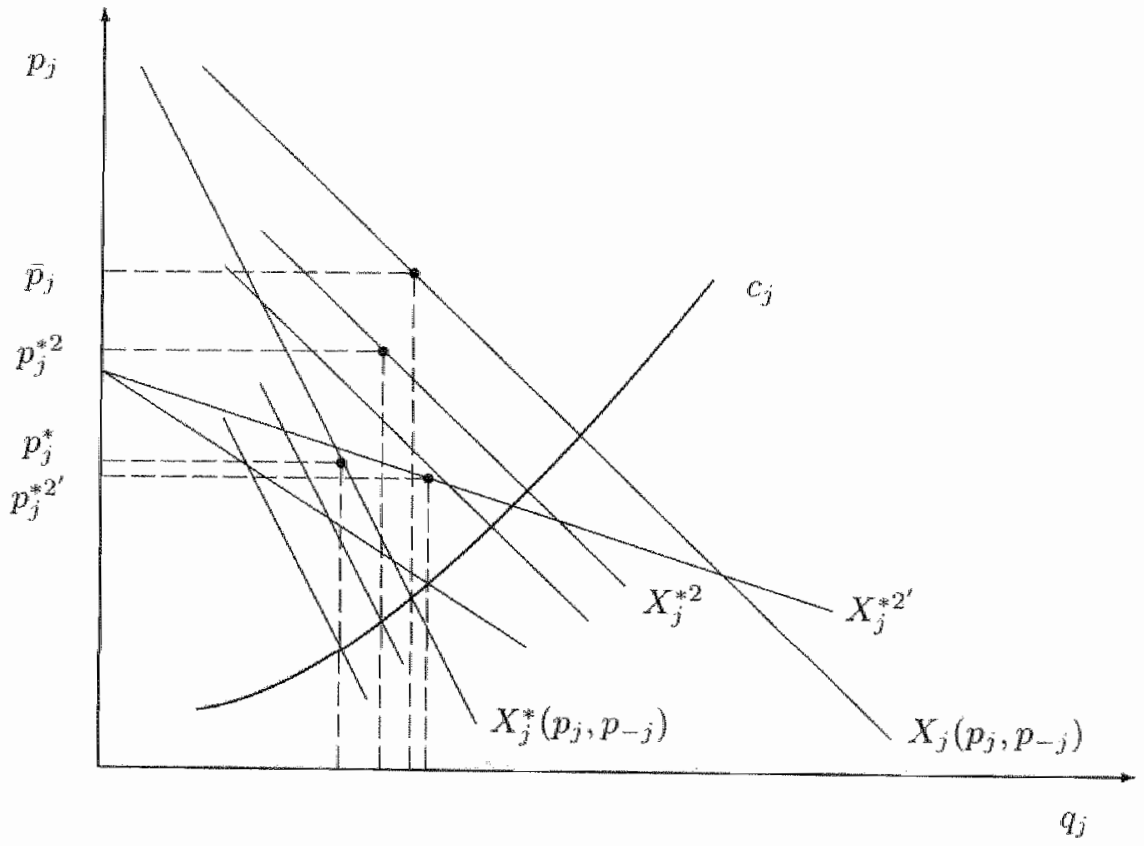

Figure 6.1 An illustration of a firm's trouble in establishing equilibrium price.

The firm specific marginal costs are $c_{j}$. They are known and invariable. $X_{j}\left(p_{j}, p_{-j}\right)$ represents the firm specific equilibrium demand curve, 2.e. demand faced at the Nash equilibrium $\bar{p} . X_{j}^{*}\left(p_{j}, p_{-j}\right)$ is an individually perceived demand curve, on the basis of which $p_{j}^{*}$ is set. Clearly, $p_{j}^{*}<\bar{p}_{j}$. Now assume that the difference between $p_{j}^{*}$ and $\bar{p}_{j}$

3 Note that the first assumption, for this one commodity-many firms model, is directly related the the gross-substitutability assumption of Negish (1961b), which studied many commodities, each supplied by only one firm. Cf. op.cit., p.454. 
is more than that between the individually perceived-and false-profit maximizing prices of all other firms to their respective system equilibrium prices. That is, firm $j$ 's price is far too low. The result of that situation is that firm $j$ 's 'next' demand curve $X_{j}^{2}\left(p_{j}, p_{-j}\right)$ lies to the right of the old perceived one, since customers move to firm $j$ for the low prices. On the basis of this new curve, the firm moves its price up in the direction of the system equilibrium price, and the system hence follows Lange's dynamics.

However, if the position of the demand curves changes relative to the equilibrium demand curve, the analysis runs into difficulties. Fisher particularly studies changes in the own price elasticity of the individual demand changes as a result of the price changes. Consider curve $X_{j}^{* 2^{\prime}}\left(p_{j}, p_{-j}\right)$, that reflects a change in the firm specific demand curve associated with an increased price elasticity. Clearly, the effect of this perception is a decrease in price, which moves the system away from equilibrium. For the relatively low prices firm $j$ demands, Fisher argues it is unlikely that the elasticity of demand goes up. It is more likely that it goes down, since it does not pay to invest in much searching. Consequently this type of problem might not arise. Analogously, for relatively high prices, it; is likely that price elasticity goes up instead of down, supporting the movement sought for.

Nevertheless, the undesirable shifts in the perceived demand curves can generally not be excluded by specifying demand conditions only, and therefore the crucial sufficient condition is, as said, eventually invoked. On the basis of that assumption Fisher (1973) provides a global stability result applying a Lyapounov function of the distance between the maximum monopolistically set price and the system equilibrium price for that firm. ${ }^{35}$

\subsection{The Fisher-Process}

Fisher's extensions of the Hahn-process discussed in Chapter 3, the contributions set out in the previous section, and his 1979 Presidential Address to the Economietric Society, titled "Stability, Disequilibrium Awareness, and the Perception of New Opportunities," published in Econometrica in 1981, culminated in 1983 in a momentous book that still represents the state-of-the-art in disequilibrium theory today, Disequilbrim Foundations of Equilibrium Economics. The model it develops deals with a large number of complicated issues that come up once one starts to think seriously about disequilibrium behavior, such as the timing of transaction, production and consumption outside of equilibrium, the existence of money, expectations that turm out false and the associated inability to follow up on contracts, possibly leading to bankruptcy.

Fisher (1983) approaches these by having households and firms recognize that their econorny is generally in disequilibrium, and that they are therefore likely not to be able to carry out their most desirable plans fully unconstrained. This is where the analysis departs from the Hahn-process, as Fisher observed that: 
"Perhaps the principal problem with earlier stability work has been the persistent assumption that agents stupidly act as if they believed the system to be in equilibrium." (Fisher, 1981, p.279)

In the Fisher-process, however, individuals do not believe this to be so, and instead hold expectations on the possible disequilibrium development of prices, as well as po tential rationing. The consequence of this disequilibrium awareness is that individual plans become rather complicated to formulate. In the dynamic optimization problems of 'arbitraging" households and firms-as Fisher (1983) refers to them-enter, apart from budget, production technology, and non-negativity constraints, storage and money constraints. Moreover, plans are made with an eye to expected transaction costs and constraints. Prices enter these problems as vectors of point expectations, that are modified over the disequilibrium process. Stocks and bonds that transfer all wealth to the households close the model.

The individual planning problems quickly become quite extensive, and their solution requires heavy formal machinery to which a large part of the monograph is devoted. They yield optimal consumption, production and transaction streams over time, with which all parties turn to the market. By identifying commodities by dealers as betore, markets are naturally order $l y .36$

To establish coordination of plans in the market asymptotically, therefore, the observation, discussed in the context of Fisher's extensions of the Hahn-process in Chapter 3 , that regret, and thus falling target utility and profit, are likely to come with irreversible decisions through disequilibrium would suffice in the Fisher-process, if individuals were not aware of the fact their economy is in disequilibrium-which they are not in the Hahn-process. Disequilibrium awareness, that is, implies the necessity to pose conditions for convergence on the level of perceptions and beliefs-largely inrespective, in fact, of the behavior of prices. The condition for global asymptotic stability of the Fisher-process is known as 'No Favorable Surprise'.

In Fisher's wording, No Favorable Surprise reads as follows.

There exists a $\Delta^{*}>0$ such that, for every agent and every $t$, the program. which is optimal for that agent at $t$ was feasible at $t-\Delta$ for every $\Delta$ such that $0 \leq \Delta \leq \Delta^{*}$." (Fisher, 1983, p.200)

Essentially, it demands that at no time there is a future date where for some agent events happen that increase the value of his or her objective function, and that the agent had not foreseen for at least a small time interval. That is, relative to what actually happens over time, No Favorable Surprise implies weak disappointment of all individuals, and strict disappointment of some of them-except in equilibrium. 3 in

Since the sum of the values of the objective function over all agents serves as a Lyaponnov function as long as it monotonically falls, it is intuitively clear that No

36 A valuable feature from the perspective of the strategy of proof of these plans uncler uncertanty over time is that they introduce smoothness of adjusments throngh the housellolds spheading their demands over various firms, and frrms facing smooth transaction costs. These observations make continuty assumptions acceptable. Cf. Fisher (1983), Chapter 6 .

37 For the introduction of disequibrim awareness in the Edgeworthorocess see Stahl and Irisher (1988). 
Favorable Surprise is the sort of condition found as sufficient for global stability-in fact, some individuals are allowed to have favorable surprises, as long as 'on average' surprises are unfavorable. Fisher discusses the condition at length in chapters 4 and 8 of the monograph. Examples of exogenous favorable surprises are the appearance of new and unforeseen technological developments, unanticipated changes in tastes that benefit some firms or consumers, new sources of raw materials with important beneficial application, or new and better forms of organization. Most certainly an economy in which these type of shocks happen cannot be expected to converge to equilibrium-and Fisher discusses in relation to this the work of Schumpeter, who already had this insight.

Crucial for No Favorable Surprise, however, is that no favorable endogenous surprises should arise either. Particularly, prices should develop such that no transactions become possible that lead to a higher utility or profit than foreseen at the expected prices on which plans were based. The message is that an economy can scarcely be expected to settle down when new trading opportunities that people are willing to engage themselves in constantly arise.

No Favorable Surprise has been criticized for not being a primitive assumptionsee the review of the book by Madden (1984). This is certainly a valid criticism. "No Faworable Surprise' does not reduce to conditions on the normal fundamentals. It is an assumption on perceptions and their relationship to the objective structure of the economy, and it is not obvious where it applies without an explicit theory of how perceptions get formed, and how they change over time. As Fisher argues convincingly; however, it is the type of condition one would expect, and that is likely to be close to a necessary condition for global stability. ${ }^{38}$

The strength of 'No Favorable Surprise' is such that markets need not necessarily be orderly for the Fisher-process to converge. Also, together with the fact that trade takes place at disequilibrium prices, it allows Fisher to be less explicit about the adjustment of prices. In Fisher (1981) the dealer structure with dealers establishing market clearing prices, as in Fisher (1972) is retained, both to obtain orderly markets, and to deal with the adjustment of prices. It is discussed as unsatisfactory. Moreover; the possible dependence of perceived constraints on prices is recognized-although in the discussion of the influence of transaction constraints on the formation of plans, reference is made, among others, to Benassy (1976) for price-independent constraints only. Yet, the potential that price-dependent quantity constraints offer for the development of a theory of rational price setting and adjustment is not taken up. Instead, Fisher settles for the other alternative dealing with the possibility that plans may not be fulfilled without difficulty in disequilibrium, namely smooth transaction costs. It seems that partially this choice is made for technical reasons. More deep, however, is the issue of the nature of equilibrium that is involved here. On that, more is said in the next chapter.

In Fisher (1983) the issue of individually rational price setting is extensively discussed. Here price-dependent quantity constraints are recognized fully for the foun"In thad, it is important to note that assuming 'No Favorable Surprise' is wery far removed
inded from assuming rational expectations-unlike what Paul Madden suggests. 
dation they offer for a more acceptable theory of prices and their adjustment. After doing so, however, Fisher is swift in concluding that:

"We can deal with transaction constraints and individual price offers by supposing that agents set prices and then behave as if prices were given but that they face transaction constraints. It is not necessary to reformulate the theory." (op.cit. p. 154)

Consequently, no formal analysis is given, other than of price-independent constraints ${ }^{39}$ Again, the fact that indeed the analysis easily accommodates for prices set on the basis of perceptions without restricting the latter such that a pattern in price adjustment is guaranteed is due to the strength of No Favorable Surprise. It carries the global asymptotic stability result in Fisher (1983).

Nevertheless, the monograph time and again stresses the need for further research on these issues, and also provides a world of forceful suggestions where to look for directions. An example is the following lengthy quote.

"Departure from competitive Walrasian equilibrium does not take two separate forms: one the presence of transactions constraints and the other the presence of monopoly elements. We now see that these are the same. Thus, for example, if individuals can make price and wage offers, the relevance of quantity-constrained underemployment equilibria rests on the persistence of perceived monopoly or monopsony power.

The question of whether or not such effects disappear in equilibrium is not an easy one. (...) I believe it is not possible to answer this important question by studying equilibrium alone. The answer depends on the perceptions of agents and these, in turn, are formed as a result of experience. Since the perception of a demand curve is the perception of what could happen under differing circumstances, it is not fruitful to model the learning process which leads to these perceptions by considering equilibrium alone or even by considering static experiments, which depart from equilibrium. If such experiments are to be more than gedanken experiments on the part of the agents, they will reflect the true dynamic behavior that occurs when equilibrium is disturbed. More generally, the perceptions of agents at equilibrium will reflect the experience involved in getting there." (op.cit., p.155)

The discussions of these ideas on discarding the homunculus and considering the influence of perception on plans and price behavior are rich, but rather informal in the book. How changes in perception work out, and whether or not they lead to converging prices, Fisher explicitly leaves as an open question. Together with extensions of the point estimates of prices to an analysis that allows for subjective uncertainty

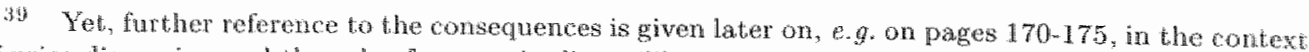

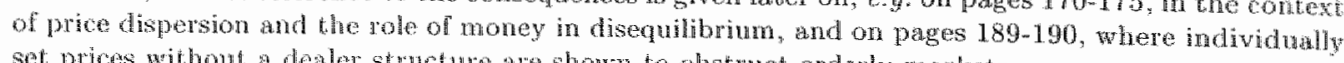
sat prices whond a ader struchue ane shown to obstruct orderly markets. 
surrounding them, these are the principal extensions Fisher stressed as interesting for future work in the concluding chapter of the book. That is, a theory of perceptions, axpectations, and learning in disequilibrium is what is called for. ${ }^{\text {th }}$

\subsection{The Austrian School of Thought}

The role of expectations and leaming in disequilibrium has traditionally been stressed in a school of thought that bas its roots in a circle around Menger in Vienna in the $1930^{\prime} \mathrm{s}$, the Austrian school, to which reference has been made before-marticularly in Chapter 3, in relation to the calculation debate "Although the Austrian school of thought is considered outside of the mainstream, it has strong ties with the origin of neoclassical economics. Yet, whereas mainstream economics adopted mathematics as a language to buil abstract general equilibrium models, the Austrians stressed the shortcomings thereof, and maintained a literary tradition. Starting with Menger.'s criticism to Walras' Elements, Austrian scepticism developed into an aversion against exact fommlations, that were held to give a false impression of precision. ${ }^{2}$ Although this withheld them from formulating an attractive alternative consensus, Austrian insights are rich. Particularly, those in market processes.

Kinzner, since the death of Hayek in 1993 the leading figure of the Anstrians, wrote Competion and Entrepreneurship in 1973 in reaction to neoclassical price theory. It readsw

"[T] The core of economic understanding consists not in the description of equilibrium states (the relevance of which Austrians would seriously question) but in the explication of the systematic market processes set in motion, at all times, by the disequilibrium features likely to characterize inarkets at any given date." (op.cit., p.25)

In the monograph. Kirzner set out to explain the role that entrepreneurs have in the competitive process. Particularly, he stresses the importance of entrepreneurial boharior in establishing a tendency towards market equilibrium. The crucial issue here is the spread of information, stressed by Hayek. Kirznew writes on it:

"[E] xposure to the decisions of others communicates sone of the information these decision-makers originally lacked. If they find that their plans

4) Fistren expressed high hopes that search theory would advance disequilitum andysis. $Q f$

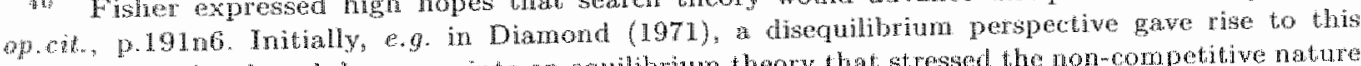
disciplne. It developed, however, into an equilbum theory that stressed the non-competitive nature

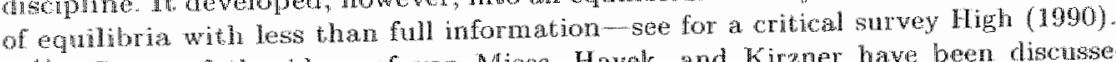

4 Some of the ideas of von Mises, Hayek, and Kirzner have been discussed eatlier. Also, as discussed, Fisher (1983) establishes a link wh Schumpeter deas on disequilbrating actions of antrepreneurs. Cf op.cht. pp.87-90. Since they led from the Nazis in the late 1930's Austrian not

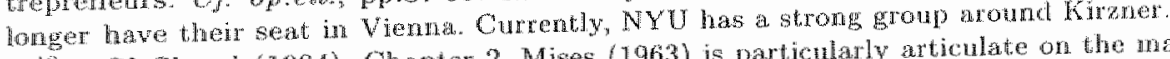

4. Cf. Shand (1984), Chapter 2. Mises (1963) is particularly articulate on the matue: To Mises economists were "wain playmg with mathematical symbots, a pastime not suited to conwey ary knowl

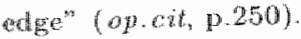


cannot be carried out, this teaches them that their anticipations concerning the decisions of others were overly optimistic. Or they may leam that their undue pessimism has caused them to pass up attractive market opportunities. This newly acquired information concerning the plans of others can be expected to generate, for the succeeding period of time, a revised set of decisions. The overambitious plane of one period will be replaced by more realistic ones; market opportunities overlooked in one period will be exploited in the next. In other words ... the decisions made in one period of time generate systematic alterations in the corresponding decisions in the succeeding period. Taken over time, this series of systematic changes in the interconnected network of market decisions constitutes the market. process." (op.cit., p.10)

These ideas are similar to the ones Fisher calls for as an extension of his theory. Individuals differ in the information they have and their view of the market. They act to the best of their knowledge. Market processes give people incentives to learn and extend their knowledge beyond that of others, as the possession of non-common intormation generates profit opportunities, e.g., through arbitrage. By the exploitation of private information, however, information gets spread. During the process the division of knowledge evens out, and the market is gradually better coordinated.

This view establishes the position of the Austrians in the calculation debate. Recall that Lauge, in particular, held the position that the increased technical capabilities of computers could eventually be relied upon to establish equilibrium prices for a centrul planning bureau. In On the Economic Theory of Socialism, first published in 1938 for example, Lange wrote:

"TThe parametric function of prices must be imposed on them by the Cen" tral Planning Boards as an accounting rule. (..) The technique of attaining this end is very simple: the Central Planning Board has to fix prices and see to it that all managers of plants, industries, and resources do their accounting on the basis of the prices fixed by the Central Planning Board, and not tolerate any use of other accounting. (...) Any mistakes made by the Central Planning Board in fixing prices would annonnce itself in at very objective way by a physical shortage or surplus of the quantity of the commodity or resources in question and would have to be corrected in order to keep production running smootbly. (...) The Central Planning. Board performs the functions of the market." (op.cit., pp.81-3)

Obviously, Lange had the traditional function of the auctioneer in mind, literally to be vested in a govermment institution. As the Austrians had little sympatlly for that metaphor in the first place, they rejected the idea that it could be embodied by a central planning bureau. Apart from the argument that the technical demands that calculations of equilibrium prices would make would surpass the then state-of-the-art in technology referred to in Chapter 3-the more fundamental objection that the 
informational requirements would be prohibitive was ventilated particularly by von Mises. ${ }^{43}$ Yet, Lange's position found quite some support. ${ }^{44}$

The Austrian dogmatic denial of the usefulness of mathematics has not helped the spread of their ideas. It has hidden the fact that these have close relationships to those of, for example, Hahn and Fisher. More modern Austrians have realized this, and attempted to formulate Austrian theory more formally. An exceptional contribution by Littlechild and Owen appesred in 1980 in the Journal of Economic Theory as "An Austrian Model of the Entrepreneurial Market Process." The model developed in the article concern the question of the discovery of markets previously unknown. To this end a division of knowledge is modelled, and the ability of entrepreneurs to learm. Markets can be directly or indirectly linked. As there is a positive probability that markets get linked as long as there is a price difference on them, eventually all markets are linked almost surely. Then, as markets get linked, it is shown that prices converge to unique limit prices. Although for that, the model relies on an auctioneertype institution, it is very interesting.

Another attempt to develop a more explicit Austrian inspired disequilibrium theory is Jack High's Macimizing, Action, and Market Adjustment, published in 1990. The book presents well informed surveys of stability and search theory, and related the ideas in these disciplines to Austrian market theory. High's main conclusion is that neither of these disciplines has been able to capture the disequilibrium process the Austrians envision. An alternative theory is developed graphically. Although presented intertwined with many semantic and conceptual issues the Austrians raise, and therefore occasionally violating the microeconomic apparatus is seeks to apply, the setup is rather interesting. The partial model High develops is, in fact, very similar to that illustrated in Figure 6.1 above. ${ }^{45}$ There the point was to show the difficulties a monopolistically competing firm experiences in establishing equilibrium prices. High eventually comes to assume perception changes work out such that prices converge. Some hand-waving is applied here. Nevertheless, the aim and structure are of interest. They call, however, for a more detailed study of learning in disequilibrium.

\subsection{Imperfect Information and Learning}

As it happens, since the early 1980's a large formal literature on learning in economic theory has developed. Extensive recent surveys of it are given in Blume and Easley (1995, 1998), and particularly Ramon Marimon, "Learning from learning in economics," published in 1997. The essence of these learning models is that individuals conjecture a certain causal relationship between relevant variables, typically price and quantity in demand or supply functions, take a particular action, typically setting a price, observe the response from the market, and use the information thus obtained to reconsider their ideas about the specifics of the perceived relation.

(3) Won Mises in Hayek (1935).

"H Cf. e.g. Dobb (1969).

品 Cf op.cie. Part III. 
Two types of leaming are particularly concerned: ordinary least squares learning and Baysian learning. ${ }^{4}$ In the former, individuals collect a given amount of observation and subsequently estimate the conjectured functional relationship between thern such that the squared difference between the observations and the predicted values is minimized. In the latter, individuals hold beliefs on the possible values of the parameters in the conjectured functional relation in the form of probability distributions, which are updated after collecting a given amount of new observations. The parameter estimates then are obtained by minimizing the squared difference between observed values ans predicted values for all possible parameter values, weighted by the distribution ove them. 4

Two other distinctions in the literature are of importance. One is that between mod. els that concern the learning process of an individual in isolation, that is, in artid setting, and leaming processes studied in a general equilibrium context. The former the oldest, and there are very many of such models. Interesting examples are Nguyen (1984), Andersen (1985), Easley and Kiefer (1988), Kiefer and Nyarko (1989), Balvers and Cosimano (1990), Nyarko (1991), and Trefler (1993). Most of these studies con sider so-called 'actively learning" firms, which separated from 'passive learning' foms. the second distinction. Actively learning firms are aware of the fact that when they set a price or a quantity, they will receive information from the market from which they can learn. Consequently, they take the potential value of learning into consideration in their strategy. The result is a rather complicated dynamic optimization problem. in which the actual learning takes only a small part.

Of the two adaptive learning processes, Bayesian learning is by far the most widely applied. Generally, Bayesian learning is referred to as 'rational learning', to set it aside from the more traditional adaptive learning processes reviewed in Section 6.2 , where the adjustment parameters are exogenous. Bayesian leaming is, however, also a ratural extension of expected utility maximization. That is, under the assumptions of expected utility maximization, Bayesian learning is rational.

Yet ordinary least squares learning, has found application as well. Particularly, there is a literature that considers their recursive form, in which every new observation returns an adjusted estimate. It builds on techniques developed by Lennart Ljung: covered most extensively in Ljung and Soderstrom (1983). Applications of these ted niques in economics are in Marcet and Sargent (1989), Woodford (1990), Sargent (1993) and Evans and Honkalupohja (2000, 2001). The analyses apply a version of the second method of Lyapomov, where an associated differential equation related to the original recursive system is studied, and found to converge under particular regularity conditions.

The logic of Bayesian learning is that of conditional probabilities. Given a structural specification and initial beliefs about the probability with which the parameters in it take on a particular value, new information adjusts that belief into a conditional belief. according to the laws of probability. That is, the conditional probability of a certain

\footnotetext{
14 "The two are related and equivtent under wery special conditions, set out in Appendix A.

47 The technques inwolved, particulaty in Bayesin learning, are set ont and applied extensinel in Chapter 8 and associated appendices.
} 
parameter value is equal to the probability of the observation given that parameter whe times the probability initially assigned to that value, divided by the total probabitity of the observation given any possible walue of the parameter multiplied by the initial probabillity assigned to that parameter value. This can be done sequentially upon each new obserwation, or after the collecting of some amount of intormation.

Bayesian learning is much wider applied than ordinary least squares leaming because it is more general. Another reason is that strong asymptotic convergence results exist: for Bayesian learming. Particularly, reference is made to an early article by Blackwell. and Dubins, titled "Merging of Opinions with Increasing Information," published the 1962 in the Annals of Mothematical Statistics, in which it is shown that when the anaunt of observations with which they are all faced increases, individuals that have different priors, that only satisfy that they assign zero probability to the same events, have their posterior beliefs converge to the same limit belief, for almost all possible histories of information-that is, almost surely. This almost sure convergence result is exploited in all of the literature discussed below.

The introduction of Bayesian learning into general equilibrium models is dne to Lawrence Blume and David Easley, who published in a special issue of Joumal of Economic Theory in 1982, "Learning to Be Rational". The issue also held an article by Margaret Bray, titled "Learning, Estimation, and the Stability of Rational Expectations." As these titles reveal, the concern of their line of research was with the question whether individuals can learn to hold rational expectations. To that end, in both papers, individuals have insight into the structure of the economy, yet not in the particulars. On them, they hold beliefs. That is, they entertain different possible wersions of reality, reflected by different values of the parameters of the structure they understand.

Although Blume and Easley particularly emphasize that when the true parameter values are in the support of the prior beliefs, Bayesian learning does not necessarily converge on the rational expectations beliefs, the main message of the literature is that wen specifications are full, rational expectations follow from rational learning. In later work, such as Blume and Easley (1984), Bray and Savin (1986), Bray and Kreps (1987), and the surveys by Blume and Easley referred to above, this is the approach. Bayesian learning over time justifies the rational expectations approach. Similar conclusions are drawn in the ordinary least squares learning literature referred to above.

In game theory, learning was studied as well. Here the core question considered is whether players that start out with imperfect information of the behavior of thein opponents, and form expectations instead, learn over time to play the Nash equilibrium associated with complete information if they adjust their beliefs in light of observed play. An early reference to Bayesian learning in simple dnopoly games is Cyert and DeGroot (1987). More general games are considered in Jordan (1991, 1992), Kalai and Lehrer (1993a, 1993b), Nyarko (1994), Jordan (1995), and Sandroni (1998). All these contributions reach similar results, under marginally different conditions A recent survey is given in Fudenberg and Levine (1999).

1. Cf the classical references DeGroot (1970) and Zellner (1971). 
However interesting the literature on learning is, the perspective given to it by the pervasive preoccupation to consider learning for the justification it can give for rational expectations equilibria has led to an underdevelopment of its full potential to addres questions of disequilibrium. Little or no reference is made also to this literature-with one notable exception, by Hahn, who published a paper in 1989 titled "Information Dynamics and Learming" in which several suggestions for truly disequilibrium models of learning are made, one of which is in fact followed up on in Chapter 8 . The prime rea son for this is apart from the fact that the Bayesian learning literature developed in relative isolation as a technical discipline that close to all learning literature presup poses a correct structural specification of the econony with all individuals. Leaming: therefore, centers on fleshing out the parameters therein, and hence, if convergence is established, it necessarily takes place on rational expectations equilibria. The first. question to address, therefore, is whether this is a grood presupposition. On that the next chapter concludes.

\subsection{Individually Rational Price Adjustment: A Conclusion}

The various anthors discussed in the previous chapter and here all eventually suggested that it is in the interplay between objective truth and subjective beliefs that insight into disequilibrium behavior is to be had. The dynamics of disequilibrium processes rest on the dymamics of changes in the perceptions of market makers and their clients: of the econony in which they operate, and of the role they themselves play there. It. is these changes in perceptions where analysis should focus, and look for convergence results. Equilibria, in other words, are to be understood as the end-points of sensible learning processes.

Authors in the Stockholm school stressed it, as did Hayek, Hahn and Clower. Ba nassy concluded that there the specification of his monopolistically competitive equilibrium was to be found, and Fisher advocated the study of knowledge and perceptions most forcefully. The literature that did eventually develop on learning, starting in the early $1980^{\prime} s$, considers particularly learning of contents in well-specified structure. geared up towards a justification of rational expectations equilibria. It does not ad. dress the question how individuals come to understand the structural specifications. The nature of their information, in other words, is given little concern.

Nevertheless, the rational learning literature offers very interesting tools for a con. timuation of the disequilibriurn research program. After all, it: is subjectively rational leaming combined with subjectively rational price setting that is what is sought for. The Bayesian learning literature offers a framework of adaptive learming and price adjustment, and suggests a route to establish global asymptotic convergence results. It is explored in Chapter 8. First, however, more constructive thoughts on specification and the nature of equilibrium. 


\section{7 \\ The Correspondence Principle in the Large}

The literature on the two essential elements of a disequilibrium theory that does not rest on a homunculus noted by Arrow has now been extensively and critically considered. In Chapter 5, it was shown that for following the first--market makers endowed with a certain power to influence prices-the literature on monopolistic competition offers an suitable context. That is, prices can be individually rationally set in a general equilibrium model. Furthermore, the second essential aspect of disequilibrium-less than full information outside of equilibrium and the need to conjecture instead-can be accommodated for in these models. In fact, the existence of monopolistically competitive equilibria is more conveniently established with subjective conjectures than with full objective knowledge of market relations.

Naturally, with prices based on beliefs, a theory of price adjustment concerns changes in beliefs. However, despite the open invitation that the literature on market makers with subjective conjectures offers for a study of disequilibrium and stability, and despite the availability of theory on learning, little formal model building developed in that direction, as related in Chapter 6 . This is all the more puzzling, as the existence and particularly the nature of each of the generally very many monopolistically competitiwe equilibria depends crucially on the perceptions of the market relations that individuals and firms have. By studying the interplay of perceptions and their counlerpart in reality, a theory of individually rational price adjustment is likely to shed light on the relevance of equilibria with rationing.

Instead, however, in the literature on monopolistic competition as well as that on imperfect and incomplete information and learning, the equilibrium perspective has been all pervasive. In this chapter an explanation for the lack of constructive use of the available material is offered. It is associated with a third suggestion in Arrow (1959), hinted upon in Chapter 4. That is, the idea that, although imperfect competition and information are disequilibrium features, equilibrium is associated with perfect 
competition and perfect information. For an argument on the inappropriateness of this perspective, an appeal to the methodological insights offered in Chapter 2 is mads. After all, epistemology is fundamentally concerned with the nature of knowledge and knowing: which is what is central here.

This brief chapter is organized as follows. The next section takes methodological stock. Section 7.2 argues that essential elements of a disequilibrium theory modify the nature of equilbrium. This is the correspondence principle in the large, the tithe of this chapter. In Secton 7.3 a final illustration of the failure of the law of supply and demand is provided by means of an extensive but sumple example that features all elements of a theory of disequilibrium behavior.

\subsection{Taking Methodological Stock}

The failure of global stability theory and thereby the alleged failure of the disequilibrum reseach program, has been attributed in Chapter 4 to the homunculus explang tion that it was led to offer, due to the conflict between the hard core of economics and the demi-demi-core of the disequilibrium sub-subprogram. Whereas economic thoory generally seeks to base its propositions on methodological individualism, stability was sought for outside of the model, postulating an unexplained auctioneer. The origin of this conflict is in the heuristic of the economic research program, which encourages the study of general argument that supports the idea that economies with free competition serve the public interest best.

The resulting methodological dichotomy has led to logical problems, and a shift of interest away from questions of convergence and stability. As a consequence, sight of their furdamental importance was gradually lost. Despite the fact that elements of a methodologically and logically sound theory of disequilibrium have been developed and are now readily available, they were not taken up. An important reason for this is in a reminiscence of the traditional global stability research, the idea that disequilibrium theory essentially is to corroborate competitive equilibrium. It put stress on the frow attempts to consider disequilibrinm issues seriously.

Two manifestations of the heuristic to substantiate competitive equilibrium are to be distinguished. The first is the failure to separate the objective structure of a model from the subjective perceptions of individuals. The second manifestation is the drive to establish the rest-points of disequilibrimm behavior as perfectly competitive equilibria, even when subjective perceptions are acknowledged ontside of equilibrium.

Obviously, the approach in the tatonnement and trading processes, as well as in the computational algorithms literature discussed in Chapter 3 is to establish the "true" aquilibria of the models to which these processes are applied. They do entertain the possibility that individuals perceive the economy they operate in differently from its objective structure, simply because, as price-takers, individuals have little use for any other information than on prices-apart from their private knowledge of preference, production techniques and endowments. This status of a neutral mechanism, ontside of the model, has been criticized extensively. In models with price-makers this is funda mentally different. There, the refusal to differentiate between model and perception is 
also principle in the objective demand approach, the dominant position in the study of monopolistic competition-even though better example was available. And, of course, most prominently, the rational expectations approach equips all individuals with full insight into their economy, or at least with a correct structural specification in which rational learning does the rest.

Several times now, it has been argued that to assume all individuals hold all relevant information of the structure and the specifics of the economy, are able to identify its equilibria, and all pick the same single one of them, stretches the imagination. Yet, Muth's original argument that, when economists are able to model an econony, individuals should be able to do so equally well, and hence take advantage of that, is appealing. It is, however, a methodological misconception.

The fact that it is possible to construct simple models - of which it may indeed be strong to assume only economists understand them-does not mean the reality they are to describe is simple. Quite the contrary, abstract models are a means to understand essential elements of reality. They are, in fact, the only way in which reality is accessible, since theory determines observation, as set out in Chapter 2 . Therefore, theories are constructed for the sole purpose of driving a wedge between all infuences upon any given situation and some that are deemed particularly relevant.

The theories held by individuals in an economy need to obey the epistemological rules for theories as well. That is, they are related to, but necessarily different from the economy on which they are had. If they were not, they would not be theories. Hence, to devise a theory, and assume that the ones to which the theory applies hold the very same theory and base their behavior on it, implies that what was built in the first place was not a theory, but a replica of reality. That, however, is of no use. Reality already exists and will not be understood by reproducing it. ${ }^{1}$

Once it is realized that it is both empirically and logically false to assume all individwals know everything about the economy they inhabit, a valid analysis of perceptions, expectations, and learning is recognized as one that makes a difference between the objective truth of the model and the subjective perceptions of individuals modelled. This difference consists essentially of two elements. In the first place will the perception of the structure of the economy differ from the true structure. That is, subjective theories differ fundamentally from the objective truth they seek to describe. Secondly, as a consequence, the perceived specific contents of the perceived structure will differ from the true contents. That is, the parameters that flesh out the conjectures structure, as they do not have an exact counterpart in reality, will take on objectively false values.

These insights are, of course, not new. They were, in fact, quite prominent in economics in the 1930 's. Hayek particularly advanced this perspective. He stated in 1936 , in his lecture Economics and Knowledge:

"There seems to be no possible doubt that these two concepts of "data," on the one hand, in the sense of the objective facts, as the observing economists is supposed to know them, and on the other, in the subjective

For a collection of seminal contributions to the understanding of human understanding, see Bernecker and Dretske, eds (2000). 
sense, as things known to the persons whose behavior we try to explain, are really fundamentally different and ought to be carefully distinguished. And, as we shall see, the question why the data in the subjective sense of the term should ever come to correspond to the objective data is one of the main problems we have to answer." (Hayek, 1949, p.39)

In philosophy of science, these ideas were central in the influential work of Popper-who had a very close relationship with Hayek, to whom Conjectures and Refutations, first published in 1963, is dedicated. Popper is not an extreme anti-realist, holding that reality is fundamentally unknowable in its deeper structure. Instead, as shown in Chapter 2, Popper stressed the need to confront conjectured theories and hypothe ses with empirical observations and use that interaction to consider the adequacy of theory. Theory, in that view, is only true for the time being, and to the extent that it corresponds to observed facts. Yet, Popper believed that a truth exists to which theory aspires gradually. Although all past and current theory is fallible, the aim of science is to discover the truth about reality. This position is referred to in philosophy of science as conjectural realism. It is adhered to by Popper's followers, particularly Lakatos. ${ }^{2}$

Of course, the idea that knowledge is accepted as a truth as long as it corresponds to the observed reality is perfectly in line with the notion of conjectural equilibrium. It is, therefore, no wonder that Hayek was comfortable with that concept. ${ }^{3}$ Peculiarly enough, however, very little acknowledgment that models are necessarily truncated specifications of reality can be found in modern economic theory.

The very few exceptions did not gain very much recognition. Apart from those already presented in Chapter 5 -that is, the models of monopolistic competition of Negishi and Benassy-interesting exceptions in the learning literature are Blume and Easley (1982), Nyarko (1991), Kirman (1975, 1983, 1995) and Kalai and Lehrer (1995). If mentioned at all, they come under a small and pejoratively titled section "misspecified models." The fact that these analyses show that Walrasian, rational expectations, or Nash equilibria with complete information are generally not the rest-points of rational learning, or that convergence may not take place at all, is used against themwhereas they are, of course, signs of a good theory of disequilibrium. In Blume and Easley (1998) it is concluded that any specification of the structure or the space of possible parameters is an ad hoc choice of the modeler that "rational learning was introduced to avoid." Therefore, they settle for a complete structure.

In ecomonetrics, however, the fact that conjectured relations do generally not cowrespond to the true ones does have some history, in a discipline referred to equally misgtniding as 'misspecification analysis'. Prominent work om the consequences of estimation on the basis of approximations of the true relations by which the data are generated has been done by Halbert White and Alain Monfort. ${ }^{5}$ Generally, in this

See on realism and anti-realism, Chalmers (1999), Chapter 15.

Cf. «. . Hayek (1.949), p.53.

Cf. Bhume and Easley (1998), p.64. Their 'Misspecified models' section is barely two pages.

pp.98-100. Wore on the models of Nyarko and Kirman ceferred to below.

Cf. White (1994) and Mronfort (1996) 
literature, the search is for conditions under which the parameters estimated in the "misspecified" form converge to values that minimize the squared error with the true rehation. To that end, an explicit difference is made between the objective structure at relation to be estimated, which generated the data, and the truncated version of it, which the data are applied.

The motivation for this research is well put in Whites motto in Estmation, Inferwhe and Specification Amalysis. From Heraclitus's The Cosmic Fragments it reads:

"The real constitution of things is accustomed to hiding itself." (op.cit., p.vi)

In their critique of the rational expectations approach, Hirshleifer and Riley (1992) rightly state that:

"[R]ational expectations corresponds, in effect, to assuming that ordinary individuals can be taken to be both pretty good economists and pretty good econometricians, at least on average." (op.cit., p.254)

If it were the case that a good economist and econometrician pulling together held a full grip on economic reality, this would be quite something to ask from everybody indeed. The fact is that they do not and can not. "Misspecification" of the complete reality is part of the nature of a good theory. ${ }^{6}$

\subsection{On a Competitive Ending}

Economics has struggled with the "main problem', as Hayek referred to it, of the extent to which perception and truth can correspond. Certainly, to assume they are the sane initially nullifies the theory. Yet, to leave a specifically specified structure unchanged over the full extent of the analysis seems an extreme approach as well. It has thereby been guided by the second aspect of the heuristic noted above. Perhaps this is best put by Smale although his contribution to disequilibrium theory has been rather mechanistic, as set out in Chapter 3. In his 1976 literary account "Dynamics in General Equilibrium Theory," earlier referred to, Smale stated on the issue of disequilibrium:

"A completely satisfactory dynamics (which isn"t available) for this problem would construct and analyze paths over time in the space of states, that is commodity vectors for each agent and price systems (or sets of price systems). These paths should obey economically justifiable axioms of exchange and price adjustment, and probably should lead, at least under

(5) For a different and wery interesting critique on the literature that seeks to establish rationall expectations as the result of rational learning, and that also finds inspiration in the work of Hayek, see Fydman (1982). There, the argument is made thai individuals cannot bese expectations on economy wide awerages, if they thenselves are part of the constitution thereof. On how the rational learning theory harks back to classical conditions for global stability on rational expectations equilibria, see Foster and Frierman (1990). 
some economic conditions to a Walrasian equilibrium, starting from an endowment allocation and any price system. At the most satisfactory level, these paths should be given interpretations in terms of individual agent's actions in price offerings and purchases." (op.cit., pp.292-3)

Better focussed contributors to the disequilibrium research program have been led by this idea as well. Fisher has the dealers in his 1972 model adjust prices as to clear markets at competitive price levels for this reason. In Fisher (1973) the tension between individually rational disequilibrium adjustment and market power at equilibrium shows most clearly. Although the first part of the article-discussed here in Chapter 5 stages monopolistically competing firms that set prices rationally and eventually at equilibrium levels, the second part seeks to have monopoly power erode away asymptotically at low enough prices. To that effect, it is argued that firm-specific demand flattens out as consumers are able to find low-priced firms perfectly. Consequently, an increase of prices over that level leads to a significant reduction of sales. It is assumed that this is particularly so at competitive equilibrium levels, so that firms. monopolistically and rationally set competitive prices at equilibrium. ${ }^{7}$

The structure of assumptions necessary to obtain this result are a case in point of a setup suggested by the heuristic referred to. Fisher (1973) states in the introduction that the paper is

\begin{abstract}
"...an attempt ... to provide a sensible disequilibrium story with a competitive ending. Departing partly on one's predilections, however, the story may seem rather less than more sensible, and, indeed, one way of looking at the result is as showing how hard it is to tell a sensible competitive disequilibrium story." (op.cit, pp.447-8)
\end{abstract}

How this is so appears particularly from assumptions necessary towards the end of the article, when the dealer structure and the eroding market influence of individuals dealers are combined. The problem rises that eroded power halts the further adjustment of prices. This should not happen before prices are at competitive levels.

"...so that the adjustment process does not get trapped by the market being too perfect, as it were." (op.cit., p.465)

In Fisher (1978)- the link between the Benassy models and the Hahn process-the same program can be found. In this article, Fisher acknowledged Benassy's idea of awrareness on the side of individuals that they may be rationed, yet sought for conditions under which the perceptions of rationing constraints would at equilibrium be non-binding. It is found in the assumption of "eventual experimentation", which assures that when individuals are caught in a conjectural equilibrium in which they are rationed due to the fact that they all expect to be rationed there as well as on other markets - but objectively need not be rationed, because perceptions have no counterpart in the objective structure of the model, they will experiment with

op.cit. pp. $456-7$ 
demand and supply around their beliefs to see if they are correct. ${ }^{8}$ As a consequence, Kequilibria that are non-Walrasian will be unstable, which allows Fisher to prove globul stability on a Walrasian equibrium.

In the 1983 monograph, Fisher departs from this. In fact, there reference to the antier stories with competitive endings is made as "... complex and perhaps something of a fary tale." Global stability of the intricate disequilibrim process developed in the book is established, but the nature of the equilibrium eventually established left open. Fisher states on this:

"While the analysis of the present model shows stability, it is silent on whe question of whether or not the equilibrium asymptotically attained is Walrasian. Indeed, the present analysis shows stability even when there are monopoly or monopolistically competitive elenents which stem from camses other than conjectured demand curves and lack of information so that the basic structure is not competitive. Even with an underlying competitive structure, however, resolution of the important question of when equilibrium will itself be competitive requires a more detailed set of assumptions on the adjustment process than I use here. It is a major issue for further work.". (op.cit., p.156)

Nevertheless, Fisher's preference still is a competitive ending. ${ }^{10}$

Yet, by the logic applied above, it is quite questionable whether the theories of individuals will indeed ever be able to approach the true structure of the ecomomy. Such theories will need to abstract from some infuences to be operational. Add to this that there are real costs involved in obtaining a foll insight in structure and content of the economy, and that these costs are likely at a certain level to outweigh the benefits of further specification of subjective conjectures to objective relations-as established in the search theory literature-and the fact that there are endogenous processes that keep markets from changing--which is the Austrian perspective-and individuals will both need and want to settle for less than full specifications.

The upshot of this is a resolution of the paradox how ower the course of the equilibrating process simultaneously monopoly power comes to erode and prices set, on the basis of it. Unti] the end of times individuals and firms deal on the basis of more of less sophisticated subjective theories of the economy. They obtain signals as to the appropriateness of their actions from the objective economy, yet mold them into then subjective structure to be able to cope with then. Framk Knight wrote on this in his Fisk, Uncertainty, and Profits, first published in 1921:

"The action which follows upon an opinion depends as nuch upon the amount of confidence in that opinion as it does upon the favorableness of the opinion itself. The ultimate logic, or psychology of these deliberations is obscure, a part of the scientifically unfathomable mystery of life and mind. We must simply fall back upon a 'capacity' in the intelligent animal

Op.cit. p. 26 for a formal definition.

Op.cit, p.50.

(1) Private conmunications. Fisher (1983) also provides several clues to this. 
to form more or less correct judgements about things, and intuitive sense of values. We are so buitit that what sems to us reasonable is likely to be confirmed by experience, or we could not live in the world at all." (op.cit., p.227)

Consequently, the local monopoly power of market makers, or dealers, required as a seat for individually rational price adjustment as well as for a necessary organization of markets, settles in a moderate amount of objective monopolistic and monopsonistic infuence on markets which results from the fact that it is fundamentally impossible, as well as perfectly rational, to form subjective perceptions of the objective world."

This is the correspondence principle in the large. A stable decentralized economic system comes at a cost. It requires a departure from perfect competition and its efficiency properties, not only outside of equilibrium, but structurally. The structure of imperfect competition may change over time. Certain products may be relatively new and sold strictly monopolistically, others may be under fierce competition, and hence sold with little infuence on prices. Also, entrepreneurs have a constant incentive to throw up new local monopolies, particularly through product differentiation, that they can exploit especially in disequilibrium. Equilibrium may therefore never be attamed at all. But when it is, global asymptotic stability of the process has ramifications for the nature of equilibrium.

As noted in Chapter 4, Arrow seemingly provided ground for the search for a competitive ending in the quote from his 1959 article. Yet, towards the end of it Arrow stated the following:

"The incomplete competitiveness of the economy under disequilibrium conditions implies a departure from the maximum of possible efficiency in the use of resources. To be sure, it does not necessarily follow that greater efficiency is necessarily achievable under feasible alternative rules. Any method of resource allocation requires a process for equating supply and demand (or some equivalent), and such a process may be in itself costly. though such costs are not considered in the usual formal analysis of welfare economics. Thus, a completely centralized system will incur high computational and informational costs. The monopolistic and monopsonistic misallocations implied by the model of the present paper may be thought of as costs alternative to those associated with centralization" (op.cite, p.50)

Market processes are to be understood as locally monopolistically competitive, with decisions taken on the basis of subjective perceptions, and, if convergence takes place at all, settling in conjectural equilibrium. The disequilibrium story with a competitive ending is the "Holy Grail' of economic theory. It is a non-existent ideal that cannot be found. Moreover, the search for it has led the profession astray from modelling accepto able disequilibrium processes, and has discredited the disequilibrium research progran in the eyes of outsiders. Either one believes perfectly competitive equilibrium is the

\footnotetext{
11 Of course, this does not address how it cones about that markets are organized as they are, and what infuences changes therein. Yet, the prime concern here is to investigate the cansequence of the acknowledgment of some social convention on this structure for diseguilibrium theory.
} 
proper framework for economic analysis, and then a theory of how it is established is imposible, or one acknowledges that such a theory is of central importance, and then competitive equilibrium is unattainable. ${ }^{12}$

\subsection{On the Law of Supply and Demand Again}

In order to illustrate the potential of the appropriate structure for disequilibrium research now fully uncovered, this section introduces a simple example. It serves two purposes. Firstly, it settles the issue of the law of supply and demand that the sporadic stability analyses kept staging. Secondly, the current exposition serves to introduce the next chapter, in which a general version and a global stability result are offered in answer to questions that rise in the present setup here.

The model below is in line with that in Fisher (1973), illustrated in Figure 5.2, which showed how monopolistically competing firms have trouble establishing the Lange-conjecture It is, however, also importantly different. Apart from the fact that it features only two contestants, that each offer a differentiated product, dealers have incomplete and imperfect information about the market, and deal with it by means of conjectures and learning. Therefore, the disequilibrium problems are more obvious than they are in Fisher (1973).

In fact, the model is slightly more general, but very closely related to one stuclied by Kirman in a series of papers - the most complete account of which is published as "Apparent Conwergence of Learning Processes in Mis-specified Games" in 1992, with Vincent Brousseau. ${ }^{13}$ In the Kirman version, firms learn in an ordinary least squares manner from past experiences. Under suitable assumptions, however, the two learning processes are identical-cf. Appendix A. ${ }^{14}$

Consider an economy with two different commodities, $j=(1,2)$, traded in monopolistically by two different dealers-similarly identified. For simplicity, the supply to each dealer is known and perfectly elastic, so that the marginal purchasing costs are constant-and normalized to be equal to zero. Suppose market demand for commodity $x_{j}$ is given as

$$
x_{j}=\alpha_{j}-\beta_{j} p_{j}+\gamma_{j} p_{-j}
$$

where $p_{j}$ is the price of commodity $j$ and $p_{-j}$ that of the concurrent commodity, and $\alpha_{j}, \beta_{j}$ and $\gamma_{j}$ are positive parameters.

12 Interestingly enough, in his 1994 Koopmans Lecture of the Cowles Foundation, titled "The Reappraisal of Misspecified Econometric Models," published in Econometric Theory, 1996, Alain Monfort compares the search for a complette specification with that for the Holy Grail. Cf. op.cit. p.597.

13 Cf. Kirman (1975) for a first, and Kirman (1983) for a full account. More recently, aspects of the model are reported on also in Brousseau and Kirman (1992) and Kirmarn (1995).

It Finally, the model developed below is loosely related to Nyarko (1991), which features a single monopolist that has a correct structure of demand, but only two possible-and well-chosenparameter walnes to decide between. As a result, Bayesian learning generates alternating beliefs in the two possibilities, and hence cycling prices. 
Dealers are neither able nor willing to understand all influences on their dealerspecific demand, and form conjectures instead. In this very simple setup, that is, conjectured demand is a function of the dealer's own price only, as follows.

$$
x_{j}=a_{j}-b_{j} p_{j}+e_{j}
$$

where $a_{j}$ and $b_{j}$ are positive parameters, and $e_{j}$ is a perceived error term that makes up for the awareness on the side of the dealer that his conjecture is necessarily structurally truncated. It is believed to be clistributed normally:

$$
e_{j} \sim N\left(0, \sigma_{e_{j}}^{2}\right)
$$

where $\sigma_{e_{j}}^{2}$ is a finite perceived variance. Let the values $x_{j}$ can take on be in $X_{j}=$ $\not R$-note that this allows that perceived sales can be negative, which is essentially a parameter specification problem.

Of course, in this very simple economy one would expect dealers to have little difficulty identifying the influence of their competition on the demand they serve. The point, however, is to illustrate the principle of subjective conjectures, and for that this is the simplest possible structure.

Note that each dealer's perception of the distribution of $e_{j}$ returns a distribution of $x_{j}$. As the conjectured error term is perceived to be distributed normally, for any given parameter values, the subjective measure $g_{j}\left(x_{j t} \mid \theta_{j t}\right)$ of $x_{j}$ is distributed normally as well, with mean $a_{j t}-b_{j t} p_{j}$ and variance $\sigma_{e_{j}}^{2}$.

At time $t$, dealer $j$ has certain beliefs on the values of the parameters $a_{j}$ and $b_{j}$. Let $\theta_{j}=\left(a_{j}, b_{j}\right)^{T}$ be a $2 \times 1$ vector collecting the parameters of conjectured demand, and let $\theta_{j} \in \Theta_{j}=I^{2}$ be the parameter space of $\theta_{j}$-again ignore sign-issues. Suppose the beliefs dealer $j$ has on the value of $\theta_{j}$ at any particular point in time are given as represented by a distribution $\mu_{j t}\left(\theta_{j}\right)$, which is multivariate normal. That is,

$$
\theta_{j} \sim N\left(\theta_{j t}, \Sigma_{j t}\right),
$$

where $\Sigma_{j t}$ a $2 \times 2$ finite and non-singular matrix with diagonal elements $\sigma_{a_{j t}}^{2}$ and $\sigma_{b_{j t}}^{2}$, and off-diagonal covariance $\sigma_{a_{2, j}, b_{j t}}$. Furthermore, dealers believe $\theta_{j}$ and $e_{j t}$ are uncorrelated for all $t$.

On the basis of his view of the world, each dealer sets its price to maximize expected profits, conjectured as

$$
\begin{aligned}
\pi_{j t}\left(p_{j}\right) & \equiv \int_{X_{j}} \int_{\Theta_{j}}\left(a_{j}-b_{j} p_{j}+e_{j}\right) p_{j} \mu_{j t}\left(d \theta_{j}\right) d x_{j} \\
& =\widehat{a}_{j t} p_{j}-\widehat{b}_{j t} p_{j}^{2}
\end{aligned}
$$

where $\hat{a}_{j t}$ and $\hat{b}_{j t}$, are the Bayesian least squares estimates of the parameters $a_{j}$ and $b_{j}$ of conjectured demand at time $t$, respectively. ${ }^{15}$ Let $\widehat{\theta}_{j t}=\left(\widehat{a}_{j t}, \widehat{b}_{j t}\right)^{T}$ collect these.

15. That is the values that minmize the expected summed squared diference between the parkm. eter vector and the estmator, given he posterior distribution. The technicalities behind this are set. out extensively in Chaptar 8 and asociated appendices. 
Then, in this example, $\widehat{\theta}_{j t}=\theta_{j t}$, the mean of the most up-to-date perceived distribuhon of $\theta_{j}$.

With conjectures thus fleshed out, each dealer sets his perceived optimal selling price at time tequal to

$$
p_{j t}=\frac{\hat{a}_{j t}}{2 \hat{b}_{j t}}
$$

which exists as generically $\hat{b}_{j t}$ is different from zero. Note that, although $\theta_{j}$ is a random wriable, prices are established point values.

Clearly, the value and development over time of $\widehat{\theta}_{j \text { }}$ determine prices and their adjustment. Note that objective demand is constant, and thus no trade at disequilibrium prices is involved-or, alternatively, this represents the markets for perishable commodities in constant demand. As trade at disequilibrium prices only helps convergence results, they are stronger in the absence of it.

With prior beliefs $\mu_{j 0}\left(\theta_{j}\right)=N\left(\theta_{j 0}, \Sigma_{j 0}\right), \hat{\theta}_{j 0}=\theta_{j 0}$, and dealers simultaneously set prices equal to

$$
p_{j 0}=\frac{a_{j 0}}{2 b_{j 0}}
$$

At those prices, dealer $j$ receives a quantity signal from the market equal to

$$
x_{j 0}=\alpha_{j}-\beta_{j} \frac{a_{j 0}}{2 b_{j 0}}+\gamma_{j} \frac{a-j 0}{2 b_{-j 0}} .
$$

This is the amount he can sell in total at going prices. It will generally differ from the expected salles, which are equal to

$$
\widehat{x}_{j 0}=a_{j 0}-b_{j 0} \frac{a_{j 0}}{2 b_{j 0}}=\frac{1}{2} a_{j 0} .
$$

Dealers will use the new information $\left(p_{j 0}, x_{j 0}\right)$ they got out of the market to update heir beliefs about the distribution of the parameter vector $\theta$. To that end, they apply Bayes" rule. That is, for any set $A \subseteq \Theta_{j}$

$$
\mu_{j 1}(A)=\frac{\int_{A} g_{j}\left(x_{j 0} \mid \theta_{j}\right) \mu_{j 0}\left(d \theta_{j}\right)}{\int_{\Theta_{j}} g_{j}\left(x_{j 0} \mid \theta_{j}\right) \mu_{j 0}\left(d \theta_{j}\right)}
$$

The posterior $\mu_{j 1}\left(\theta_{j}\right)$ from this combination of two nomal distribution is also normal with a well defined mean $\theta_{j 1}$ and covariance matrix $\Sigma_{j 1}$, and serves as a basis for the Bayesian least squares estimate $\hat{\theta}_{j \Perp}=\theta_{j}$, which in turn serves to formulate prices $p_{j 1}$ to collect $x_{j 1}$. The intermediate posterior is, therefore, normal for each $t=1, \ldots$ In fact, the posterion mean and covariance matrix follow a recursive system that is well defined for this special normal case ${ }^{16}$ 
A conjectural equilibrium of the sequential price adjustment process thus specified has to satisfy that notional sales are equal to effective sales at the prices believed io be profit maximizing. That is, conjectural equilibrium exists from time $T$ onwards if $\widehat{x}_{j T}=x_{j T}$ or,

$$
a_{j T}-b_{j T} p_{j T}=\alpha_{j}-\beta_{j} p_{j T}+\gamma_{j} p_{-j T} .
$$

As $p_{j}=\frac{a_{y T}}{2 k_{j} T}$, the set of conjectural equilibria $\left(p_{1}^{*}, x_{1}^{*}, p_{2}^{*}, x_{2}^{*}\right)$ is characterized by estimates $a_{j}^{*}>0$ and $b_{j}^{*}>0$ that satisfy

$$
\alpha_{j}-\beta_{j} \frac{a_{j}^{*}}{2 b_{j}^{*}}+\gamma_{j} \frac{a_{-j}^{*}}{2 b_{-j}^{*}}=\frac{1}{2} a_{j}^{*}, \text { for } j=(1,2) .
$$

Generally, there exists a set of parameters that thus support conjectural equilibrium, so that conjectural equilibrium is not unique. ${ }^{17}$

Of particular interest is the illustration the example provides of several of the features of disequilibrium theory stressed before. One of them is full exposure of the necessity to discard the law of supply and demand. Another is that, although there exists an infinite amount of conjectural equilibria, the disequilibrium process closes in on one of them, depending on the initial beliefs.

These features are illustrated by means of simulation studies-where use is made of the sequential version derived in Appendix A. Consider Figure 7.1 below.

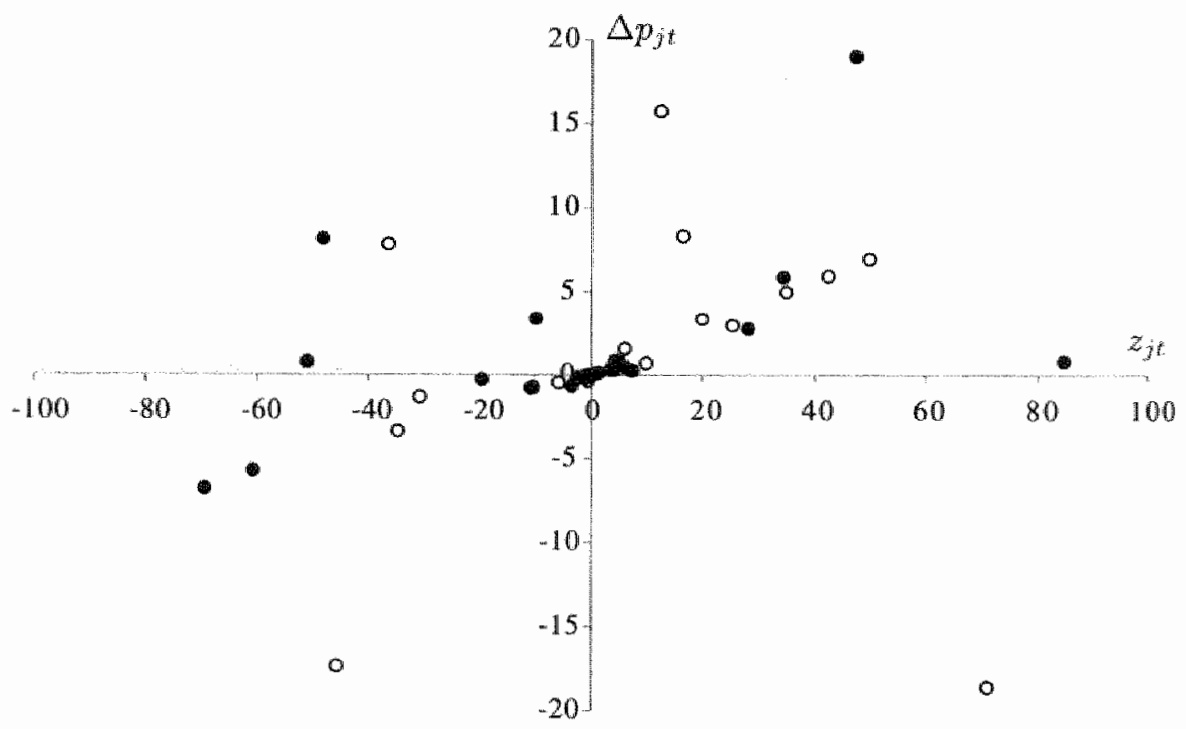

Figure 7.1 An illustration of the general failure of the law of supply and demand.

The figure displays, for reasonable parameter values, not specially chosen, excess

if Among these is the Nash equilibrium that would be established in one shot were all information perfect and complete. 
demand $z_{j t} \equiv x_{j t}-\widehat{x}_{j t}$ of each of two dealers, set out on the horizontal axis, against the subsequent change in price $\Delta p_{j t}=p_{j, t+1}-p_{j t}$, vertically-dealer 1 is represented by clossed balls, dealer 2 by open balls. 18 Obviously, the law of supply and demand prescribes that all pairs of values in this scatter plot should be found in the first and third quadrant. Several values, however, are found in the upper-left quadrant (and one for dealer 2 in the lower-right one). These indicate that in the face of effective sales surpassing (falling below) motional trades-which effectively means dealers have purchased insufficient stock to keep up with demand (respectively too much stock) dealers decrease (increase) prices. This clearly violates the law of supply and demand, this falsifying it. It is, in other words, not necessarily individually rational to follow the law of supply and demand. ${ }^{19}$

Interestingly enough, the simulations also display a faimly rapid global stability of the adjustment process. In Figure 7.1, the cluster of dots around the origin are observations in later time periods of the simulation, when convergence of price gradually equates notional and effective sales for both dealers-the open balls converge to 0 as well, yet fall together with the closed ones. ${ }^{20}$

Typically, prices develop over time as in Figure 7.2 below.

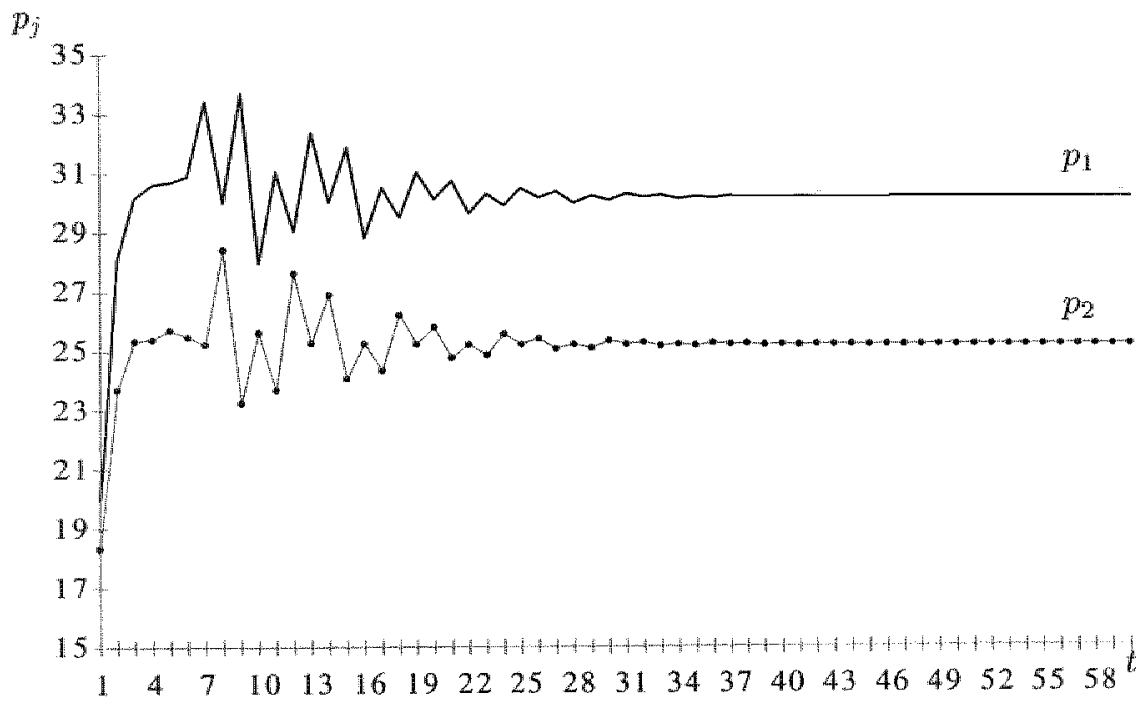

Figure 7.2 Typical individually rational price adjustment.

Again, the figure is drawn for non-specifically chosen parameters. As displayed,

\footnotetext{
Is Simulations were carried ont in Microsoft Excel, with which the following graphs were produced. The specific purameters of Figure 7.1 are: $\alpha_{1}=50, \alpha_{2}=50_{1}, \beta_{1}=4, \gamma_{1}=3, \beta_{2}=3, \gamma_{2}=2, c_{1}=15$, and $c_{2}=20$. The variance of conjectured demand, $\sigma_{e_{j}}^{2}$, is set equal to 1 .

ig It should be noted, however, that, ewen though in general some walues in the second and fourth Guadrant are found, the majority of simulations seems, for arbitrary parameter values, to display a strong majority of sign-preserving price adjustments.

20 In Figure 7.1 prices converge after about 40 periods to the values $p_{1}=16,9$ and $p_{2}=7,8$.
} 
prices tend to fluctuate wildly for some time, to then setile down after sufficienty many periods - even for quite sought out parameter values, for which the initial phase of fluctuation displays a chaotic grid, eventually a flat line is hit from which the proces no longer deviates. In Figure 7.2 , prices converge after about 50 periods to values of around $p_{1}=30$, displayed by the upper straight line, and $p_{2}=25,3$, the lower, dotted line. 21

The andlytical analysis of this apparent global asymptotic stability of the proces are fairly complicated, however. In fact, Kimman's studies of the ordinary least squars equivalent of the model above extend over so many years because convergence resulis were, although robustly suggested by large varieties of simulations, hard to substanti. ate. Early on, in his 1983 paper, Kiman conjectured the process was globally stable. In Brousseau and Kirman (1992, 1993), however, this is withdrawn and convergence of prices and sales is attributed to the fact that when the number of observations grows, the influence that new observations have on prices vanishes. ${ }^{22}$ This idea is co:roborated by truncating the memory of past observations-see Appendix A. Also, the 1992 papers present a theoretical result of local imstability for the set of conjectural equilibria.

The latter, however, is quite obviously true as conjectural equilibrium are not isalated, and has no bearing on the global stability issue. Also, discarding old observations during adjustment amounts to a displacement of the learning process while possiby converging. Therefore, these are not very strong arguments against possible global asymptotic stability of the process. Moreover, simulation experiments in which the gain factor associated with new observations does not vanish still display convergence of prices. ${ }^{23}$ Nevertheless, the apparent manifestation of global convergence on the set of conjectural equilibria has never been substantiated theoretically. In the next chap ter, a more general version of the example given here is offered, in which global stability result is available. ${ }^{24}$

\footnotetext{
21 Here $\alpha_{1}=7 w_{2} \alpha_{2}=50, \beta_{1}=3, \gamma_{1}=2, \beta_{2}=4, \gamma_{2}=2, c_{1}=15$, and $c_{2}=20$. Again, $\sigma_{e_{j}}^{2}=1$. 22 Op.cil. p. 317 .

23 On these, as well as experiments with non-linear objective demand tunctions, wh th which agin stimulating convergence results are obtained, see Tuinstra (1999), Chapter 6 .

24 On tho convergence and nature of Bayesian estimators when the explanatory variables are independenty and identically distributed which they quite essentially are not in the example miven here, as prices are set-see Schinkel (1999).
} 


\section{A Theory of Disequilibrium Behavior}

The essential elements of a meaningful theory of disequilibrium behavior-imperfect competition, incomplete and imperfect information-can now be combined. In this chapter, some progress is made by doing so in a relatively general model. That is, in the following a model of individually rational price setting and price adjustment is developed. The monopolistically competitive dealer structure is retained. That is, dealers are staged, that monopolistically compete, each offering its own commodity in a shop. Customers, both consumers and firms, visit these shops to buy as well as to sell. Dealers set prices to maximize their perceived profits, which derives from the difference between the prices against which they purchase and those against which they sell. Perceptions are generally different from the objective market relations. Over the disequilibrium process, when there is reason to do so, they are adjusted in the light of market experiences gained with the price proposals. Consequently, so do prices, which specifies a price adjustment process.

The chapter sets out the structure for modelling this type of disequilibrium process, and presents a general condition that is necessary and sufficient for global asymptotic convergence of prices. This condition is rather strong, and will be discussed and related to existing stability conditions-particularly No Favorable Surprise. The present model is still rather special. Only the sales side is explicitly considered, for example, and there is no trade at disequilibrium prices, so that demand functions do not vary over the process, other than as a result of price changes. Yet, the technicalities involved in introducing conjectured supply are analogous to the analysis of demand offered, and 30 are the qualitative conclusions on stability. Also, it has already been said that trade at disequilibrium prices generally helps convergence results. In all, the present model is a generalized version of the example given towards the end of the previous chapter.

The chapter is organized as follows. In the next section the economy is set out. Its objective demand structure and the subjective perception of it are introduced. Section 
8.2 presents the leaming dynamics. In Section 8.3 the concept of equilibrimm appropriate for the economy is defined. As there is uncertainty in objective demand, it is a stochastic variant of conjectural equilibrium. Several elementary technical properties of the rationd leoming process are specified in Section 8.4. Section 8.5 presents the convergence result obtained on beliefs and prices. Section 8.6 discusses their nature. Finaly, Section 8.7 presents the condition for almost sure asymptotic convergence, as

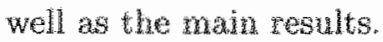

\subsection{Objective Demand and Subjective Perceptions}

Consider an economy with $n$ commodities traded in by $n$ different dealers in monopolistic price competition. "Thus each dealer $j$ is the sole supplier of a quantity $x_{j} \in X_{j}$ of its commodity $j$. The structure of shops and shop-owners is exogenously given, and assumed not to change over the disequilibrimm process. It can perhaps best be thought of as reflecting a social convention. Naturally, this assumption dodges important questions on the evolution of such a structure in the competitive process. One would expect shops to go out of business, and new ones to give competition by entering the market, so that several dealers end up selling similar products. All this is abstracted from. Instead, emphasis here is on the price adjustment process. Howewer, assuming the absence of entry is not as strong as it may seem. Since products are de fined by dealer, product differentiation will guarantee local monopolistic power even in the face of entry. Moreover, the results found are sufficiently strong to incorporate changes in objective demand. Also, in the current exposition the demand of the dealers, who have, of course, two sides to their shops, is ignored. Such an analysis wonld. under some appropriate independence assumptions on perception be analogous to the following.

For technical reasons $X_{j}$ is assumed to be a compact metric space. Let $\mathcal{B}_{X_{j}}$ be the Borel $\sigma$-algebra constructed with this metric, and let $\nu_{j}$ be an arbitrary probability measure on $\mathcal{B}_{X_{j}}$. Together, they constitute a Borel measure space $\left(X_{j}, \mathcal{B}_{X_{j}}, \nu_{j}\right)$. It is assumed that for any open set $U \subseteq X_{j}$, it holds that $\nu_{j}(U)>0$ - that is, the support. of $\nu_{j}$ equals $X_{j}$. For each commodity space $X_{j}$ there is a price space $P_{j}$ which is assumed to be a compact convex subspace of a normed space. Let $\mathcal{B}_{p_{j}}$ be the Borel $\sigma$-algebra bised on the distance norm.

Demand depends on price. Objective demand for commodity $x_{j}$ is conditionally distributed according to the probability density function

$$
f_{j}\left(\cdot \mid \mathbf{p}, \psi_{j}\right)
$$

with respect to $\nu_{j}$. The vector $\mathrm{p}=\left(p_{1,}, \ldots, p_{n}\right) \in P=x_{j=1}^{n} P_{j}$ is the price vector of the $n$ commodities. Naturally, objective demand relates to the preferences of consumers.

I This section is mainly technical-albeit of a more essential nature than the technicalitios tro the appendices $B$ and $C$ and con be skipped withon loosing the line of reasoning. 
The partmeter $\psi_{j}$ is an element of the space $\psi_{j}$, a compact metric space. Its associated Borel o-algebra is denoted by $\mathcal{B}_{\Psi_{j}}{ }^{2}$

By $f_{j}\left(\mid \mathbf{p}_{i} \psi_{j}\right)$ being defined with respect to $\nu_{j}$, it is meant that

$$
\int_{X_{j}} f_{j}\left(\cdot \mid \mathbf{p}, \psi_{j}\right) \nu_{j}\left(d x_{j}\right)=1
$$

Furthermore, it is assumed that the function $f_{j}: X_{j} \times P \times \Psi_{j} \rightarrow \mathbb{R}$ is continuous.

Mone of the dealers is fully aware of the mechanism that generates the objective demand it faces. Instead, each dealer conjectures that it serves a demand function that is conditionally distributed according to the probability density function

$$
g_{3}\left(\cdot \mid p_{j}, \theta_{3}\right)
$$

with respect to $\nu_{j}$. Again, $\theta_{j} \in \Theta_{j}$ is a parameter and $p_{j} \in P_{j}$ is dealer $j$ 's choice variable. Also, it is assumed that $\Theta_{j}$ is a compact metric space with the Borel $\sigma$-algebra $B_{\theta_{j}}$. Note that $\Theta_{j}$ is initially mot related to $\Psi_{j}$. It holds that

$$
\int_{X_{j}} g_{j}\left(\cdot \mid p_{j}, \theta_{j}\right) \nu_{j}\left(d x_{j}\right)=1
$$

Furthermore, the function $g_{j}: X_{j} \times P_{j} \times \Theta_{j} \rightarrow \mathbb{R}$ is continuous.

Subjective demand conjectures deviate importantly from objective demand: each dealer only considers the effect of its own price on the demand for its commadity, and neglects the influence of the prices of the other commodities. That is, each dealer believes it is a monopolist on its own market. This structural mis-specification reflects incomplete information on the side of the dealers. Focus is here on the extreme situation where only the own price effect is considered for reasons of exposition. The analysis could be extended to include less severe forms of incomplete information, 4. 9 . structures in which the price effects of seweral of the nearest competitors are included. Yet, the presence of some incomplete information is a crucial disequilibrium phenomenon in any case.

Within its structural mis-specification, each dealer believes that there exists a true parameter vector $\theta_{j}^{0} \in \Theta_{j}$, the value of which it does not know. Instead, the dealer's perception of the world is stochastic. It forms beliefs $\mu_{j} \in P\left(\Theta_{j}\right)$, where $P\left(\Theta_{j}\right)$ is the set of probability measures on $\Theta_{j}$. Thus, a belief assigns to each Borel subset $A$ of $\theta_{j}$ real number $\mu_{j}(A)$ that retlects the probability of the real parameter $\theta_{j}^{0}$ being an element of $A$. Since $\Theta_{j}$ is the space of worlds the dealer perceives as possible, it is matural to assume that initially for all $j, \mu_{j 0}(U)>0$ for all open sets $U \subseteq \Theta_{j}$.

Let

$$
\pi_{j}\left(p_{j}, x_{j}\right) \in \mathbb{R}
$$

2 Although the parameter $\psi_{j}$ does not immediately play role here, it is relevant to specify it for whist is to come. 
be the net profit of demand $x_{j}$ at $p_{j}$. It is assumed that $\pi_{j}$ is continuous. Given the belief $\mu_{j}$, subjectively expected net profit of dealer $j$ if it sets price $p_{j}$, is given by

$$
\Pi_{j}\left(p_{j}, \mu_{j}\right)=\int_{\Theta_{j}} \int_{X_{j}} \pi_{j}\left(p_{j}, x_{j}\right) g_{j}\left(x_{j} \mid p_{j}, \theta_{j}\right) \nu_{j}\left(d x_{j}\right) \mu_{j}\left(d \theta_{j}\right)
$$

If possible, the second variable in the notation will be suppressed, and refer to subjective expected net profit as $\Pi_{j}\left(p_{j}\right)$.

Maximizing (8.3) with respect to $p_{j}$ returns an optimal price. Clearly this optimal price depends upon the beliefs over the parameters $\theta_{j}$. Therefore, it will be denoted by $p_{j}\left(\mu_{j}\right)$. The following assumption is made for convenience.

Assumption 8.1 For each $\mu_{j} \in P\left(\Theta_{j}\right)$ there is a unique price $p_{j}\left(\mu_{j}\right)$ that maximizes $\Pi \Pi_{j}\left(p_{j}, \mu_{j}\right)$.

Note that for arbitrary beliefs, the prices $p_{j}\left(\mu_{j}\right)$ need not maximize expected profits in an objective sense. This is so since, although the world is in fact stochastic, it is stochastic in a way different from perception. More specifically, given individual price strategies, objective demand is distributed according to

$$
f_{j}\left(\mid p_{1}\left(\mu_{1}\right), \ldots, p_{n}\left(\mu_{n}\right), \psi_{j}\right)
$$

which shows how the true sales opportunities depend on the beliefs of all dealers, which together determine the objective expected net profit. Let

$$
\mathbf{p}=\left(p_{1}\left(\mu_{1}\right), \ldots, p_{n}\left(\mu_{n}\right)\right)
$$

be the vector of prices. The objective expected net profit of dealer $j$ at $\mathbf{p}$ then is in fact given by

$$
\int_{X_{j}} \pi_{j}\left(p_{j}, x_{j}\right) f_{j}\left(x_{j} \mid \mathbf{p}, \psi_{j}\right) \nu_{j}\left(d x_{j}\right)
$$

No dealer is, of course, capable of tuning its behavior to this true expected net profit.

\subsection{Learning Dynamics}

Dealers are aware of the fact that they have imperfect information abont the value of $\theta_{j}^{i}$, and are eager to leam more about it from market experience. They do so in the following way. Upon their prior beliefs $\mu_{0}=\left(\mu_{10}, \ldots, \mu_{n_{0}}\right)$ dealers set perceived optimal prices $p_{j}\left(\mu_{j 0}\right)$. The objective demand equation (8.4) then establishes the quantities that can actually be sold at these prices, $x_{j 1}$. Generally, this information is ground for a revision of beliefs through a learning process, as follows.

At a given time $\tau$, each individual dealer has been able to record histories of finits length $\tau$, denoted as

$$
h_{j \tau}=\left\{x_{j t}\right\}_{t=1}^{T}
$$


This market information is the basis of beliefs at time $\tau$. That is, conditional on observed histories up until $\tau$, dealer $j$ has a posterior $\mu_{j \tau}\left(\theta_{j} \mid h_{j \tau}\right)$. It then sets a price $p_{j}\left(\mu_{j T}\right)$ given its past observations and its current beliefs on $\theta_{j}$. This price serves as a signal that returns an observation of associated quantities $x_{j, r+1}$.

In the following, let the subjectively optimal choice $p_{j}\left(\mu_{j \tau}\right)$ be denoted by $p_{j \tau}$, and let $\mathbf{p}_{\tau}=\left(p_{1 \tau}, \ldots, p_{n \tau}\right)$. Note that the decision on $p_{j \tau}$ the dealer takes at time $\tau$ is a function only of the beliefs at time $\tau$, which in turn derive from the initial beliefs $\mu_{j 0}$ and the recorded history up until $\tau$. Hence, it is sufficient to record sequences of observed quantities, as the dealers do.

Beliefs are updated according to the Bayesian updating rule, as follows. After setting $p_{j \tau}$ and observing $x_{j, \tau+1}$, for each Borel set $A \in B_{\Theta_{j}}$

$$
\mu_{j, \tau+1}\left(A \mid h_{j \tau}, x_{j, \tau+1}\right)=\frac{\int_{A} g_{j}\left(x_{j, \tau+1} \mid p_{j \tau}, \theta_{j}\right) \mu_{j \tau}\left(d \theta_{j} \mid h_{j \tau}\right)}{\int_{\Theta_{j}} g_{j}\left(x_{j, \tau+1} \mid p_{j \tau}, \theta_{j}\right) \mu_{j \tau}\left(d \theta_{j} \mid h_{j \tau}\right)}
$$

Hence, the posterior probability that $\theta_{3}^{0} \in A$ is equal to the prior perceived ratio of the probability of the observed value of $x_{j}$ when $\theta_{j}$ is in $A$, and the probability of the observed value for all possible values of $\theta_{3}$. That is, for each given way in which prices follow from beliefs, the learning process the dealers apply yields a mapping

$$
B_{j}: P\left(\Theta_{j}\right) \times X_{j} \rightarrow P\left(\Theta_{j}\right),
$$

from the space of probability measures and the space of quantities $X_{j}$ back to the space of probability measures. ${ }^{3}$ Note that posterior beliefs are thus found as $B_{j}\left(\mu_{j}, x_{j}\right)$. This particular updating method is firmly founded in probability theory, so that it is sensible from the dealers' perspective to extract information from past observations in this way. Yet, it is important to note that dealers do not anticipate that they will learn from experience. That is, they do not set prices with a view just to obtaining new knowledge from the resulting market signals. In other words, they are passive learners as opposed to active learners. Moreover, signals are trade proposals; they are not actually carried out.

\subsection{Conjectural Equilibrium}

Although it makes perfect sense from the perspective of the dealers, the learning process described is ill-founded in objective terms since it is based on an mnrecognized structural mis-perception of demand. Hence, in general it cannot be hoped that subjective perceptions will come to explain the true demand for a commodity. Yet, there is a natural candidate for beliefs that are in 'equilibrium' with the objective world. Consider a single dealer. The dealer's beliefs are in equilibrium if perceived optimal prices set on the basis of it return quantities that are no ground for a revision of beliefs. This is the concept of individual conjectural equilibrium.

In Section 8.4 conditions are set out under which this mping is well-behaved 
Definition 8.1 An individual conjectural equilibrium for dealer $j$ is a price $p_{j}$, wh

$$
p_{j}=\operatorname{argmax} \mathbb{I}_{j}\left(p_{j}, \mu_{j}\right)
$$

for which for all $x_{j} \in X_{j}$

$$
B_{j}\left(p_{j}\left(\mu_{j}\right), x_{j}\right)=\mu_{j}
$$

Since the observed sales depend upon the prices of all dealers, it is quite special for a single dealer to be in individual conjectural equilibrium. Yet, if all dealers multaneously are in individual conjectural equilibrium, none has a reason to deviate unilaterally from its price, since none believes it can improve its position by doing $s 0$. This leads to the following notion of an equilibrium for the economy.

Definition 8.2 A conjectural equilibrium is a price vector

$$
\mathbf{p}=\left(p_{1}\left(\mu_{1}\right), \ldots, p_{n}\left(\mu_{n}\right)\right)
$$

with

$$
p_{j}=\arg \max \Pi_{j}\left(p_{j}, \mu_{j}\right)
$$

for which for all $x_{j} \in X_{j}$

$$
B_{j}\left(p_{j}\left(\mu_{j}\right), x_{j}\right)=\mu_{j} \text { for ald } j
$$

Reference to the conjectural equilibrium price vector will be as $\mathbf{p}^{*}$.

\subsection{Elementary Properties of Rational Learning}

For the Bayesian learning process to be well specified, it is necessary that there are no objectively possible observations $x_{j}$ that are assigned probability zero at any time by the dealer. A Bayesian learner, namely, would simply not be able to deal with such events. By the construction of the quantity spaces $X_{j}$, it is natural to assume that $f_{j}\left(\mid \mathbf{p}, \psi_{j}\right)$ assigns positive probability to each event $x_{j}, i . e$, that for all $\mathbf{p}_{j}$

$$
f_{j}\left(x_{j} \mid \mathbf{p}, \psi_{j}\right)>0 \text { for all } x_{j} \in X_{j}
$$

With this knowledge, the following sufficient condition can be specified."

" It is in feli only necessary that for all ind all $p$

$$
\left\{x_{i} \mid f_{i}\left(x_{i} \mid \mathbf{p}, \psi_{i}\right)>0\right\} \subseteq\left\{x_{i} \mid \int_{\Theta_{i}} g_{i}\left(x_{i} \mid p_{i}, \theta_{i}\right) \mu_{i \tau}\left(d \theta_{i} \mid h_{i, \tau}\right)>0\right\} \text { for all } \tau \text {. }
$$

This condition allows for dealers to assign zero probability only to events that actually have objective probability zero. On the other hand, positive probability can be assigned to events that will newar' happen objectively. 
Assumption 8.2 For all $p_{j}$ and all $\theta_{j}$,

$$
g_{j}\left(x_{j} \mid p_{j}, \theta_{j}\right)>0 \text { for all } x_{j} \in X_{j}
$$

That is, all dealers are assumed to have sufficiently wide world views.

With this assumption, there is assurance that no Bayesian learming process will be bindered, by the following result.

Proposition 8.1 For all $x_{j}$,

$$
\int_{\Theta_{j}} g_{j}\left(x_{j} \| p_{j}, \theta_{j}\right) \mu_{j \pi}\left(d \theta_{j} \| h_{j T}\right)>0 \text { for all } \tau \text {. }
$$

Proof. Since $\mu_{j \tau}$ is a probability distribution on $\Theta_{j}$, it holds for all $T$ that

$$
\int_{\Theta_{j}} \mathbb{L}_{\Theta_{j}} \mu_{j r}\left(d \theta_{j} \mid h_{j \tau}\right)=\mu_{j \tau}\left(\Theta_{j} \mid h_{j \tau}\right)=1
$$

The function $g_{j}\left(x_{j} \mid p_{j}, \theta_{j}\right)$ is continuous in $x_{j}$ for given $p_{j}$ and $\theta_{j}$. Moreover, $X_{j}$ is compact, so that there exists a real number $\varepsilon>0$, such that $g_{j}\left(x_{j} \mid p_{j}, \theta_{j}\right) \geq \varepsilon$ for all $\mathbb{a}_{j} \in X_{j}$. Comsequently, for all $x_{j} \in X_{j}$ and all $\tau$

$$
\begin{aligned}
\int_{\Theta_{j}} g_{j}\left(x_{j} \mid p_{j}, \theta_{j}\right) \mu_{j \tau}\left(d \theta_{j} \mid h_{j \tau}\right) & \geq \int_{\Theta_{j}} \varepsilon \mathbb{H}_{\Theta_{j}} \mu_{j \tau}\left(d \theta_{j} \mid h_{j \tau}\right) \\
& =\varepsilon \int_{\Theta_{j}} \mathbb{I}_{\Theta_{j}} \mu_{j \tau}\left(d \theta_{j} \mid h_{j \tau}\right)=\varepsilon
\end{aligned}
$$

which is positive.

Moreover, it assures that for finite time, no value of $\theta_{j}$ will be discarded.

Proposition 8.2 For all $A \in B_{\Theta_{j}}$,

$$
\text { if } \mu_{j 0}(A)>0 \text { then } \mu_{j \tau}(A)>0 \text { for all } T<\infty \text {. }
$$

Proof. By Assumption 8.2, $g_{j}\left(x_{j 1} \mid p_{j 0}, \theta_{j}\right)>0$ for all $x_{j 1} \in X_{j}$. Consequentily, since $\mu_{j 0}(A)>0$ for all $A \in \mathcal{B}_{\Theta_{j}}$,

$$
\int_{A} g_{j}\left(x_{j 1} \mid p_{j 0}, \theta_{j}\right) \mu_{j 0}\left(d \theta_{j}\right)>0 \text { for all } A \in \mathcal{B}_{\Theta_{j}}
$$

The result now follows inductively from the observation that

$$
\mu_{j \mathbb{I}}\left(A \mid x_{j 1}\right)=\frac{\int_{A} g_{j}\left(x_{j 1} \mid p_{j 0}, \theta_{j}\right) \mu_{j 0}\left(d \theta_{j}\right)}{\int_{\Theta_{j}} g_{j}\left(x_{j 1} \mid p_{j 0}, \theta_{j}\right) \mu_{j 0}\left(d \theta_{j}\right)}>0
$$

where the denominator is positive by Proposition 8.1 .

Finally, with the assumptions sufficient for the learning process the dealers apply to be well-specified in place, it can be shown that the rational learning process is continuous. This requires several intermediate results, that are presented first. 
Since the cenominator in the definition of Bayesian updating is larger than zero by Proposition 8.1, it is easy to see that $B_{j}\left(\mu_{j}, x_{j}\right)$ is a non-negative function on the Borel $\sigma$-algebra on $\Theta_{j}$. The $\sigma$-additivity of $B_{j}\left(\mu_{j}, x_{j}\right)$ follows from the $\sigma$-additivity of the integral and finally it is obvious that $B_{j}\left(\mu_{j}, x_{j}\right)\left(\Theta_{j}\right)=1$. So $B_{j}\left(\mu_{j}, x_{j}\right)$ is indeed a probability measure, and the Bayes operator thus only takes on values in $P\left(\Theta_{j}\right)$. Consider the following technicalities.

Lemma 8.1 Suppose there is a sequence $\left(p_{j k}\right)_{k \in \mathbb{N}}$ that converges to some $p_{j}$. Then there is a number $K$ such that for all $k>K$, all $x_{j}$ and all $\theta_{j}$

$$
\left|\pi_{j}\left(p_{j k}, x_{j}\right) g_{j}\left(x_{j} \mid p_{j k}, \theta_{j}\right)-\pi_{j}\left(p_{j}, x_{j}\right) g_{j}\left(x_{j} \mid p_{j}, \theta_{j}\right)\right|<\varepsilon .
$$

Proof. Suppose not. Then for every number $n$ there is a number $k(n) \geq n$ and points $\left(x_{j}(n), \theta_{j}(n)\right)$ such that

$$
\left|\pi_{j}\left(p_{j k(n)}, x_{j}(n)\right) g_{j}\left(x_{j}(n) \mid p_{j k(n),}, \theta_{j}(n)\right)-\pi_{j}\left(p_{j}, x_{j}(n)\right) g_{j}\left(x_{j}(n) \mid p_{j}, \theta_{j}(n)\right)\right| \geq \varepsilon .
$$

Since both $X_{j}$ and $\Theta_{j}$ are compact it can without loss of generality be assumed that the sequence $x_{j}(n)_{n \in \mathbb{N}}$ converges to a point $x_{j}$ and the sequence $\theta_{j}(n)_{n \in \mathbb{N}}$ converges to a point $\theta_{j}$. However, since $k(n) \geq n$ by construction, it follows that $p_{j k(n)} \rightarrow p_{j}$. Hence, taking limits yields

$$
0=\left|\pi_{j}\left(p_{j}, x_{j}\right) g_{j}\left(x_{j} \mid p_{j}, \theta_{j}\right)-\pi_{j}\left(p_{j}, x_{j}\right) g_{j}\left(x_{j} \mid p_{j}, \theta_{j}\right)\right| \geq \varepsilon_{,}
$$

which is a contradiction.

Proposition 8.3 The function $p_{j}: P\left(\Theta_{j}\right) \rightarrow P_{j}$ is continuous.

Proof. The proof is in two parts. Part (i). It will be shown that the expected pay-off function

$$
\Pi_{j}: P_{j} \times P_{j}\left(\Theta_{j}\right) \rightarrow \mathbb{R}
$$

is continuous. Suppose that $P_{j}\left(\theta_{j}\right)$ is endowed with the weak topology. Note that this topology is metrizable by Theorem B.3 in Appendix B. Therefore, it is sufficient to establish convergence of $\Pi_{j}$ over sequences. To this end, take a sequence $\left(p_{j k}, \mu_{j k}\right) \rightarrow$ $\left(p_{j}, \mu_{j}\right)$. It is shown that, given $\varepsilon>0$, there exists a natural number $K$, such that for all $k \geq K$,

$$
\left|\Pi_{j}\left(p_{j k}, \mu_{j k}\right)-\Pi_{j}\left(p_{j}, \mu_{j}\right)\right|<2 \varepsilon .
$$

By the triangle inequality

$$
\begin{aligned}
& \left|\Pi_{j}\left(p_{j k}, \mu_{j k}\right)-\Pi_{j}\left(p_{j}, \mu_{j}\right)\right| \\
\leq & \left|\Pi_{3}\left(p_{j k}, \mu_{j k}\right)-\Pi_{j}\left(p_{j}, \mu_{j k}\right)\right|+\left|\Pi_{j}\left(p_{j}, \mu_{j k}\right)-\Pi_{j}\left(p_{j}, \mu_{j}\right)\right|,
\end{aligned}
$$

so that it is only required to show that

$$
\left|\Pi_{j}\left(p_{j k}, \mu_{j k}\right)-\Pi_{j}\left(p_{j}, \mu_{j k}\right)\right|+\left|\Pi_{j}\left(p_{j}, \mu_{j k}\right)-\Pi_{j}\left(p_{j}, \mu_{j}\right)\right|<2 \varepsilon
$$


tor sufficiently large $k$.

The first term reads

$$
\begin{aligned}
& \left|\int_{\theta_{j}} \int_{X_{j}}\left(\pi_{j}\left(p_{j k}, x_{j}\right) g_{j}\left(x_{j} \mid p_{j k}, \theta_{j}\right)-\pi_{j}\left(p_{j}, x_{j}\right) g_{j}\left(x_{j} \mid p_{j}, \theta_{j}\right)\right) \nu_{j}\left(d x_{j}\right) \mu_{j k}\left(d \theta_{j}\right)\right| \\
\leq & \int_{\Theta_{j}} \int_{X_{j}} \mid \pi_{j}\left(p_{j k}, x_{j}\right) g_{j}\left(x_{j} \mid p_{j k}, \theta_{j}\right) \\
& -\pi_{j}\left(p_{j}, x_{j}\right) g_{j}\left(x_{j} \mid p_{j}, \theta_{j}\right) \mid \nu_{j}\left(d x_{j}\right) \mu_{j k}\left(d \theta_{j}\right) .
\end{aligned}
$$

Now take $K$ as in Lemma 8.1. Then, since $\nu_{j}$ and $\mu_{j k}$ are all probability measures, so that $\nu_{j}\left(X_{j}\right)=\mu_{j k}\left(\Theta_{j}\right)=1$, for each $k \geq K$

$$
\begin{aligned}
& \int_{\Theta_{j}} \int_{X_{j}}\left|\pi_{j}\left(p_{j k}, x_{j}\right) g_{j}\left(x_{j} \mid p_{j k}, \theta_{j}\right)-\pi_{j}\left(p_{j}, x_{j}\right) g_{j}\left(x_{j} \mid p_{j}, \theta_{j}\right)\right| \nu_{j}\left(d x_{j}\right) \mu_{j k}\left(d \theta_{j}\right) \\
\leq & \int_{\Theta_{j}} \int_{X_{j}} E \mathbb{I}_{\Theta_{j} \times X_{j}}\left(\theta_{j}, x_{j}\right) \nu_{j}\left(d x_{j}\right) \mu_{j k}\left(d \theta_{j}\right)=\varepsilon .
\end{aligned}
$$

The second term, $\left|\Pi_{j}\left(p_{j}, \mu_{j k}\right)-\Pi_{j}\left(p_{j}, \mu_{j}\right)\right|$, reads

$$
\begin{aligned}
& \int_{\Theta_{j}} \int_{X_{j}}\left[\pi_{j}\left(p_{j}, x_{j}\right) g_{j}\left(x_{j} \mid p_{j}, \theta_{j}\right) \mu_{j}\left(d x_{j}\right) \mu_{j k}\left(d \theta_{j}\right)\right] \\
& \left.-\pi_{j}\left(p_{j}, x_{j}\right) g_{j}\left(x_{j} \mid p_{j}, \theta_{j}\right)\right] \nu_{j}\left(d x_{j}\right) \mu_{j}\left(d \theta_{j}\right) .
\end{aligned}
$$

Because it is assumed that $P\left(\Theta_{j}\right)$ is endowed with the wealk topology, it suffices to show that

$$
F_{p}\left(\theta_{j}\right) \equiv \int_{X_{j}} \pi_{j}\left(p_{j}, x_{j}\right) g_{j}\left(x_{j} \mid p_{j}, \theta_{j}\right) \nu_{j}\left(d x_{j}\right)
$$

is continuous in $\theta_{j}$. To that end, take a sequence $\theta_{j m} \rightarrow \theta_{j}$. Let $\varepsilon>0$ be an arbitrary real number. Let $G_{p}$ be a positive real number such that

$$
\left|\pi_{j}\left(p_{j}, x_{j}\right)\right| \leq G_{p} \text { for all } x_{j} \in X_{j} .
$$

This number exists because $\pi_{j}\left(p_{j}, x_{j}\right)$ is contimuous in $x_{j}$ and $X_{j}$ is compact. Now take a natural number $M_{p}$, such that for all $m \geq M_{p}$,

$$
\left|g_{j}\left(x_{j} \mid p_{j}, \theta_{j m}\right)-g_{j}\left(x_{j} \mid p_{j}, \theta_{j}\right)\right| \leq \frac{\varepsilon}{G_{p}} .
$$

Then for all $m \geq M_{p}$

$$
\begin{aligned}
\left|F_{p}\left(\theta_{j m}\right)-F_{p}\left(\theta_{j}\right)\right| & =\left|\int_{X_{j}} \pi_{j}\left(p_{j}, x_{j}\right)\left(g_{j}\left(x_{j} \mid p_{j}, \theta_{j m}\right)-g_{j}\left(x_{j} \mid p_{j}, \theta_{j}\right)\right) \nu_{j}\left(d x_{j}\right)\right| \\
& \leq \int_{X_{j}}\left|\pi_{j}\left(p_{j}, x_{j}\right)\right|\left|g_{j}\left(x_{j} \mid p_{j}, \theta_{j m}\right)-g_{j}\left(x_{j} \mid p_{j}, \theta_{j}\right)\right| \nu_{j}\left(d x_{j}\right) .
\end{aligned}
$$


Consequently, since $\nu_{j}\left(X_{j}\right)=1$,

$$
\left|F_{p}\left(\theta_{j m}\right)-F_{p}\left(\theta_{j}\right)\right| \leq \int_{X_{j}} G_{p} \frac{\varepsilon}{G_{p}} \nu_{j}\left(d x_{j}\right)=\varepsilon_{.}
$$

Part (ii). Now let $\left(\mu_{j k}\right)_{k \in \mathbb{N}}$ be a sequence converging to $\mu_{j}$ in the weak topology. Then, since $P_{j}$ is a compact part of a normed space, every sequence has a converging subsequence by Theorem B.4. So it may without loss of generality be assumed that $p_{j}\left(\mu_{j k}\right)$ converges to some price $p_{j}^{*}$. It will be shown that $p_{j}^{*}=p_{j}\left(\mu_{j \infty}\right)$, so that $p_{j}^{*}=p_{j \infty}$. It is known that for an arbitrary $p_{j}$ it holds that

$$
\Pi_{j}\left(p_{j}\left(\mu_{j k}\right), \mu_{j k}\right) \geq \Pi_{j}\left(p_{j}, \mu_{j k}\right) \text { for all } k \text {. }
$$

So by the continuity of $\Pi_{j}(\cdot)$ it holds that

$$
\Pi_{j}\left(p_{j}^{*}, \mu_{j \infty}\right) \geq \Pi_{j}\left(p_{j}, \mu_{j \infty}\right)
$$

and $p_{j}^{*}$ is an optimal action given beliel $\mu_{i}$ since $p_{j}$ was arbitrarily chosen. Hence, $p_{j}^{*}=p_{j}\left(\mu_{j \infty}\right)$ by Assumption 8.1.

Furthermore, notice that $g_{j}: X_{j} \times P_{j} \times \Theta_{j} \rightarrow \mathbb{R}$ is also continuous. So, the function $h: X_{j} \times P\left(\Theta_{j}\right) \times \Theta_{j} \rightarrow \mathbb{R}$ defined by

$$
h\left(x_{j}, \mu_{j}, \theta_{j}\right) \equiv g_{j}\left(x_{j}, p\left(\mu_{j}\right), \theta_{j}\right),
$$

is continuous as well.

Now suppose there is a sequence $\left(x_{j n}, \mu_{j n}\right)_{n \in \mathbb{N}}$ converging to some limit $\left(x_{j}, \mu_{j}\right)$. Define functions $f_{n}$ and $f$ from $\Theta_{j}$ to $\mathbb{R}$ by

$$
f_{n}\left(\theta_{j}\right) \equiv h\left(x_{j n}, \mu_{j n}, \theta_{j}\right) \text { and } f\left(\theta_{j}\right) \equiv h\left(x_{j \infty}, \mu_{j \infty}, \theta_{j}\right) \text {. }
$$

Now take an arbitrary $\varepsilon>0$. Then the following lemma is had.

Lemma 8.2 There exists a natural number $N$ in $\mathbb{N}$ such that for all $n \geq N$,

$$
\left|f_{n}\left(\theta_{j}\right)-f_{\infty}\left(\theta_{j}\right)\right|<\varepsilon
$$

Proof. Suppose not. Then there is a subsequence $\left(f_{k}\right)_{k \in \mathbb{N}}$ of $\left(f_{n}\right)_{n \in \mathbb{N}}$ and a sequence $\left(\theta_{j k}\right)_{k \in \mathbb{N}}$, such that

$$
\left|f_{k}\left(\theta_{j k}\right)-f\left(\theta_{j k}\right)\right| \geq \varepsilon
$$

for all $k \in \mathbb{N}$. Since $\Theta_{j}$ is compact, without loss of generality a converging sequence $\theta_{j k} \rightarrow \theta_{j}$ can be assumed, where $\theta_{j}$ is some limit. Then for all $k \in \mathbb{N}$

$$
\varepsilon \leq\left|f_{k}\left(\theta_{j k}\right)-f\left(\theta_{j k}\right)\right|=\left|h\left(x_{j k}, \mu_{j k}, \theta_{j k}\right)-h\left(x_{j \infty}, \mu_{j \infty}, \theta_{j k}\right)\right| .
$$

However, since $x_{j k} \rightarrow x_{j \infty}, \mu_{j k} \rightarrow \mu_{j \infty}$, and $\theta_{3 k} \rightarrow \theta_{j}$, the continuity of $h$ now yields that

$$
\varepsilon \leq\left|h\left(x_{j \infty}, \mu_{j \infty}, \theta_{j}\right)-h\left(x_{j \infty}, \mu_{j \infty}, \theta_{j}\right)\right|,
$$

so that a contradiction is arrived at.

This lemma is instrumental in the proof of the following prime result. 
Proposition 8.4 The Bayesian learning process is continuous.

Proof. Suppose that $\left(\mu_{j n}, x_{j n}\right)_{n \in \mathbb{N}}$ converges to $\left(\mu_{j \infty}, x_{j \infty}\right)$. It has to be shown that

$$
B_{j}\left(\mu_{j n}, x_{j n}\right) \rightarrow B_{j}\left(\mu_{j \infty}, x_{j \infty}\right)
$$

as $n$ goes to infinity. For this, it is sufficient to establish (3) of Theorem B.8. To this end, let $F$ be a closed $\mu_{j}$-continuous subset of $\Theta_{j}$. What has to be shown is that

$$
B_{j}\left(\mu_{j n}, x_{j n}\right)(F) \rightarrow B_{j}\left(\mu_{j \infty}, x_{j \infty}\right)(F) .
$$

By the definition of the Bayes operator,

$$
B_{j}\left(\mu_{j}, x_{j}\right)(F)=\frac{\int_{F} g_{j}\left(x_{j} \mid p\left(\mu_{j}\right), \theta_{j}\right) \mu_{j}\left(d \theta_{j}\right)}{\int_{\Theta_{j}} g_{j}\left(x_{j} \mid p\left(\mu_{j}\right), \theta_{j}\right) \mu_{j}\left(d \theta_{j}\right)} .
$$

Now Proposition 8.1 above guarantees that the denominator is strictly positive. So, since $\Theta_{j}$ itself is an instance of a closed set $F$ whose boundary has measure zero (after all, the boundary of $\Theta_{j}$ is the empty set), it suffices in turn to show that, given $\varepsilon>0$,

$$
\left|\int_{F} g_{j}\left(x_{j n} \mid p\left(\mu_{j n}\right), \theta_{j}\right) \mu_{j n}\left(d \theta_{j}\right)-\int_{F} g_{j}\left(x_{j \infty} \mid p\left(\mu_{j \infty}\right), \theta_{j}\right) \mu_{j n}\left(d \theta_{j}\right)\right|<2 \varepsilon
$$

for sufficiently large $n$.

To that end, first take an $N$ as in Lemma 8.2. Then for all $n \geq N$,

$$
\begin{aligned}
& \left|\int_{F} g_{j}\left(x_{j n} \mid p\left(\mu_{j n}\right), \theta_{j}\right) \mu_{j n}\left(d \theta_{j}\right)-\int_{F} g_{j}\left(x_{j \infty} \mid p\left(\mu_{j \infty}\right), \theta_{j}\right) \mu_{j n}\left(d \theta_{j}\right)\right| \\
\leq & \int_{k^{F}}\left|f_{n}\left(\theta_{j}\right)-f\left(\theta_{j}\right)\right| \mu_{j n}\left(d \theta_{j}\right) \leq \int_{\Theta_{j}}\left|f_{n}\left(\theta_{j}\right)-f\left(\theta_{j}\right)\right| \mu_{j n}\left(d \theta_{j}\right) \\
\leq & \int_{\Theta_{j}}\left|f_{n}\left(\theta_{j}\right)-f_{\infty}\left(\theta_{j}\right)\right| \mu_{j n}\left(d \theta_{j}\right) \leq \varepsilon \mu_{j n}\left(\Theta_{j}\right)=\varepsilon,
\end{aligned}
$$

where the last inequality follows from the choice of $n$ and $N$. So now it only remains to show that for all $\varepsilon>0$, there exists an $N \in \mathbb{N}$ such that for all $n \geq N$

$$
\left|\int_{F} g_{j}\left(x_{j \infty} \mid p\left(\mu_{j \infty}\right), \theta_{j}\right) \mu_{j n}\left(d \theta_{j}\right)-\int_{F} g_{j}\left(x_{j \infty} \mid p\left(\mu_{j \infty}\right), \theta_{j}\right) \mu_{j \infty}\left(d \theta_{j}\right)\right|<\varepsilon .
$$

In other words, it is reguired to establish the existence of a natural number $N$ such that for every $n \geq N, \mu_{j n}$ is an element of the set of probability measures $w_{j}$ with

$$
\left|\int_{F} f\left(\theta_{j}\right) \mu_{j n}\left(d \theta_{j}\right)-\int_{F} f\left(\theta_{j}\right) \mu_{j \infty}\left(d \theta_{j}\right)\right|<\varepsilon
$$

This set, however, contains an element $C$ of $\mathcal{C}$ with $\mu_{i} \in C$ by Lemma $B .1$ in Appendix $B$. Hence, such an $N$ exists since $\left(\mu_{j n}\right)_{n \in \mathbb{N}}$ weakly converges to $\mu_{j}$ and $C$ is a basis of the weak topology by Lemma B.2. 


\subsection{Convergence of Beliefs and Prices}

A well-specified continuous process is thus constructed, in which beliefs $\mu_{-}$lead to perceived optimal prices $p_{\tau}$, which serve as endogenous signals to obtain new information about the parameters of the distribution of objective demand. This new information. in turn, leads to an update of beliefs $\mu_{\tau+1}$, and therefore, to new optimal prices $\mathrm{p}_{\tau+\mathrm{r}}$, as illustrated in Figure 8.1 below

$$
\left.\left.\left.\begin{array}{c}
\mu_{10} \rightarrow p_{10} \\
\vdots \\
\mu_{j 0} \rightarrow p_{j 0} \\
\vdots \\
\mu_{320} \rightarrow p_{n 0}
\end{array}\right\} \begin{array}{c}
x_{11} \rightarrow \mu_{11} \rightarrow p_{11} \\
\vdots \\
x_{j 1} \rightarrow \mu_{j 1} \rightarrow p_{j 1} \\
\vdots \\
x_{n 1} \rightarrow \mu_{n 1} \rightarrow p_{n 1}
\end{array}\right\} \begin{array}{c}
x_{12} \rightarrow \ldots \\
x_{j 2} \rightarrow \ldots \\
\vdots \\
x_{n 2} \rightarrow \ldots
\end{array}\right\} \ldots
$$

Figure 8.1 The development of beliefs and prices.

The process that drives the price dynamics of the model thus embodies both stibjectively rational learning and subjectively rational actions. The principal question of interest put to this model is whether for the dynamic price system constructed there is convergence to a conjectural equilibrium for arbitrary initial prices po. That is, the question asked is whether, and under what type of conditions, for the prior $\mu_{0}$ learning through self-generated signals will eventually teach some invariable posterior ideas, or whether and when perceptions, and thus prices, will keep on changing for ever. For an answer to this question, use can be made of martingale convergence theory.

\subsubsection{Infinite Histories and Beliefs}

For the purpose of applying martingale theory, it is necessary to construct an underlying probability space on which martingales can be identified. This is the space of all possible future developments of history a dealer $j$ foresees at the beginning of tine. Let

$$
H_{j r}=x_{t=1}^{r} X_{j}
$$

be the space of all histories $l_{j y}$ of length $\tau$. Analogously, let $H_{j \infty}=x_{t=1}^{\infty} X_{j}$ be the space of infinite histories. A specific element of $H_{j \infty}$ is denoted by $h_{j \infty}$. The $\sigma$-algebra on the product space $H_{j \infty}$ is the Borel $\sigma$-algebra $\mathcal{B}_{H_{j \infty}}$ that corresponds to the product topology on $H_{j \infty}$, constructed from the metric on $X_{j}$.

To complete the probability space of all future histories, a measure $\lambda_{j}$ on $\mathcal{B}_{H_{2}}$ is needed. Formally this $\lambda_{j}$ is defined inductively on histories of finite length, combined with infinite extensions. That is, for a given set $D_{\tau} \subset \times_{t=1}^{T} X_{j}$, for $t=1, \ldots, \tau$, it is sufficient to specify the numbers

$$
\lambda_{j}\left(D_{\mathrm{T}} \times\left(x_{t=\mathrm{T}+\mathbb{1}}^{\infty} X_{j}\right)\right)
$$


because once these numbers are known, there is a unique way to extend $\lambda_{j}$ to $B_{H_{j}}$. That is, it is required to construct $\lambda_{j}$ on $x_{t=1}^{\tau} X_{j}$. For notational convenience, only the numbers

$$
\lambda_{j T}\left(x_{t=1}^{r} D_{i}\right)
$$

are considered, since once these numbers are known, $\lambda_{j}$ follows straightforwardly-in anct,

$$
\lambda_{j}\left(\left(x_{t=1}^{T} D_{t}\right) \times\left(x_{t=\tau+1}^{\infty} X_{j}\right)\right) \equiv \lambda_{j \tau}\left(x_{t=1}^{T} D_{i}\right)
$$

the probability that an infinite history starts with a history $h_{j}$ in the set $x_{t=1}^{r} D_{i}$.

To specify the above number the following. First, note that for $\tau^{\circ}=0$ maturally it bolds that $\lambda_{j o}(0)=1$. For $\tau=1$,

$$
\lambda_{j 1}\left(D_{1}\right)=\int_{D_{1}} \int_{\Theta_{j}} g_{j}\left(x_{j} \mid p_{j 0}, \theta_{j}\right) \mu_{j 0}\left(d \theta_{j} \mid h_{j 0}\right) \nu_{j}\left(d x_{j}\right) .
$$

In order to now define $\lambda_{j, \tau+1}$ inductively, assume that $\lambda_{j \tau}$ is known. Then, given a history $h_{j \tau}$ of length $\tau$, the transition probability $\gamma_{j, \tau+1}\left(D_{\tau+1} \mid h_{j \tau}\right)$ for $D_{\tau+1} \subseteq X_{j}$ can be defined as

$$
\gamma_{j, \tau+1}\left(D_{r+1} \mid h_{j \tau}\right) \equiv \int_{D_{\tau+1}} \int_{\Theta_{j}} g_{j}\left(x_{j} \mid p_{j \tau}, \theta_{j}\right) \mu_{j \tau}\left(d \theta_{j} \mid h_{j \tau}\right) \omega_{j}\left(d x_{j}\right) .
$$

The transition probability gives the subjective probability of an observation $x_{j, \tau+1}$ being in $D_{r+1}$ given that the dealer has already observed history $h_{j \pi}$, and subsequently believes that $\mu_{j}$ is the appropriate probability distribution over $\theta_{j}$. Then, the following holds.

$$
\begin{aligned}
& A_{j, \tau+1}\left(x_{t=1}^{T+1} D_{t}\right) \equiv \int_{H_{j \tau}} \int_{X_{j}} \mathbb{I}_{x_{i+1}^{*+1} D_{t}} \gamma_{j, \tau+1}\left(d x_{j, \tau+1} \mid h_{j \tau}\right) \lambda_{j \tau}\left(d h_{j \tau}\right) \\
& =\int_{H_{j}} \int_{X_{j}} \mathbb{1}_{X_{i=1}^{T}} D_{t} \cdot \mathbb{I}_{D_{T+1}} \gamma_{j, T+1}\left(d x_{j, T+1} \mid h_{j, T}\right) \lambda_{j T}\left(d h_{j T}\right) \\
& =\int_{H_{j \tau}} \mathbb{H}_{\times_{i=1}^{\tau}, 1} D_{i} \int_{X_{j}} \mathbb{I}_{D_{\tau,+}, \gamma_{j},+1}\left(d x_{j, \tau+1} \|_{j \tau}\right) \lambda_{j \tau}\left(d h_{j \tau}\right)
\end{aligned}
$$

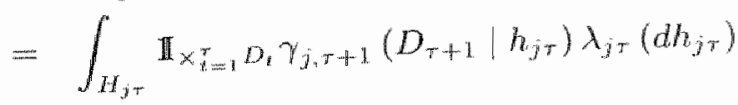

$$
\begin{aligned}
& =\int_{x_{t=1}^{T} D_{t}} \gamma_{j, T+1}\left(D_{T+1} \mid h_{j \tau}\right) \lambda_{j \tau}\left(d h_{j T}\right)
\end{aligned}
$$

The definition reflects how $\lambda_{j, \tau+1}$ derives as the weighted 'sum' (i.e., the integral) of all transition probabilities, where the weights are the probabilities $\lambda_{j \pi}$ the dealer assigns to the observation that conditions the particular transition probability. The first step easily follows from rewriting the indicator function on the product set as a product of indicator functions. The second step uses the fact that the first part of this 
product is fixed at time $\tau$, and hence can therefore be taken outside the integral over $X_{j}$. It is then observed that

$$
\int_{X,} \mathbb{I}_{D_{\tau+1}} \gamma_{j, \tau+1}\left(d x_{j, \tau+1} \mid h_{j \tau}\right)=\gamma_{j, \tau+1}\left(D_{\tau+1} \mid \gamma_{j, \tau}\right)
$$

Finally, the indicator function is replaced by the restricted integral.

Having thus constructed the numbers $\lambda_{j \pi}$ for all cylinder sets $x_{i=1}^{\top} D_{i}$, notice that since the above computation implies that for all sets $D_{\tau}$ in $\mathcal{B}_{H_{j \tau}}$ it holds that

$$
\begin{aligned}
\lambda_{j+1}\left(D_{\tau} \times X_{j}\right) & =\int{ }_{D_{\tau}} \gamma_{j, \tau+1}\left(h_{i \tau}\right)\left(X_{j}\right) \lambda_{j \tau}\left(d h_{j \tau}\right) \\
& =\int D_{\tau} \mathbb{I}_{H_{j \tau}} \lambda_{j \tau}\left(d h_{j \tau}\right)=\lambda_{j \tau}\left(D_{\tau}\right) .
\end{aligned}
$$

the measures $\lambda_{j \pi}$ are consistent. Therefore, by Kolmogorov's Theorem, there is a unique probability measure $\lambda_{j}$ on infinite histories on $\mathcal{B}_{H_{j} \infty}$ such that

$$
\lambda_{j}\left(D_{r} \times\left(x_{i=r+1}^{\infty} X_{j}\right)\right)=\lambda_{j \tau}\left(D_{\tau}\right)
$$

for all Borel sets $D_{\tau}$ in $\mathcal{B}_{H_{j,}}{ }^{5}$

An appealing and appropriate way to think about $\lambda_{j}$ is as the probability dealer $j$ initially gives, based on its prior beliefs and its awareness of the learning process it is about the engage in, to observing the infinite history $h_{j \infty} \in H_{j \infty}$ over time.

\subsubsection{Subjective Almost Sure Convergence of Beliefs and Prices}

It will now be shown that, on the probability space $\left(H_{j \infty}, \mathcal{B}_{H_{j \infty}}, \lambda_{j}\right)$ constructed above, each sequence of beliefs forms a martingale. To see this, first note that, since upon actions $p_{j t}$ each $\mu_{j t}(A)$ for $A \in \mathcal{B}_{\Theta_{j}}$ is a function of realizations $x_{j t} \in X_{j}$ of $a$ stochastic variable, the sequence $\left(\mu_{j t}(A)\right)_{t \in \mathbb{N}}$ is a stochastic sequence. Also, over time it is possible to identify $\sigma$-algebra's $\mathcal{B}_{H_{j}}$ generated by the sample path that forms a truncated histary $h_{j,}$, such that $\mathcal{B}_{H_{j}} \subseteq \mathcal{B}_{H_{j \infty}}$, and each $\mu_{j \tau}(A)$ is $\mathcal{B}_{H_{j,}}$-measurable. Since information once obtained is never again forgotten, the sequence $\left(\mu_{j t}(A)\right)_{\text {ief }}$

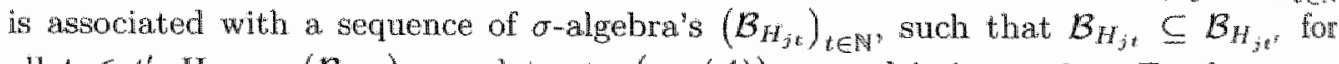
all $t \leq t^{\prime}$. Hence, $\left(\mathcal{B}_{Y_{j t}}\right)_{t \in \mathbb{N}}$ relates to $\left(\mu_{j t}(A)\right)_{t \in \mathbb{N}}$ and is increasing. Furthermore; for each development of history and each $A \in \mathcal{B}_{\Theta_{j}}, \mu_{j t}(A) \in P(A)$ is a real number between zero and one, so that it is certainly bounded. Moreover, the following can be had.

Proposition 8.5 For each $A \in \mathcal{B}_{\Theta_{j}},\left(\mu_{j t}(A), \mathcal{B}_{H_{j t}}\right)_{t \in \mathbb{N}}$ is a uniformly bounded marthingale wo.r.t. $\lambda_{j}$.

Proof. Let $A \in \mathcal{B}_{\Theta_{j}}$ and $C \in \mathcal{B}_{H_{j}}$. It is required to check that for all $\tau \leq \tau^{\prime}$

$$
\int_{C} \mu_{j \pi}(A) \lambda_{j \pi}\left(d h_{j \tau}\right)=\int_{C} \mu_{j \tau^{\prime}}(A) \lambda_{j \gamma^{\prime}}\left(d h_{j T^{*}}\right) \text {. }
$$

(3) Billingsley $(1968), p .230$ 
First, this will be shown for $\tau$ and $\tau+1$.

Since $C$ is an element of $B_{H_{j}}$, it can be written as

$$
D_{\tau} \times\left(x_{t=1}^{\infty} X_{j}\right)
$$

hor some Borel set $D_{\tau}$ in $H_{j \tau}$. So, since $\lambda_{j}$ agrees with $\lambda_{j, \tau+1}$ on $\mathcal{B}_{H_{j, r}, \mathrm{l}}$, use can be made of the following identity. For a general integrable function $\phi$ on $H_{j, \tau+1}$,

$$
\begin{aligned}
& \int_{H_{j, \tau+1}} \phi\left(x_{j, \tau+1} \mid h_{j \tau}\right) \lambda_{j, \tau+1}\left(d h_{j, \tau+1}\right) \\
= & \int_{H_{j \tau}} \int_{X_{j}} \int_{\Theta_{j}} \phi\left(x_{j, \tau+1} \mid h_{j \tau}\right) g_{j}\left(x_{j, \tau+1} \| p_{j \tau}, \theta_{j}\right) \\
& \times \mu_{j \tau}\left(d \theta_{j} \mid h_{j \tau}\right) \nu_{j}\left(d x_{j}\right) \lambda_{j \tau}\left(d h_{j \tau}\right) .
\end{aligned}
$$

by Fatou's Lemma. Applied to the present problem, it holds for all $A \in \mathcal{B}_{\Theta}$, and $D_{\tau} \in \mathcal{B}_{H_{j}}$ that

$$
\begin{aligned}
& \int_{D_{\tau} \times X_{j}} \mu_{j, \tau+1}\left(A \mid h_{j \tau}, x_{j, \tau+1}\right) \lambda_{j, \tau+1}\left(d h_{j, \tau+1}\right) \\
= & \int_{D_{\tau}} \int_{X_{j}} \int_{\theta_{j}} \mu_{j, \tau+1}\left(A \mid h_{j \tau}, x_{j, \tau+1}\right) g_{j}\left(x_{j, \tau+1} \mid p_{j \tau}, \theta_{j}\right) \\
& \times \mu_{j \tau}\left(d \theta_{j} \mid h_{j \tau}\right) \nu_{j}\left(d x_{j}\right) \lambda_{j \tau}\left(d h_{j \tau}\right) .
\end{aligned}
$$

Observing that $\mu_{j_{1, T+1}}$ does not depend on $\theta_{j}$, and making use of Bayes" rule to relate $\mu_{j, \tau+1}$ to $\mu_{j \tau}$, it follows that

$$
\begin{aligned}
& \int_{D_{\tau}} \int_{X_{j}} \mu_{j, \tau+1}\left(A \mid h_{j \tau}, x_{j, \tau+1}\right) \\
& \times \int_{\theta_{j}} g_{j}\left(x_{j, \tau+1} \mid p_{j \tau}, \theta_{j}\right) \mu_{j \tau}\left(d \theta_{j} \mid h_{j \tau}\right) \nu_{j}\left(d x_{j}\right) \lambda_{j \tau}\left(d h_{j \tau}\right) \\
= & \int_{D_{\tau}} \int_{X_{j}} \frac{\int_{A} g_{j}\left(x_{j, \tau+1} \mid p_{j \tau}, \theta_{j}\right) \mu_{j \tau}\left(d \theta_{j} \mid h_{j \tau}\right)}{\int_{\Theta_{j}} g_{j}\left(x_{j, \tau+1} \mid p_{j \tau}, \theta_{j}\right) \mu_{j \tau}\left(d \theta_{j} \mid h_{j \tau}\right)} \\
& \times \int_{\Theta_{j}} g_{j}\left(x_{j, \tau+1} \mid p_{j \tau}, \theta_{j}\right) \mu_{j \tau}\left(d \theta_{j} \mid h_{j \tau}\right) \nu_{j}\left(d x_{j}\right) \lambda_{j \tau}\left(d h_{j \tau}\right) \\
= & \int_{D_{\tau}} \int_{X_{j}} \int_{A} g_{j}\left(x_{j, \tau+1} \mid p_{j \tau}, \theta_{j}\right) \mu_{j \tau}\left(d \theta_{j} \mid h_{j \tau}\right) \nu_{j}\left(d x_{j}\right) \lambda_{j \tau}\left(d h_{j \tau}\right),
\end{aligned}
$$

where the final step folows from the fact that the two integrals over $\theta_{j}$ cancel out. 
Applying Fubini's Theorem to the last expression, the order of integration over $X_{j}$ and $\Theta_{j}$ can be switched, so that

$$
\begin{aligned}
& \int_{D_{\tau}} \int_{X_{j}} \int_{A} g_{j}\left(x_{j, \tau+1} \mid p_{j \tau}, \theta_{j}\right) \mu_{j \tau}\left(d \theta_{j} \mid h_{j \tau}\right) \nu_{j}\left(d x_{j}\right) \lambda_{j \tau}\left(d h_{j \tau}\right) \\
= & \int_{D_{\tau}} \int_{A} \int_{X_{j}} g_{j}\left(x_{j, \tau+1} \mid p_{j \tau}, \theta_{j}\right) \nu_{j}\left(d x_{j}\right) \mu_{j \tau}\left(d \theta_{j} \mid h_{j \tau}\right) \lambda_{j \tau}\left(d h_{j \tau}\right) \\
= & \int_{D_{\tau}} \int_{A} \mathbb{I}_{\Theta_{j} \mu_{j \tau}}\left(d \theta_{j} \mid h_{j \gamma}\right) \lambda_{j \tau}\left(d h_{j \tau}\right) \\
= & \int_{D_{\tau}} \mu_{j \tau}\left(A \mid h_{j \tau}\right) \lambda_{j \tau}\left(d h_{j \tau}\right),
\end{aligned}
$$

where the second equality results from the fact that $\int_{X_{j}} g_{j}\left(x_{j, \tau+1} \mid p_{j \tau}, \theta_{j}\right) \nu_{j}\left(d x_{j}\right)=$ 1 , since it is a probability measure. ${ }^{7}$ By induction, it holds that for all $A \in \mathcal{B}_{\Theta_{j}}$ and $D_{r} \in \mathcal{B}_{H_{j} \tau}$ and any $\tau \leq \tau^{\prime}$

$$
\int_{D_{\tau} \times \times_{t=r+1}^{r^{\prime}} X_{j \tau}} \mu_{j \tau^{*}}\left(A \mid h_{j \tau}\right) \lambda_{j \tau^{\prime}}\left(d h_{j \tau^{\prime}}\right)=\int_{D_{\tau}} \mu_{j \tau}\left(A \mid h_{j \tau}\right) \lambda_{j \tau}\left(d h_{j \tau}\right)
$$

This result may not be very surprising. It states that the nature of Bayesian learning is such that a dealer does not expect to change its beliefs in the future. Of course, an actual observation will in general change beliefs, but based upon current beliefs on future realizations of sales, a dealer ex ante predicts it will not. One way to interpret. this is as Bayesian learning being sufficient, in that the information present at times is used to the full.

With the result in hand, the Martingale convergence theory set out in Appendix $C$ can be applied in order to study the limit beliefs of agents, and hence of prices. The following can thus be concluded.

Proposition 8.6 The probability measure $\mu_{j t}$ converges weakly to $\mu_{j \infty} \in P\left(\theta_{j}\right)$. $\lambda_{j}$-almost-surely.

Proof. The proposition states that there exists a Borel set $S$ of infinite histories in $H_{j \infty}$ with $\lambda_{j}$-probability one, on which the sequence $\left(\mu_{j t}\right)_{t \in \mathbb{N}}$ converges for every history. First, consider the construction of $S$. Since $\Theta_{j}$ is compact and metric, there exists a countable basis of the topology. Let $\mathcal{U}$ be the collection of finite intersections of elements of this basis. Take a fixed element $U$ of $\mathcal{U}$. By Proposition 8.5, the sequence $\left(\mu_{j,}(U)\right)_{t \in \mathbb{N}}$ is a martingale. So, by Theorem $C .2$ of Appendix $C$ there is a set $S(U)$ of infinite histories in $H_{j \infty}$ with $\lambda_{j}(S(U))=1$ such that $\left(\mu_{j t}\left(U \mid h_{j \infty}\right)\right)_{t \in \mathbb{f}}$ converges to every history $h_{j \infty}$ in $S(U)$.

Now since $\mathcal{U}$ is the collection of finite intersections of a countable collection, it is a countable set itself. This implies that

$$
S \equiv \operatorname{lu} \in \mathcal{U}(U)
$$

7 of. op.cit, 1359 
has $\lambda_{j}$ probability one, since it is a countable intersection of sets $S(U)$, all having $\lambda_{j}$-probability one.

The construction of the limit probability measure can be done as follows. Take a mistory $h_{j \infty}$ in $S$. Since $P\left(\Theta_{j}\right)$ is sequentially compact by Theorems $B .3, B .4$, and $B .5$ af Appendix $B$, it is known that a subsequence of $\left(\mu_{j t}\left(h_{j \infty}\right)\right)_{t \in \text { N }}$ converges weakly to sone probebility measure, say $\mu_{j \infty}\left(h_{j \infty}\right)$. It can be shown that the original sequence converges weakly to this probability measure. To see this, notice that

$$
\mu_{j}\left(U \mid h_{i \infty}\right) \rightarrow \mu_{j \infty}\left(U \mid h_{i \infty}\right) \text { for all } U \in \mathcal{U}
$$

for the original sequence, since this sequence is convergent for every element $U$ in $U$ by construction of $S$ and the above holds for the weakly convergent subsequence. Morewer, $U$ is closed under finite intersections and each open set is obviously a combable miom of elements of $\mathcal{U}$ since $\mathcal{U}$ contains a countable basis of the topology on $\Theta_{j}$ by construction. Hence, by Lemma $B .3,\left(\mu_{j t}\left(h_{j \infty}\right)\right)_{t \in \mathbb{N}}$ converges weakly to $\mu_{j \infty}\left(h_{j \infty}\right)$ and the proof is complete since $h_{j \infty}$ was chosen arbitrarily in $S$.

The following consequence of the result on convergence of beliets is had as a central result.

Theorem 8.1 The price $p_{j t}$ converges to a unique limit price $p_{j \infty}, \lambda_{j}$-almost-surely.

Proof. By the contimuity of $p_{j}$ established in Proposition 8.3 above, it is known that the sequence $p_{j}\left(\mu_{j t}\left(h_{j \infty}\right)\right)_{t \in \mathbb{N}}$ of optimal decisions given beliefs at time $t$ converges to $p_{j}\left(\mu_{j \infty}\left(h_{\infty}\right)\right)$ whenever the sequence $\mu_{j t}\left(h_{j \infty}\right)_{i \in N}$ of beliefs converges to $\mu_{j \infty}\left(h_{j \infty}\right)$. This happens with $\lambda_{j}$-probability one by Proposition 8.6 .

\subsection{The Nature of Limit Beliefs and Prices}

It is now known that in the model beliefs, and consequently prices, converge to limit beliefs and unique limit prices respectively, for $\lambda_{j}$-almost-all developments of history. The meaning of the $\lambda_{j}$-almost-all nature of this result and its relation to objective convergence is investigated in the next subsection. Here some properties of the limit beliefs and prices are denived. It is shown that limit beliefs are unique and that they support an indiridual conjectural equilibrium.

\subsubsection{Unique Limit Beliefs}

For an analysis of the limit properties of beliefs and prices, consider the following construction. Let $\mu_{j}$ be a probability measure on $\Theta_{j}$. Evidently, $\theta_{j}$ is a compact set with $\mu_{j}\left(\Theta_{j}\right)=1$. So, the collection

$$
K \equiv\left\{K \subset \theta_{j} \mid K \text { is compact and } \mu_{j}(K)=1\right\}
$$


is not empty. Hence, it is possible define the support of $\mu_{j}$ by

$$
\operatorname{supp}\left(\mu_{j}\right) \equiv \cap_{K \in \mathcal{K}} K,
$$

and have the following results.

Lemma $8.3 \mu_{j}\left(\operatorname{supp}\left(\mu_{j}\right)\right)=1$.

Proof. Note that the topology on $\Theta_{j}$ has a countable basis, say $\mathcal{B}$, since $\theta_{j}$ is separable and metric. So,

$$
\operatorname{supp}\left(\mu_{j}\right)=\cap_{B \in \mathcal{B}: \mu_{j}(B)=0} \Theta_{j} \backslash B .
$$

The result then follows by the subadditivity of $\mu_{j}$.

A more colloquial definition of the support of a probability measure $\mu_{j}$ on $\Theta_{j}$ is to say that it is the smallest compact subset $K$ of $\Theta_{j}$ with $\mu_{j}(K)=1$. Anyhow, it makes the following available.

Definition 8.3 A belief $\mu_{j}$ does not distinguish if there exists a function $h_{j}: X_{j} \rightarrow$ $\mathbb{R}$, such that for any $\theta_{j} \in$ supp $\mu_{j}$

$$
g_{j}\left(x_{j} \mid p_{j}\left(\mu_{j}\right), \theta_{j}\right)=h_{j}\left(x_{j}\right) \text { for all } x_{j} \in X_{j} .
$$

This condition on $\mu_{j}$ states that $\mu_{j}$ does not distinguish if every possible belief $\theta_{j}$ in the support of $\mu_{j}$ generates the same density function on $X_{j}$. Consequently, when this is the case, no signal $x_{j}$ will give dealer $j$ reason to change its beliefs. A more interesting fact is that the converse of this observation is also true. That is, the following result holds.

Proposition 8.7 Belief $\mu_{j}$ does not distinguish if and only if

$$
B_{j}\left(\mu_{j}, x_{j}\right)=\mu_{j} \text { for all } x_{j} \in X_{j} \text {. }
$$

Proof. Suppose that $\mu_{j t}$ does not distinguish. Then $h_{j}: X_{j} \rightarrow \mathbb{R}$ can be taken such that

$$
h_{j}\left(x_{j}\right)=g_{j}\left(x_{j} \mid p_{j t}, \theta_{j}\right) \text { for all } \theta_{j} \in \operatorname{supp} \mu_{j t} .
$$

Consequently, for any $x_{j} \in X_{j}$, and any $A \in \mathcal{B}_{\Theta_{j}}$ for which $A \cap$ supp $\mu_{j t} \neq \emptyset$-i.e., any $A \in \mathcal{B}_{\Theta_{j}}$ by Proposition 8.2

$$
\begin{aligned}
\frac{\int_{A} g_{j}\left(x_{j} \mid p_{j t}, \theta_{j}\right) \mu_{j t}\left(d \theta_{j}\right)}{\int_{\Theta_{j}} g_{j}\left(x_{j} \mid p_{j t}, \theta_{j}\right) \mu_{j t}\left(d \theta_{j}\right)} & =\frac{\int_{A} h_{j}\left(x_{j}\right) \mathbb{I}_{\Theta_{j}} \mu_{j t}\left(d \theta_{j}\right)}{\int_{\Theta_{j}} h_{j}\left(x_{j}\right) \mathbb{I}_{\Theta_{j}} \mu_{j t}\left(d \theta_{j}\right)} \\
& =\frac{h_{j}\left(x_{j}\right) \mu_{j t}(A)}{h_{j}\left(x_{j}\right) \mu_{j t}\left(\Theta_{j}\right)}=\mu_{j t}(A) .
\end{aligned}
$$

Suppose, on the other hand, that $\mu_{j \ell}$ distinguishes. Then, from the proof of the previous proposition, it is known that there is a pair $\theta_{j}, \theta_{j}^{\prime} \in \operatorname{supp} \mu_{j t}$, and an $x_{j t}^{*} \in X_{j}$ for which

$$
g_{j}\left(x_{j t}^{*} \mid p_{j t}, \theta_{j}\right)>g_{i}\left(x_{j t}^{*} \mid p_{j t}, \theta_{j}^{t}\right) .
$$


So two positive numbers $U, L \in I R$ and neighborhoods $N_{\theta_{j}} \ni \theta_{j}, N_{\theta_{3}} \ni \theta_{j}^{\prime}$ can be found, such that

$$
\begin{aligned}
& g_{j}\left(x_{j t}^{*} \mid p_{j t}, \theta_{j}\right) \geq U \text { for all } \theta_{j} \in N_{\theta_{j}} \\
& g_{j}\left(x_{j t}^{*} \mid p_{j t}, \theta_{j}\right) \leq L \text { for all } \theta_{j} \in N_{\theta_{j}},
\end{aligned}
$$

and $U>L$.

Now notice that $\mu_{j}\left(N_{\theta_{j}}\right)>0$ since otherwise $\operatorname{supp}\left(\mu_{j}\right) \backslash N_{\theta_{j}}$ would be a compact set with $\mu_{j}$-probability one that is strictly included in supp $\left(\mu_{j}\right)$. For the same reason $\mu_{j}\left(N_{\theta_{j}}\right)>0$. Then, however, the following relation on the ratio of the posterior probabilities assigned to $\theta_{j} \in N_{\theta_{j}}$ and $\theta_{j} \in N_{\theta_{j}^{\prime}}$ respectively (the nominator is divided out) is had.

$$
\frac{\int_{N_{a_{j}}} g_{j}\left(x_{j} \mid p_{j t}, \theta_{j}\right) \mu_{j t}\left(d \theta_{j}\right)}{\int_{N_{\theta_{j}^{\prime}}} g_{j}\left(x_{j} \mid p_{j t}, \theta_{j}\right) \mu_{j t}\left(d \theta_{j}\right)} \geq \frac{\int_{N_{\theta_{j}}} U \mathbb{H}_{\Theta_{j}} \mu_{j t}\left(d \theta_{j}\right)}{\int_{N_{\theta_{j}^{\prime}}} \mathbb{I}_{\theta_{j}} \mu_{j t}\left(d \theta_{j}\right)}=\frac{U \mu_{j}\left(N_{\theta_{j}}\right)}{L \mu_{j}\left(N_{\theta_{j}^{\prime}}\right)}>\frac{\mu_{j t}\left(N_{\theta_{j}}\right)}{\mu_{j t}\left(N_{\theta_{j}^{\prime}}\right)} .
$$

That is,

$$
\begin{aligned}
\text { either } \frac{\int_{N_{\theta_{j}}} g_{j}\left(x_{j} \mid p_{j t}, \theta_{j}\right) \mu_{j j}\left(d \theta_{j}\right)}{\int_{\Theta_{j}} g_{j}\left(x_{j} \mid p_{j t}, \theta_{j}\right) \mu_{j t}\left(d \theta_{j}\right)} \neq \mu_{j t}\left(N_{\theta_{j}}\right) \\
\quad \text { or } \frac{\int_{N_{\theta_{j}^{\prime}}} g_{j}\left(x_{j} \mid p_{j t}, \theta_{j}\right) \mu_{j t}\left(d \theta_{j}\right)}{\int_{\Theta_{j}} g_{j}\left(x_{j} \mid p_{j t}, \theta_{j}\right) \mu_{j t}\left(d \theta_{j}\right)} \neq \mu_{j t}\left(N_{\theta_{j}}\right) \text {, }
\end{aligned}
$$

so that it necessarily follows that

$$
\frac{\int_{A} g_{j}\left(x_{j} \mid p_{j,}, \theta_{j}\right) \mu_{j t}\left(d \theta_{j}\right)}{\int_{\Theta_{j}} g_{j}\left(x_{j} \mid p_{j t}, \theta_{j}\right) \mu_{j t}\left(d \theta_{j}\right)} \neq \mu_{j l}(A) \text { for all } A \in \mathcal{B}_{\Theta_{j}} \text { and all } x_{j} \in X_{j}
$$

The interpretation of the proposition is straightforward. A belief $\mu_{j}$ does not disfinguish if and only if Bayesian updating has no effect on the belief for any possible obserwation $x_{j}$. This fact has important implications, particularly as it is possible to show that the limit beliefs $\mu_{j \infty}\left(h_{j \infty}\right)$ are in fact fixed points of the Bayesian updating method.

To that end, the following preliminary result is required. Let $\mathcal{B}$ be a countable basis of the topology on $X_{j}$. Let $W$ be the collection of sample paths $\left(x_{j t}\right)_{t \in \mathrm{N}}$ in $H_{j \infty}$ for which there is a basis element $B$ in $\mathcal{B}$ such that $\left\{x_{j t} \mid x_{j l} \in B\right\}$ is finite. Then the tollowing is true.

Lemma $8.4 \lambda_{j}(W)=0$.

Proof. Let $B$ be an element of $\mathcal{B}$ and let $T$ be a natural number. Define

$$
W(B, T)=\left\{\left(x_{i j}\right)_{t \in \text { 陪 }} \mid x_{j t} \notin B \text { for all } t \geq T\right\}
$$


Note that this construct $W=\cup_{B \in B}, T \in W(B, T)$. So, $W$ is the countable union of sets $W(B, T)$. Hence, by subadditivity of $\lambda_{j}$,

$$
\lambda_{j}(W)=\lambda_{j}\left(U_{B \in B}, T \in \mathbb{N} W(B, T)\right) \leq \sum_{B \in B^{\prime}} \sum_{T \in \mathbb{N}} \lambda_{j}(W(B, T)),
$$

so that it is left to prove that $\lambda_{y}(W(B, T))=0$ for any choice of $B$ and $T$.

To this end, notice that

$$
W(B, T)=\prod_{t=\pi}^{T-1} X_{j} \times \prod_{t=1+T}^{\infty} B^{c}
$$

Now take some $\tau \geq T$. Denote the subset $\prod_{l=1}^{T-1} X_{j} \times \prod_{l=1+T}^{\infty} B^{c}$ of the set $H_{j \mathrm{r}}$ of finite histories up to time $\tau$ by $W_{j \tau}$. Then, for a history $h_{j \tau}$ in $W_{j r}$, the one-step transition probability $\gamma_{j, \tau+1}\left(B \mid h_{j \tau}\right)$ to $B$ is

$$
\begin{aligned}
\gamma_{j, \tau+1}\left(B \mid h_{j \tau}\right) & \equiv \int_{B} \int_{\Theta_{j}} g_{j}\left(x_{j} \mid p_{j \tau}, \theta_{j}\right) \mu_{j \tau}\left(d \theta_{j} \mid h_{j \tau}\right) \nu_{j}\left(d x_{j}\right) \\
& \geq \int_{B} \int_{\Theta_{j}} \varepsilon \mu_{j \tau}\left(d \theta_{j} \mid h_{j \tau}\right) \nu_{j}\left(d x_{j}\right) \\
& =\varepsilon \int_{B} \int_{\Theta_{j}} \mathbb{I} x_{j} \times \Theta_{j} \mu_{j \tau}\left(d \theta_{j} \mid h_{j \tau}\right) \nu_{j}\left(d x_{j}\right) \\
& =\varepsilon \int_{B} \mathbb{I}_{X_{j} \nu_{j}}\left(d x_{j}\right)=\varepsilon \nu_{j}(B) .
\end{aligned}
$$

Here $\varepsilon>0$ is chosen such that $g_{j}\left(x_{j} \| p_{j r}, \theta_{j}\right) \geq E$ for all $x_{j} \in B, \theta_{j} \in \Theta_{j}$, which can. be done by the compactness of $X_{j}$, the continuity of $g_{j}(*)$ and the assumption that $g_{j}(\cdot)$ is larger than zero on $X_{j}$. Consequently, $\gamma_{j, \tau+1}\left(B^{c} \mid h_{j \tau}\right) \leq 1-\varepsilon \nu_{j}(B)$. Using this result,

$$
\begin{aligned}
\lambda_{j, \tau+1}\left(W_{j, \tau+1}\right) & \equiv \int_{W_{\tau}} \gamma_{j, \tau+1}\left(B^{c} \mid h_{j r}\right) \lambda_{j \tau}\left(d h_{j \tau}\right) \\
& \leq \int_{W_{r}}\left(1-\varepsilon \nu_{j}(B)\right) \lambda_{j \tau}\left(d h_{j \tau}\right) \\
& =\left(1-\varepsilon v_{j}(B)\right) \lambda_{j t}\left(W_{j r}\right) .
\end{aligned}
$$

Now backsubstitution yields

$$
\begin{aligned}
\lambda_{j, r+1}\left(W_{j, T+1}\right) & \leq\left(1-\varepsilon \nu_{j}(B)\right)^{T-T+1} \lambda_{j T}\left(W_{j T}\right) \\
& \leq\left(1-\varepsilon \nu_{j}(B)\right)^{T-T+1} \lambda_{j T}\left(\prod_{i=1}^{T} X_{j}\right) \\
& =\left(1-\varepsilon \nu_{j}(B)\right)^{T-T^{2}+1}
\end{aligned}
$$

since $\lambda_{j} T\left(\prod_{t=1}^{T} X_{j}\right)=1$. Furthermore, since $B$ is an open set, $\nu_{j}(B)>0$ by assumption. Using the fact that $0<1-E \nu_{j}(B)<1$, the conclusion is arrived at that

$$
\lim _{\tau \rightarrow \infty} \lambda_{j, \tau+1}\left(W_{j, r+1}\right)=0
$$


Findly:

$$
0 \leq \lambda_{j}(W(B, T)) \leq \lambda_{j \tau}\left(W_{j \tau}\right) \text { forall } T \geq T
$$

where the second inequality follows from the monotonicity of $\lambda_{j}$ and the equality from consistency of $\lambda_{j}$ with $\lambda_{j}$. In all, it follows that $\lambda_{j}(W(B, T))=0$.

The interpretation of this result is that dealers expect a prion that the signals they will receive are persistently exciting. That is, they expect to observe all possible quantities infinitely many times over the course of their learning process, so that they will be able to indeed extract sufficient information from them. The sufficiency of information is reflection in the following proposition.

Proposition 8.8 Belief $\mu_{j \infty}$ does not distinguish $\lambda_{j}$-almost surely.

Proof. Let $S$ be as in the proof of Proposition 8.6 and let $W$ be as in the above lemma. Write $Z \equiv V \backslash W$. Clearly, $\lambda_{j}(Z)=1$, since $\lambda_{j}(V)=1$ and $\lambda_{j}(W)=0$ by Lemma 8.4. Take a history $\left(x_{j \tau}\right)_{\tau=1}^{\infty}$ in $Z$. Then, since $\left(x_{j \tau}\right)_{\tau=1}^{\infty} \in Z \subset V$, it is known that $\mu_{j \infty}\left(h_{j \infty}\right)$ exists. It will be shown that it does not distinguish.

By Proposition 8.7 it suffices to show that for all $x_{j} \in X_{j}, B\left(\mu_{j \infty}, x_{j}\right)=\mu_{j \infty}$. that is that the limit beliefs are a fixed point of the Bayes' rule. To that end, take an $x_{j}^{*} \in X_{j}$. Since $\left(x_{j \tau}\right)_{r=1}^{\infty} \notin W$, it intersects each element of the basis $B$ infinitely many times. So, since $X_{j}$ is metric this implies a subsequence $\left(x_{j, \alpha}(\tau)\right)_{r=1}^{\infty}$ of $\left(x_{j r}\right)_{r=1}^{\infty}$ can be found, such that $x_{j, \alpha(\tau)} \rightarrow x_{j}^{*}$ at $\tau \rightarrow \infty$-where $\alpha: \mathbb{N} \rightarrow \mathbb{N}$ is a one-to-one function, with $n<m \rightarrow \alpha(n)<\alpha(m)$.

However, on the one hand

$$
B\left(\mu_{j, \alpha(\tau)}, x_{j, \alpha(\tau)}\right)=\mu_{j, \alpha(\tau)+1} \rightarrow \mu_{j \infty}
$$

in the weak topology since the above sequence is a subsequence of $\left(\mu_{j t}\left(h_{j \infty}\right)\right)_{\text {tel }}$ which converges to $\mu_{j \infty}\left(h_{j \infty}\right)$ in the weak topology by the choice of $S$. On the other hand,

$$
B\left(\mu_{j, \infty}(\tau), x_{j, \alpha(\tau)}\right) \rightarrow B\left(\mu_{j \infty}, x_{j}^{*}\right)
$$

since $B$ is continuous by Proposition 8.4 . Hence, since the space $P\left(\Theta_{j}\right)$ is Hausdorf, $\mu_{j \infty}=B\left(\mu_{j \infty}, x^{*}\right)$

Note that if the natural assumption is made that conjectured density functions of demand are unicuely characterized by the value of $\theta_{j}$, the proposition implies that the posterior distribution converges to a point mass on one particular $\theta_{j} \in \Theta_{j}$.

Assumption 8.3 For any $p_{j} \in P_{j}, g_{j}\left(\cdot \mid p_{j}, \theta_{j}\right)=g_{j}\left(\cdot \| p_{j}, \theta_{j}\right)$ for all $x_{j} \in X_{j}$ if and ondy of $\theta_{j}=\theta_{j}^{\prime}$.

The measure that puts probability one on a parameter $\theta_{j} \in \Theta_{j}$ is called a point mass-or Dirac measure. The following result is had.

Proposition 8.9 Limit belief $\mu_{j \infty}$ is a point mass, $\lambda_{j}$-almost surely. 
Proof. By Proposition 8.8, for any $\left(\theta_{j}, \theta_{j}^{\prime}\right) \in \operatorname{supp} \mu_{j \infty}$,

$$
g_{j}\left(\cdot \mid p_{j \infty}, \theta_{j}\right)=g_{j}\left(\cdot \mid p_{j \infty}, \theta_{j}^{\prime}\right)
$$

for the unique limit price $p_{j \infty} \in P_{j}$ and all $x_{j} \in X_{j}$. By Assumption 8.3, this can only be the case if $\theta_{j}=\theta_{j}^{\prime}$. Hence, supp $\mu_{j \infty}$ is a singleton and $\mu_{j \infty}$ a point mass.

\subsubsection{Individual Conjectural Equilibrium}

It is now well established that, provided the structure of perceptions satisfies assumptions 8.1-8.3, the $\lambda_{j}$-almost-sure convergence of $\mu_{j t}$ to $\mu_{j \infty}$ thus establishes each dealer $j$ with unique limit beliefs on prices $p_{j \infty}$, as well as on the point value of the parameter $\theta_{j}$. Let this unique limit point value be $\theta_{j \infty}$. The pair $\left(\theta_{j \infty}, p_{j \infty}\right)$ then specifies the limit stochastic view of the world of each dealer. That is, each dealer $j$ perceives demand to be distributed in the limit as

$$
g_{j}\left(\cdot \mid p_{j \infty}, \theta_{j \infty}\right),
$$

which assigns positive probability to each $x_{j} \in X_{j}$. These results can now straightforwardly be related with the concept of equilibrium defined above.

Theorem 8.2 The conjectures and prices of each dealer $j$ converge to an individual conjectural equilibrium, $\lambda_{j}$-almost surely.

Proof. From Proposition 8.8 and Proposition 8.9 , it is known that $\lambda_{j}$-almost surely, $\mu_{j \infty}$ putting point mass on $\theta_{j \infty}$, such that $\mu_{j \infty}$ does not distinguish. By Proposition 8.7 , therefore,

$$
B_{j}\left(p_{j}\left(\mu_{j \infty}\right), x_{j}\right)=\mu_{j \infty} \text { for all } x_{j} \in X_{j} .
$$

By construction, $p_{j}\left(\mu_{j \infty}\right)=p_{j \infty}=\arg \max \Pi_{j}\left(p_{j}, \mu_{j \infty}\right)$, which is unique by Asstmption 8.1. Hence, $\mu_{j \infty}$ leads to prices that support an individual conjectural equilibrium.

\subsection{Objective Convergence to Conjectural Equilibrium}

It is now known that for almost all development-paths of history to which a dealer initially assigns non-zero probability, its beliefs on the parameters of conjectured market demand, and thereby the price it sets, converge to a unique limit belief that puts point-mass on a single parameter of conjectured demand. For each dealer, the limif price is an individual conjectural equilibrium.

Since these results hold for every individual dealer $j$, conclusions on the behavior a the economy are within reach. However, since the conjectures that deallers entertair are structurally mis-specified, their beliefs of possible developments of history neec not necessarily match with the objective sequence of market demand they face. Con sequently, actual histories may unfold that have $\lambda_{j}$-probability zero for some dealers 
Dealers facing such probability zero histories will be unable to cope with it: Bayesian learning breaks down under such shocking surprises, and convergence fails. In order to exclude the rise of such paths, therefore, a condition is needed that relates beliefs to objective probabilities.

The objective probability measure on the space of sample paths of the form $h_{j \infty 0} \in$ $H_{f \infty}$ is potentially influenced by the behavior of all dealers through the objective demand functions $f_{j}\left(\cdot \mid \mathrm{p}, \psi_{j}\right)$. In fact, for given initial beliefs $\mu_{0}$ of the population, the unfolding sequence of individual actions $\left(\mathbf{p}_{t}\right)_{t \in \mathbb{N}}$ that derives from the dealers' sequenthal individual application of Bayes' rule within their conjectured demand structures, lays out a complete history of the world, when performed in the interrelated objective demand structures. For given priors, the only stochastic influence on the individually abserved history $h_{j \infty}$ is from $f_{j}\left(\cdot \mid \mathbf{p}_{t}\left(\mu_{t}\right), \psi_{j}\right)$ for each $t$.

The construction of objective probabilities on space $H_{j \infty}$ requires an objective probability measure $\rho_{j}$ on $\mathcal{B}_{H_{j} \infty}$ Like $\lambda_{j}, \rho_{j}$ is formally defined inductively on histories of finite length, combined with infinite extensions. That is, for any given set $D_{\tau} \subset \times_{i=1}^{\tau} X_{j}$, for $t=1, \ldots, \tau$, it is sufficient to specify the number

$$
\rho_{j}\left(D_{\tau} \times\left(\times_{t=\tau+1}^{\infty} X_{j}\right)\right),
$$

because once again these numbers are known, there is a unique way to extend $\rho_{j}$ to $B_{H_{j \rightarrow \infty}}$. For notational convenience, again only the probability that an infinite history starts with a history $h_{j \tau}$ in the set $\times_{t=1}^{T} D_{t}$ is considered, i.e.,

$$
\rho_{j \tau}\left(\times_{t=1}^{\tau} D_{t}\right) \equiv \rho_{j}\left(\left(\times_{t=1}^{\tau} D_{t}\right) \times\left(\times_{t=\tau+1}^{\infty} X_{j}\right)\right) \text {. }
$$

For $\tau=0$, naturally $\rho_{j 0}(\emptyset)=1$. For $\tau=1$,

$$
\rho_{j 1}\left(D_{1}\right)=\int_{D_{1}} f_{j}\left(x_{j} \mid \mathbf{p}_{1}, \psi_{j}\right) w_{j}\left(d x_{j}\right) .
$$

In order to now define $\rho_{j, \tau+1}$ inductively, assume that $\rho_{j \tau}$ is known. Then, given a history $h_{j,}$ of length $\tau$, the transition probability $\delta_{j, \tau+1}\left(D_{\tau+1} \mid h_{j, r}\right)$ can be defined for $D_{t+1} \subseteq X_{j}$ as

$$
\delta_{j, \tau+1}\left(D_{\tau+1} \mid h_{j \tau}\right)=\int_{D_{\tau+1}} f_{j}\left(x_{j} \mid \mathbf{p}_{r}, \psi_{j}\right) \nu_{j}\left(d x_{j}\right) .
$$

Then

$$
\begin{aligned}
& \rho_{j, \pi+1}\left(\times_{i=1}^{\tau+1} D_{t}\right) \equiv \int_{H_{j},} \int_{X_{j}} \mathbb{1}_{x_{t=1}^{\tau+1} D_{i}} \delta_{j, \tau+1}\left(d x_{j, \pi+1} \mid h_{j \tau}\right) \rho_{j \tau}\left(d h_{j \tau}\right) \\
& =\int_{H_{j \sigma}} \int_{X_{j}} \mathbb{I}_{\times_{i=1}^{T} D_{t}} \cdot \mathbb{1}_{D_{r+1}} \delta_{j, \tau+1}\left(d^{\prime} x_{j, \tau+1} \mid h_{j \gamma}\right) \rho_{j \gamma}\left(d h_{j \tau}\right) \\
& =\int_{H_{j \tau}} \mathbb{I}_{x_{i=1}^{\tau} D_{i}} \int_{X_{j}} \mathbb{I}_{D_{\tau+\tau-1}} \delta_{j, \tau+1}\left(d x_{j, \tau+1} \mid h_{j \tau}\right) \rho_{j \tau}\left(d h_{j \tau}\right) \\
& =\int_{H_{j \tau}} \mathbb{I}_{X_{i=1}^{\tau} D_{i}} \delta_{j, \tau+1}\left(D_{r+1} \| h_{j \tau}\right) \rho_{j \tau}\left(d h_{j \tau}\right) \\
& =\int_{\times_{t=1}^{+} D_{t}} \delta_{j, \tau+1}\left(D_{\tau+1} \mid h_{j \tau}\right) \rho_{j \tau}\left(d h_{j \tau}\right) \text {, }
\end{aligned}
$$


where the respective steps are analogous to those taken to obtain $\lambda_{j, \tau+1}$. Consistency of $\rho_{j,}$ allows for the application of Kolmogorov's Theorem, which completes the cotstruction of $\left(H_{j \infty}, \mathcal{B}_{H_{j \infty}, \rho_{j}}\right)$.

The following relationship between the objective and subjective probability measures $\rho_{j}$ and $\lambda_{j}$ is now important.

Definition 8.4 The measure $\rho_{j}$ is absolutely contimusous with respect to measure $\lambda_{j}$, denoted as $\rho_{j} \ll \lambda_{j}$, if $\rho_{j}(S)>0$ implies $\lambda_{j}(S)>0$ for all $S \subseteq H_{j \infty}$.

In the interpretation offered for the measures $\lambda_{j}$ and $\rho_{j}$, absolute continuity of $\rho_{j}$ with respect to $\lambda_{j}$ implies that no actual development is possible that was not a priori foreseen as a possibility by the dealer concerned. There is, therefore, 'No Statistical Surprise' on the side of dealers. Figure 8.2 illustrates.

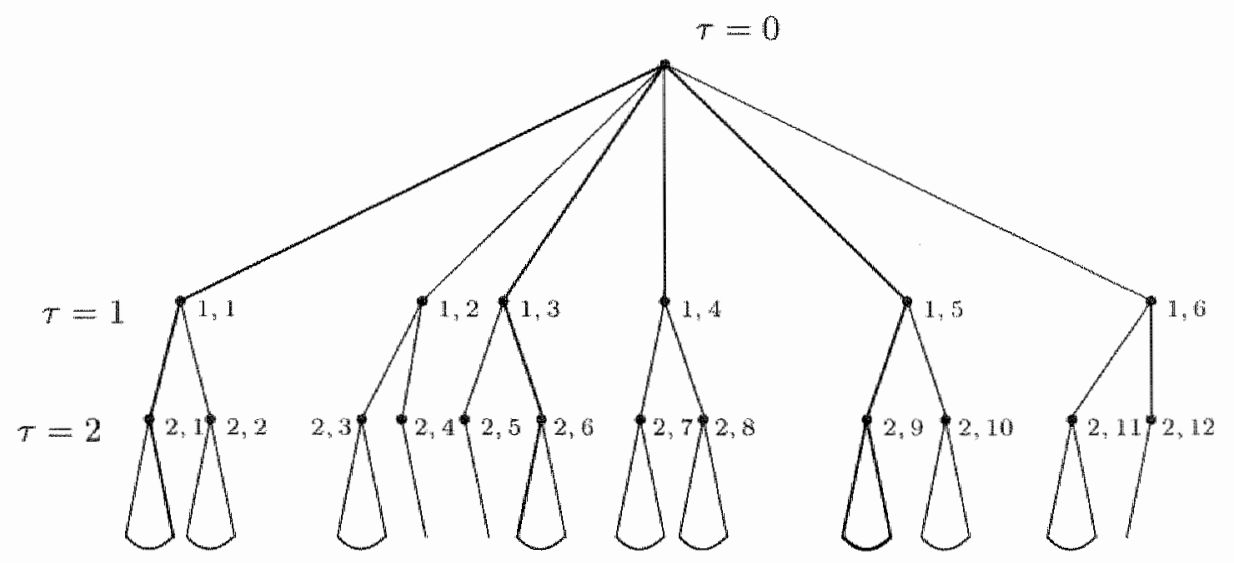

Figure 8.2 An illustration of 'No Statistical Surprise'.

All the possible developments of history at $\tau=0$ envisioned by dealer $j$ and indicated by the thin lines, are at least to cover all the possible developments over time, indicated by the thicker lines. It is perfectly fine if dealers believe histories may unfold that will actually have no chance. Yet, it should not be the other way around. Expectations should allow for all possible future's.

No Statistical Surprise seems a natural condition necessary for beliefs to settle down, as one can hardly expect beliefs to converge if all the time new and unforeseen events stir up ones learning. It is, however, also rather strong. Most importantly, like No Favorable Surprise, No Statistical Surprise is not a primitive condition. That is, since it is a condition on histories, it is not immediately established for given priors. Yet. it clearly bears a close kinship to No Favorable Surprise in the context of subjective beliefs expressed in probability distributions. 
With the assumption of No Statistical Surprise, as well as Assumption 8.1-8.3 introduced above, the following principal result is had.

Theorem 8.3 Suppose $\rho_{j} \ll \lambda_{j}$. Then each dealer $j$ converges to an individual conjectural equilibriam, $\rho_{j}$-almost surely.

Proof. From Theorem 8.2 it follows that each dealer $j$ converges to an individual conjectural equilibrium $\lambda_{j}$-almost surely. Since $\rho_{j}$ is absolutely continuous with respect to $\lambda_{j}$, no path that has positive $\rho_{j}$-probability has zero $\lambda_{j}$-probability. Hence, convergence is $\rho_{j}$-almost-surely

Consider the extension the assumption of absolute continuity of $\rho_{j}$ with respect to $\mu_{j}$ to all dealers.

Assumption $8.4 \rho_{j} \ll \lambda_{j}$ for all $j$.

In all, the main result is now arrived at.

Theorem 8.4 Let perceptions satisfy Assumption 8.1-8.4. Then the price vector $\mathbf{p}_{0}$ converges $\rho_{j}$-almost surely to a unique conjectural equilibrium price vector $\mathbf{p}^{*}$.

Proof. By Theorem 8.3 each individual dealer converges to an individual conjectural equilibrium with unique lirnit beliefs and prices when assumptions 8.1-8.3 hold, and $\rho_{j} \ll \lambda_{j}$. By Assumption $8.4 \rho_{j} \ll \lambda_{j}$ for all $j$, so that all dealers converge to an individual conjectural equilibrium. Such a situation is a conjectural equilibrium with a unique equilibrium price vector $\mathrm{p}^{*}$. 

9

\section{Concluding Thoughts}

In this book, the issue of disequilibrium has been addressed. The critical reflections on the history of thought concerned with disequilibrium provided in the first part of the book led to the conclusion that economics, in its theory as well as in its practice, relies on a homunculus explanation where it is concerned with equilibrium-which it predominantly is. The limited number of interesting results possible in this approach, in turn, led to a degeneration of the discipline of stability theory. The deus ex machina approach to disequilibrium, sought for its falsely presumed generality, thus foreclosed interesting research to address the fundamental issue of out-of-equilibrium behavior. As a result, Samuelson's seminal idea of the correspondence principle got lost.

Yet, it is not the correspondence principle that is to be faulted. Quite to the contrary. The disequilibrium processes operating in an economy are more than likely to have a substantial influence on the nature of the equilibrium on which they eventually settle that is, if convergence takes place at all. Although this insight, as well as elements necessary to substantiate it, was already had early in the development of modern economics, little progress along these lines was made. The elements of a meaningful theory of disequilibrium-i.e., imperfect competition, imperfect and incomplete information, outside of as well as in equilibrium-were first ignored and then developed mainly as equilibrium concepts. Nevertheless, the work that was done points towards a falsification of the law of supply and demand, as well as theories on learning within the confines of subjective conjectures.

Most prominent are the findings of Fisher. In Fisher (1983), he laid down an elaborate rnodel in which rational individuals, that are aware of the fact that their economy is generally in disequilibrium and take action to benefit to the best of their abillities from the arbitrage opportunities thrown up by that circumstance, will be driven to an equilibrium in which such opportunities disappear. Two conditions are essential in that result. The condition of No Favorable Surprise, that rules out the rise of new 
and unforeseen exogenous and endogenous events from which individuals can benefit. and the condition of Eventual Experimentation, that introduces some incentive to try out new dealing proposals, even when the general perception is that they hold little promise, in order to destabilize non-generic equilibria.

After explaining how his model repairs some strikingly awkward features of earlier Samuelsonian-type disequilibrium adjustment processes, Fisher extensively discussed directions for further research. The first development called for is the extension of No Favorable Surprise to situations with subjective uncertainty, where individuals do not hold point expectations, but foresee different developments with different probabilities instead. Fisher stated:

"The principal issues which must be faced-aside from the precise modeling of uncertainty itself when information comes in over time-are the nature of equilibrium and the precise statement of No Favorable Surprise." (op.cit., p.214)

The second principal point of further research Fisher suggested is the study of price adjustment based in individually rational behavior. Although in Fisher (1983) the strength of No Favorable Surprise allows individual consumers and firms to set and adjust prices-if necessary violating the law of supply and demand-little specific modelling of these processes is provided. The concluding chapter reads:

"[I]n fact, we know very little about how ... adjustments take place. The analysis in earlier chapters ... merely observes that prices will refect perceived demand and supply curves, or equivalently, the shadow prices of perceived transaction constraints. It says nothing about how such perceptions are formed." (op.cit., p.215)

Albeit still very partially, the model presented here in Chapter 8 , extends on both these two key issues. It develops an economy in which dealers responsible for the trade in a particular commodity set prices on the basis of their subjective world view, tailoned to the information on prices and quantities they were able to observe in the past. They do so perfectly subjectively rational, even though they are boundedly informed and myopic in the sense that they do not foresee the informative qualities of the future prices they control. New incoming information in the form of offers and sales proposed by customers at the prices set, namely, is used to update the probability distributions over the parameters of demand and supply. As a consequence, perceptions change, and with that so do prices.

The complete price adjustment process thus described is shown to be stable under the condition of No Statistical Surprise, which bears a close kinship to No Favorable Surprise. It states that no individual dealer is to be confronted with a sale or purchase possibility which was not initially included in the support of his beliefs. In other words. no exogenous or endogenous events should rise that were initially given zero probability. It is no surprise that the type of Bayesian learning that drives the adjustment of beliefs and prices requires an assumption of this kind. Obviously, Bayesian updating breaks down when probability-zero events happen. Yet, it still is only a sufficient condition. Moreover, it is certainly not a primitive assumption. 
It has been argued at length in this book that equilibria should be considered that are the rest-points of interesting dynamics. Consequently, the importance of conditions such as Eventual Experimentation, that rule out "unwanted" equilibria, is down-played. If it so happens that economies can end up in situations where rationing takes place, whout it necessarily having an objective ground, and it being solely subjectively rational for individuals, then there are important lessons to be learned from that. Moreover, the nature of the conjectural equilibria found in the model presented here is - although the equilibria are generic-non-Walrasian by construction. Walrasian equilibria as rest points of sensible disequilibrium dynamics has been argued to be too much to ask for-a Holy Grail. There exists, in other words, a trade-off between static efficiency and stability.

The ommipresence of non-Walxasian equilibria establishes a strong link with a literature that is generally considered quite distinct from stability issues, yet turns out to be very much related. It is in the ream of macroeconomics and concerned with monopolistically competitive equilibria. One striking feature of this literature as well as of the small leaming literature on so-called mis-specified models considered in Chapter 7-is that the set of potential equilibria is very large. The characterization of equilibrian, in other words, is difficult, as there is no obvious 'right one' among them. An appeal to what has been dubbed "the Correspondence Principle in the Large" has been made therefore. That is, a theory of comparative dynamics is required, in which the nature of the equilibrium is established by means of the features of the disequilibum process leading towards it from given initial conditions.

On the foumdations laid in the model presented here, a substantive theory of comparative dynamics is to be erected. In comparatiwe dynamics, equilibria are appreciated for the fact that they are the limits of reasonable disequilibrium adjustment processes instead of the other way around, adjustment processes appreciated for the fact they bring about equilibria that are a priori deemed interesting. It concerms the infuence of particular disequilibrium behavior on equilibrium. This corversion has important implications for economic analysis and policy advice. For one thing, it seriously questions the validity of comparative statics of the type widely applied to accompany policy advice. Also, it opens up initial conditions. such as initial perceptions, as a policy variable.

There is a clear demand for this type of theory. In Chapter 1, macroeconomic monetary policy was mentioned as an example of goverment intervention based on theory to which a disequilibrium perspective is of relevance. Joaquim Silvestre, concludes his 1993 Joumal of Economic Literature survey "The Market-Power Foundations of Macroeconomic Policy" as follows."

"Any equilibrium model relies, implicitly or explicitly, on dynamics. One difference between a model with a unique equilibrium and one with three equilibria is that the predictions of the former are global: they do not

It is yet another sad example of the gap between micro- and macrocenomice, that Silvestrt (1993) has no reference to Fisher (1983), although the latier repeatedly discusses the possible lack of inupat of monetary policy when individuals falsely perceive their money constraints to be binding C. P.g., op.cit., p. 176 
depend on initial conditions, although they are based implicitly on the assumption that the equilibrium is globally stable. The model with three equilibria, on the contrary, requires explicit dynamics and initial conditions for a point prediction.

The literature does not offer explicit dynamic mechanisms that incorporate the policy variables and their role in the transition to a superior equilibrium. (...) A first step in this direction has been the theoretical and empirical work supporting the observation that history plays a role in the determination of equilibrium, but the explicit disequilibrium dynamics in models of coordination problems is still in its infancy." (op.cit., p.137)

Although perhaps a start, the dealer model presented here has many shortcomings and entries for further research on extensions. A first, and already noted extension. would be the inclusion of subjective uncertainty on supply. A model incorporating both demand and supply conjectures, that simultaneously are adjusted over time when market experiences are made, is not likely to change the qualitative conclusions reached in Chapter 8. Yet, the technicalities of such a model, even though completely analogous to those of the present model, are likely to be demanding. ${ }^{2}$

Another extension that presents itself is to further specify the relationship between objective demand and supply structures and their subjective counterparts on which bellawior is based. The results presented here are based on a given subjective structure, that is little specified. The earlier papers by Kirman, a version of which is in Chapter 7, make specific, though rather simplistic, assumptions, namely that objective and subjective demand and supply are linear, and the latter is a truncated version of the former. Typically, firms will apply crude econometric techniques to determine the best structural specification to work with, in which the costs of including additional explanatory variables, or sharper functional forms are weighted against the expected benefits of more precise predictions. ${ }^{3}$ It is an open question-although the answer to it is quite likely to be affirmative whether subjective conjectures that in structure in the limit approach the objective demand and supply structures, coupled with the type of Bayesian learning and price adjustment presented here, will converge to objective monopolistically competitive equilibrim. Yet, a cost-benefit analysis in which the costs of lurther sharpening the world-view are weighted against the expected benefits is likely to lead to an optimal level of mis-specification that differs substantially from full objective demand.

Related to this is the concept of active learning, where dealers reckon with the fact that their prices will provide future information that can be used to increase profits. The type of non-myopic price setting that results from this has been studied in a partial setting, e.g. in Easley and Kiefer (1988) and Kiefer and Nyarko (1989), where convergence results similar to the ones obtained here are established. The present price adjustment model would benefit greatly from an extension of dealer behavior in this

2 On the existence of conjectural equibra under watious adapt we learning processes see Siltesse (1977). Ranpa (1989) presents an interesting local stability result an ordinary least squares learning. Cf. Godfrey (1988) and White (1994). 
drection, even though No Statistical Surprise is probably powerful enough to again assure almost sure convergence.

The dealer model presented here relies on a specific and exogenously given structure of the market. Certain dealers make it their business to act as intermediaries in the trade of a particular good. Casually, this setup has been defended by an appeal to product differentiation and transaction costs. It is to represent a socially accepted shopping area structure. Although the identification of commodities with dealers, which naturally leads to this market structure, seems quite appropriate in many markets, further specification of these underlying properties of markets is called for. Particularly, the consequences of entry and exit, and the possibility to compete for locally dominant dealerships raises interesting questions. For one thing, efforts to endogenize the market structure may well result in entry conditions that have the dealer model sound more than currently like a disequilibrium story with a competitive ending. ${ }^{-1}$

Closely related to these extensions in a general equilibrium context are applications in industrial organization of the exact same principle. There is a small literature on socalled sporadic price discrimination, which is a form of market skimming in which the demand for a new product is being established through a particular market penetrar tion strategy - see e.g., Bork (1995). The idea that what appears to be straightforward price-discrimination, which is deemed anti-competitive in antitrust legislation and jurisprudence, is in fact a symptom of a learning process that may well lead to welfare improvements over time, provides a new argument in competition policy--although it does have an Austrian ring to it. This type of intervention, in other words, may well linder the socially beneficial spread of information. The present model can substantiate this argument, which is a direction of further research worth pursuing.

Likewise, there are interesting questions raised when one considers the actions of customers in light of the price adjustment driven by learning dealers. Disequilibrium awareness on the side of firms and consumers may lead them to delay purchases and sales when beneficial future price changes are foreseen. By hindering the learning process that relies on trade proposals as input signals, these waiting-game type situations can well hold up potentially mutually beneficial trades. On the other hand, patience starts to play a role of importance in such situations. Individual time preferences, established for example by the simple basic necessity to eat, may in such a way become the basis of a theory of speed of adjustment-which is the third major open research question Fisher (1983) points to, and on which little or nothing was said here.

Another route by which, among others, these issues of timing can come into play is related to an altogether different question. That is whether people actually learn in a Bayesian fashion. This may be quite questionable. Yet, the present model structure opens up many possibilities for the study of price adjustment processes by introducing different learning rules. There is quite a large literature in psychology that considers the cognitive processes involved in learning. One possible direction for further research is to tap into this literature. By an early and unhappy division of labor, economic theory largely stayed away from psychology. Fleshing out learning by applying insights 
from psychology is likely to lead to a better understanding of disequilibrium behavior, including essential elements that influence adjustment speeds.

The distinction between structural learning and 'soft' parameter learning characteristic of the model presented in Chapter 8 is common in the cognitive sciences. Although early learning theory, such as classical and operant conditioning, was largely based on the learning behavior of animals-as well as rather behavioristic-particularly with the work of Bandura in the 1960's the special faculties of conscientious human learning were exploited. Formal modelling in mathematical psychology also started then, e.g., with Helson (1964). A recent comprehensive survey of relevant issues is provided in Domjan (1998). It offers a world of insights that can find good application in the explanation of disequilibrium dynamics by specifying dealer behavior. ${ }^{5}$

Empirical research is also likely to shed light on the particulars of disequilibrium adjustment, and therefore an interesting field of research. After all, Walras' theory of tatonnement, from which all theoretical work in disequilibrium theory took off, was originally inspired by casual observations on the Paris Stock Exchange. Recently, in economics there is a renewed interest in this type of empirical research. Examples are Hărdle and Kirman (1995), Blinder (1991), Blinder, Caneti, Lebow and Rudd (1998), and Ruggles and Ruggles (1999). These studies suggest that the processes at work in actual markets are far and importantly more complex than those that have found their way into abstract theory. The dealer structure offers a way to explain elenents of their findings that seems worth pursuing. Walras' method of decreasing abstraction naturally leads right back here.

Yet, on matters of disequilibrium it is hard to do direct empirical research or even surveys. The reason is that it is difficult, if not impossible, to disentangle equilibrium from disequilibrium observations, particularly ex post. ${ }^{6}$ One possible way out of this is offered by controlled experimental setups. A large literature on laboratory experiments into adjustment behavior is developing, e.g., Bronfman, McCabe, Porter, Rassenti and Smith (1996) and Rassenti, Reynolds, Smith and Szidarovsky (2000), which relate to Smith (1982), a seminal contribution to experimental economics, and Marimon, Spear and Sunder (1993). Findings in both these directly empirical and experimental studies, as well as in simulation analyses, e.g., in Albin and Foley (1992), corroborate the observation that out-of-equilibrium processes are to be considered in general equilibrium models. Moreover, they provide creative suggestions as to how this could be done - as well as to set up new experiments, e.g., into the willingness to accept disequilibrium trade offers, or the objective manipulability of rationing processes and the subjective perceptions thereof. This research can serve as a body of data from which to induce general results to substantiate disequilibrium analysis with.

Some of the policy implications of the type of disequilibrium perspective developed in this book - such as the insight that subjective perceptions and possibilities for their modification over time are crucial, and consequently profits, that play an important role in this process, are not 'bad' per se-have been hinted upon above. Yet, a con-

" For an application of some theories from psychology to economics see Cross (1983) of wan Raaij, "Information Processing and Decision Making: Cognitive Aspects of Economic Behavior" in Raaij, Veldhoven and Waerneryd, eds (1988).

") On this see Allinghan (1972) and Quandt (1988). 
sistent exploration of them requires an understanding of the welfare consequences of diseculibrium adjustment processes. Such a disequilibrium welfare analysis can take ksentially two forms. It could stay close to equilibrium welfare analysis and restrict itself to statements on Pareto improvements, where no individual's well-being is de creased. Alternatively, it could encompass a theory of compensation, in which the side-payments necessary to undo the decreases in well-being of some individuals, that prewously benefited from disequilibriwm situations when these disappear over time, are considered. The latter requires an appeal to cardinal welfare analysis, which is quite comtrowersial and for good reasons. Yet, this is the direction in which economics is to develop. Often general equilibrium theory is misused to support libertatian ideas. In imspiring a literature that set ont to prove that societies in which individuals focussed on their own well-being tend to coordinate on efficient equilibria, Adam Smith falled to counter Mandeville's Fable of the Bees. Many of the contributors to general aquibrium theory in the 1960's and 1970's never intended this to happen. A theory of disequilibrium behavior that positively seeks to understand the question of the rise of equilibria- which is scarcely answered by proof of existence, nor uniqueness, for that matter can really come to answer those strongly politically tavored issues. The theory's current state of underdevelopment shows that, although in principle free markets can support efficient trade, there is no particularly good justification for resting assured with that such will indeed happen. 



\section{Appendix A \\ Ordinary Least Squares Learning}

The illustration of the setup of a disequilibrium theory in which prices are set and adjusted individually rationally, provided in Chapter 7 has been noted to bear a very close relationship to a model studied by Kirman, where dealer apply ordinary least squares (OLS) to learn from past observations. The precise nature of the relation, used to perform the simulation studies reported in Chapter 7 , is set out in this appendix. The route to the equivalence result under specific conditions is rather long. It uses results obtained in the vast engineering literature on recursive identification and adaptive control. "It runs over showing that Bayesian and OLS learning generate identical recursive systems. In passing, several characteristics of the example stated in the chapter will be established.

Kirman's dealers operate in an objective economy in which they each face the objective demand given as $(j=(1,2))$

$$
x_{j}=\alpha-\beta p_{i}+\gamma p_{-j},
$$

but each perceive demand subjectively as

$$
x_{j}=a_{j}-b_{j} p_{j}+e_{j}
$$

where

$$
e_{j} \sim N\left(0, \sigma_{e_{j}}^{2}\right)
$$

Consequently, the static structure is identical to the one presented in Chapter 7 for the specification $\alpha_{j}=\alpha_{-j}, \beta_{j}=\beta_{-j}$ and $\gamma_{j}=\gamma_{-j}$.

1 See particularly Sternby (1977) and Ljung and Sóderström (1983) 
The parameters $a_{j}$ and $b_{j}$ are estimated in each period $t$ as $\widehat{a}_{j t}$ and $\widehat{b}_{j t}$, applying ordinary least square estimation to all information avalable to each dealer, in cosu all past observations of (self-made) prices and associated demand signals. Hence. for $j=1,2$, at time $t$, having $t-1$ observations on price-quantity pairs avalable

$$
\hat{b}_{j t}=-\frac{\sum_{k=1}^{k-1}\left(d_{j k}-\bar{d}_{j l}\right)\left(p_{j k}-\bar{p}_{j t}\right)}{\sum_{k=1}^{t-1}\left(p_{j k}-\bar{p}_{j t}\right)^{2}},
$$

and

$$
\hat{a}_{j t}=\bar{d}_{j t}+\hat{b}_{j t} \bar{p}_{j t}
$$

where

$$
\bar{d}_{j t}=\frac{\sum_{k=1}^{t-1} d_{j k}}{t-1} \text { and } \bar{p}_{j t}=\frac{\sum_{k=1}^{t-1} p_{j k}}{t-1}
$$

In the following, it is convenient to apply vector notation. In each period $t$ each dealer $j$ faces a price dependent market demand $x_{j t}$ for its commodity. Conjectures of demand read ( $T$ for transpose)

$$
x_{j t}=\varphi_{j t}{ }^{T} \theta_{j}+e_{j t}
$$

where

$$
\varphi_{j t}=\left[\begin{array}{c}
1 \\
p_{j t}
\end{array}\right] \text {, and } \theta_{j}=\left[\begin{array}{c}
a_{j} \\
-b_{j}
\end{array}\right]
$$

Also, slightly more general, suppose that each dealer perceives the error terms in his conjecture to be distributed with finite private, possibly time-varying second moments $\sigma_{0, t}^{2}$

Let. $\hat{\theta}_{j t}$ collect realized estimates at time $t$, so that

$$
\widehat{\theta}_{j t}=\left[\begin{array}{c}
\widehat{a}_{j t} \\
-\widehat{b}_{j !}
\end{array}\right]
$$

Prices again are set to maximize immediate profits as

$$
p_{j t}=\frac{\widehat{a}_{j t}}{2 \hat{b}_{j t}}
$$

by each dealer $j$.

The following lemma will be instrmmental in the proofs below.

Lemma A.1 (Natrix Inversion) Let $A, B, C$ and $D$ be matrices of compatible dimensions so that the product BCD and the sum $A+B C D$ exist. Then

$$
[A+B C D]^{-1}=A^{-1}-A^{-1} B\left[D A^{-1} B+C^{-1}\right]^{-1} D A^{-1}
$$


Proof. See Ljung and Söderström (1983), p.19.

Let $P_{j t}$ be an invertible $2 \times 2$ matrix for each $t$. Consider now the following system of difference equations:

$$
\begin{aligned}
& \widehat{\theta}_{j t}=\widehat{\theta}_{j, t-1}+L_{j t}\left\{x_{j, t-1}-\varphi_{j, t-1}^{T} \widehat{\theta}_{j, t-1}\right\} \\
& L_{j t}=\frac{P_{j, t-1} \varphi_{j, t-1}}{\sigma_{e_{j, t}, t}^{2}+\varphi_{j, t-1}^{T} P_{j, t-1} \varphi_{j, t-1}} \\
& P_{j t}=P_{j, t-1}-\frac{P_{j, t-1} \varphi_{j, t-1} \varphi_{j, t-1}^{T} P_{j, t-1}}{\sigma_{e_{j, t-1}^{2}}^{2}+\varphi_{j, t-1}^{T} P_{j, t-1} \varphi_{j, t-1}} .
\end{aligned}
$$

Observe that this is a first-order recursive system, in which the update of $\widehat{\theta}_{j t}$ is a linear function of the error of estimation $\varepsilon_{j, t-1}$, with

$$
\varepsilon_{j, t-1} \equiv x_{j, t-1}-\varphi_{j, t-1}^{T} \widehat{\theta}_{j, t-1}
$$

The system has the following interpretation.

Proposition A.1 System (A.3), started at $t=0$ with any arbitrary $2 \times 1$ wector $\widehat{\partial}_{j 0}$ and any arbitrary invertible $2 \times 2$ matrix $P_{j 0}$, represents the development of a sequence of estimates $\left\{\widehat{\theta}_{j t}\right\}$ that minimizes at each $t$

$$
\sum_{k=1}^{t-1} \frac{1}{\sigma_{e_{j}, t}^{2}}\left(x_{j k}-\varphi_{j k_{k}}^{T} \theta_{j}\right)^{2}
$$

with respect to $\theta_{j}$.

Proof. Equation (A.5) is a quadratic function, so minimization can be done andlytically and returns

$$
\hat{\theta}_{j t}=\left[\sum_{k=1}^{l-1} \frac{1}{\sigma_{e_{j}, k}^{2}} \varphi_{j k} \varphi_{j k}^{T}\right]^{-1} \sum_{k=1}^{t-1} \frac{1}{\sigma_{k_{j}, k}^{2}} \varphi_{j k} x_{j k} .
$$

This is the well known generalized least squares estimator of $\theta_{j}$. Note its resemblance (apart from the weighting factor) to the estimator presented in the previous section.

To write this system recursively define

$$
R_{j t} \equiv \sum_{k=1}^{t-1} \frac{1}{\sigma_{e_{j}, k}^{2}} \varphi_{j k} \varphi_{j k}^{T}
$$

so that at time $t$, with $t-1$ observations, (A.6) can be rewritten as

$$
\widehat{\theta}_{j t}=R_{j t}^{-1} \sum_{k=1}^{t-1} \frac{1}{\sigma_{e_{j}, k}^{2}} \varphi_{j k} x_{j k}
$$


and hence

$$
\sum_{k=1}^{t-1} \frac{1}{\sigma_{e_{j}, k}^{2}} \varphi_{j k} x_{j k}=R_{j t} \widehat{\theta}_{j k}
$$

Definition (A.7) implies that

$$
R_{j, t-1}=R_{j t}-\frac{1}{\sigma_{e_{j}, t-1}^{2}} \varphi_{j, t-1} \varphi_{j, t-1}^{T}
$$

Hence, $\widehat{\theta}_{j t}=$

$$
\begin{aligned}
& R_{j t}^{-1}\left[\sum_{k=1}^{t-2} \frac{1}{\sigma_{e_{j}, k}^{2}} \varphi_{j k} x_{j k}+\frac{1}{\sigma_{e_{j}, t-1}^{2}} \varphi_{j, t-1} x_{j, t-1}\right] \\
= & R_{j t}^{-1}\left[R_{j, t-1, \theta_{j, t-1}}+\frac{1}{\sigma_{e_{j}, t-1}^{2}} \varphi_{j, t-1} x_{j, t-1}\right] \\
= & R_{j t}^{-1}\left[R_{j t} \widehat{\theta}_{j, t-1}+\frac{1}{\sigma_{e_{j, t}}^{2}} \varphi_{j, t-1}\left\{-\varphi_{j, t-1}^{T} \widehat{\theta}_{j, t-1}+x_{j, t-1}\right\}\right] \\
= & \hat{\theta}_{j, t-1}+R_{j t}^{-1} \varphi_{j, t-1} \frac{1}{\sigma_{e_{j}, t-1}^{2}}\left\{x_{j, t-1}-\varphi_{j, t-1}^{T} \widehat{\theta}_{j, t-1}\right\} .
\end{aligned}
$$

With (A.8) this constitutes a fully recursive algorithm.

For computational convenience, it is generally written using

$$
P_{j t} \equiv R_{j t}^{-1}
$$

and Lemma A.1, as follows.

It was derived above that

$$
R_{j t}=R_{j,-1}+\frac{1}{\sigma_{e_{j, t}-1}^{2}} \varphi_{j, t-1, \varphi_{j, t-1}^{T}}^{T}
$$

Hence,

$$
P_{j t}=\left[P_{j, t-1}^{-1}+\frac{1}{\sigma_{\epsilon_{j}, t-1}^{2}} \varphi_{j, t-1} \varphi_{j, t-1}^{T^{2}}\right]^{-1}=\left[P_{j, t-1}^{-1}+\varphi_{j, t-1} \frac{1}{\sigma_{c, j, t-1}^{2}} \varphi_{j, t-1}^{T^{2}}\right]^{-1}
$$

And by the lemma consequently,

$$
\begin{aligned}
P_{j t} & =P_{j, t-1}-P_{j, t-1} \varphi_{j, t-1}\left[\varphi_{j, t-1}^{T} P_{j, t-1} \varphi_{j, t-1}+\sigma_{\varepsilon_{j}, t-1}^{2}\right]^{-1} \varphi_{j, t-1}^{T} P_{j, t-1} \\
& =P_{j, t-1}-\frac{P_{j, t-1} \varphi_{j, t-1} \varphi_{j, t-1}^{T} P_{j, t-1}}{\sigma_{\epsilon_{j}, t-1}^{2}+\varphi_{j, t-1}^{T} P_{j, t-1} \varphi_{j, t-1}} .
\end{aligned}
$$


Then

$$
\begin{aligned}
\mathbb{R}_{j t}^{-1} \varphi_{j, t-1} \frac{1}{\sigma_{\epsilon_{j}, t-1}^{2}} & =\frac{1}{\sigma_{\epsilon_{j}, t-1}^{2}}\left[P_{j, t-1}-\frac{P_{j, t-1} \varphi_{j, t-1} \varphi_{j, t-1}^{T} P_{j, t-1}}{\sigma_{\epsilon_{j}, t-1}^{2}+\varphi_{j, t-1}^{T} P_{j, t-1} \varphi_{j, t-1}}\right] \varphi_{j, t-1} \\
& =\frac{1}{\sigma_{\epsilon_{j}, t-1}^{2}} P_{j, t-1} \varphi_{j, t-1}-\frac{\frac{1}{\sigma_{j, t-1}^{2}} P_{j, t-1} \varphi_{j, t-1} \varphi_{j, t-1}^{T} P_{j, t-1} \varphi_{j, t-1}}{\sigma_{\epsilon_{j}, t-1}^{2}+\varphi_{j, t-1}^{T} P_{j, t-1} \varphi_{j, t-1}} \\
& =\frac{P_{j, t-1} \varphi_{j, t-1}}{\sigma_{\epsilon_{j}, t-1}^{2}+\varphi_{j, t-1}^{T} P_{j, t-1} \varphi_{j, t-1}}=L_{j t} .
\end{aligned}
$$

This is system (A.3). The initial conditions need only to have matching orders, and $P_{50}$ to be invertible.

The objective function (A.5) is, of course, a least squared error loss-function in which each observation is weighted by $\frac{1}{\sigma_{2}^{2}, 2}$, the inverse of its perceived variance (referred to as its perceived 'precision"). Consequently, the proposition identifies system (A.3) as the recursive form of the generalized least squares estimator of $\theta_{j}$ with that particular weighting factor. So in (A.3) an explicit recursive form of the sort of learning applied by Kirman is provided. Note that no particular restrictions were put on the (perceived) distribution of the error terms, except for finiteness of its second moments for all $t$. As promised, this detour allows a connect with Bayesian learning.

It was stated in Chapter 7 that the sequence of posterior distributions under the normality assumptions made in the duopoly model presented there, is a sequence of normal distributions with means and covariance matrices that follow a known recursive system. It will now be identified as system (A.3).

Consider the following assumptions on the dealers' perceptions of the stochastics in their subjective demand conjectures.

Assumption A.1 For each dealer $j,\left\{e_{j t}\right\}$ is perceived to be a sequence of independent, normally distributed variables with zero mean and non-negative variance, i.e.,

$$
\begin{aligned}
e_{j t} & \sim N\left(0, \sigma_{e_{j, t}}^{2}\right), \text { and } \\
E\left(e_{j e} e_{j t}\right) & =0 \text { for } a l l(s, t), s \neq t .
\end{aligned}
$$

Assumption A.2 For each dealer $j$, the true parameter vector $\theta_{j}$ is perceined to be normally distributed with a priori mean $\theta_{j 0}$ and a priori covariance matrix $P_{j 0}$.

Assumption A.3 For each dealer $j, \theta_{j}$ and $e_{j}$ are percetued to be independent for all t, i.e.

$$
E\left(\theta_{j} e_{j t}\right)=0 \text { for all } t \text {. }
$$

These assumptions were made in the duopoly model considered in Chapter 7 . They allow for the following result.

Proposition A.2 Under assumptions A.1, A.2 and A.3 the posterior distribution of $\hat{\theta}_{j}, \mu_{j t}$ is normal with mean $\hat{\theta}_{j i}$ and variance matrix $P_{j t}$, where $\hat{\theta}_{j t}$ and $P_{j t}$ satisfy system (A.3), starting with $\theta_{j 0}$, and $P_{j 0}$. 
Proof. Induction will provide the desired result in steps, applying Bayes' nule in the form

$$
\mu_{j t}\left(\theta_{j}\right)=\frac{g_{j}\left(x_{j, t-1} \mid \theta_{j}\right) \mu_{j, t-1}\left(\theta_{j}\right)}{g_{j}\left(x_{j, t-1}\right)}
$$

to probability density functions, where the denominator is independent of $\theta_{j}$, which has been integrated out.

Step 1. The perceived prior for the $2 \times 1$ parameter vector $\theta_{3}$ reads

$$
\mu_{j 0}\left(\theta_{j}\right)=\frac{1}{2 \pi \sqrt{\operatorname{det} P_{j 0}}} e^{\left\{-\frac{3}{2}\left(\theta_{j}-\theta_{j 0}\right)^{T^{7}} P_{j 0}^{-1}\left(\theta_{j}-\theta_{j 0}\right)\right\}}
$$

by Assumption A.2.

Step 2. It is natural to assume therefore that

$$
\mu_{j, t-1}\left(\theta_{j}\right)=\frac{1}{2 \pi \sqrt{\operatorname{det} P_{j, t-1}}} e^{\left\{-\frac{1}{2}\left(\theta_{j}-\theta_{j, t-1}\right)^{T} P_{j, i-1}\left(\theta_{j}-\theta_{j, i-1}\right)\right\}} .
$$

Step 3. From the empirical conjectures (A.1) it follows that

$$
e_{j t}=x_{j t}-\varphi_{j t}^{T} \theta_{j}
$$

By Assumption A.1

$$
\left.g_{j}\left(x_{j, t-1} \mid \theta_{j}\right)=\frac{1}{\sqrt{2 \pi \sigma_{\theta_{j}, t-1}^{2}}} e^{\left\{-\frac{1}{2 \sigma \sigma_{j, t-1}^{2}}\left(x_{j, t,-1}-\phi_{j, t \cdots, 2}^{T} \theta_{j}\right)^{2}\right.}\right\} .
$$

Step 4. The necessary elements of (A.10) are now available to derive

$$
\mu_{j t}\left(\theta_{j}\right)=c e^{-\Gamma^{n}}
$$

where

$$
\Gamma=\frac{1}{2 \sigma_{v_{j, t-1}}^{2}}\left(x_{j, t-1}-\varphi_{j, t-1}^{T} \theta_{j}\right)^{2}+\frac{1}{2}\left(\theta_{j}-\widehat{\theta}_{j, t-1}\right)^{T} P_{j, t-1}^{-1}\left(\theta_{j}-\hat{\theta}_{j, t-1}\right)
$$

and $c$ is some normalization factor independent of $\theta_{j}$.

With the perceived posterion distribution now in hand, a convenient expression of its moments can be given. Through some manipulation of (A.11):

$$
\begin{aligned}
-2 \ln \mu_{j t}\left(\theta_{j}\right)= & c^{\prime}+\frac{x_{j, t-1}^{2}}{\sigma_{e_{j}, t-1}^{2}}-\frac{x_{j, t-1} \theta_{j}^{T} \varphi_{j, t-1}}{\sigma_{e_{j}, t-1}^{2}}-\frac{\varphi_{j, t-1}^{T} \theta_{j} x_{j, t-1}}{\sigma_{e_{j}, t-1}^{2}} \\
& +\frac{\varphi_{j, t-1}^{T} \theta_{j} \theta_{j}^{T} \varphi_{j, t-1}}{\sigma_{e_{j} t-1}^{2}}+\theta_{j}^{T} P_{j, t-1}^{-1} \theta_{j}-\theta_{j}^{T} P_{j, t-1}^{1} \widehat{\theta}_{j, t-1} \\
& -\hat{\theta}_{j, t-1}^{T} P_{j, t-1}^{1} \theta_{j}+\widehat{\theta}_{j, t-1}^{T} P_{j, t-1}^{-1} \widehat{\theta}_{j, t-1}
\end{aligned}
$$


Where $c$ is a parameter independent factor again.

Define

$$
\bar{P}_{j}^{-1} \equiv P_{j, t-1}^{-1}+\frac{1}{a_{e_{j}, t-1}^{2}} \varphi_{j, t-1} \varphi_{j, t-1}^{\mathrm{T}}
$$

Then (A.12) can be rewritten as

$$
\begin{aligned}
& c^{\prime}+\frac{1}{\sigma_{e_{j}, t-1}^{2}} x_{j, t-1}^{2}+\widehat{\theta}_{j, t-1}^{T} P_{j, t-1}^{-1} \widehat{\theta}_{j, t-1}+\theta_{j}^{T} \bar{P}_{j}^{-1} \theta_{j} \\
& -\theta_{j}^{T}\left[\frac{1}{\sigma_{e_{j}, t-1}^{2}} \varphi_{j, t-1} x_{j, t-1}+P_{j, t-1}^{-1} \hat{\theta}_{j, t-1}\right] \\
& -\left[\frac{1}{\sigma_{e_{j}, t-1}^{2}} \varphi_{j, t-1} x_{j, t-1}+P_{j, t-1}^{-1} \widehat{\theta}_{j, t-1}\right]^{T} \theta_{j}
\end{aligned}
$$

using the fact that $\theta_{j}^{T} \varphi_{j, t-1}=\varphi_{j, t-1}^{T} \theta_{j}$ and hence

$$
\varphi_{j, t-1}^{T} \theta_{j} \theta_{j}^{T} \varphi_{j,-1}=\theta_{j}^{T} \varphi_{j, t-1} \varphi_{j, t-1}^{T} \theta_{j}
$$

Regrouping and the introduction of a new normalization factor allows for the following reformulation of (A.13)

$$
\begin{aligned}
& c^{\prime \prime}+\left[\theta_{j}-\bar{P}_{j} \frac{1}{\sigma_{v_{j}, t-1}^{2}} \varphi_{j,-1} x_{j,-1}-\bar{P}_{j} P_{j, t-1}^{-1} \hat{\theta}_{j, t-1}\right]^{T} \\
& \bar{P}_{j}^{1}\left[\theta_{j}-\bar{P}_{j} \frac{1}{\sigma_{e_{j}, t-1}^{2}} \varphi_{j, t-1} x_{j, t-1}-\bar{P}_{j} P_{j, t-1}^{1} \hat{\theta}_{j, t-1}\right]
\end{aligned}
$$

where $c^{\prime \prime}$ is again a new normalization factor independent of $\theta_{j}$.

Since.

$$
\begin{aligned}
\bar{P}_{j} P_{j, t-1}^{-1} & =\left[P_{j, t-1}-\frac{P_{j, t-1} \varphi_{j, t}-1 \varphi_{j, t-1}^{T} P_{j, t-1}}{\sigma_{j, t-1}^{2}+\varphi_{j, t-1}^{T} P_{j, t-1} \varphi_{j, t-1}}\right] P_{j, t-1}^{-1} \\
& =I-\frac{P_{j, t-1}-1 \varphi_{j, t-1} \varphi_{j, t-1}^{T}}{\sigma_{\epsilon_{j}, t-1}^{2}+\varphi_{j, t-1}^{T} P_{j, t-1} \varphi_{j, t-1}}
\end{aligned}
$$


and

$$
\begin{aligned}
& P_{j} \frac{1}{\sigma_{\epsilon_{j}, t-1}^{2}} \varphi_{j, t-1} \varphi_{j, t-1}^{T} \\
&= {\left[P_{j, t-1}-\frac{P_{j, t-1} \varphi_{j, t-1} \varphi_{j, t-1}^{T} P_{j, t-1}}{\left.\sigma_{\epsilon_{j}, t-1}^{2}+\varphi_{j, t-1}^{T} P_{j, t-1} \varphi_{j, t-1}\right]} \frac{1}{\sigma_{\epsilon_{j}, t-1}^{2}} \varphi_{j, t-1} \varphi_{j, t-1}^{T}\right.} \\
&= \frac{P_{j, t-1} \varphi_{j, t-1} \varphi_{j, t-1}^{T}\left[\sigma_{\epsilon_{j}, t-1}^{2}+\varphi_{j, t-1}^{T} P_{j, t-1} \varphi_{j, t-1}\right]}{\sigma_{\epsilon_{j}, t-1}^{2}\left[\sigma_{\epsilon_{j}, t-1}^{2}+\varphi_{j, t-1}^{T} P_{j, t-1} \varphi_{j, t-1}\right]} \\
&= \frac{P_{j, t-1} \varphi_{j, t-1} \varphi_{j, t-1}^{T} P_{j, t-1} \varphi_{j, t-1} \varphi_{j, t-1}^{T}}{\sigma_{\epsilon_{j, t}-1}^{2}\left[\sigma_{\epsilon_{j}, t-1}^{2}+\varphi_{j, t-1}^{T} P_{j, t-1} \varphi_{j, t-1}\right]} \\
&= \frac{P_{j, t-1} \varphi_{j, t-1} \varphi_{j, t-1}^{T} \sigma_{\epsilon_{j,}, t-1}^{2}}{\sigma_{\epsilon_{j}, t-1}^{2}\left[\sigma_{\epsilon_{j}, t-1}^{2}+\varphi_{j, t-1}^{T} P_{j, t-1}^{2} \varphi_{j, t-1}\right]} \\
& \sigma_{\epsilon_{j}, t-1}^{2}+\varphi_{j, t, 1}^{T} P_{j, t-1} \varphi_{j, t-1}
\end{aligned}
$$

it follows that

$$
\bar{P}_{j} P_{j, t-1}^{-1}=I-\bar{P}_{j} \frac{1}{\sigma_{\omega_{j}, t-1}^{2}} \varphi_{j, t-1} \varphi_{j, t-1}^{T}
$$

Hence, defining,

$$
\bar{\theta}_{j} \equiv \widehat{\theta}_{j, t-1}+\frac{1}{\sigma_{e_{j, t-1}^{2}}} \bar{P}_{j \varphi_{j, t-1}}\left[x_{j, t-1}-\varphi_{j, t-1}^{T} \widehat{\theta}_{j, t-1}\right]
$$

reduces (A.13) to

$$
\mu_{y y}\left(\theta_{j}\right) \propto e^{\left\{\left[\theta_{j}-\bar{\theta}_{j}\right]^{\mathrm{T}} \bar{P}_{j}^{-1}\left[\theta_{j}-\bar{\theta}_{j}\right]\right\}}
$$

The posterior distribution at time $t$ is thus defned as normal with mean $\bar{\theta}_{j}$ and covariance matrix $P$ as defined above.

From the definition (A.12) of $\bar{P}_{j}^{-1}$

$$
\begin{aligned}
\vec{P}_{j} & =\left[P_{j, t-1}^{-1}+\frac{1}{\sigma_{\epsilon_{j}, t-1}^{2}} \varphi_{j, t-1} \varphi_{j, t-1}^{T}\right]^{-1} \\
& =\left[P_{j, t,-1}^{-1}+\varphi_{j, t-1} \frac{1}{\sigma_{\epsilon_{j}, t-1}^{2}} \varphi_{j, t-1}^{T}\right]^{-1}
\end{aligned}
$$

Application of the matrix inwersion lemma once more returns

$$
\begin{aligned}
\tilde{P}_{j} & =P_{j, t-1}-P_{j, t-1} \varphi_{j, t-1}\left[\varphi_{j, t-1}^{T} P_{j, t-1} \varphi_{j, t-1}+\sigma_{\epsilon_{j}, t-1}^{2}\right]^{-1} \varphi_{j, t-1}^{T} P_{j, t-1} \\
& =P_{j, t-1}-\frac{P_{j, t-1} \varphi_{j, t-1} \varphi_{j, t-1}^{T} P_{j, t-1}}{\sigma_{\epsilon_{j}, t-1}^{2}+\varphi_{j, t-1}^{T} P_{j, t-1} \varphi_{j, t-1}} .
\end{aligned}
$$


And therefore,

$$
\begin{aligned}
L_{j t} & =\frac{1}{\sigma_{\epsilon_{j, t}, t-1}^{2}} \bar{P}_{j} \varphi_{j, t-1} \\
& =\frac{1}{\sigma_{\epsilon_{j}, t-1}^{2}}\left[P_{j, t-1}-\frac{P_{j, t-1} \varphi_{j, t-1} \varphi_{j, t-1}^{T} P_{j, t-1}}{\sigma_{\epsilon_{j}, t-1}^{2}+\varphi_{j, t-1}^{T} P_{j, t-1} \varphi_{j, t-1}}\right] \varphi_{j, t-1} \\
& =\frac{\Delta}{\sigma_{\epsilon_{j}, t-1}^{2}+\varphi_{j, t-1}^{T} P_{j, t-1} \varphi_{j, t-1}} \\
& =\frac{P_{j, t-1} \varphi_{j, t-1}}{\sigma_{\epsilon_{j}, t-1}^{2}+\varphi_{j, t-1}^{T} P_{j, t-1} \varphi_{j, t-1}}
\end{aligned}
$$

in which

$$
\begin{aligned}
\Delta \equiv & {\left[\frac{1}{\sigma_{\epsilon_{j}, t-1}^{2}} P_{j, t-1} \varphi_{j, t-1}\right]\left[\sigma_{\epsilon_{j}, t-1}^{2}+\varphi_{j, t-1}^{T} P_{j, t-1} \varphi_{j, t-1}\right] } \\
& -\frac{1}{\sigma_{\epsilon_{j, t-1}}^{2}}\left[P_{j, t-1} \varphi_{j, t-1} \varphi_{j, t-1}^{T} P_{j, t-1} \varphi_{j, t-1}\right]
\end{aligned}
$$

to fit the frame. Together these make up system (A.3).

When it is realized that, for given parameters of objective demand, initial beliefs generate identical histories, it is seen that under assumptions A.1, A.2, and A.3, taking $\theta_{j 0}=\theta_{j 0}$ for all dealers $j$, generalized least squares learning in which the error terms are weighted by their perceived precision and Bayesian learning generate the same sequences of estimates $\left\{\widehat{\theta}_{j t}\right\}$, given by system (A.3). And since prices are a function of parameter estimates for each individual dealer $j$ in (A.2), this implies that the sequence of price vectors $\left\{\mathbf{p}_{t}\right\}$ develops identically under either form of learning.

Consequently, since Kirman applies the ordinary least squares loss-function

$$
\sum_{k=1}^{t-1}\left(x_{j k}-\varphi_{j k}^{T} \theta_{j}\right)^{2}
$$

and the minimum of this function with respect to $\theta_{3}$ is obviously not influenced by a premultiplication with a constant factor, his analysis is unchanged with the lossfunction

$$
\frac{1}{\sigma_{e_{j}}^{2}} \sum_{k=1}^{t-1}\left(x_{j k}-\varphi_{j k}^{T} \theta_{j}\right)^{2}=\sum_{k=1}^{t-1} \frac{1}{\sigma_{c_{j}}^{2}}\left(x_{j k}-\varphi_{j k}^{T} \theta_{j}\right)^{2}
$$

where $\sigma_{e,}^{2}$ is the constant variance of the normal distribution with which dealers in Kirrnan's setup perceive the error terms to be distributed.

The OLS learning applied by Kirman thus is a form of generalized least squares learning, and analogous to the way Bayesian dealers learn, provided the perceptions of the latter satisfy assumptions A.1, A.2, and A.3. Of these, Assumption A.1 is satisfied with a (finite) time-invariant variance of the error term. Assumption A.2 is 
alien to the ordinary least squares learners. One way to look at it is to consider lear squares learners as Bayesian learners that put all probability mass on the mean of distribution of $\theta_{j}$. As such Assumption A.2 is less restrictive than adopting a no Bayesian approach to the estimation problem. Finally, Assumption A.3 is natura:] satisfied for an ordinary least squares learner, since $\theta_{j}$ is perceived to be a constan and so $\theta_{j} E\left(\epsilon_{j t}\right)=0$ as $E\left(\epsilon_{j t}\right)=0$ for all $t$. 


\section{Appendix B}

\section{Topics in Real Analysis}

This appendix provides in Section $B .1$ some basic measure theoretic notions and in Section B.2 the concept of weak convergence applied in the text in Chapter 8 , as well as some relevant associated results that make the book self-contained. The latter are offered here without proofs - which are occasionally quite extensive. These can be found in Schinkel, Tuinstra and Vermeulen (2000).

\section{B.1 Probability Measures}

Before the concept of (probability) measures can be introduced, the notion of an algebra is needed. Consider a (non-empty) set $X$.

Definition B.1 (algebra) A collection $\aleph$ of subsets of $X$ is called an algebra if:

(i) $\theta \in \mathbb{N}$;

(ii) if $A \in \mathbb{N}$ then $X \backslash A \in \mathbb{N}$; and

(iii) if $A_{1}, \ldots, A_{n k}$ are elements of $\mathcal{N}$, then $\cup_{i=1}^{n} A_{i} \in \mathbb{N}$.

Conditions (ii) and (iii) antomatically imply that finite intersections of elements of $N$ are also elements of $k$.

Definition B.2 ( $\sigma$-algebra) An algebra $\aleph$ is called a $\sigma$-algebra if it moreover holds that:

(20) if $A_{1}, A_{2}, \ldots$ is a countable sequence of elements of $\mathrm{N}_{\text {, then }} \cup_{i=1}^{\infty} A_{i}$ is also an dement of $\mathrm{N}$. 
A sequence $A_{1}, A_{2}, \ldots$ is called mutually disjoint (m.d. for short) if the intersection of $A_{i}$ and $A_{j}$ is empty whenever $i$ is not equal to $j$. Now let $N$ be a $\sigma$-algebra on $X$. The central notion of measure theory is

Definition B.3 (measure) A non-negative function

$$
\mu: \mathbb{W} \rightarrow \mathbb{R}
$$

is called a measure if for cuery m.d. sequence $A_{1}, A_{2}, \ldots$ in $N$ it holds that

$$
\mu\left(\cup_{i=1}^{\infty} A_{i}\right)=\sum_{i=1}^{\infty} \mu\left(A_{i}\right) .
$$

Naturally, the expression on the right hand side of the equality is taken to exist. This condition is called the $\sigma$-additivity of $\mu$.

Definition B.4 (probability measure) A measure $\mu$ with $\mu(X)=1$ is called a probability measure.

Suppose that there is a topology $\tau$ on $X$. With this topology it is possible to associate a $\sigma$-algebra on $X$ in a very natural way. To see this, first note that the collection $2^{f}$ of all subsets of $X$ is a $\sigma$-algebra that contains $\pi$. So, the collection $\nu$ of all $\sigma$-algebra's that contain $\tau$ is not empty. This means that

$$
\mathcal{B} \equiv \cap_{\text {wev }}
$$

is a non-empty collection of subsets of $X$. Even better, it is a $\sigma$ algebra that, evident by construction, contains $\tau$. It is said that $\tau$ generates this $\sigma$-algebra.

Definition B.5 (Borel $\sigma$-algebra) The o-algebra generated by the topology $\mathrm{r}$ is called the Borel $\sigma$-algebra generated by $\tau$.

Let $\mathcal{B}$ be the Borel $\sigma$-algebra associated with a metric space $(X, d)$ and let $\mu$ be a probability measure on $\mathcal{B}$.

Definition B.6 (regularity) It is said that $\mu$ is regnlar if for every Borel set $A$ th $B$ and every real number $E>0$ it is passible to find a closed set $F$ and an open set $U$ such that $F \subset A \subset$ and $\mu(U \backslash F)<\varepsilon$.

That is, a measure is regular if every Borel set can be enclosed by an open set, and can itself enclose a closed set, such that the measure of the difference between the sandwiching sets is arbitrarily close to zero.

Theorem B.1 Every probability measune $\mu$ on $\mathcal{B}$ is regular.

\section{B.2 Weak Convergence}

In Chapter 8, the convergence of beliefs over time is discussed. The type of convergence used is commonly kmown as weak convergence on the set $P(\Theta)$ of probability 
measures on $\theta$. That is, the following concept is applied. Let $C$ ( $\Theta$ ) be the collection of pontinuous functions $f: \Theta \rightarrow \mathbb{R}$. Note that each of these functions is bounded, since $\theta$ is compact. With each $f$ in $C(\theta)$ and $\mu \in P(\theta)$ a number

$$
\int_{\Theta} f(\theta) d \mu
$$

an therefore be associated, i.e., the integral of $f$ with respect to $\mu$. The following teminology is used.

Definition $\mathbf{B} .7$ A sequence $\left(\mu_{n}\right)_{n=1}^{\infty}$ of probabilty measures in $P(\Theta)$ converges weakly to a probability measure $\mu_{\infty}$ in $P(\Theta)$ if for each $f \in C(\Theta)$

$$
\int_{\Theta} f(\theta) d \mu_{n} \rightarrow \int_{\Theta} f(\theta) d \mu_{\infty} .
$$

Note that this is just a definition. It is clear that there is a topology in which the above sequences do converge. What is not immediately clear is that there is a topology in which these are the only convergent sequences. Nevertheless, it will subsequently be shown that this is in fact the case. Furthermore, a number of different descriptions of this topology will be prowided

\section{B.2.1 Topology}

One helpful interpretation of this notion of convergence of measures is in terms of pointwise convergence of functionals. ${ }^{1}$ Let $C(\Theta)^{*}$ be the collection of functionals on $C(\Theta)$ that are continuous with respect to the max-norm on $C(\theta)$. The max-norm $\|f\|_{\infty}$ of a function $f$ in $C(\theta)$ is defined as the real number

$$
\|f\|_{\infty} \equiv \max \{\| f(\theta)|| \theta \in \theta\}
$$

The collection $C(\theta)$ is called the (first) dual space of $C(\theta)$. It is said that a sequence $\left(I_{n}\right)_{n=1}^{\infty}$ in $C(\Theta)^{*}$ converges pointwise to $I \in C(\Theta)^{*}$ if for all points $f$ in the domain $\mathrm{C}(\theta)$

$$
I_{n}(f) \rightarrow I(f)
$$

Now let $\mu$ be a probability measure in $P(\Theta)$. With this probability measure a functional $I(\mu)$ in $C(\Theta)^{*}$ can be associated by

$$
I(\mu)(f) \equiv \int_{\Theta} f(\theta) d \mu .
$$

Then, it is easilly seen that $\left(\mu_{n}\right)_{n=1}^{\infty}$ converges weakly to $\mu_{\infty}$ if and only if $\left(I\left(\mu_{n}\right)\right)_{n=1}^{\infty}$ converges pointwise to $I\left(\mu_{\infty}\right)$. Thus weak convergence is linked to the product topology on $C(\theta)^{*}$.

1. A functional is a linear function from some vector space to the real numbers. 
Weak convergence of a sequence of probability measures is also related to the concept of topological convergence. In order to see this connection, take a sequence $x_{0}, x_{1}, x_{2}, \ldots$ of elements of a topological space $(X, \tau)$. It is said that the sequence converges to $x$ in topology $\tau$ if for every set $U \in T$ with $x \in U$ there exists an $N \in N$ such that $x_{x !} \in U$ for all $n \geq N$.

Now there is a topology on $P(\Theta)$ such that the converging sequences according to this topology coincide with the weakly conwerging sequences. This topology is called the weak topology on $P(\theta)$ and it is denoted by $W$.

$W$ is defined as the topology generated by the collection $B$ of sets $B \subset P(\theta)$ for which there is a probability measure $\mu$ in $P(\Theta)$ and a sequence $f_{1}, \ldots, f_{n}$ of contimus functions on $\Theta$ as well as a sequence $\varepsilon_{1}, \ldots$, $\varepsilon_{n}$ of positive numbers in $R$ such that

$$
B=\left\{\nu \in P(\Theta)|| \int_{\Theta} f_{k}(\theta) d \mu-\int_{\Theta} f_{k}(\theta) d \nu \mid<\varepsilon_{k} \text { for all } k=1, \ldots, n\right\} .
$$

It is elementary to check that B is indeed a basis and that convergence in the topology $\mathcal{W}$ generated by it coincides with weak convergence.

In terms of applicability, a more convenient basis for $\mathcal{W}$ is the collection $C$ of subsets $C$ of $\Theta$ for which there is a probability measure $\mu$ on $\Theta$, a sequence $A_{1}, \ldots, A_{n}$ of $\mu$ continuous Borel sets and a sequence $\varepsilon_{1}, \ldots, \varepsilon_{r}$ of positive numbers such that

$$
C=\left\{\nu|| \mu\left(A_{k}\right)-\nu\left(A_{k}\right) \mid<\varepsilon_{k} \text { for all } k=1, \ldots, n\right\}
$$

At least it is clear that $\mathrm{C}$ is indeed a basis and therefore generates some topology. The following two different descriptions of this topology, respectively offer a basis for the use of it made in Chapter 8, and establish that the topology generated by $\mathrm{C}$ is indeed $\mathrm{W}^{2}$

Lemma B.1 Let $\mu$ be a probability measure on $\Theta$ and let $f$ be a continuous function on $\Theta$. Funther suppose that there is a closed $\mu$-continuous set $F$ and a real number $\varepsilon>0$. Then the set $B$ of probabitity measures $p$ for which

$$
\left|\int_{F} f(\theta) d \nu-\int_{F} f(\theta) d \nu\right|<\varepsilon
$$

contams an element $C$ of $\mathrm{C}$ whth $\mu$ in $C$.

Lemma B.2 The topology generated by Coincides with $W$.

Next it is stated that the weak topology coincides with the topology induced by the following distance function on $P(\Theta)$ as well. Let $\mu$ and $\nu$ be two elements of $P(\theta)$. Then the Prohorow distance $\rho(\mu, \nu)$ is defined as the infinum over those real numbers $\varepsilon>0$ for which every Borel set $A$ in $\Theta$ satisfies both

$$
\mu(A) \leq \nu\left(A_{\varepsilon}\right)+\epsilon \text { and } \nu(A) \leq \mu\left(A_{\varepsilon}\right)+\varepsilon .
$$

First, the following is relevant. III. 
Theorem B.8 (Portmanteau) Let $\mu_{\infty}, \mu_{1}, \mu_{2}, \ldots$ be probability measures on $\Theta$. The the following statements are equivalent.

(1) $\mu_{1}, \mu_{2}, \ldots$ converges weakly to $\mu_{\infty}$;

(2) $\lim _{n \rightarrow \infty} \mu_{n}(A)=\mu_{\infty}$ (A) for all $\mu_{\infty}$-continuous Borel sets $A$; and

(3) $\lim _{n \rightarrow \infty} \mu_{n}(F)=\mu_{\infty}$ (F) for all closed $\mu_{\infty}$-continuity sets $F$ in $\Theta$.

Finally, a variant used in Chapter 8 is the following lemma-which is, in fact a: immediate consequence of part (3) of Theorem B.8. Consider a subset $\mathcal{U}$ of the Bore $\sigma$-algebra $\mathcal{B}$ such that:

(1) finite intersections of elements of $\mathcal{U}$ are also elements of $\mathcal{U}$; and

(2) each open set in $\Theta$ is the countable union of elements of $\mathcal{U}$.

Lemma B.3 A sequence $\left(\mu_{n}\right)_{n=1}^{\infty}$ in $P(\Theta)$ converges weakly to a probability measur $\mu_{\infty}$ on $\Theta$ whenever $\left(\mu_{n}(U)\right)_{n=1}^{\infty}$ converges to $\mu_{\infty}(U)$ for every element $U$ of $U$. 


\section{Appendix C}

\section{Martingale Convergence Theory}

In this appendix the theory on martingales is set out. A complete proof of (a simple version of) the martingale convergence theorem is provided in Section C.2, taking only the Radon-Nikodym Theorem as given. To that end, in Section C.1 some features of conditional expectations are presented. ${ }^{1}$

All work is within a fixed probability space, denoted by $(\Omega, \mathcal{N}, \lambda)$. It is assumed that $\Omega$ is a compact metric space. This is not strictly needed in the proofs, but it does make matters easier and it is the setup in which the results discussed here are applied in Chapter 8 . Furthermore, $N$ is assumed to be a $\sigma$-algebra on $\Omega$ and $\lambda$ is a probability measure on 2 .

\section{C.1 Conditional Expectation}

In this section the theory concerning the existence and uniqueness of the conditional expected value of a random variable with respect to $\lambda$ will be briefly discussed. The basic theorem is the Radon-Nikodym theorem, which is introduced first. Note that the assumption of $\sigma$-finiteness is not required, since it is assumed that every measure is finite.

First some definitions. Assume for the moment that there is a $\sigma$-subalgebral $\mathcal{A}$ of $k^{2}$ Furthermore, suppose thee exist two measures $\mu$ and $\nu$ on $\mathcal{A}$.

1 This appendix is self-contained, yet based on an established literature. Cf. Doob (1953), Billingsiey (1968) and Chung (1974).

2 A $\sigma$-subalgebra of $N$ is a subset of $N$ that is a $\sigma$-allgebra. 
Definition C.1 The measure is sad to be absolutely continuous with respect bo if for every $A$ in $A$ with $\mu(A)=0$ it holds that $\nu(A)=0$.

Definition C.2 An A-measurable function $f: \Omega \rightarrow \mathbb{R}$ is a density of $\nu$ writh respe to $\mu$ if for all $A$ in $A$

$$
\nu(A)=\int_{A} f d \mu .
$$

Theorem C.1 (Radon-Nikodym) Suppose that the measure $\nu$ is absolutely continuow with respect to $\mu$. Then $w$ has a density with respect to $\mu$. Moreover, if $f$ and $g$ an two such densities, then $f=g \mu$-almost surely."

Using this result, the existence of the conditional expected value of a random variabl can be showm. ${ }^{4}$

Definition $C .3$ A random warioble $X$ on $A$ is called integrable with respect to $A$ if

$$
\int_{\Omega}|X(\omega)| d x
$$

is a real number.

Now let $X$ be an integrable random variable w.r.t. $\lambda$.

Definition C.4 An expected value of $X$ conditional on $A$ is an A-measurable an integrable function $f$ on $\Omega$ such that for all $A$ in $A$

$$
\int_{A} f d \lambda=\int_{A} X d \lambda
$$

\section{C.1.1 Existence}

Existence of a conditional expected value of $X$ on $A$ can easily be derived from the Radon-Nikodym theorem. In order to do that, assume for the moment that $X$ if non-negative. "Then the formula

$$
\nu(A) \equiv \int_{A} X d \lambda \text { for all } A \in A
$$

defines a measure on $\mathcal{A}$. Furthermore it is easy to check that this measure is absolutely continuous w.r.t. the restriction of $\lambda$ to $A$. Hence, according to the Radon-Nikodym theorem there exists an $\mathcal{A}$-measurable function $f$ such that for every $A$ in $A$

$$
\int_{A} f d \lambda=\nu(A)=\int_{A} X d \lambda
$$

3 Cf. Kolmogorov and fomin (1970), p. 347. By this is meant that the collection of worlds where the equation is true has $\mu$-probebility one.

4 Aandom variable (on 4 ) is simply a real-valued 4 -measurable function on $\Omega$ 
5o, this function $f$ is indeed an expected value of $X$ conditional an $A$.

Now, for a general random variable, note that the non-negative functions $X_{+}$and $X_{-}$on $\Omega$ defined by

$$
X_{+}(\omega) \equiv \max \{X(\omega), 0\} \text { and } X_{-}(\omega) \equiv \max \{-X(\omega), 0\}
$$

are both random variables w.r.t. $\lambda$. Consequently, there are expected values $f_{+}$and $f$ of $X_{+}$and $X_{-}$resp. conditional on 4 . It is now easy to check that $f \equiv f_{t}-f_{-}$is an expected value of $X$ conditional on $A$.

\section{C.1.2 Uniqueness}

The second part of the Radon-Nikodym states that two different conditional expected values of $X$ on $\mathcal{A}$ will be equal with probability one according to $\lambda$. This means that the collection of expected values of $X$ conditional on $A$ is an equivalence class of the equivalence relation $\sim$ on the collection of random variables on $\mathcal{A}$ defined by

$$
f \sim g \text { if and only if } f=g \quad \lambda \text {-almost surely }
$$

This equivalence class is denoted by $I E(X \mid A)$. Any element of the class $\mathbb{E}(X \mid A)$ is called a version of $\mathbb{E}(X \mid \mathcal{A})$.

This class is obviously uniquely defined. Nevertheless, slightly abusing notation, the symbol $I E(X \mid \mathcal{A})$ is also used to indicate an element of this class. In that sense the conditional expected value is defined only modulo sets having probability zero.

The following simple observation will be used in the next section.

Jemma C.1 Let $X$ and $Y$ be two K-measurable and integrable functions such that $X \leq Y$ with $\lambda$-probability one. Then

$$
\not E(X \mid \mathcal{A}) \leq \mathbb{I E}(Y \mid \mathcal{A})
$$

whth A-probability one.

\section{C.2 Martingales}

Let $\left(K_{i}\right)_{t=1}^{\infty}$ be a sequence of $\sigma$-subalgebras of $N^{*}$, i.e, each $\sigma$-algebra $K_{1}$ is a subset of N. Such a sequence is said to provide information if $\mathcal{N}_{t}$ is a subset of $\mathbb{K}_{\prime \prime}^{\prime}$ for each $t^{\prime} \geq t$. The expression "providing information" refers to the fact that in most applications the sequence of $\sigma$-algebras is generated by a sequence of partitions of $\Omega$ each partition reflecting the amount of information available at that time.

Definition C.5 A sequence $\left(X_{t}\right)_{t=1}^{\infty}$ of random variables on is sadd to provide information if each $X_{i}$ is $\aleph_{i}$-measurable.

It is assumed in the following that such a sequence is uniformly bounded, i.e, there exists a number $K$ such that for all $t$ and $\omega$

$$
\left|X_{\ell}(\omega)\right| \leq K
$$


This requirement is of course only a technicality. It is imposed because it makes lit easier and because the condition is satisfied in the use made of martingales in Chapte 8. Its main consequence is that each $X_{t}$ is integrable w.r.t. $\lambda$ and that the expecte value

$$
\mathbb{E}\left(\left|X_{t}\right|\right) \equiv \int_{\Omega}\left|X_{t}(\omega)\right| d \lambda
$$

of $\left|X_{t}\right|$ is also bounded by $K$.

Definition C.6 A sequence $\left(X_{t}\right)_{t=1}^{\infty}$ that provides information is called a submartin gale if

$$
X_{t} \leq \mathbb{E}\left(X_{t+1} \mid \mathbb{N}_{t}\right)
$$

for all $t$. In the special case of equality the sequence is called a martingale.

Note that the submartingale condition states that $X_{t}$ is dominated by a version c $\operatorname{IE}\left(X_{i+1} \mid M_{i}\right)$. This means that the condition is equivalent to the requirement that

$$
\int_{A} X_{t} d \lambda \leq \int_{A} X_{t+1} d \lambda
$$

should hold for all $A$ in $\aleph_{t}$. Similarly, being a martingale is equivalent with having equality in the displayed inequality. Of this formulation particular use will be made.

A martingale converges $\lambda$-almost surely. In other words, the probability that th sequence will keep changing, e.g. cycle, is zero. The remaining part of this section it devoted to a proof of this result.

Let $\left(X_{t}, N_{t}\right)_{t=1}^{\infty}$ be a submartingale. Let $r$ be a real number. Define $Z_{t}: \Omega \rightarrow \mathbb{R}$ by

$$
Z_{t}(\omega) \equiv \max \left\{r_{;} X_{t}(\omega)\right\} .
$$

Lemma C.2 The sequence $\left(Z_{t}\right)_{t=1}^{\infty}$ is a submartingale.

Proof. It is immediately clear that each $Z_{t}$ is $\sum_{t}$-measurable. Furthermore,

$$
\left|Z_{t}(\omega)\right|=\left|\max \left\{r, X_{t}(\omega)\right\}\right| \leq \max \left\{|r|,\left|X_{t}(\omega)\right|\right\} \leq \max \{|r|, K\}
$$

which implies that the sequence has a uniform upper bound. So it is only necessary to check the submartingale condition. To this end note that

$$
X_{t+1} \leq Z_{t+1} \text { and } r \leq Z_{t+1}
$$

So, by Lemma C.1,

$$
\mathbb{E}\left(X_{t+1} \mid \mathbb{N}_{t}\right) \leq \mathbb{E}\left(Z_{t+1} \mid \mathcal{N}_{t}\right) \text { and } r=\mathbb{E}\left(r \mid \aleph_{t}\right) \leq \mathbb{E}\left(Z_{t+1} \mid \aleph_{t}\right)
$$

with $\lambda$-probability one. Hence,

$$
Z_{t}=\max \left\{r, X_{t}\right\} \leq \max \left\{r, \mathbb{E}\left(X_{t+1} \mid \aleph_{t}\right)\right\} \leq \mathbb{E}\left(Z_{t+1} \mid \aleph_{t}\right)
$$


with A-probability one. This concludes the proof.

Now take a fixed natural number $n$. Only at the end of the proof this number will become variable again.

First some notation is required. Take a world $\omega$ in $\Omega$. Then $X_{1}(\omega), \ldots, X_{n}(\omega)$ is a sequence of real numbers. Now take two real numbers $r$ and $s$ with $r<s$. Define $T_{0}(\omega) \equiv 0$, and recursively for $k=1,2,3, \ldots$

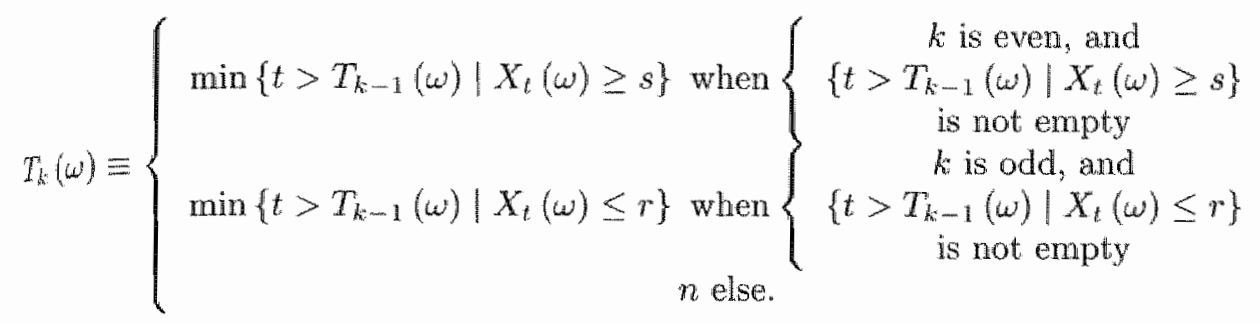

It is easy to see that both the above sets

$$
\left\{t>T_{k-1}(\omega) \mid X_{t}(\omega) \geq s\right\} \quad \text { and } \quad\left\{t>T_{k-1}(\omega) \mid X_{t}(\omega) \leq r\right\}
$$

have at most $n-k$ elements. Hence, the sequence $T_{10}(\omega), T_{1}(\omega), \ldots$ is first strictly increasing up till a certain value of $k$ indicated by $K(n)(\omega)$, while for values of $k$ larger than $K(n)(\omega)$ the value of $T_{k}(\omega)$ will be constantly equal to $n$. Formally,

$$
K(n)(\omega) \equiv \min \left\{k \mid T_{k}(\omega)=n\right\} .
$$

With this sequence a sequence of indicator functions can be associated. Formally, for a natural number $k$, let $I_{k}(\omega): \mathbb{N} \rightarrow\{0,1\}$ be defined by

$$
I_{k}(\omega)(t) \equiv\left\{\begin{array}{c}
1 \text { when } T_{k-1}(\omega)<t \leq T_{k}(\omega) \\
0 \text { else. }
\end{array}\right.
$$

Note that for values of $k>K(n)(\omega)$ the corresponding "indicator" function $I_{k}(\omega)$ is constantly equal to zero. These functions $I_{k}$ ( $\left.\omega\right)$ for values $k$ larger than $K(n)$ (w) are not really needed, but they do keep notation simple in the proof. "The following shorthand notation is used.

$$
\left[I_{k}(t)=1\right] \equiv\left\{\omega \in \Omega \mid T_{k-1}(\omega)<t \leq T_{k}(\omega)\right\},
$$

with the convention that this is the empty set for values of $k$ larger than $K(n)(\omega)$. Then, for $t=1,2, \ldots$, the following holds.

Lemma C.3 The set $\left[I_{k}(t)=1\right]$ is $\mathrm{N}_{t-1}$-measurable for all $k=1,2, \ldots 5$

Proof. First note that

$\left[I_{k}(t)=\mathbb{1}\right]=\left\{\omega \mid T_{k-1}(\omega)<t \leq T_{k}(\omega)\right\}=\left\{\omega \mid T_{k-1}(\omega)\right\}<\left\{t \cap \omega \mid T_{k}(\omega)<t\right\}^{k}$. 


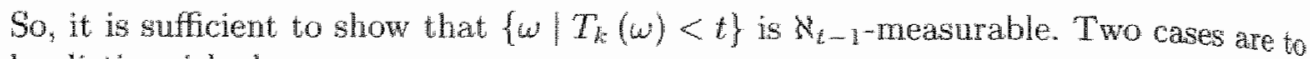
be distinguished.

A. In case $t \geq n+1$. In this case $\left\{\omega \mid T_{k}(\omega)<t\right\}$ equals $\Omega$ and is therefore surely Mt-medsurable.

B. In case $1 \leq t \leq n$. It is clearly sufficient to show that the set

$$
\left\{\omega \mid T_{k}(\omega)=u\right\}
$$

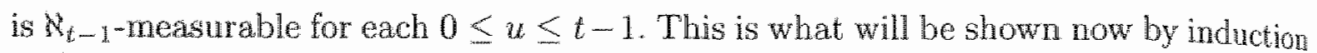
to $k$.

Step 1. For $k=0$. The set $\left\{\omega \mid T_{0}(\omega)=u\right\}$ is either equal to $\Omega$ (for $u=0$ ) or to the empty set (for all other values of $u$ ). In both cases though it is clearly an element: of $\aleph_{t-1}$.

Step $k+1$, in case $k+1$ is odd. Suppose it is known that $\left\{\omega \mid T_{k}(\omega)=u\right\}$ is an element of $k_{t-1}$ for all $0 \leq u \leq t-\mathbb{1}$. Then

$$
\begin{aligned}
& \left\{\omega \mid T_{k+1}(\omega)=u\right\}= \\
& \left.\bigcup_{v=0}^{u-1}\left\{\omega \mid T_{k}(\omega)=v\right\} \cap\left\{\omega \mid X_{n+1}(\omega)>r, \ldots, X_{n-1}(\omega)>r, X_{k}(\omega) \leq n\right\}\right]
\end{aligned}
$$

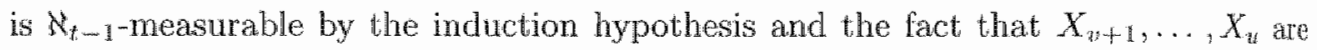
$N_{1-1}$-measurable. Obviously something similar can be done in case $k+1$ is even.

Now, let $U_{n}(\omega)$ be defined by

$$
U_{n}(\omega) \equiv \max \left\{0 \leq k \leq K(n)(\omega) \mid k \text { is even and } X_{T_{k}(\omega)}(\omega) \geq s\right\} .
$$

This number is called the number of upcrossings over $(r, s)$. It counts the number of times the sequence goes from being less than or equal to $x^{*}$ to being more than or equal. to s. Figure C.l illustrates the case in point.

The following result holds.

Lemma C.4 Given the above setting,

$$
M:\left(U_{n}\right) \leq \frac{2}{s-r} \max \{|x|, K\}+1
$$

Proof. From Lemma C.2 it is already known that the sequence

$$
Z_{t} \equiv \max \left\{r, X_{t}\right\}
$$

is a submartingale as well. Furthermore, it is easy to see that the random wariables $T_{k}, K(n), I_{k}(t)$ and $U_{n}$ are identical for both $\left(X_{t}\right)_{t=1}^{\infty}$ and $\left(Z_{t}\right)_{t=1}^{\infty}$. So,

$$
\begin{aligned}
Z_{n}(\omega)-Z_{1}(\omega) & =\sum_{t=2}^{n}\left(Z_{i}(\omega)-Z_{i-1}(\omega)\right) \\
& =\sum_{t=2}^{n} \sum_{k=1}^{n} I_{k}(\omega)(t)\left(Z_{t}(\omega)-Z_{t-1}(\omega)\right)
\end{aligned}
$$




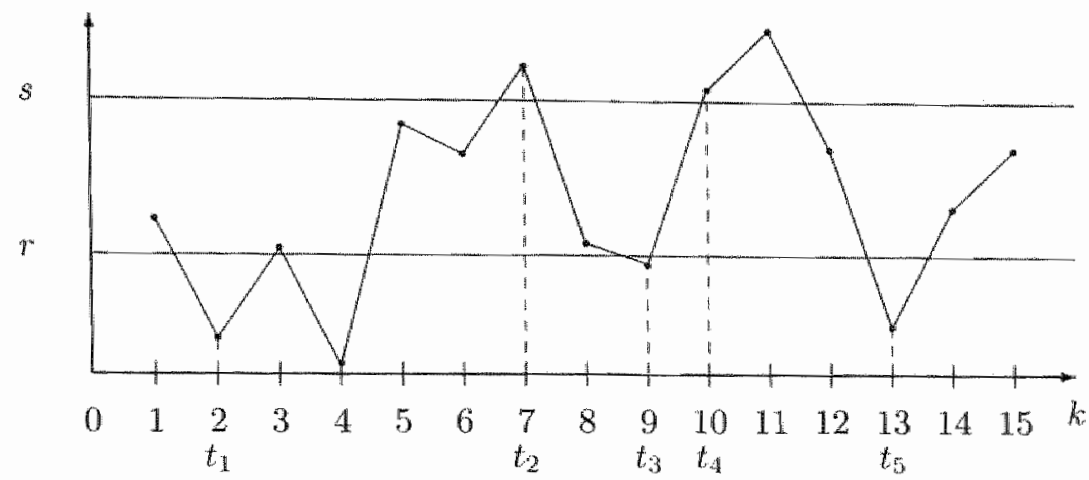

Figure C.1 Up-and downcrosings of a martingale...

where the second equality follows from the observation that for each $2 \leq t \leq n$ exactly ane element of the sequence $I_{1}(\omega)(t), \ldots, I_{n}(\omega)(t)$ will be equal to one, while the ther elements are equal to zero. Now split the latter term, the double summation, into the two terms

$$
\begin{aligned}
& E_{n}(\omega) \equiv \sum_{t=2}^{n} \sum_{\substack{k=1 \\
k \in v_{k}}}^{n} I_{k}(\omega)(t)\left(Z_{t}(\omega)-Z_{t-1}(\omega)\right), \text { and } \\
& O_{n}(\omega) \equiv \sum_{t=2}^{n} \sum_{\substack{k=1 \\
k=0 d d}}^{n_{k}} I_{k}(\omega)(t)\left(Z_{t}(\omega)-Z_{t-1}(\omega)\right) .
\end{aligned}
$$

note that both $E_{n}$ and $O_{n}$ are $\lambda$-integrable since they are $\aleph$-measurable and bounded wer $\Omega$. In other words, they both have an expected valne. The two terms will be teated separately for the moment, and lower bounds for their respective expected values will be found.

A. Concerning the odd term $O_{n}$, note that

$$
\begin{aligned}
\mathbb{E}\left(O_{n}\right) & =\int_{\Omega} O_{n}(\omega) d \lambda \\
& =\sum_{t=2}^{n} \sum_{\substack{k=1 \\
k=1}}^{n} \int_{\Omega} I_{k}(\omega)(t)\left(Z_{t}(\omega)-Z_{t-1}(\omega)\right) d \lambda \\
& =\sum_{t=2}^{n} \sum_{k=1}^{n}\left(\int_{\left[Y_{k}(t)=1\right]} Z_{t}(\omega) d \lambda-\int_{\left[I_{k}(t)=\mathbb{1} \mid\right.} Z_{t-1}(\omega) d \lambda\right)
\end{aligned}
$$

However, since $\left(Z_{2}\right)_{t=1}^{\infty}$ is a submartingale, it follows that

$$
\int_{\left[I_{k}(t)=1\right]} Z_{t}(\omega) d \lambda-\int_{\left[I_{k}(t)=1\right]} Z_{l-1}(\omega) d \lambda \geq 0
$$


for each $t$ by Lemma C.3. Hence, $\mathbb{E}\left(O_{n}\right) \geq 0$.

B. Concerning the even term $E_{n}$, note that

$$
\begin{aligned}
& E_{n}(\omega)=\sum_{t=2}^{n} \sum_{\substack{k=1 \\
k=1}}^{n} I_{k}(\omega)(t)\left(Z_{t}(\omega)-Z_{t-1}(\omega)\right) \\
& =\sum_{\substack{k=1 \\
k=1, n}}^{n} \sum_{t=2}^{n} I_{k}(\omega)(t)\left(Z_{t}(\omega)-Z_{t-1}(\omega)\right) \\
& =\sum_{\substack{k=1 \\
k \text { eqeen }}}^{n}\left(Z_{T_{k}(\omega)}(\omega)-Z_{T_{k-1}(\omega)}(\omega)\right) \\
& =\sum_{\substack{k=1 \\
k \text { ovenn }}}^{K(n)(\omega)}\left(Z_{T_{k}(\omega)}(\omega)-Z_{T_{k-1}(\omega)}(\omega)\right) \\
& K(n)(\omega)-1 \\
& =\sum_{\substack{k=1 \\
k \text { even }}}\left(Z_{T_{k}(\omega)}(\omega)-Z_{T_{k-1}(\omega)}(\omega)\right) \\
& +\mathbb{1}_{[K(n)(\omega) \text { is even }]}(\omega)\left(Z_{n}(\omega)-r\right) \\
& \geq(s-r)\left(U_{n}(\omega)-1\right)+0=(s-r)\left(U_{n}(\omega)-1\right),
\end{aligned}
$$

where the inequality $Z_{n}(\omega)-r \geq 0$ follows from the construction of the random variables $Z_{k}$. Hence, $\mathbb{E}^{(}\left(E_{n}\right) \geq(s-r)\left(\mathbb{E}\left(U_{n}\right)-1\right)$.

C. Combined, this yields

$$
\begin{aligned}
(s-r)\left(\mathbb{E}\left(U_{n}\right)-1\right) & \leq \mathbb{E}\left(E_{n}\right)+\mathbb{E}\left(O_{n}\right)=\mathbb{E}\left(Z_{n}-Z_{1}\right) \\
& \leq \mathbb{E}\left(\left|Z_{n}\right|\right)+\mathbb{E}\left(\left|Z_{1}\right|\right) \leq 2 \max \{|r|, K\}
\end{aligned}
$$

which completes the proof.

Now all elements are in place for the martingale convergence theorem. For each world $\omega$ in $\Omega$ for which the sequence $\left(X_{t}(\omega)\right)_{t=1}^{\infty}$ converges, define

$$
X_{\infty}(\omega) \equiv \lim _{l \rightarrow \infty} X_{l}(\omega)
$$

With this, it is possible to have the following theorem.

Theorem C.2 Let $\left(X_{t}, \aleph_{t}\right)_{t=1}^{\infty}$ be a martingale. Then $X_{\infty}$ exists $\lambda$-almost surely.

Proof. Suppose not. Let $X_{*}$ be the $\aleph$-measurable function defined by

$$
\begin{gathered}
X_{*}(\omega) \equiv \lim _{t \rightarrow \infty} \inf _{t}(\omega), \text { and similarly } \\
X^{*}(\omega) \equiv \lim _{t \rightarrow \infty} X_{t}(\omega)
\end{gathered}
$$


Wote that both are well-defined since the martingale is assumed to have a uniform bound. Then from the assumption that $X_{\infty}$ is not almost everywhere defined, it follows that

$$
\lambda\left\{\omega \in \Omega \mid X_{*}(\omega)<X^{*}(\omega)\right\}>0 .
$$

Take two rational numbers $r<s$. Let.

$$
B(r, s) \equiv\left\{\omega \in \Omega \mid X_{*}(\omega)<r<s<X^{*}(\omega)\right\} .
$$

Since $\left\{\omega \in \Omega \mid X_{*}(\omega)<X^{*}(\omega)\right\}$ is the countable union of all such sets $B(r, s)$, from the subadditivity of $\lambda$ it follows that $\lambda\left(B\left(r^{*}, s^{*}\right)\right)>0$ for some $r^{*}$ and $s^{*}$. Then it is clear that on $B\left(r^{*}, s^{*}\right)$ the number of upcrossings $U_{n}$ over the interval $\left(r^{*}, s^{*}\right)$ increases to infinity as $n \rightarrow \infty$. In particular this implies that $\mathbb{E}\left(U_{n}\right) \rightarrow \infty$. However, in Lemma C.4 it was shown that $\mathbb{E}\left(U_{n}\right)$ is bounded by $\frac{2}{s-r} \max \{|r|, K\}+1$. This is a contradiction. 



\section{References}

Abraham, H. and J. Whittaker, "Is Dynamic Stability of Walrasian Equilibrium Achieved Through Falling Target Utilities?" Intemational Economic Revieu, $1989,30(3), 507-511$.

Albin, P. and D. K. Foley, "Decentralized, Dispersed Exchange Without an Auctioneer: A Simulation Study," Joumal of Economic Behavior and Organization, 1992 , $18(1), 27-51$.

Alen, B. and M. Hellwig, "Price-Setting Firms and the Oligopolistic Foundations of Perfect Competition," American Economic Review, 1986, 76 (2), 387-392.

Allingham, M. G., "Tatonnement Stability: An Econometric Approach," Econometrica, $1972,40(1), 27-41$.

Andersen, T. M., "Price Dynamics under Imperfect Information," Journal of Economic Dymamics and Control, 1985, $9(3), 339-361$.

Arrow, K. J., "Toward a Theory of Price Adjustment," in W. Abramovitz, ed., The Allocation of Economic Resources, Stanford: Stanford University Press, 1959, pp. 41-51.

" "Price-Quantity Adjustments in Multiple Markets and Rising Denands," in K. J. Arrow, S. Karlin, and P. Suppes, eds., Mathematical Methods in the Socinl Sciences, 1959: Proceedings of the First Stanford Symposium, Stanford: Stanford University Press, 1960, pp. 3-15.

and F. H. Hahn, General Competitive Analysis, Amsterdam: North-Holland, 1971. 
and L. Hurwicz, "On the Stability of the Competitive Equilibrium, I," Econ. metrica, $1958,26(4), 522-552$.

and ___ "Competitive Stability under Weak Gross Substitutability: Nonlinea Price Adjustment and Adaptive Expectations," International Econonic Revieu $1962,3(2), 233-255$.

— and M. Nerlove, "A Note on Expectations and Stability" Econometrica, 1958 $26(2), 297-305$.

H. D. Block, and L. Hurwicz, "On the Stability of the Competitive Equilibrium II," Econometrica, 1959, 27 (1), 82-109.

Aumann, R., "Markets with a Continuum of Traders," Econometrica, 1964, 32(1-2) $39-50$

Bacon, F., Nowum Organum: Aphorisms Concerning the Interpretation of Nature an the Kingdom of Man, Chicago: Benton, 1952.

Balvers, R. J. and T. F. Cosimano, "Actively Learning About Demand and The Dy. namics of Price Adjustment," Economic Journal, 1990, 100 (402), 882-898.

Barro, R. J., "A Theory Of Monopolistic Price Adjustment," Review of Economix Studies, $1972,39(1), 17-26$.

Becker, G. S., "Irrational Behavior and Economic Theory," Journal of Political Economics, $1962,70,1-13$.

Benassy, J.-P., "Neo-Keynesian Disequilibrium Theory in Monetary Econorny," Revieu of Economic Studies, 1975, $42(4), 503-523$.

, "The Disequilibrium Approach to Monopolistic Price-Setting and General Monopolistic Equilibrium," Review of Economic Studies, 1976, 43(1),69-81.

_- The Economics of Market Disequilibrium, New York: Academic Press, 1982.

- "The Objective Demand Curve in General Equilibrium with Price-Makers," Economic Joumal, 1988, $98(390), 37-49$.

, "Monopolistic Competition" in K. J. Arrow and M. D. Intriligator, eds., Handbook of Mathematical Economics, Volume IV, Amsterdam: North-Holland, 1991, pp. $1997-2045$.

Bernecker, S. and F. Dretske, eds, Knowledge: Readings in Contemparary Epistemol ogy, Oxford: Oxford University Press, 2000.

Bernheim, B. D., "Rationalizable Strategic Behavior," Econometrica, 1984, 52 (4), $1007-1028$.

Bertrand, J., "Review," in A. F. Daughety, ed., Cournot Oligopoly: Characterizations and Applications, Cambridge: Cambridge University Press, 1988, pp. 73-81. 
Billingsley, P., Convergence of Probability Measures, New York: Wiley, 1968.

Blackwell, D. and L. Dubins, "Merging of Opinions with Increasing Information," Annals of Mathematical Statistics, 1962, 39, 882-886.

Blanchard, O. J. and S. Fischer, Lectures on Macroeconomics, Cambridge, MA: MTT Press, 1989.

Blaug, M., "Kuhn versus Lakatos, or Paradigms versus Research Programmes in the History of Economics," History of Political Economy, 1975, 7 (4), 399-433. , The Methodology of Economics, Cambricge: Cambridge University Press, 1980.

Blinder, A. S., "Why Are Prices Sticky? Preliminary Results from an Interview Study," American Economic Review, 1991, 81 (2), 89-96.

E. Caneti, D. Lebow and J. Rudd, Asking About Prices: A New Approach to Understanding Price Stickiness, New York: Russell Sage Foundation, 1998.

Blume, L. E. and D. Easley, "Learning to Be Rational," Journal of Economic Theory, $1982,26(2), 340-351$.

and ___ "Rational Expectations Equilibrium: An Alternative Approach," Journal of Economic Theory, 1984, 34 (1), 116-129.

and __ , "What Has Rational Learning Literature Taught Us?," in A. P. Kirman and M. Salmon, eds., Learning and Rationality in Economics, Oxford: Blackwell, 1995, pp. 12-39.

and __ "Rational Expectations and Rational Learning," in M. Majumdar, ed., Organizations with Incomplete Information: Essays in Economic Analysis: A Tribute to Roy Radner, Cambridge: Cambridge University Press, 1998, pp. 61109.

Bölum, V., "The Foundations of the Theory of Monopolistic Competition Revisited," Joumal of Economic Theory, 1994, 63(2), 208-218.

Border, K. C., Fixed Point Theorems with Appications to Economics and Gome Theory, Cambridge: Cambridge University Press, 1985.

Bork, R. H., The Antitrust Panadox: Policy at War with Itself, New York: Free Press, 1995.

Bottazzi, J.-M., "Accessibility of Pareto Optima by Walrasian Exchange Processes," Joumal of Mathematical Economics, 1994, 23 (6), 585-603.

Bray, M. M., "Learning, Estimation, and the Stability of Rational Expectations," Joumal of Economic Theory, 1982, 26 (2), 31.8-339.

and D. M. Kreps, "Rational Learning and Rational Expectations," in G. R. Feiwel, ed., Arrow and the Ascent of Modern Economic Theory, London: MacMillan, 1987 , pp. $597-625$. 
and N. E. Savin, "Rational Expectations Equilibria, Leaming, and Model Sper ifcation," Econometrica, 1986, 54 (5), 1129-1160.

Bronfrnan, C. K. McCabe, D. Porter, S. Rassenti, and V. L. Smith, "An Experimen tal Examination of the Walrasian "Tatonnement" Mechanism," Rand Joumal . Economics, 1996, 27 (4), 681-699.

Brousseau, V. and A. P. Kimman, "Apparent Converence of Learning Processes it Mis-Specified Games," in B. Dutta, D. Mookherjee, T. Parthasarathy, T. E. S Raghavan, D. Ray, and S. Tijs, eds., Game Theory and Economic Applications Berlin: Springer-Verlag, 1992, pp. 303-331.

and __ "The Dynamics of Learning in N-Person Games with the Wrong N" in K. Binmore, A. P. Kirman, and P. Tani, eds, Frontiers of Games Theon Cambridge, MA: MIT Press, 1993 , pp. $71-93$.

Bryant, W. D. A., "Misinterpretations of the Second Furdamental Theorem of Wel. fare Economics: Barriers to Better Economic Education," Joumal of Ecomomi Educatron, 1994, 25 (1), 75-80.

Buchanan, J. M. Demand and Supply of Public Goods, Chicago: Ran McNally, 1969.

Cassel, G. von, Theory of the Social Economy, New York: Harcourt Brace, 1932.

Chalmers, A. F., What is This Thing Called Science?, 3 ed., Buckingham: Open Unversity Press, 1999.

Chamberlin, E. H., The Theory of Monopolistic Competition, 5 ed., Cambridge, MA: Harvard University Press, 1947.

Champsaur, P. and B. Cornet, "Walrasian Exchange Processes," in J. Gabszewicz: J.-F. Richard, and L. Wosley, eds, Economic Decision Making: Games, Econo. metres and Optmization, Amsterdan: Etsevier, 1990, pp. 1-13.

Clumg, K. L., A Course in Probability Theory, 2 ed., New York: Acadenic Press, 1974.

Clark, J. M., "Toward a Concept of Workable Competition," American Economic Regrew, $1940,30(2), 241-256$.

Clower, R. W., "Competition, Monopoly, and the Theory of Price," Pakistan Economic Jowrmal, 1955, pp. $219-226$.

"The Keynesian Counterrevolution: A Theoretical Appraisal" in F. H. Hahn and F. P. R. Brechling, eds., The Theory of Interest Rates, London: MacMillat, 1965.

and D. W. Bushaw, "Price Determination in a Stock-Flow Economy," Exonometrica, 1954, 22, 328 .

Confucius, The Analects, New York: Penguin Books, 1979. 
Cournot, A., Researches Into the Mathematical Principles of the Theory of Wealih, London: MacMillan, 1927.

Creedy, J., "Some Recent Interpretations of Mathematical Psychics," History of Political Economy, 1980, 12 (2), 267-276.

Cross, J. G., A Theory of Adaptive Economic Behavior, Cambridge: Cambridge University Press, 1983.

Cyert, R. M. and M. H. DeGroot, Bayesian Analysis and Uncertainty in Economic Theory, Totowa, NJ: Rowman \& Littlefield, 1987.

Daal, J. van, "Did Léon Walras Spoil his Eléments?" Centre Walras Lyon Working Paper, 2000.

Davies, D. G., "A Note on Marshallian versus Walrasian Stability Conditions," Canadian Journal of Economics and Political Science, 1963, 29 (4), 535-540.

Debreu, G., Theory of Value: An Axiomatic Analysis of Economic Equilibrium, New Haven: Yale University Press, 1959.

, "Economies with a Finite Set of Equilibria," Econometrica, 1970, 38 (3), 387 392.

, "Excess Demand Functions," Journal of Mathematical Economics, 1974, 1 (1), $15-21$.

and H. E. Scarf, "A Limit Theorem on the Core of an Economy," International Economic Review, 1963, \& (3), 235-246.

DeGroot, M. H., Optimal Statistical Decisions, New York: MeGraw-Hill, 1970.

Demsetz, H., "The Nature of Equilibrium in Monopolistic Competition," Journal of Political Economics, 1959, 67, 21-30.

_- Welfare and Empirical Implications of Monopolistic Competition, Oxford: Blackwell, 1989.

Dennet, D. C., Brainstorms: Philosophical Essays on Mind and Psychology, Cambridge, MA: MIT Press, 1981.

Descartes, R., Discourse On the Method of Rightly Conducting the Reason and Seeking for Thuth in the Sciences, Chicago: Benton, 1952.

Diamond, P. A., "A Model of Price Adjustment," Journal of Economic Theory, 1971, $3(2), 156-168$.

Dierker, E., "Two Remarks on the Number of Equilibria of an Economy," Econometrica, 1972, $40(5), 951-953$.

and H. Dierker, "The Local Uniqueness of Equilibria," Econometrica, 1972, 40 (5), $867-881$. 
Dobb, M. Welfare Economics and The Economics of Socialism: Towards a Common. sense Critique, Cambridge: Cambridge University Press, 1969.

Theories of Value and Distribution Since Adam Smith: Ideology and Economic Theory, Cambridge: Cambridge University Press, 1973.

Dockmer, E. J., "A Dynamic Theory of Conjectural Variations," Journal of Industrial Economics, $1992,40(4), 377-395$.

Domjan, M., The Principles of Learning and Behavior, 4 ed. Pacific Grove: Brooks/Cole, 1998.

Doob, J.L., Stochastic Processes, New York: Wiley, 1953.

Drèze, J. H., "Existence of an Exchange Equilibrium under Price Rigidities," International Economic Review, 1975, $16(2), 301-320$.

- Underemployment Equilibria: Essays in Theory, Econometrics and Polcy, Camm bridge: Cambridge University Press, 1991.

Dubey, P., "Strategic Market Games: A Survey of Some Results" in J.F. Mertens and S. Sorin, eds., Game-Theoretic Methods in General Equilibrium Analysis, Dordrecht: Kluwer Academic, 1994, pp. $209-224$.

Easley, D. and N. M. Kiefer, "Controlling a Stochastic Process with Unknown Parameters," Econometrica, 1988, 56 (5), 1045-1064.

Edgeworth, F. Y., Mathematical Physics: An. Essay on the Application of Mathematics to the Moral Sciences, New York: Kelley, 1967.

Ekelund, R. B. and R. F. Hébert, A History of Economic Theory and Method, 3 ed.; New York: McGraw-Hill, 1990.

Enthoven, A. C. and K. J. Arrow, "A Theorem on Expectations and the Stability of Equilibrimn," Econometrica, 1956, 24 (3), 288-293.

Evans, G. W. and S. Honkapohja, "Learning Dynamics," in J. B. Taylor and M. Woodford, eds., Handbook of Macroeconomics, Amsterdam: Elsevier, 1999.

and _. Learning and Expectations in Macroeconomics, Princeton: Princeton University Press, 2001.

Fisher, F. M., "On the Analysis of History and the Interdependence of the Social Sciences," Philosophy of Science, $1960,27(2), 147-158$.

"The Stability of the Cournot Oligopoly Solution: The Effects of Speeds of Adjustment and Increasing Marginal Costs," Review of Economic Studies, 1961 , $28(2), 125-135$

- "Quasi-Competitive Price Adjustment by Individual Firms: A Preliminary Paper," Joumal of Economic Theory, 1970, 2 (2), 195-206. 
"On Price Adjustment Without an Auctioneer," Review of Economic Stqdies, $1972,39(1), 1-15$.

_- "Stability and Competitive Equilibrium in Two Models of Search and Individual Price Adjustment," Joumal of Economic Theory, 1973, 6 (5), 446-470.

- "The Hahn Process with Firms But No Production," Econometrica, 1974, 48 (3), $471-486$.

"A Non-Tatonnement Model with Production and Consumption": Econometrica, 1976, 44 (5), 907-938.

_ "Quantity Constraints, Spillovers and the Hahn Process," The Revew of Economic Studies, 1978, 45 (1), 19-31.

- , "Stability, Disequilibrium Awareness, and the Perception of New Opportunities," Econometrica, 1981, 49 (2), 279-318.

, Disequilibriwm Foundations of Equilibrium Economics, Cambridge: Cambridge University Press, 1983.

___ "It Takes T* to Tango: Trading Coalitions with Fixed Prices," Review of Economic Studies, 1989, 56 (3), 391-404.

Fisher, I., Mathematical Investigations in the Theory of Value and Prices, New Haven: Yale University Press, 1925.

Foster, J. E. and M. Frierman, "Learning Rational Expectations: Classical Conditions Ensure Uniqueness and Global Stability," Economica, 1990, 57 (228), 439-453.

Friedman, J. W., Oligopoly Theory, New York: Cambridge University Press, 1983.

Friedman, M., The Invisible Hand in Economics and Poltics: Inaugural Singapore Lecture, Singapore: Institute of Southeast Asian Studies, 1981.

Frisch, R, "On the Notion of Equilibrium and Disequilibrium," Review of Economic Studies, 1935, 3, 100-105.

Fyydman, R., "Towards an Understanding of Market Processes: Individual Expectations, Learning, and Convergence to Rational Expectations Equilibrium," American Economic Review, 1982, 72 (4), 652-668.

Fudenberg, D. and D. K. Levine, The Theory of Learning in Games, Cambridge, MA: MIT Press, 1999.

and J. Tirole, Game Theory, Cambridge, MA: MTT Press, 1995.

Fulton, G., "Research Programmes in Economics," History of Political Economy, 1984, $16(2), 187-205$.

Gabszewicz, J. J. and J.-P. Vial, "Oligopoly "A la Coumot" in a General Equilibrium Analysis," Journal of Economic Theory, 1972, 4 (3), 381-400. 
Gale, D., "The Law of Supply and Demand," Mathematica Scandinavica, 1955, 3, $155-169$.

"A Note on Global Instability of Competitive Equilibrium," Naval Research Logistics Quarterly, 1963, 10, 81--87.

Gandolfio, G., Mathematical Methods and Models in Economic Dynamics, 2 ed., Amsterdam: North-Holland, 1972.

Gibbons, R., A Primer in Game Theory, Hertfordshire: Harvester Wheatsheaf, 1992.

Godfrey, L. G., Misspecification Tests in Econometrics: The Lagrange Multiplier Principle and Other Approaches, Cambridge: Cambridge University Press, 1988.

Goodwin, R. M., "Iteration, Automatic Computers and Economic Dynamics," Metroeconomica, $1951,3(1), 1-7$.

Goscinny, R. and A. Uderzo, Asterix: Obelix 8 Co, Paris: Dargaud Editeur, 1976.

Graham, D. A. and E. R. Weintraub, "On Convergence to Pareto Allocations," Review of Economic Studies, 1975, 42 (3), 469-472.

_ E. Jacobson, and E. R. Weintraub, "Transactions and the Convergence of a "Trade Out of Equilibrium" Adjustment Process," International Economic Review, $1972,13(31), 123-131$.

Grandmont, J. M., "Temporary General Equilibrium Theory," Econonetrica, 1977, $45(3), 535-569$.

, "Distributions of Preferences and the "Law of Demand", Econometrica, 1987, $55(1), 155-161$.

" "Transformations of the Commodity Space, Behavioral Heterogeneity, and the Aggregation Problem," Journal of Economic Theory, 1992, 57(1), 1-35.

Grayling, A. C., An Introduction to Philosophical Logic, 3 ed., Oxford: Blackwell, 1997.

Green, J. R., "The Stability of Edgeworth's Recontracting Process," Econometrica, $1974,42(1), 21-34$.

Hahn, F. H., "Expectations and Equilibrium," Economic Journal, 1952, 62, 802-819. , "A Stable Adjustment Process for a Competitive Economy," Revrew of Economic Studies, 1962a, $29(1), 62-65$.

_- "On the Stability of a Pure Exchange Equilibrium," International Economic Review, 1962b, 3 (2), 206-213.

" "The Stability of the Cournot Oligopoly Solution," Review of Economic Studies, 1962 c, $29(4), 329-331$. 
, On the Notion of Equilibrium in Economics, Cambridge: Cambridge University Press, 1973.

, "Exercises in Conjectural Equilibria," Scandinavian Journal of Economics, 1977, $79(2), 210-226$.

_ . "On Non-Walrasian Equilibria." Review of Economic Studies, 1978, 45(1), 1-17. "Reflections on the Invisible Hand," Lloyds Bank Review, 1982a, O (144), 1-21. "Stability," in K. J. Arrow and M. D. Intriligator, eds., Handbook of Mathematical Economics, Volume II, Amsterdam: North-Holland, 1982b, pp. 745-793.

"On General Equilibrium Stability," in P. J. Dougherty, ed., Paul Samtelson and Modern Economic Theory, New York: McGraw-Hill, 1983, pp. 31-55.

"Conjectural Equilibria," in J. Eatwell, M. Milgate, and P. Newman, eds., The New Palgrave: General Equilibrium, New York: Norton, 1989, pp. 98-107.

" "Information Dynamics and Equilibrium," in $\mathbb{E}$. H. Hahn, ed., The Economics of Missing Markets, Information, and Games, Oxford: Clarendon Press, 1989, pp. $106-126$.

, "History and Economic Theory," in K. J. Arrow, ed., Issues in Contemporary Economics: Proceedings of the Ninth. World Congress of the International Economic Association, Volume 1, Markets and Welfare, London: MacMillan, 1991, pp. $67-74$.

and T. Negishi, "A Theorem of Non-Tâtomement Stability," Economerrica, $1962,30(3), 463-469$.

Hamouda, O. and R. Rowley, Expectations, Equilibrim and Dymamics: A History of Recent Economic Ideas and Practices, New York: St. Martin's Press, 1988.

Hands, D. W., "The Role of Crucial Counterexamples in the Growth of Economic Knowledge: Two Case Studies in the Recent History of Economic "Thonght:" History of Political Economy, 1984, 16 (1), 59-67.

" Restabilizing Dynamics: Construction and Constraint in the History of Walrasian Stability Theory," Economics and Philosophy, 1994, 10 (2), 243-283.

Hansson, B. A., The Stockholm School and the Development of Dymamic Method, London: Croom Helm, 1982.

"Stockholm School," in I. Eatwell, M. Milgate, and P. Newman, eds., The New Palgrave, London: MacMillan, 1987.

Hardle, W. and A. P. Kirman, "Nonclassical Demand: A Model-Free Examination of Price-Quantity Relations in the Marseille Fish Market," Journal of Econometrics, $1995,67(1), 227-257$. 
Hart, O. D., "Imperfect Competition in General Equilibrium: An Overview of Recent Work," in K. J. Arrow and S. Honkapohja, eds., Frontiers of Economics, Oxford: Blackwell, 1985, pp. 100-149.

Hayek, F. A. von, "Das Intertemporale Gleichgewichtssystem der Preise Und Die Bewegung Des Geldwertes," Weltwirtschaftiches Archiv, 1928.

- Prices and Production, Londom: Routledge, 1931.

Collectivist Economic Planning, London: Routledge, 1935.

"Economics and Knowledge," Economica, 1937, 4, 33-54.

Individualism and Economic Order, London: Routledge, 1949.

Helson, H., Adaptation-Level Theory, New York: Harper \& Row, 1964.

Hennipman, P., Welfare Economics and the Theory of Economic Policy, Brookfield: Elgar, 1995.

Herings, P. J. J., "A Globally and Universally Stable Price Adjustment Process," Journal of Mathematical Economics, 1997, 27 (1), 163-193.

_ "Recent Developments in Computing Equilibrium Prices: Appendix to The Computation of Equilibrium Prices by H. E. Scarf," in A. P. Kirman, ed., Elements of General Equilibrium Analysis: Festschrift in Honor of Gerard Debreu, Oxford: Blackwell, 1998, pp. 132-138.

Hicks, J. R., Value and Capital: An Inquiry Into some Fundamental Principles of Economic Theory, Oxford: Clarendon Press, 1939.

- Value and Capital: An Inquiry Into some Fundamental Principles of Economic Theory, 2 ed., Oxford: Oxford University Press, 1946.

, "LSE and the Robbins Circle," in J. R. Hicks, ed, Money, Interest and Wages: Collected Essays on Economic Theory, Volume II, Oxford: Blackwell, 1982.

" "Time in Economics," in đ. R. Hicks, ed., Money, Interest and Wages: Collected Essays on Economic Theory, Volume II, Oxford: Blackwell, 1982.

High, J., Maximizing, Action, and Market Adjustment: An Inquiry Into the Theory of Economic Disequilibrium, München: Philosophia, 1990.

Hildenbrand, W., "On the "Law of Demand"," Econometrica, 1983, 51 (4), 997-1019. , Market Demand: Theory and Empirical Evidence, Princeton: Princeton University Press, 1994.

and A. P. Kirman, Equilibrium Analysis: Variations on Themes by Edgeworth and Walras, Amsterdam: North-Holland, 1976. 
Hirshleifer, J. and J. G. Riley, The Analytics of Uncertainty and Information, Cambridge: Cambridge University Press, 1992.

Hsieh., C.-Y. and S. L. Mangum, A Search for Synthesis in Economic Theory, Armonk, NY.: Sharpe, 1986.

Hume, D., A Theatise of Human Nature, Oxford: Clarendon Press, 1978.

Hurwicz, L., R. Radner, and S. Reiter, "A Stochastic Decentralized Resource Allocation Process, Part 1," Econometrica, 1975a, 49(2), 187-221. and "A Stochastic Decentralized Resource Allocation Process, Part II." Eiconometrica, $1975 \mathrm{~b}, 49(3), 363-393$.

Ingrao, B. and G. Israel, "General Economic Equilibrium Theory: A History of Ineffectual Paradigmatic Shifts, $\pi_{*}$, Fundamenta Scientiae, 1985, 6 (2), 89-125. and __ The Invisible Hand: Economic Equitibrim in the History of Science, Cambridge, MA: MIT Press, 1990.

Iwai, K., Disequilibrim Dynamics: A Theonetical Analysis of Inflation and Unemployment, New Haven: Yale University Press, 1981.

Jaffe, W., "Walras" Theory of Tâtonnement: A Critique of Recent Interpretations," Joumal of Political Economy, 1967, 75 (1), 1-19.

Jordan, J. S., "Bayesian Learning in Normal Form Games," Games and Economic Behavior, $1991,3(1), 60-81$.

"Convergence to Rational Expectations in a Stationary Linear Came," Review of Economic Studies, 1992,59 (1), 109-123.

"Bayesian Learning in Repeated Games," Cames and Economic Behanior, 1995, $9(1), 8-20$

Kagawa, A. and K. Kuga, "On Professor Hahn's Tatomement Stability Theorem. Comments and Example," Review of Economic Studies, 1980, 47 (4), 813-815.

Kalai, E. and E. Lehrer, "Rational Learning Leads to Nash Fquilibrium," Econometrica, $1993,61(5), 1019-1045$.

and _- "Subjective Equilibrium in Repeated Games," Econometrica, 1993, $61(5), 1231-1240$.

and

"Subjective Games and Equilibria," Games and Economic Behatror; $1995,8(1), 123-163$.

Kaldor, N., "The Irrelevance of Equilibrium Economics," Economic Journal, 1972,82 $(328), 1237-1255$.

Keesing, E. A. G., "Het Evenwichtsbegrip in de Economische Literatuur." PhD dissertation, Universiteit van Amsterdam 1939. 
Kehoe, T. J., "Computation and Multiplicity of Equilibria," in W. Hildenbrand and H. Sonnenschein, eds., Handbook of Mathematical Economics, Volume IV. Amsterdam: Elsevier, 1991, pp. 2049-21.43.

Keynes, J. M., The General Theory of Employment, Interest and Money, London: MacMillan, 1936.

Kiefer, N. M. and Y. Nyarko, "Optimal Control of an Unknown Linear Process with Learning," International Economic Review, 1989, 30 (3), 571-586.

Kirman, A. P., "Learning by Firms About Demand Conditions," in R. Day, ed. Adaptive Economics, New York: Academic Press, 1975, pp. 137-156.

__ "On Mistaken Beliefs and Resultant Equilibria," in R. Frydman and E. S. Phelps, eds., Individual Forecasting and Aggregate Outcomes, Cambridge: Cambridge University Press, 1983, pp. 147-166.

__ , "Learning in Oligopoly," in A. P. Kirman and M. Salmon, eds., Learning and Rationality in Economics, Oxford: Blackwell, 1995, pp. 127-178.

Kirzner, I. M., Competition and Entrepreneurship, Chicago: University of Chicago Press, 1973.

Klant, J. J., Filosofie Van de Economische Wetenschappen, Leiden: Nijhoff, 1987.

Knight, F. H., Risk, Uncertainty and Profit, Boston: Houghton Mifflim, 1921.

Kolmogorov, A. N. and S. V. Fomin, Introductory Real Analysis, New York: Dover, 1970.

Koopmans, T. C., Three Essays on the State of Economic Science, New York: McGrawHill, 1957.

Koplin, H. T., "The Profit Maximization Assumption," Oxford Economic Papers, $1963,15(2), 130-139$.

Krugman, P., "History and Expectations," Quarterly Journal of Economics, 1991, 106 (2), $651-667$.

Kuhm, T., The Structure of Scientific Revolutions, 2 ed., Chicago: University of Chicago Press, 1970.

Laan, G. van der and A. J. J. Talman, "Adjustment Processes for Finding Economic Equilibria," in A. J. J. Talman and G. van der Laan, eds., The Computation and Modelling of Economic Equilibria, Amsterdam: Elsevier, 1987, pp. 85-123.

Lakatos, I., "Falsification and the Methodology of Scientific Research Programmes," in 1. Lakatos and A. Musgrave, eds., Criticism and the Growth of Knowledge, Cambridge: Cambridge University Press, 1970, pp. 91-196. 
Lange, O., "On the Economic Theory of Socialism," Review of Economic Studies, 1936, 4 (1), 123-142. (Published as book in 1938 with University of Minnesota Press (with F. M. Taylor), B. E. Lippincott, ed.).

, Price Flexibility and Employment, Bloomington: Principia Press, 1944.

"The Computer and the Market," in C. H. Feinstein, ed., Socialism, Capitalism and Economic Growth: Essays Presented to Maurice Dobb, Cambridge: Cambridge University Press, 1967, pp. 158-161.

Latsis, S. J., "A Research Programme in Economics," in S. J. Latsis, ed., Methot and. Appraisal in Ecconomics, Cambridge: Cambridge University Press, 1976, pp. 1-41.

Litdlechild, S. C. and G. Owen, "An Austrian Model of the Entrepreneurial Market Process," Joumal of Economic Theory, 1980, 23 (3), 361-379.

Ljung, L. and T. Söderström, Theory and Practice of Recursive Identification, Cambridge, MA: MIT Press, 1983.

Lucas, R. E. and T. J. Sargent, Rational Expectations and Econometric Practice, London: Allen \& Unwin, 1981.

Luenberger, D. G., Introduction to Dynamic Systems: Theory, Models, and Applications, New York: Wiley, 1979.

Lundberg, E., Studies in the Theory of Economic Expansion, Westminster: King, 1937.

Madden, P. J., "Efficient Sequences of Non-Monetary Exchange," Review of Economic Studies, 1975, 42 (4), 581-596.

__ "A Theorem on Decentralized Exchange," Econometrica, 1976, 44 (4), 787-791.

"Why the Edgeworth Assumption Isn't That Bad," Revicw of Economic Studies, $1978,45(2), 279-283$.

_- "Review of Fisher (1983)," Economic Joumal, 1984, 94 (4), 986-988.

"A Disequilibrium Rational Expectations Model with Walrasian Prices and Involuntary Unemployment," Review of Economic Studies, 1992, 59 (4), 831-844.

Magill, M. and M. Quinzii, Theory of Incomplete Markets, Cambridge, MA: MrT Press, 1996.

Maks, J. A. H., "Empirical Preference Ordeningss and Applied Dernand Analysis." $\mathrm{PhD}$ dissertation, Universiteit van Amsterdam 1980.

Wetenschapsfilosofie En Economische Theorie, Groningen: Unpublished Syllabus, 1981.

Mandeville, B., The Fable of the Bees or Private Vices, Publick Benefits, Oxford: Clarendon Press, 1924. 
Mantel, R. R., "Homothetic Preferences and Community Excess Demand Functions," Joumal of Economic Theory, 1976, 12(1), 197-201.

Marcet, A. and T. J. Sargent, "Convergence of Least Squares Learning Mechanisms in Self-Referential Linear Stochastic Models," Joumal of Economic Theory, 1989, $48(2), 337-368$.

Marimon, R.: "Learning from Learning in Economics," in D. M. Kreps and K. F. Wallis, eds., Advances in Economics and Econometrics: Theory and Applications, Seventh World Congress, Volume 1, Cambridge: Cambridge University Press, 1997, pp. 278-315.

S. E. Spear, and S. Sunder, "Expectationally Driven Market Volatility: An Experimental Study," Joumat of Economic Theory, 1993, 61 (1), 74-103.

Marschak, T. and R. Selten, General Equilibrium with Price-Making Firms, New York: Springer-Verlag, 1974.

Marshall, A., Principles of Economics: An Introductory Volume, 8 ed., London: MacMillan, 1920.

Martin, S., Industrial Economics: Economic Analysis and Public Policy, 2 ed, Englewood Cliffs: Prentice-Hall, 1994.

Mas-Colell, A., "Notes on Price and Quantity Tâtonnement Dynamics," in H. F. Sonnenschein, ed., Models of Economic Dynamics, Berlin: Springer-Verlag, 1986, pp. $49-67$.

, M. D. Whinston, and J. R. Green, Microeconomic Theory, Oxford: Oxford University Press, 1995.

Maskin, E., "The Existence of Equilibrium with Price-Setting Firms" American Economic Revicw, $1986,76(2), 382-386$.

McFadden, D., "On Hicksian Stability," in J. N. Wolfe, ed., Value, Capital, and Growth: Papers in Honour of Sir John Hicks, Edinburgh: Edinburgh University Press, 1968, pp. 329-351.

McKenzie, L. W., "Matrices with Dominant Diagonals and Economic Theory," in K. J. Arrow, S. Karlin, and P. Suppes, eds., Mathematical Methods in the Social Sciences, 1959: Proceedings of the First Stanford Symposium, Stanford: Stanford University Press, 1960, pp. 47-62.

Menger, C., Untersuchungen über Die Methode der Socialwissenschaften und der Politischen Ökonomie Insbesondere, Leipzig: Dunker Humblot, 1883.

Metcalf, J. S., "The Diffusion of Innovation: An Interpretative Survey," in G. Dosi, C. Freeman, R. Nelson, G. Silverberg, and L. Soete, eds., Technical Change and Economic Theory, London: Pinter, 1988. 
Metzler, L. A., "Stability of Multiple Markets: The Hicks Conditions," Econometrict, $1945,13(4), 277-292$.

Milgrom, P. and J. Roberts, "Rationalizability, Learning, and Equilibrium in Games with Strategic Complementarities," Econometrica, 1990, 58 (6), 1255-1277.

Mill, J. S., "On the Definition of Political Economy: and on the Method Proper to It," in J. S. Mill, ed., Essays on Some Unsettled Questions of Political Economy, London: John Parker, 1844, pp. 120-164.

- A System of Logic, Ratiocinative and Inductive: Being a Connected View of the Principles of Evidence and the Methods of Scientific Investigation, 5 ed., London: Parker Bourn, 1862.

Mises, L. won, Human Action: A Treatise on Economics, 3 ed., New Haven: Yale University Press, 1963.

Monfort. A., "A Reappraisal of Misspecified Econometric Models", Econometric Theory, $1996,12(4), 597-619$.

Morishina, Mn, "A Reconstruction of the Walras-Cassel-Leontief Model of General Equilibrium," in K. J. Arrow, S. Karlim, and P. Suppes, eds., Mathematical Methods in the Social Sciences, 1959: Proceedings of the First Stanford Symposium, Stanford: Stanford University Press, 1960, pp. $63-76$.

Mukh, J. F., "Rational Expectations and the Theory of Price Movements," Econometrica, $1961,29(3), 315-335$.

MyrdaI, G., Prisbildningsproblemet Och Föränderlichheten, Uppsala and Stockholm: Amquist \& Wiksell, 1927.

, Monetary Equilibrium, New York: Kelley, 1939.

Negishi, T., "On the Formation of Prices," International Economic Review, 1961a, 2 (1) $122-126$

" "Monopolistic Competition and General Equilibrinm," Review of Economic Studies, $1961 \mathrm{~b}, 28(77), 196-201$.

" "The Stability of a Competitive Economy: A Survey Article," Econometrica, $1962,30(4), 635-669$.

"The Stability of Exchange and Adaptive Expectations." International Economic Review, 1964, 5(1), 104-111.

General Equilibrium Theory and Intemational Trade, Amsterdam: Nonth Holland, 1972.

, Microfoundations of Keynesian Macroeconomics, Amsterdam: North-Holland. 1979. 
Newman, P. K., "Sone Notes on Stability Conditions," Review of Economic Studies, $1959,27(1), 1-9$

"Approaches to Stability Amalysis;" Economica, 1961, 28 (1), 12-29.

, The Theory of Exchange, Englewood Cliffs: Prentice-Hall, 1965.

Nguyen, D., "The Monopolistic Firm, Random Demand, and Bayesian Learning:" Operations Research, 1984, 32 (5), 1038-105..

Nikaido, H., Monopolistic Competition and Effective Demand, Princeton: Princeton University Press, 1975.

Nyarko, Y., "Learning in Mis-Specifed Models and the Possibility of Cycles," Joumal of Economic Theory, 1991, $55(2), 416-427$.

- "Bayesian Leanning Leads to Correlated Equilibria in Normal Form Games," Economic Theory, 1994, 4 (6), 821-841.

O'Driscoll, G. P. and M. J. Rizzo, The Economics of Time and Ignorance, Oxford: Blackwell, 1985.

Patinkin, D., Money, Interest, and Prices: An Integration of Monetary and Value Theory, 2 ed. New York: Harper Row, 1969.

Pearce, D. G., "Rationalizable Strategic Behavior and the Problem of Perfection," Econometrica, 1984, $52(4), 1029 \cdots 1050$.

Pheby, J., Methodology and Economics: A Critical Reftection, London: MacMillan, 1988.

Phelps, E. S., "The New Microeconomics in Employment and Inflation Theory:" in E. S. Phelps, ed., Microeconomic Foundations of Emplownent and Inflation Theory New York: Norton, 1970, pp. 1-23.

Pirsig, R. M, Zen and the Art of Motorcycle Maintenance: An Mrqumy Into Vahes, New York: Morrow Quill, 1974.

Popper, K. R, The Logic of Scientific Discowery, Ijondon: Hutchinson, 1959.

, Conjectures and Rerutations: The Growth of Sctentific Knowledge, New York: Harper Row, 1963.

Quandt, R. E. The Econometrics of Disequithrinu, New York: Blackwell, 1988.

Quirk, J. and R. Saposnik, Introduction to General Equibrium Theory and Welfore Economics, New York: McGraw-Hill, 1968.

Raaij, F., G. H. Veldhowen, and K. E. Waenneryd, eds, Handbook of Economic Psychology, Dordrednt: Kluwer Academic, 1988. 
Radner, R., "Existence of Equilibrium Plans, Prices and Price Expectations in a Sequence of Markets," Econometrica, 1972, 40 (2), 289303.

- "Rational Expectations Equilibrium: Generic Existence and the Infonmation Revealed by Prices," Econometrica, 1979, 47 (3), 655-678.

Rampa, G." "Conjectures, Learning, and Equilibria in Monopolistic Competition," Jounnal of Economics, 1989,49 (1), 139-163.

Rassenti, S., S. S. Reynolds, V. L. Smaith, and F. Szidarovsky, "Adaptation and Convergence of Behavion in Repeated Experimental Cournot Games," Jownal of Economic Behaviom and Organization, $2000,41(2), 117-147$.

Reder, M. W. "Chicago Economics: Permanence and Change," Journal of Economic Literature, $1982,20(1), 1-38$.

Redman, D. A., Economics and the Philosophy of Science, Oxlord: Oxford Uniwersity Press, 1991.

Remenyi, J. V., "Core Demi-Core Interaction: Toward a General Theory of Disciplinary and Subdisciplinary Growth," History of Political Economy, 1979, 11 (1), $30-63$.

Robbins, L., An Essay on the Nature and Significance of Economic Science, 2 ed., London: MacMillan, 1935.

Roberts, J. and H. Sonnenschein, "On the Foundations of the Theory of Monopolistic Competition," Econometrica, 1977, 45(1), 101-113.

Robinson, J., The Economics of Imperfect Competition, London: MacMillan, 1933.

Rothschild, E., "Adam Smith and the Invisible Hand," American Economic Review, $1994,84(2), 319-322$.

Ruggles, N. D. and R. Ruggles, Pricing Systems, Indexes, and Price Behavior, Northampton: Elgar, 1999.

Sari, D. G., "Mathematical Complexity of Simple Economics," Notices of the American Mathematical Society, 1995, 42 (2), 222-230.

and C. P. Simon, "Effective Price Mechanisns," Econometrica, 1978, 46 (5), $1097-1125$.

- and S. R. Williams, "On the Local Convergence of Economic Mechanisms," Joumal of Economic Theory, 1986, 40 (1), 152-167.

Salle, J. and S. Lefschetz, Stability by Liapunov's Direct Method: With Applications, New York: Academic Press, 1961.

Samuelson, P.A. "The Stability of Equilibrium: Comparative Statics and Dynamics," Econometrica, $1941,9(2), 97-120$. 
" "The Relation Between Hicksian Stability and True Dynamic Stability," Econo. metrica, $1944,12(3-4), 97-120$.

_- Foundations of Ecanomic Analysis, Cambridge, MA.: Harvard University Press, 1963.

Sandroni, A., "Does Rational Leaming Lead to Nash Equilibrium in Finitely Repeated Games?" Joumal of Economic Theory, 1998, 78 (1), 195-218.

Sargent, T. J., Bounded Rationality in Macroeconomics, Oxford: Oxford University Press, 1993.

Scarf, H. E., "Some Examples of Global Instability of the Competitive Equilibrium," International Economic Review, 1960, 1 (3), 157-172.

_- "The Approximation of Fixed Points of a Continuous Mapping," SIAM Journal on Applied Mathematics, 1967, 15 (5), 1328-1343.

The Computation of Economic Equilibria, New Haven: Yale University Press, 1973. (with the collaboration of T. Hansen).

__ "Computation of General Equilibria," in J. Eatwell, M. Milgate, and P. Newman, eds., The New Palgrave: General Equilibrium, New York: Norton, 1989, pp. 84-97.

Schecter, S., "Accessibility of Optima in Pure Exchange Economies," Journal of Mathematical Economics, 1977, 4 (1), 197-216.

Schinkel, M. P., "The Asymptotic Behavior of Bayesian Estimators in Linear Normal Approximations of Unknown Regression Functions," Meteor Research Memarandum, 1999, RM/99/091, 6 .

, ed., Microeconomics, Essays in Theory and Applications, Collected Works of Franklin M. Fisher, Volume IV, New York: Cambridge University Press, 1999.

, J. Thinstra, and D. Vermeulen, "Bayesian Learning in Mis-Specified Models," Meteor Research Memorandum, 2000, RM/00/008, 66.

Schultz, H., The Theory and Measurement of Demand, Chicago: University of Chicago Press, 1938.

Schumpeter, J. A., Capitalism, Socialism and Democracy, 4 ed., London: Allen \& Unwin, 1974.

Scitovsky, T., Welfare and Competition: The Economics of a Fully Employed Economy, London: Allen \& Unwin, 1963.

Seade, J., "The Stability of Cournot Revisited," Journal of Economic Theory, 1980, $23(1), 15-27$.

Shackle, G. L. S., Time in Economics, Amsterdam: North-Holland, 1958. 
, Decision Order and Time in Human Affairs, Cambridge: Cambridge University Press, 1961.

Shand, A. H., The Capitalist Alternative: An Introduction to Neo-Austrian Economics, Brighton: Harvester Press, 1984.

Shapley, L.S. and M. Shubik, "On Market Games," Journal of Economic Theory, 1969, $1(1), 9-25$.

Silvestre, J., "A Model of General Equilibrium with Monopolistic Behavior," Journal of Economic Theory, $1977,16(2), 425-442$.

_- "The Market-Power Foundations of Macroeconomic Policy," Journal of Economic Literature, 1993, 31 (2), 105-141.

Smale, S., "Dynamics in General Equilibrium Theory," American Economic Review, $1976 \mathrm{a}, 66(2), 288-294$.

_- "Exchange Processes with Price Adjustment," Journal of Mathematical Economics, 1976b, 3(2), 211-226.

"A Convergent Process of Price Adjustment and Global Newton Methods," Journal of Mathematical Economics, 1976c, 3(1), 107-120.

Smith, A., An Inquiry Into the Nature and Causes of the Wealth of Nations, Oxford: Oxford University Press, 1979.

Smith, V. L., "Markets as Economizers of Information: Experimental Examination of the "Hayek Hypothesis"," Economic Inquiry, 1.982, 20(2), 165-179.

Sonnenschein, H., "Market Excess Demand Functions," Econometrica, 1972, 40 (3), $549-563$.

"Do Walras' Identity and Continuity Characterize the Class of Community Excess Demand Functions?," Journal of Economic Theory, 1973, 6 (4), 345-354.

Spulber, F. D., Market Microstructure: Intermediaries and the Theory of the Firm. Cambridge: Cambridge University Press, 1999.

Stackelberg, H., The Theory of the Market Economy, London: Hodge, 1952.

Stahl, D. O. and F. M. Fisher, "On Stability Analysis with Disequilibrium Awareness," Joumal of Economic Theory, 1988, 46 (2), 309-321.

Sternby, J., "On Consistency for the Method of Least Squares Using Martingale TheOry," IEEE Transactions on Automatic Control, 1977, 22 (3), 346-352.

Takayama, A., Mathematical Economics, 2 ed., Cambridge: Cambridge University Press, 1985.

Theocharis, R. D., "On the Stability of the Cournot Solution on the Oligopoly Problem," Review of Economic Studies, 1959-1960, 27 (2), 133-134. 
Tinbergen, J., "Bestimmung und Deutung Von Angebotskurven: Ein Beispiel," Zeitschrift für Nationalöonomie, 1930, 1 (5), 669-679.

Thefler, D." "The Ignorant Monopolist: Optimal Learning with Endogenous Information," Intemational Economic Review, 1993, 34 (3), 565-581.

Triffin, R., Monopolistic Competition and General Equilibrium Theory, Cambridge, MA: Harvard University Press, 1940.

Tsai, D., "On Supermodularity and the Complexity of Forming Trading Coalitions," Master's thesis, Massachusetts Institute of Technology 1993.

Tuinstra, $\mathbb{d}$., "Price Dynamics in Equilibrium Models." PhD dissertation, Universiteit van Amsterdam 1999.

Uzawa, H., "Walras" Tatonnement in the Theory of Exchange," Review of Economic Studies, 1959, 27, 182-194.

"The Stability of Dynamic Processes," Econometrica, 1961, 29, 617-631.

"Walras' Existence Theorem and Brouwer's Fixed Point Theorem," Economic Studies Quarterly, 1962a, 13, 59-62.

_ "On the Stability of Edgeworth's Barter Process," International Economic Review, $1962 \mathrm{~b}, 3(2), 218-232$.

Varian, H. R., "On Persistent Disequilibrium," Journal of Economic Theory, 1975, 10 (2), 218-228.

__ "Non-Walrasian Equilibria," Econometrice, 1977, 45 (3), 573-590. , Microeconomic Analysis, 2 ed., New York: Norton, 1984.

Walker, D. A., "Edgeworth's Theory of Recontract," Economic Joumal, 1973, 89 (329), $138-149$.

"Edgeworth versus Walras on the Theory of Tatonnement," Eastern Economic Journal, 1987, 19(2), 155-165.

Walras's Market Models, Cambridge: Cambridge University Press, 1996.

Walras, L., Elements of Pure Economics: or The Theory of Social Wealth, London: Allen \& Unwin, 1954.

Waters, R, Amused to Death, London: Pink Floyd Music Publishers Inc. (BMI), 1992.

Weintraub, E. R., Microfoundations: The Compatibility of Microeconomics and Macroeconomics, Cambridge: Cambridge University Press, 1979.

-General Equilibrium Analysis: Studies in Appraisal, Cambridge: Cambridge University Press, 1985. 
_. Stabilizing Dynamics: Constructing Economic Knowledge, Cambridge: Cambridge University Press, 1991.

White, H., Estimation, Inference and Specification Analysis, Cambridge: Cambridge University Press, 1994.

Williams, S. R., "Necessary and Sufficient Conditions for the Existence of a Locally Stable Message Process," Journal of Economic Theory, 1985, 35 (1), 127-154.

Witteloostuijn, A. and J. A. H. Maks, "Walras: A Hicksian Avant La Lethe," Economie A ppliquée, 1989, 41(3), 596-608.

Woodford, M., "Learning to Believe in Sunspots," Econometrica, 1990, 58 (2), 277307.

Zellner, A., An Introduclion to Bayesian Interference in Econometrics, New York: Wiley, 1971. 



\section{Samenvatting (Summary in Dutch)}

Eén van de meest aangehaalde passages in de economische literatuur is Adam Smith's bespreking van de 'onzichtbare hand'. Deze metafoor voor marktwerking vat de gedachte dat een systeem wan competitieve markten, met weinig of geen directe overheidsinterventie, als vanzelf de ongeorkestreerde keuzes van individuen kanaliseert en leidt tot een maatschappelijk te prefereren en stabiele orde. Deze gedachte is bijzonder wijd verbreid, en lijkt aan populariteit te winnen, getuige beleid gericht op privatisering van taken voorheen beschouwd als best volbracht door overheidsinstanties. Omgekeerd wordt als verklaring van liet falen van maatschappelijke organisatievormen die niet op een systeem van vrije markten zijn gebaseerd doorgaans gewezen op belemmeringen van de onzichtbare hand. De poëtische notie speelt derhalve cen rol van grote betekenis is de politieke economie.

Vreemd genoeg echter heeft de economische wetenschap vrijwel geen robuuste theorie voortgebracht om de werking van de onzichtbare hand mee te begrijpen. In plaats daarvan heeft zij zich vooral geconcentreerd op evenwichten, situaties waarin de hand zijn veronderstelde werk volledig heeft verricht. Over wat er buiten deze evenwichten p]aatsvindt heeft haar theorie bijzonder weinig te melden. Dit is een buitengewoon opmerkelijke situatie. Immers, de centrale vraagstelling in de economische wetenschap is of, en door welke combinatie van institutionele structuur en marktwerking, een samenleving met heterogene individuen in staat is een verdeling van schaarse, alternatief aanwendbare middelen tot stand te brengen waarin iedereen zijn of haar plannen kan uitvoeren en zichzelf kan verbeteren. Met haar evenwichtstheorieën kan de economische wetenschap slechts antwoorden op deze vraag geven waarin zulke coördinatie al reeds volledig heeft plaatsgevonden.

Toch rijzen de problemen die zich voordoen indien men wel serieus over een onevenwichtigheidstheorie nadenkt-en verschillende economen van naam, zoals Walras, Hayek, en Hahn hebben dat gedaan-al wanneer men het meest simpele coör- 
dinatieprobleem beschouwt, dat van twee individuen die trachten twee verschillende goederen te ruilen. Tegen een willekeurige gegeven ruilwoet wensen de twee elk verschillende hoevedheden van het ene goed op te geven voor het andere. Hoewel, indien de mitiele verdeling voldoende ongelijk is, wat de ene hebben wil doorgans ook wel door de andere wordt aangeboden, rijn de hoeveetheden warin dat gebeurt niet noodzakelijk gelijk. Ten minste ến wan de twee individuen wordt gerantsoeneerd. De vraag is nu wat er gebeurt. Er kan een gedealtelije ruil plaatsvinden. Er kan ook een niewwe ruilwoet worden woorgesteld, waartegen dan nieuwe aanbiedingen kunnen wor. den voogesteld. Maer wie van de twee doet een nieuw voorstel? En onder wat voor condities word dat aanvard? Wanneer is het verstandig om te wachten met handelen? Wanneer dient men toe te slaan? Al dit soort vragen kunnen alleen aran een serieuze theorie van onevenwichtigheidshandelen worden gesteld. Daarin spelen elementen als de verdeling van ongelijke en onvolledige informatie en werwachtingen een rol, en ook aampassingstijd en snelheden. Dit introduceert de mogelijkheid van veranderingen in de voorkeuren en admezige midelen tijdens het onevenwichtigheidsproces. Tenslotte werpt een dergelijke theorie de vaag op wie er verantwoondelijk is voor de anpassing van prijzen.

Het is van buitengewoon belang dergelike vragen te beschowwen. Ten eerste kunnen slechts bevredigende antwoorden erop een rechtvardiging verschaffen voor het alom vertegenwoordigde evenwichtsdenken in de economische wetenschap. Een tweede reden is dat belangxijke economische processen wel ens onevenwichtigheidsprocessen zouden kumen zijn. Ten derde kan een onevenwichtigheidstheorie antwoord geven op de vraag well evenwicht relevant is, indien evenwichtstheorie het bestain van meerdere even. wichten aantoont. Welke daarvan vanuit een initiele verdeling wordt gereikt hangt af van de specificaties van het aanpassingsproces. In het verlengde hiervan ligt een vierde reden. Het is zeer waarschijnlijk dat het evenwicht bereikt door een onevenwichtigheidproces geen deel ritmakkt van de set van evenwichten die correspondeert met de initiele verdeling. Dit is het geval indien er tijdens het aanpassingsproces bijvoorbeeld wordt geconsumeerd of geproduceerd. Een vijfde reden vor het bestuderen van onevenwichtigheidgedrag is dat het zeer wel mogelijk is dat de fundamenten wan de evenwichtistheorie aanpassing behoeven on een serieuze onevenwichtigheidstheorie toe te stan. Met name da aaname van prijonemend gedrag, zoals bijvoorbeeld gemaakt in het model van volkomen mededinging, stat op gespannen voet met theorie over de ampassing van prijzon nar evenwichtswarden. Zij is echter cruciaal woor het resultaat dat Walrasiawne evenwichten Pareto effcient zijn. Tenslotte zijn er fenomenen waarvoor de evenwichtstheorie maar moellijk een verklaring bieden kan. Een voorbeeld is het bestaan van geld. De transactiekostenverlagende rol ervan wordt ypisch gespeeld in de totstandkoming van een evenwichtsallocatic.

De doelstelling van dit boek is de interesse woor het werken an een begrip van onevenwichtigheidprocessen nieuw leven in te blazen, en wel op twee manieren: middels een kritische reflectie op de bestaande literatur en door cen substantiële bijdrage. Daartoe wordt in Hoofdstuk 2 met behulp van inzichten nit de wetenschapsfilosofie een kader geschetst warbinnen de ontwikkeling van de economische wetenschap in het algemeen, en onevenwichtigheidtheorie in het bijzonder, kan worden begrepen. Hoofdstuk 3 beschouwt van hieruit de traditionele stabiliteitsliteratuur. In Hoofdstuk 4 wordt die literatuur bekritiseerd, en wordt aangegeven watrom zij heeft 
gefaald. Voorts worden richtingen voor het herleven van onevenwichtigheidsonderzoek aangegeven, alsmede elementen van een betere theorie geïdentificeerd, te weten imperfecte mededinging, en imperfecte en onvoledige informatie. In de hoofdstukken 5 en 6 wordt de literatuur over die elementen beschouwd. In Hoofdstuk 7 wordt geconcludeerd dat deze literatuur vooral een evenwichtsbenadering heeft gekozen. Voorst worden een rudimentaire onevenwichtstheorie voorgesteld. In Hoofdstuk 8 wordt deze volledig uitgewerkt in een algemene opzet, en wordt een convergentie stelling afgeleid onder voorwaarden die zeer naw aansluiten bij de meest recente onevenwichtigheidsliteratuur. Hoofdstuk 9 concludeert en geeft enkele lijnen aan voor verder onderzoek.

Elke opgetekende geschiedenis, ook een van het denken, is geschreven vanuit een bepaald kader, belangrijk bepaald door kennis van latere ontwikkelingen. Het is daarom wan belang vooraf duidelijkheid te scheppen over het kader van walaruit de geschiedenis is betracht. De wetenschapsfilosofie verstrekt hiertoe middelen. In Hoofdstuk 2 wordt uiteengezet hoe de wetenschapsfilosofieën van Popper en Lakatos een middenweg vinden tussen het inductivisme en het deductivisme, die beiden op grote problemen stuiten. Waar het inductivisme de noodzakelijke a priori organisatie van de oneindig veel potentieel interessante observaties verwerpt, en daarom niet tot algemene uitspraken komen kan, blijft de waarachtigheid van stellingen in het deductivisme onduidelijk door een gebrek aan mogelijkheden voor empirische toetsing. Popper's falsificationisme verbindt theorie en observatie door van theorieën te eisen dat ze onafhankelijk toetsbare uitspraken doen, die leiden kunnen tot falsificatie. Dit staat het woorlopige gebruik van metafysische aannamen toe. Op de vraag welk deel daarvan verworpen dient te worden indien een afgeleide uitsprak gefalsifieerd is geeft Lakatos een antwoord met zijn methodologie van de wetenschappelijke onderzoeksprogramma"s. Een onderzoeksprogramma bevat aannamen die niet aan onaflnankelijke tests worden blootgesteld, en in plaats daarvan worden afgeschermd door hulphypothesen. Onderzoeksprogramma's zijn progressief indien ze op basis van hun harde kern tot uitspraken komen die, indien gefalsifieerd, niet met ad hoc veranderingen in de hulphypothesen, maar door vergroting van de empirische en logische inhoud worden aangepast. Binnen onderzoeksprogramma's kunnen sub-pogramma's worden onderscheiden, volgens de theorie van Remenyi. Eén van hun functies is de bescherming van de harde kern tegen falsificatie. Met het empirische apriorisme heeft de economische wetenschap vanaf haar ontstaan een ontwikkeling doorgemaakt die nauw aansluit bij de Lakatosiaanse methodologie. Het is dan ook een volwassen wetenschap, waarvan het mogelijk is de harde kern op te stellen. Een prominente rol daarin wordt gespeeld door de algemene evenwichtstheorie. Zij beschermt met name het idee van de superioriteit van vrije markten, gevat in de onzichtbare hand boven besproken.

Hoofdstuk 3 beschouwt de ontstaansgeschiedenis van theorieên over onevenwichtigheidsprocessen en hun stabiliteit. Deze kan worden begrepen in vijf belangrijke stappen. De eerste werd gezet door Walras, de grondlegger van de algemene evenwichtstheorie. Walras observeerde dat de prijzen op de beurs in Parijs zich aanpasten in de richting van het vraagoverschot. Hij stelde op basis daarvan de wet van vraag en aanbod op, die zegt dat de prijs van een goed stijgt als de vraag groter is dan het aanbod, en daalt indien het aanbod groter is dan de vraag. Hoewel Walras worstelde met de vraag welke andere processen zich tijdens het aanpassen van de prijzen wellicht nog 
afspeelden, veronderstelde hij die uiteindelijk allen weg. De globale stabiliteit van het zo ontstane tătonnement proces was voor Walras evident. Hicks' en Samuelson's latere nadere studies wan Walras' theorie, die een tweede stap in de ontwikkeling vormden, identificeerde echter bijzonder specifieke condities waaronder het proces lokaal stabiel is. Het zelfde geldt voor Arrow, Block en Hurwicz, die globale stabiliteit bestudeerden in een vierde ontwikkeling. Deze stabiliteitscondities werden gezocht op het niveau van de geaggregeerde vraagoverschotsfuncties. Een vijfde belangrijke ontwikkeling, geleid door Scarf, toonde echter aan dat deze niet zonder meer uit individuele eigenschappen volgen konden. Dit legde het onevenwichtigheidsonderzoek voor lange tijd lam. ten gunste van afgeleide onderzoeksgebieden, met name berekeningsalgorithmen en de zogenaamde 'verdelingsbenadering' die respectievelijk de Walrasiaanse veilingmeester preciezere aanpassingsregels wilde laten volgen en in heterogeniteit van individuen alsnog een rechtvaardiging voor de gevonden condities op de geaggregeerde vraagstelsels zocht. Als een weg uit deze problematiek stelde Hahn voor het aanpassingsproces zelf verder te preciseren. Deze zesde stap leidde tot de vruchtbare ontwikkeling van zogenaamdle handelsprocesser, met name het Hahn-proces waarop Fisher uitbreidde. Het Fisher-proces representeert de huidige kennis van onevenwichtigheidsgedrag.

In Hoofdstuk 4 worden de problemen waarin de onevenwichtigheidsliteratuur verkeert teruggevoerd op het feit dat het tatonnement proces, en daarmee vrijwel alle latere processen, inchusief het Fisher-proces, een homunculus verklaring biedt voor prijsaanpassingen buiten het evenwicht. Het postuleert letterlijk een mannetje, de veilingmeester, die alleen verantwoordelijk wordt geacht voor het coördinatieproces dat de theorie tracht te verklaren. Coördinatie is bij gevolg opgelegd, en niet verklaard. De rol van sub-discipline ter bescherming van de harde kern van de algemene evenwichtstheorie die de onevenwichtigheidstheorie sinds Walras heef gehad, heeft bijgedragen aan de late ontmaskering van deze schijnverklaring. Voor een serieuze theorie van gedrag buiten evenwichten dient de homunculus te worden verlaten. Al in de jaren 50 wezen verschillende theoretici, met name Clower en Arrow, op elementen wan een theorie die erwoor in de plaats zou moeten komen: imperfecte mededinging en imperfecte en onvolledige informatie.

Beide vormen van imperfecties zijn uitvoerig bestudeerd, zij het in een evenwichtscontext. Hoofdstuk 5 bespreekt de literatunr over 'markt-makers', individuen met een zekere marktmacht, die hen in staat stelt ver antwoordelijkheid voor het aanpassen van prijzen en hoeveelheden te nemen. Het bestaan van evenwichten met markt-makers is aangetoond door Negishi en later Benassy, eerst voor het geval waarin monopolistisch mededingende prijszetters een subjectief idee hebben van hum macht, dat afwijken kan van hun objectieve invloed, en later voor het gevall waarin de objectieve individuele vraag- en aanbodsrelaties bij de markt-makers bekend zijn. Opvallend genoeg is de laatste literatuur geaccepteerd als de standaard, maar kent het tegelijkertijd de meeste problemen: de existentie van evenwichten is er niet gegarandeerd, ook niet voor niet-gedegenereerde gevallen. De subjectieve vraag benadering biedt de grootste belofte voor een vervanging van de veilingmeester, maar lost die met haar evenwichtsbenadering niet in.

De gedachte dat informatie niet noodzakelijk perfect en volledig is, en de ruimte die dat creëert voor subjectieve wereldbeelden, verwachtingen en theorieën over leren, heeft ook tot een omvangrijke literatuur geleid, beschouwd in Hoofdstuk 6. Ze gaan 
tenminste terug tot de jaren 30 en de Oostenrijkste en Stockholm school-bijvoorbeeld een invloed op Halhn. De formele beschouwing wan werwachtingen in een algemene evenwichtscontext heeft niet geleid tot veel inzicht in onevenwichtigheidsprocessen, net 2o min als de literatuur over zogenaamde 'conjecturele variaties'. Echter, de relatie met de eerder besproken modellen van Negishi en Benassy bieden ruimte voor een studie van het aanpassen van subjectieve percepties. Een vroege bijdrage langs die lijn is van Fisher. Hij laat handelaren prijzen zetten op basis van verkeerd veronderstelde vraag- en aanbodcurven, die vervolgens worden bijgesteld. Dit gebeurt echter, zonder duidelijk aanwijsbare reden, zo dat de wet van vraag en aanbod niet wordt geschonden. In het latere Fisher-proces is de aanpassing van prijzen minder precies uitgewerkt. Echter, markt-makers kunnen dit wel degelijk individueel rationeel doen. Onder de woorwaarde dat er zich geen zogenaamde "aangename verrassingen' voordoen tijdens het aanpassingsproces is het Fisher-proces globaal stabiel. De moderne leerliteratuur tenslotte, biedt veel aanknopingspunten voor het bestuderen van aanpassingsprocessen in onevenwichtigheidssituaties. Hoewel het vooral gericht is op het rechtvaardigen van rationele verwachtingen evenwichten biedt de methodiek alle mogelijkheden van leren op basis van minder informatie, bijvoorbeeld over de structurele specificaties van de marktmacht die markt-makers hebben.

Hoewel elementen voor individueel rationele onevenwichtigheidsaanpassingen derhalve beschikbaar zijn, zijn zij tot op heden niet of nauwelijks systematisch voor dit doel aangewend. Hoofdstuk 7 maakt een begin met zo een aanwending. Fen eerste abstakel is de drang leerprocessen te modelleren in een structureel volledig met de objectieve werkelijkheid overeenkomende opzet. De wetenschapsfilosofie leert dat een eigenschap van goede theorie is dat zij een abstractie van de werkelijkheid biedt. De theorieên op basis waarvan markt-makers in een theorie over onevenwichtigheidsgedrag hun prijzen aanpassen dienen derhalve ook abstracties te zijn van de werkelijkheid waarin die markt-makers opereren. Met andere woorden, de theorie dient structurele misspecificaties toe te staan. In de econometrie is dit gemeengoed. Een tweede vooringenomenheid die een zinvolle onevenwichtigheidstheorie in de weg heeft gestaan is de gedachte dat de uiteindelijke evenwicht waarnaar een aanpassingsproces convergeert-aangenomen dat het inderdaad convergeert--een volkomen mededingingsevenwicht dient te zijn. Deze gedachte leidt bijwoorbeeld in het vroege werk van. Fisher tot monopolistische mededingingsmacht die langzaam, maar betrekkelijk arbitrair, verdwijnt als het de economie convergeert naar een evenwichtsallocatic. Ook deze gedachte dient in eerste instantie te worden verlaten. Een goede theorie over onevenwichtigheidsaanpassingen is eenvoudig niet verenigbaar met volkomen mededinging, en indien zo een theorie belangrijk wordt gevonden dient de conclusie te worden geaccepteerd dat de uiteindelijke evenwichten niet noodzakelijk Pareto efficiënt zijn. Er is, met andere woorden, een uitruil tussen efficiëntie en stabiliteit.

Hoofdstuk 7 presenteert vervolgens een eenvoudig model van twee markt-makers die elk de lineaire objectieve vraag naar hun goed, die van hun eigen prijs en die van hun concurrent afhangt, inschatten als lineair afhankelijk van slechts hun eigen prijs. De discrepanties die dit over de tijd veroorzaakt tussen verwachtte vraag en geobserveerde vraag schrijven ze toe aan een stochastische factor, die de vorm heeft van witte ruis. Ze zetten prijzen om de winst te maximaliseren op basis van puntschatingen van de parameters van de subjectieve vraag percepties. De reeks van geobserveerde gevraagde 
hoeveelheden strekt tot lerimg in de vorm van aangepaste puntschattingen, gebruk makend van een gewone kleinste kwadraten schatting. Het prijsaanpassingsproces dat zo ontstat in dit simpele model dat voldoet an alle eigenschappen aangewezen als van belang voor een betekenisvolle theorie van onewenwichtigheidsaanpassingen, vertoont opmerkelijk gedrag. Na enige fuctuaties vinden de markt-makers prijsniveaus waarop geen van hen, ondanks het feit dat werkelijkheid en perceptie structureel verschillen, zijn prijzen nog langer wenst aan te passen. Het model is dus stabiel. Interessant genoeg voldoen de prijsaanpassingen over de tijd bovendien niet aan de wet van vaag en aubod.

In Floofdstuk 8 worden de eigenschappen van dit simpele model nader bestudeerd amn de hand wan een algemene wersie ervan. Markt-makers hebben een structureel verkeerd beeld van de objectieve vradg, die zelf nu ook stochastisch is. De verdelingen kumnen ongespecificeerd worden gelaten. De subjectieve vraag wordt geacht een functie te zijn wan een aantal parameters, waarvan de markt-maker denkt dat er een juiste waarde voor bestaat, die hij echter onderkent niet te kennen. In plaats daarvan specificeet hij een prior verdeling over alle waarden van deze parameters die hij voor mogelijk houdt. In de loop van het leerproces, dat wederom gedreven wordt door observaties van de gevraagde hoevelheden, uitgelokt door zelf gezette prijzen in combinatie met de prijzen wan alk andere markt-makers, die elk hun eigen product verkopen, wordt deze verdeling aanpast volgens de regel van Bayes. Het leergechag is in die zin volledig rationeel, zij het subjectief, immers de structurele vorm wordt verkeend gepercipieerd. Maximalisatie van de verwachte winst leidt tot een prijs, die in de markt een geuite vraag tot gevolg heeft. De reeks van verdelingen over de parameter ruimte, de bijbehorende prijzen en geobserveerde hoeveelheden, die weer tot nieuwe verdelingen, prijzen, etcetera aanleiding geeft, wordt vervolgens aangetoond te convergeren voor bijna alle mogelijke ontwikkelingen van de geschiedenis, indien de percepties van de markt-makers aan een strenge eis voldoet. Zij dienen namelijk initieel zo vooruitziend te zijn, dat alle objectief mogelijke ontwikkelingen wan de geschiedenis ook subjectief voor mogelijk worden gehouden. Dat wil zeggen, er dienen zich geen 'statische verrassingen' voor te doen. Deze conditie is een stochastische uitbreiding van de globale stabiliteitsconditie tot dusver bekend in de onevenwichtigheidstheorie, de ender besproken conditie van geen "angename verrassingen" van Fisher. 


\section{Professional Curriculum Vitae}

Maarten Pieter Schinkel was born on May 29, 1971 in Hazerswoude, The Netherlands. He attended ongedeeld atheneum at the Bonaventura College in Leiden between 1983 and 1989, when he graduated cum laude. Between 1989 and 1994, he studied. Algemene Economie (Economics) and Kiwantitatieve Economie (Econometrics) at the Universiteit Maastricht. The academic year 1993/1994, he visited Universitat Regensburg in Germany, supported by a DAAD stipend. Both at Universiteit Maastricht and Universität Regensburg he worked as a research and a teaching assistant. In 1994 he graduated cum laude in both Algemene Economie en Kwantitatieve Economie. Between 1994 and 1996 Maarten Pieter Schinkel was lecturer at the Department of Economics of Universiteit Maastricht. The academic year 1996/1997 he spent as visiting scholar at the Department of Economics of the Massachusetts Institute of Technology in Cambridge, U.S.A., supported by a Fulbright Fellowship. Between 1997 and 2000 he was Ph.D.-student at Universiteit Maastricht, graduating from the NAKE-program in 1998. Since September 2000 Maarten Pieter Schinkel is assistant professor of economics at Universiteit Maastricht, and maitre de conference at Université de Liège, Belgium.

Maarten Pieter Schinkel's research and teaching interests include, apart from disequilibrium theory: history of economic thought, philosophy of science, microeconomics, industrial organization, competition policy, and the economics of information. 